\title{
Dýnamis hermeneutiké.
}

Visiones interdisciplinares del pasado

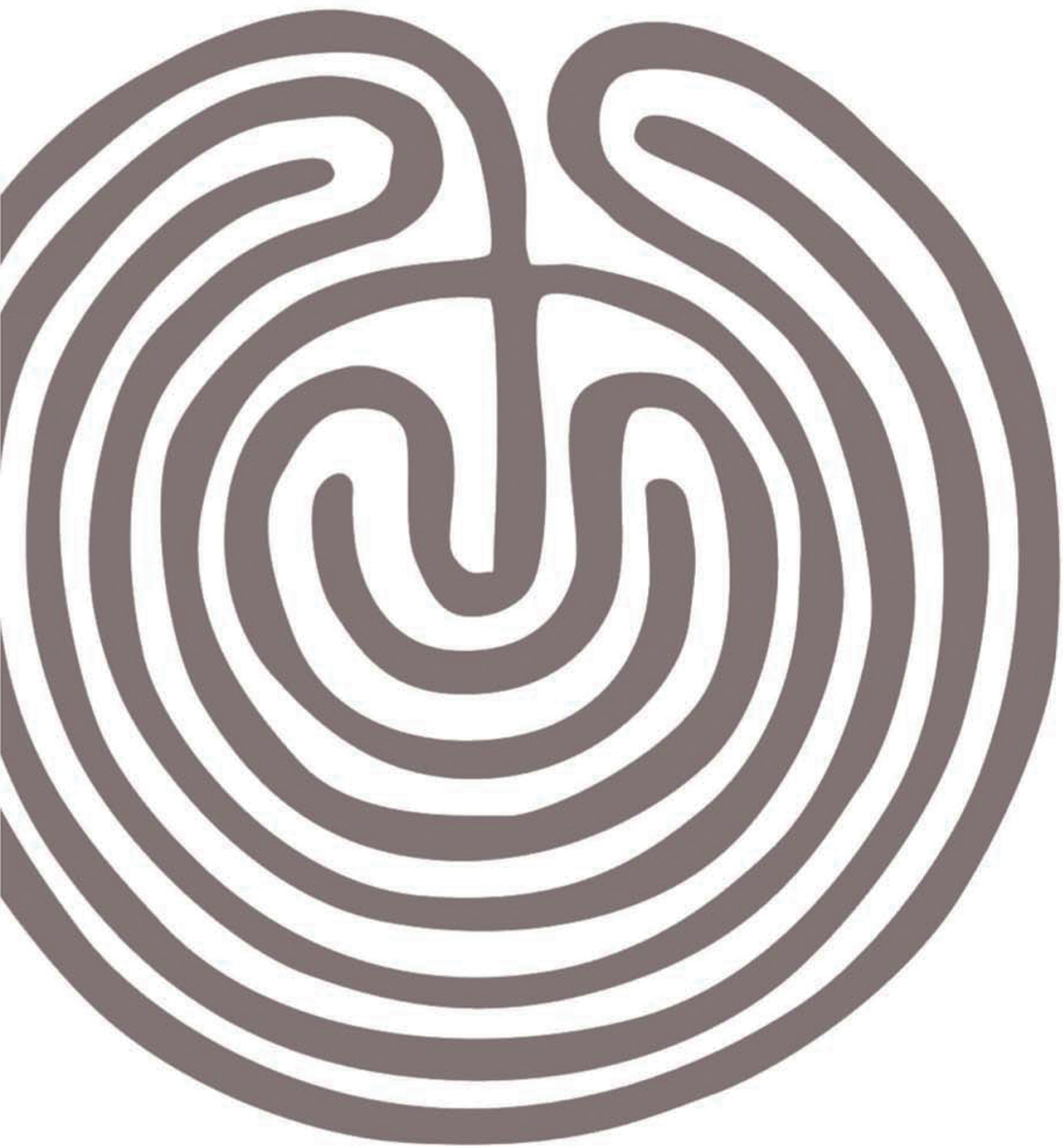

Editores:

GABRIEL SANZ CASASNOVAS

EDUARDO A. GALLEGO CEBOLLADA

FRANCISCO BALLESTA ALCEGA 
Dýnamis hermeneutiké. Visiones interdisciplinares del pasado.

Gabriel Sanz Casasnovas, Eduardo A. Gallego Cebollada, Francisco Ballesta Alcega, Rubén Escorihuela Martínez (coords.)

ISBN 978-84-16723-96-6 


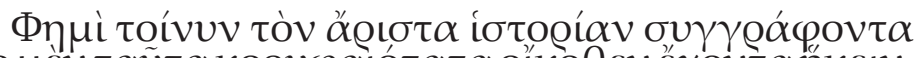

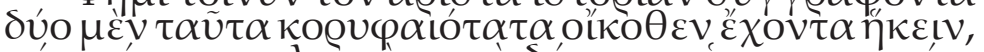

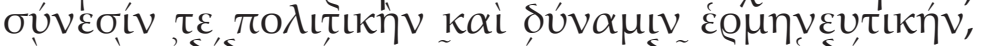

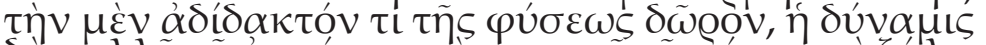

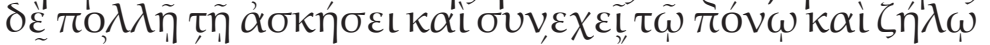

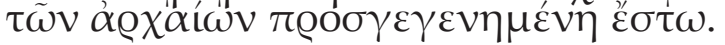

(Luc. Hist.Conscr. 34) 



\section{ÍNDICE}

Prólogo

Maria Angustias Villacampa Rubio .................................... 7

El poblamiento durante el Paleolítico Superior en la provincia de Burgos.

María Cases ........................................................................ 11

Urbanización en la Italia centro-tirrena (ss. X-VI).

Jordi Calvo Cortés .................................................................. 23

Limitaciones, dificultades y claves para el estudio del estatus de los animales en el pensamiento griego antiguo.

Leire Morrás Aranoa .......................................................... 41

Bellas atroces. Figuras femeninas monstruosas griegas: una aproximación al estado actual de la investigación.

Paula Arbeloa Borbón......................................................... 53

ảvícoos en la literatura clásica.

Silvia Vergara Recreo....................................................... 73

A propos d'une histoire connectée du culte de Sarapis en Égypte hellénistique.

Efstathia Dionysopoulou

Los templos egipcios de época ptolemaica en el Alto Egipto: ¿lugares de acción o falsas apariencias?

Sergio Sistac Marina.... 105 
Las guerras en la Hispania postnumantina como medio de promoción política.

Simón Ruiz Charro

La exposición de los cadáveres en la arqueología celtibérica: ¿un espejismo historiográfico?

Diego Suárez Martínez................................................... 145

Las villae en Aragón: un estado de la cuestión.

Celia Corbatón Martínez.................................................. 163

La bona conscientia en Séneca. La educación del ser humano frente a la ira.

Daniel Arenas Casado................................................. 183

Magia 'agonística' en las Metamorfosis de Apuleyo (I, 9): realidad y ficción.

Diego Meseguer González

Problemas metodológicos en el estudio del ceremonial tardoantiguo. A propósito de Amiano Marcelino.

Miriam Soler González.. 


\section{PRÓLOGO}

En primer lugar, quiero expresar mi agradecimiento a Gabriel Sanz Casasnovas, coordinador de las IV Jornadas Doctorales en Ciencias de la Antigüedad, por permitirme presentar la publicación de las actas de dichas Jornadas, celebradas en Zaragoza durante los día 31 de enero y 1 de febrero de 2019.

El Departamento de Ciencias de la Antigüedad lleva organizando estas jornadas desde el año 2015, y una rápida mirada hacia atrás permite comprobar cómo desde entonces el número de jóvenes investigadores de Máster y de Doctorado que han acudido a Zaragoza ha ido creciendo no sólo en número (de 14 a 33), sino en las diversa procedencia de los mismos, que se ha visto ampliada a trece universidades espańolas y otras cuatro europeas.

Asimismo, desde las III Jornadas, se decidió introducir acertadamente una serie de ponencias como preámbulo a la presentación de comunicaciones de los jóvenes investigadores. En esta edición, fueron invitados Carmen Sánchez Mañas, de la Universidad Pompeu Fabra; Patricia González Gutierrez, de la Universidad Nacional de Educación a Distancia; Eva Alarcón García, de la Universidad de Granada; y Luis Arboledas Márquez, de la Universidad de Granada.

Pero, como sabemos, los verdaderos protagonistas de estas jornadas fueron esos 33 jóvenes investigadores que llegaron a Zaragoza para ofrecernos una primicia de sus progresos en el desarrollo de sus tesis doctorales 
o de sus trabajos de Máster. El gran número de participantes en esta cuarta edición demuestra la consolidación de estas Jornadas en el panorama científico y académico de la Universidad espańola, con una pequeña apertura, aunque todavía tímida, al ámbito europeo, que, esperamos, se vaya ampliando en las próximas ediciones.

Desde su aparición, estas Jornadas se han caracterizado por abordar temas muy variados, pero bajo un mismo hilo conductor: en 2015, Problemas y limitaciones en el estudio de las fuentes; en 2016, Temas y tendencias actuales de investigación; y, en 2017, Respuestas al cambio en la Prehistoria y el Mundo Antiguo. En la presente edición de 2019, el tema elegido ha sido Visiones interdisciplinares del pasado. Siendo todos los enfoques de ańos anteriores muy interesantes, esta vez creemos que se ha puesto el énfasis en lo que todos consideramos que es la principal virtud y fuerza de nuestro Departamento desde su creación: su naturaleza interdisciplinar. Estudiar el pasado desde la exégesis de las fuentes literarias, los restos arqueológicos, los textos epigráficos y las acuñaciones monetarias es la tarea de todos los que se dedican al estudio del Mundo Antiguo.

Ya desde la Antigüedad Clásica, los historiadores griegos y romanos reconocían, en mayor o menor medida, haber utilizado diversidad de testimonios para aproximarse al conocimiento del pasado más o menos remoto. Las reflexiones metodológicas de Heródoto, Tucídides y Polibio, entre otros, así lo evidencian, y, con las diferencias metodológicas que separan al historiador clásico de la historiografía moderna, sabemos que todas las disciplinas que conforman el Departamento de Ciencias de la Antigüedad son imprescindibles para el estudio del Mundo Antiguo, complementándose de forma muy eficaz.

Por otro lado, como afirmaba Luciano en el famoso opúsculo Cómo se debe escribir la historia, estos jóvenes investigadores de la Prehistoria y el Mundo Antiguo se han enfrentado a sus investigaciones «equipados con dos cualidades fundamentales: inteligencia política y capacidad de expresión; la primera es un don innato de la naturaleza, y la segunda se produce a continuación de un intenso ejercicio, un esfuerzo continuado y la imitación de los antiguos». Pues también, siguiendo a Luciano, «la historia no es una de las cosas fáciles de manejar, ni de las que puedan componerse con negligencia, sino que necesita mucha meditación». Coloquios como este permiten realizar el esfuerzo de comunicar resultados recientes de in- 
vestigaciones en curso, avances de tesis doctorales y, además, reflexionar sobre problemas metodológicos, líneas de investigación y otras cuestiones relacionadas con el trabajo del historiador. El desarrollo de las Jornadas demostró que se cumplieron esos objetivos, de lo que es un testimonio muy elocuente la publicación que tengo el placer de prologar.

Finalmente, quiero recordar a todas las entidades patrocinadoras de estas Jornadas: el Departamento de Ciencias de la Antigüedad, los grupos de investigación Hiberus, Byblion y Primero Pobladores del Valle del Ebro, y, por último, el Instituto Universitario de Investigación en Ciencias Ambientales de Aragón. No puedo tampoco olvidarme de todos aquellos becarios de investigación del Departamento de Ciencias de la Antigüedad que colaboraron, con su presencia, entusiasmo y acogida a los participantes, para que estas IV Jornadas Doctorales en Ciencias de la Antigüedad fueran un rotundo éxito.

Maria Angustias Villacampa Rubio

Directora del Departamento de Ciencias de la Antigüedad 



\title{
EL POBLAMIENTO DURANTE EL PALEOLÍTICO SUPERIOR EN LA PROVINCIA DE BURGOS: SÍNTESIS Y PROPUESTAS
}

\author{
The settlement during the Upper Paleolithic in the \\ province of Burgos: synthesis and proposals \\ María Cases ${ }^{1}$
}

Resumen: Esta síntesis ofrece una visión del poblamiento en la región de Burgos durante el Paleolítico Superior, recopilando los datos bibliográficos disponibles y registros de materiales. Para ello se parte de la tesis publicada por Clark en 1979, que sigue siendo el único estudio sistemático del territorio. Se trata de considerar si realmente hay un vacío demográfico o un problema en cuanto al enfoque de la investigación y dejar abierta la vía de que sea una zona asimilable a los focos clásicos de poblamiento durante el Paleolítico Superior en la Península Ibérica. Ibérica.

Palabras clave: Paleolítico Superior, poblamiento, Burgos, Meseta

Abstract: This synthesis shows a vision of the settlement in Burgos during the Upper Paleolithic, through available bibliographic data and material records. The starting point has been the thesis published by G. Clark in 1979, which remains the only systematic study of the territory. The question is to considerer if there is really a demographic vacuum or there is a problem in terms of research approach, and leave an open way to

1 Estudiante de Máster. Universidad de Zaragoza. Correo electrónico: maria237cases@gmail.com. 
think it as an area comparable to the classic focus of settlement during the Upeer Paleolithic on the Iberian Peninsula.

Keywords: Upper Paleolithic, settlement, Burgos, Iberian Meseta.

El argumento climático es la base de las hipótesis acerca del poblamiento durante el Paleolítico Superior para el territorio burgalés y el conjunto de la Meseta Norte. Se ha venido asumiendo que un escenario climático sujeto a constantes cambios favorecería una situación poco apta para los asentamientos humanos en el Pleistoceno Superior Final. ${ }^{2}$ Esto, unido a las características geográficas de la zona, se aduce como justificante para las escasas evidencias arqueológicas de este territorio.

En la actualidad las posturas predominantes son dos. Por un lado, se plantea que las ocupaciones serían estacionales y limitadas a los periodos más cálidos (Ripoll et al. 1997, pp.55-87; Corchón 2002, pp.85-142). Por otro lado, se sostiene que también podría haberse dado una ocupación continua de la zona de la meseta durante los momentos fríos (Alcolea 2013, p.137). Estas hipótesis se centran en que el grueso de yacimientos con industrias líticas se han datado en Magdaleniense y Aziliense, lo cual se corresponde con una fase de clima algo más cálido. Y, a su vez, consideran que, al estar estos lugares a una altitud muy elevada, el frío y las condiciones habrían sido más duras para la ocupación, por lo que los grupos humanos habrían evitado estos establecimientos. Se trata pues de una postura para la que el clima sería un determinante del comportamiento y adaptación de estas gentes.

A esto hay que ańadir la problemática de la escasez de lugares excavados, que ha constituido uno de los pilares fundamentales para argumentar esta presencia tan limitada. El posicionamiento que defiende una presencia más continuada se basa en algunas ocupaciones magdalenienses estudia-

2 Efectivamente, durante el Paleolítico Superior nos situamos en el Pleistoceno Superior Final, dentro de los estadios isotópicos 3 y 1, que coinciden con el Último Máximo Glacial, durante el cual el Hemisferio Norte estuvo sujeto a una enorme variabilidad climática, recogida en la alternancia de dos episodios Dansgaard/Oeschger y seis eventos Heinrich (Burroughs, 2005). 
das en abrigos castellanos como Vergara o Alejandre (Soria, Deza), que se corresponden con momentos fríos (Utrilla y Blasco, 2000, pp.10-63) del Dryas I y III, así como la Peña de Estebanvela (Segovia), el Solutrense de Peña Capón (Segovia) o de Delicias (Madrid). En cualquier caso, ambas perspectivas parecen insuficientes a día de hoy para decantarse por una de las opciones.

En 1979 Clark llevó a cabo un reconocimiento sistemático de yacimientos arqueológicos en la cabecera de la cuenca del Ebro (Clark, 1979). Para ello, se basó en informaciones locales, haciendo reconocimientos sistemáticos a pie en zonas que consideró propensas a una densa concentración de restos, como las cuencas de los ríos y sus costados, y se ayudó de referencias en antiguas publicaciones. Registró un total de 59 zonas con potencial para albergar yacimientos, 57 de las cuales estarían en cuevas o abrigos. Estos posibles lugares se agruparon en cinco grupos (Clark, 1979, pp.21-153): San Felices de Sedano/Covanera (Río Rudrón), Orbaneja del Castillo (Río Ebro), Frías (Río Ebro), Oña (Río Molinar) y Cornejo (Río Ojo Guareña). En su trabajo, Clark realiza un inventario con los materiales arqueológicos recogidos, pero se debe tener en cuenta que solo se hicieron pequeños sondeos en 22 lugares, de los que 13 no tenían testimonios de ocupación. Asimismo, señala ocupaciones de la Edad del Bronce y el Hierro en algunos lugares y materiales del Paleolítico Superior en La Blanca. Con esta información, el autor elaboró un inventario de materiales, concluyendo que en las zonas cercanas a cursos de agua primarios o secundarios hubo mayor probabilidad de ocupación. En conjunto, consideró que las evidencias del periodo pleistoceno eran escasas y reducidas a arte e industria de poco valor diagnóstico.

Desde que se publicara este estudio no se han realizado demasiados avances en el tema y cabe señalar que no se ha tenido apenas en cuenta la posibilidad de que existiesen campamentos al aire libre. En consecuencia, este trabajo subraya la posibilidad de que ese supuesto vacío poblacional puede deberse a ciertas carencias en los focos de la investigación. Para ello se hace hincapié en cómo el territorio dispone de los recursos necesarios para la supervivencia, en que el argumento climático no es totalmente determinante y en que es necesario profundizar en el registro arqueológico. Se trata, en definitiva, de ofrecer otras perspectivas a partir de los datos ya estudiados. 


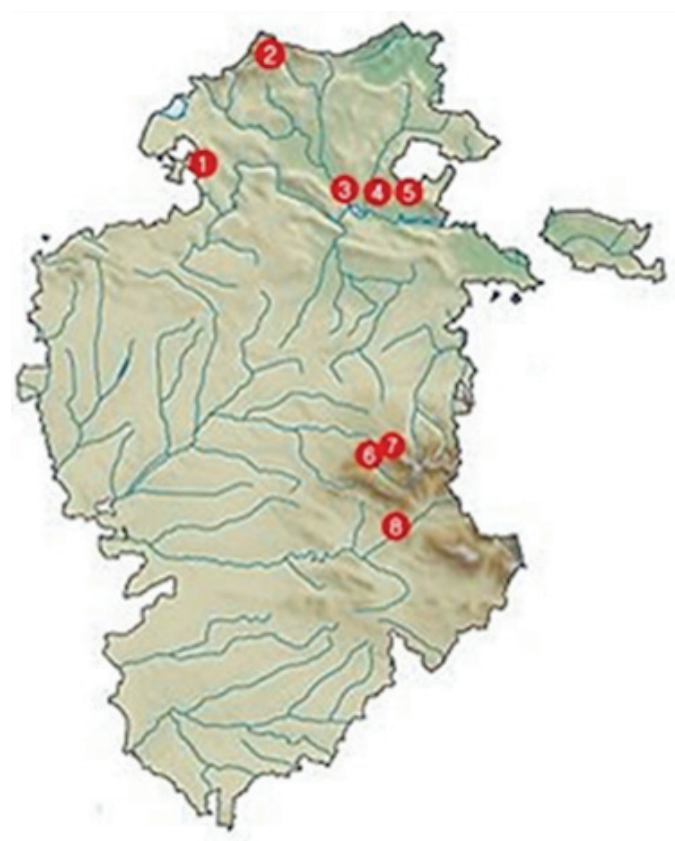

Fig. 1. Elaboración propia. 1- El Níspero, 2-Cueva Palomera, 3- Penches, 4-La Blanca, 5-El Caballón, 6-Cueva Mayor, 7- Valle de las Orquídeas, 8- La Aceńa.

La bibliografía existente ha permitido tanto conocer los yacimientos como valorar las circunstancias de su excavación, que por lo temprano de sus fechas y metodologías han de tenerse en consideración. También se ha recurrido a los inventarios de materiales disponibles, los cuales se han replanteado en función de aspectos como las condiciones ambientales. Se ha trabajado con un total de ocho lugares que corresponden cronológicamente con el Paleolítico Superior (Delibes de Castro y Díez Martín, 2006, pp.11-35). ${ }^{3}$ Estos se han divido geográficamente en los siguientes núcleos; valle del río Oca, Sierra de Atapuerca y margen izquierda del río Ebro.

3 En este resumen, la explicación de los yacimientos ha sido reducida al mínimo por cuestión de espacio. No así en el trabajo inédito del cual deriva, Paleolítico Superior en la Provincia de Burgos, presentado en el Máster Interuniversitario en Evolución Humana de la Universidad de Burgos (2014-2015). 
El primero de los núcleos, el valle del río Oca (Clark, 1979, pp.5582), reúne los yacimientos de La Blanca, El Caballón y Penches. Abarca una zona entre el Pirineo y las montañas de la zona cántabra y asturiana, suponiendo un paso natural hacia las zonas centrales. De La Blanca (Oña) (Rodríguez Fernández, 1917, pp.155-157; Ibero, 1923, pp.449-452) no se conserva demasiada información, más allá de la reconstrucción de la estratigrafía que llevó a cabo Corchón (2002) y unos pocos materiales. Esta ha permitido identificar un nivel Musteriense y otro del Magdaleniense Superior, sobre la base a la industria y las faunas; teniendo en cuenta que se carece de dataciones directas.

El abrigo de El Caballón, en la orilla opuesta a La Blanca, se ha identificado con Magdaleniense Superior en cuanto a la aparición de azagayas de hueso y un bastón de mando perdido en la actualidad, pero del que se conservan dibujos que muestran la decoración de este con un capriforme estilizado, típico del Magdaleniense Superior cantábrico. En el utillaje lítico hay predominio de lascas laminares, y también apareció un colgante sobre costilla de cabra. Se identificó con una única ocupación tanto por Ibero como por Corchón (Ibero, 1923, pp.449-452; Corchón, 2002, p.96).

Por último, estaría la única estación artística de este núcleo, el pequeño abrigo de Penches (Barcina de los Montes) (García et al., 2001, pp.932) también conocida como Cueva de los Moros. Cronoestilísticamente, se ha datado en el Magdaleniense Superior y presenta algunos convencionalismos similares a los de la placa de Villalba (Soria). Alberga cápridos, motivos esquemáticos y antropomorfos, con un horizonte artístico que ofrece algunos paralelos que se han datado en el arte mueble durante el Magdaleniense Superior, y ciertas similitudes estilísticas con la placa de Villalba (Soria).

El segundo de los núcleos se sitúa en la sierra de Atapuerca, localizada en Ibeas de Juarros (Clark, 1979, pp.87-134), entre los sistemas montañosos de la Cordillera Cantábrica y el Sistema Ibérico; allí están Cueva Mayor de Atapuerca, el Valle de las Orquídeas y La Aceña. Cueva Mayor ha quedado fuera de este trabajo dadas las controversias sobre su autenticidad y ausencia de restos arqueológicos (Marcos et al., 2001, pp.153-169). Los últimos estudios (García et al., 2001, pp.9-32), señalan que lo más probable es que la pintura que alberga — una supuesta cabeza de caballo— sea contemporánea. 
En cuanto al Valle de las Orquídeas (Diez Fernández-Lomana y Navazo, 2005, pp.39-54; Mosquera et al., 2007, pp.143-155), se trata del único yacimiento al aire libre por el momento, situado en la parte alta de la sierra, al sur de Matagrande. Ha proporcionado un conjunto lítico asociado a depósitos de terra rossa datado por termoluminiscencia en $27507 \pm 2295 \mathrm{BP}$ y $29955 \pm 2319$ BP. Alberga 306 piezas tecnológicamente homogéneas con un sustrato típico del Paleolítico Medio y pocos rasgos del Superior, que se han identificado con la actividad propia de un taller con gran producción de lascas. Las materias primas provienen del entorno, y cabe señalar que por esa misma área de Matagrande se han documentado varias concentraciones de restos líticos en superficie, pero afectadas por un camino que atraviesa esa zona (Mosquera et al., 2007, p.146).

La Aceña (Breuil et al., 1913, pp.15-22), un abrigo del río Valpoza, en el alto Duero, es el más elevado de todos los yacimientos burgaleses, con una altitud de 1030 metros. No posee una adscripción cronológica demasiado concreta, pero Breuil y Saturio González, quienes lo excavaron en 1912, identificaron uno de sus niveles con el periodo Aurińaciense sobre la base de los restos líticos. El otro nivel se compone de restos de fauna fragmentada, que quizá se deban a una alternancia en la ocupación. En cuanto a los materiales, aportó unos 60 soportes líticos de sílex y cuarcita, lascas en su mayoría, y lo que Breuil identificó como una punta de la Gravette ${ }^{4}$ (Breuil et al., 1913, p.5). Corchón ya señaló en su momento (Corchón et al., 2000, pp.100-103) que se trata de un conjunto muy escaso para atribuirlo con seguridad a una etapa concreta del Paleolítico Superior, y a esto hay que ańadir la problemática actual para localizarlo. Breuil y Obermaier lo situaban en las cercanías de La Aceña, a unos $20 \mathrm{~km}$ de Salas de los Infantes, siendo la tendencia más aceptada. Para otros autores como Santa Olalla estaría en las cercanías de Santo Domingo de Silos.

El último núcleo corresponde a la margen izquierda del río Ebro (Clark, 1979, pp.136-148), y en él se encuentran El Níspero y Cueva Palomera, en la vertiente meridional de la cordillera Cantábrica. El Níspero, en

4 Personalmente he decidido interpretarla como una hoja con retoques laterales dadas sus características, considerando demasiado optimista su identificación como punta de la Gravette. 
Orbaneja del Castillo (Corchón, 1990, pp.83-100) acumula sus materiales en seis niveles, que por su industria lítica microlítica se ha atribuido al Epipaleolítico Medio No Geométrico, y respondería a un asentamiento ocasional sobre la base de los restos de fauna consumida. Aunque se distancia en principio de la cronología del resto de yacimientos, se ha tenido en cuenta por su inmediata continuidad temporal, y especialmente por el nivel VI, que fue atribuido a un posible Paleolítico Final o Epipaleolítico Antiguo.

Para terminar, Cueva Palomera, dentro del sistema kárstico de Ojo Guareña, en el valle de Sotoscuevas, es la única estación rupestre de este núcleo. En su interior se encuentran pinturas, grabados y macarroni, así como improntas de manos y rodillas y restos de una antorcha carbonizada. En total unas 93 representaciones entre zoomorfos, formas geométricas y antropomorfos (Ortega y Marín Merino, 1986, pp.10-23). Hay predominio de la pintura sobre el grabado, con un estilo sencillo, lineal y en color negro. Cronológicamente, se ha asignado al Magdaleniense Inferior y Magdaleniense Aziliense, y en este caso sí que se dispone de una datación radiocarbónica (Corchón et al., 1997, pp.37-60). Los resultados se corresponden con la segunda mitad del Greenland Interstadial, y en términos generales con fases cálidas. En cuanto a la datación cronoestilística se corresponde con el horizonte artístico Magdaleno-Aziliense. La antorcha carbonizada también fue datada, y mostró un resultado que sugiere la frecuentación del complejo también durante el Magdaleniense Inferior, durante la fase fría del Greenland Stadial 2 (Corchón et al., 1997, p.52).

Volviendo al punto de partida que motiva este trabajo, la tesis de Clark (1979), quizá el estudio queda limitado por su propia metodología de prospección, pues los sondeos que constata son de pequeño tamaño y poco sistemáticos, y en otras ocasiones, aunque destaca el potencial de determinados lugares, no llegó a realizarlos (Clark, 1979, pp.47, 58, 70, 81, $89,93,118,139)$. A todo esto cabe unir que apenas se tienen en cuenta los lugares al aire libre, lo que considero un sesgo importante a la hora de valorar el territorio. De aquí parte la enorme desproporción entre los yacimientos al aire libre, cuyo único representante es el Valle de las Orquídeas, y los situados en cueva o abrigo.

En general, se hacen necesarios nuevos estudios sobre los materiales, pues, aunque de manera habitual se utilizan materias primas del entorno, sería interesante conocer los porcentajes de la importada. También es des- 
tacable que, en cuanto a las industrias líticas, hay una amplia presencia de conjuntos de lascas que parecen más típicos del Paleolítico Medio que del Superior, lo que quizá simplemente deba interpretarse como un elemento de continuidad. Los estudios tafonómicos y taxonómicos de la fauna son también muy limitados, pero con los datos actuales se puede inferir que el consumo mayoritario es de cabra (Capra ibex), y en este aspecto sería interesante plantearse si pudo deberse a una especialización.

Asimismo, es claro que el horizonte arqueológico más representado es el Magdaleniense. En este sentido, durante la última pulsación fría sí que hubo ocupación en la cuenca del Ebro y los Prepirineos, en asentamientos que por altitud y nichos ecológicos se asemejan a la zona. Merece la pena tener en cuenta a la hora de considerar el territorio el caso de Treviño, a $55 \mathrm{~km}$ en línea recta de Burgos y que presenta tanto yacimientos al aire libre como en cueva durante todo el Paleolítico Superior. También es conveniente señalar que esta explosión Magdaleniense es común a todo el territorio peninsular, y que bien podría asimilarse a una baja demografía en etapas previas a este momento y sesgos en el registro arqueológico.

Mayoritariamente se trata de cuevas o abrigos con orientación de la boca SE-SW, es decir, que recibirían luz solar durante todo el día en el invierno. En este sentido, y como suele ser habitual, cabe señalar la diferenciación del uso entre aquellos lugares que fueron de habitación y los que fueron estaciones rupestres. Otra característica común es su localización general en valles abrigados, lo que por un lado permite una buena visual del territorio y por otro la existencia de microclimas, un elemento a tener en cuenta a la hora de considerar los recursos de caza. En este sentido, también se emplazan cercanas a cursos de agua.

En cuanto a las comunicaciones, están en vías o lugares de paso natural que facilitan el paso a la Cornisa Cantábrica. En general se observan comunicaciones hacia el Sur con el Duero y el Ebro, y con el Norte hacia la Cordillera Cantábrica. Además, parece que hay relaciones que se observan tanto en el arte parietal de las estaciones rupestres, como en el bastón de mando de La Blanca. Esto puede apoyarse en la presencia de yacimientos en el paso natural que lleva al valle del Ebro del Portilla de la Sia, al Sur de Cantabria, que alberga arte rupestre en la Cueva de los Santos (De Quirós y Neira Campos, 1993). También conviene nombrar la zona de paso a través del valle del Mena y el paso de los Tornos. 
Por último, tan solo hay un yacimiento al aire libre, que cronológicamente es uno de los más antiguos, y que presenta dudas en cuanto a interpretación y asignación cronológica, que se ha situado entre el 34600 \pm 22900 BP (Diez Fernández-Lomana y Navazo, 2005, pp.39-54). Podría considerarse que haya una sobrerrepresentación de objetos líticos al ser un yacimiento a cielo abierto expuesto a las inclemencias del clima y la erosión, lo cual podría dar lugar a una interpretación sesgada. Asimismo, hay que pensar en una posible contaminación con materiales del Paleolítico Medio con Paleolítico Superior. Para ello me baso en la complicada definición del conjunto material, que no parece encajar por completo en ninguno de los periodos. Además, si observamos los morfotipos de configurados, podemos pensar que nos encontramos ante un Musteriense de denticulados, ya que suponen el 52,3 \% del total (Mosquera et al., 2010, pp.143-155) En cuanto a las dataciones por termoluminiscencia de los depósitos de terra rossa en los que aparecieron los materiales, también pueden ser dudosas si se tiene en cuenta que lo que se datan son los depósitos, y no la deposición del conjunto lítico. Todo ello factores que hacen pensar más bien en un Paleolítico Medio que en un Paleolítico Superior, un momento de transición, o un estadio Chatelperroniense. En cualquier caso, merece la pena tener en cuenta sus características a la hora de localizar otros emplazamientos.

Como conclusiones, en primer lugar, cabe recordar cómo la perspectiva de la Península Ibérica es escasa a la hora de abordar este territorio y sus características. Sería deseable solucionar este problema prestando atención a la perspectiva del territorio europeo, donde hay claros ejemplos de ocupaciones al aire libre durante momentos fríos (Kostenki, Rydno, Molodova). En la misma línea, el realizar los sondeos solo en cuevas o abrigos plantea un importante sesgo en las investigaciones y sus resultados, así como a la hora de valorar las perspectivas que estos ofrecen. Es necesario también, considerar los aspectos propios de la zona. Es fácil que muchos yacimientos se hayan visto alterados o destruidos, tanto por acción humana como geológica, pues se dan procesos erosivos y es muy frecuente la reactivación de los sistemas kársticos de la zona.

Otro tema destacable es la relación con la Cornisa Cantábrica, la cual queda reflejada en aspectos como el arte rupestre y mobiliar. Lamentablemente, el elemento más informativo, el bastón de mando de La Blanca, solo ha llegado a nosotros gracias a ilustraciones de Cabré (García Soto, 
1988, pp.9-32). Pero tanto por la tipología como por la decoración de una cabra esquemática, este lleva a pensar en el Magdaleniense Superior Cantábrico, lo cual enlazaría el territorio burgalés con la zona cantábrica, indicando movilidad o contacto (Corchón, 2002, pp.103-110).

En cuanto a la cantidad de cronologías Magdalenienses, como se ha comentado, bien podría ser asumible al aumento demográfico que se da de manera general en la península. Solo se trata de un cambio demográfico que puede llevar a plantear que las ocupaciones fuesen puntuales pero reiterativas, y quizá en relación con actividades de consumo primarias como la caza, por lo que sería deseable estudiar la movilidad y áreas de captación del territorio.

Como propuestas para futuras investigaciones, se plantean varias sugerencias. En primer lugar, sería necesario crear un registro de datos paleoambientales para facilitar el estudio del contexto de las ocupaciones. Sería también deseable realizar una revisión actualizada de los conjuntos de materiales, dado lo temprano de las fechas en que se trabajó con ellos en la mayoría de los casos y los avances actuales que podrían permitir extraer nuevas informaciones. Y, por último, deberían realizarse nuevos sondeos sobre la base de modelos predictivos desarrollados con Sistemas de Información Geográfica, que recojan tanto aspectos de movilidad y comunicaciones como de captación de recursos. En definitiva, se trata de potenciar los estudios multidisciplinares para poder aportar una visión general y más amplia de este escenario, poniendo en relación los yacimientos con sus entornos y perfilando modelos de ocupación, territorialidad y movilidad, superando sesgos y carencias de estudios pasados, y remarcando la importancia de este territorio como vía de comunicación entre la zona cantábrica, la Meseta y el Levante.

\section{BibLIOGRAFÍA}

Alcolea, J., 2013. Entre el Gravetiense y el Solutrense: el nivel 3 de Peña Capón (Valle del Sorbe, Guadalajara). Santander: Monografías del Museo Nacional y Centro de Investigación de Altamira.

Breuil, H., Obermaier, H. y Alcalde del Río S., 1913. La Pasiega à Puente Viesgo, Santander (Espagne). Mónaco: Chêne. 
Burroughs, W.J., 2005. Climate change in Prehistory. The end of the reign of chaos. Cambridge: Cambridge University Press.

Clark, G.A. 1979. The north Burgos Archaeological survey. Bronze and Iron Age archaeology on the Meseta del Norte (Province of Burgos, North-Central Spain). Tempe: Arizona State University.

Corchón, M.S., 1990. Datos sobre el Epipaleolítico en la Meseta Norte: la Cueva del Níspero (Orbaneja del Castillo, Sedano, Burgos). Zephyrus, XLI-XLI, pp. 83-100.

Corchón, M.S., 2002. El Tardiglaciar y la transición al Postglaciar en la Meseta Norte española: una visión de síntesis (Reflexiones acerca de las investigaciones realizadas en los últimos diez años en el territorio de Castilla-León). Zephyrus, 55, pp. 85-142.

Corchón, S., et alii. 1997. Datación de las pinturas y revisión del arte paleolítico de Cueva Palomera (Ojo Guareńa, Burgos, España). Zephyrus, XILX, pp. 37-60.

Delibes de Castro, G., Díez Martín, F. 2006. El Paleolítico Superior en la Meseta Norte Española. Valladolid: Universidad de Valladolid.

De Quirós, B., Neira Campos, A. 1993. Paleolítico Superior Final de Alta Montaña en la Cordillera Cantábrica (Noreste de León). Pyrenae, 24, pp. 17-22.

Diez Fernández-Lomana, C. y Navazo, M., 2005. Apuntes sociales y geográficos a partir de los yacimientos del Paleolítico Medio en la zona nororiental de la Meseta castellano-leonesa. En R. Montes y J.A Lasheras, eds. 2005. Neandertales Cantábricos. Estado de la Cuestión. Santander: Monografías del Museo Nacional y Centro de Investigación de Altamira, pp. 29-54.

García, M., et alii. 2001. Arte rupestre de estilo Paleolítico del Portalón de Cueva Mayor de la Sierra de Atapuerca (Ibeas de Juarros, Burgos): ¿Cronología Paleolítica o contemporánea?. Trabajos de Prehistoria, 58 (1), pp. 153 - 169.

García Soto, E. 1988. Materiales Paleolíticos (Colecciones de Saturio González y José Ma Ibero. En: G. Delibes, A. Esparza, E. García-Soto y M. Mariné, eds. La Colección Arqueológica del padre Saturio González en Santo Domingo de Silos. Burgos: Serie Monografías Burgalesas, Diputación de Burgos, pp. 9-32. Ibero, J. M. 1923. Sepulcros antiguos en los alrededores de Oria, Burgos. Razón y Fe, 66, pp.428-450.

Mosquera, M. et alii. E. 2007. Valle de las Orquídeas: un yacimiento al aire libre del Pleistoceno Superior en la Sierra de Atapuerca (Burgos). Trabajos de Prehistoria, 64 (2), pp.143-155.

Ortega, A. I. y Martín Merino, M.A. 1986. El arte rupestre de Ojo Guareńa. Singularidad y pervivencia en el tiempo. Cubia, 19, pp.10-23.

Ripoll López, S., Cacho Quesada, C., Municio González, J.L. 1997. El Paleolítico Superior en la Meseta. Espacio, Tiempo y Forma, Prehistoria y Arqueología, 10 (1), 55-87. 
Rodríguez Fernández, J.M. 1917. Cueva de la Blanca Ońa. Revista Ibérica, 166, pp.155-157.

Utrilla, P. y Blasco, F. 2000. Dos asentamientos magdalenienses en Deza (Soria). Boletin del Seminario de Arte y Arqueología, 46, pp.9-63. 


\section{URBANIZACIÓN EN LA ITALIA CENTRO- TIRRENA (SS. X-VI A. C.)}

\section{Urbanization in Central Tyrrhenian Italy (10th-6th centuries $B C$ )}

Jordi Calvo Cortés ${ }^{1}$

Resumen: Las investigaciones de la arqueología mediterránea en los últimos años han propiciado un cambio en la forma en la que se construye el relato historiográfico en torno a los fenómenos de urbanización protagonizados por las comunidades humanas de esta extensa zona durante la primera mitad del último milenio antes de nuestra era. De unas perspectivas difusionistas, y de evolución lineal homogénea, se ha pasado a observar la urbanización como una serie de fenómenos de variabilidad contingente, con gran importancia de los factores locales y de la acción humana. El caso de la Italia central bañada por el mar Tirreno es un buen ejemplo de este giro.

Palabras clave: Lacio, Etruria, Edad del Hierro, Urbanización mediteránea, ciudad antigua.

Abstract: Mediterranean archaeology research has provided evidences in the last years that have led a change in the historiographical discourse about ancient urbanization. How the peoples that lived in the Mediterranean during the first half of the last millennium BC change their life's way into new urban forms. Initially seen with diffusionist perspectives, and a homogeneous linear evolution, now urbanization is seen more as a series

1 Doctorando. Universitat Pompeu Fabra. Correo electrónico: jordi.calvo01@estudiant.upf.edu. 
of several phenomena of contingent variability, with great importance of local factors, and human agency. The case of central Tyrrhenian Italy is a good example to watch this turn.

Keywords: Latium, Etruria, Iron Age, Mediterranean urbanization, ancient city.

La ciudad antigua ha sido objeto de estudio y debate por parte de la historiografía moderna desde bien temprano. La monografía La Cité antique de Fustel de Coulanges (2009 [1866]) es una muestra de ese interés por el fenómeno urbano en las comunidades antiguas. Se trataba de un análisis que ponía su foco en el desarrollo de un tipo concreto de urbes, las griegas y romanas del período clásico, las llamadas póleis. En su origen, este término griego $(\pi 0$ $\lambda \iota \varsigma)$ se disociaba en dos significados: por un lado, el relativo a la misma extensión material del asentamiento urbano; $y$, por otro lado, a su sentido político. El objeto de análisis que se primaba más era el correspondiente a este segundo significado, es por ello, que para referirse al mismo se articulara el término ciudad-estado (city-sate, Stadtstaat). Con ello, se vinculaba la formación de las ciudades con la del Estado; es decir, ver cómo se formaban las ciudades antiguas era ver cómo se formaban sus Estados. A este enfoque sobre el aspecto político de la vida urbana, que no solo aplicaba el historiador francés, se añadía un concepto evolutivo, dónde esas ciudades-estado se iban fraguando al pasar por diferentes estadios en una línea de progreso continua. Las ideas de autores como Morgan y Engels se pueden rastrear en esa construcción, al determinar que la evolución de las estructuras familiares (de fratrias a curias, y luego a tribus), dentro del marco institucional de leyes y ritos religiosos, eran las que iban conformando el paso hacia la forma cívica o estatal (Fustel de Coulanges, 2009 [1866], pp.150-156). Este binomio entre estructura cívica (urbana) y estatal ha perdurado largamente en el tiempo.

En los primeros ańos del siglo XX destaca la influencia de los trabajos del sociólogo alemán Max Weber, como The Agrarian Sociology of Ancient Civilizations (2013 [1909]), y el póstumo The City (1958 [1921]). Para este autor, a la impronta de las instituciones se debía añadir el factor económico, estableciendo la ciudad como el nexo entre la sociedad y las instituciones. Emergía la ciudad como centro administrativo y espacio de 
intercambio económico, de mercado. Si bien este modelo weberiano partía del mundo antiguo clásico, se centraba, en especial, en las raíces medievales de la ciudad moderna occidental. Tras Weber, otro autor de gran influencia será Moses I. Finley y su The Ancient Economy (1999 [1973]), que aúna tanto el factor político como el económico de las urbes y los Estados de la Antigüedad clásica. La impronta del modelo weberiano es grande, y se manifiesta en la forma en que se trata de definir qué es lo que hace a una ciudad serlo. Es decir, que la ciudad ya no constituye una simple aglomeración de personas, sino más bien un espacio que adquiere toda una serie de condiciones arquitectónicas tales, que permitan la interacción social y económica (Finley, 1977, p.305). Se formulan criterios poblacionales y funcionales, tratando de encontrar un modelo universal. Modelos que muestran a las ciudades como centros de diversificación de labores, y de especialización, donde satisfacer las necesidades que no permite el autoabastecimiento. A los que se suma la aparición de una serie de estructuras materiales que facilitan esa interacción económica, y también la política, como son templos y ágoras, o puertas y murallas, o cualquier otra arquitectura que delate un uso público.

Pero tratar de encontrar un modelo universal que todo el mundo acepte es algo complicado. Algo que no solo el mismo Finley asumía ${ }^{2}$ : antes que él, el arqueólogo Gordon Childe abría su influyente artículo «The Urban Revolution» advirtiendo de la notoria dificultad que se encuentra a la hora de tratar de definir qué es una ciudad. Para este autor, la ciudad ${ }^{3}$ tiene su historia, y esta es resultado de una revolución (Childe, 1950). Se trata de otro planteamiento evolutivo, propuesto desde la arqueología, en el que la ciudad es el fruto de toda una serie de procesos que conducían a un incremento de la complejidad social, y a la formación de estructuras estatales. Una interpretación que será explotada por la llamada New Archaeology durante los ańos 60-70 del pasado siglo. $\mathrm{Al}$ interpretar que todo proceso de urbanización sería, pues, indicativo de la emergencia del Estado, se reforzaba ese viejo binomio de ciudad y Estado, dejando de lado otras

2 Sentencia Finley que ni geógrafos, ni sociólogos, ni historiadores han tenido éxito en acordar una definición para ciudad; las dificultades para articular todo lo esencial, sin excluir períodos enteros de la historia, se hace complejo (Finley, 1977, p.307).

3 La ciudad en singular, como ente abstracto y no concreto. 
opciones, como si no se diera la posibilidad que hubiera habido ciudades sin Estado, y Estado sin ciudades (Cowgill, 2004, p.526). En conjunto son todos unos modelos que parten de una concepción jerárquica y analizada desde la perspectiva misma de la ciudad, con grandes procesos que no incorporan a las gentes que las construyen y viven. Esto es algo que ya intuye Lewis Mumford, que pese a seguir las líneas de Childe, argumenta que la ciudad es algo más que una serie de procesos e instituciones: es un contenedor, no solo de gentes, sino de vidas y memorias, donde elementos antes dispersos se concentran en un espacio reducido, acotado, en el que se genera un estado dinámico de tensión e interacción social (Mumford, 1961, p.31). Esa interacción puede ser el motor que hay tras los cambios que se producen en los procesos de urbanización.

Mas no será hasta la crítica posmoderna cuando se empiece a poner en relieve la acción humana, su valor práctico en la acción (Bourdieu, 1977 [1972]), destacándose que la dimensión espacial tiene un impacto en la vida social de los humanos (Lefebvre, 1991 [1974]; Foucault, 1977 [1975]). Esto hace que se pueda ver la ciudad como un espacio construido no por meros sujetos pasivos, sino por personas vivas y activas, que tienen un papel central en la producción y reproducción social. La ciudad no es un simple contendor, sino un espacio generador (Soja, 2000); espacio vivido, que se imbuye de sentido, identidad y memoria. Esto es, que las ciudades son modeladas activamente, a través de las experiencias y la práctica diaria, por las personas que las habitan a lo largo del tiempo. Esta dimensión de espacios vividos hace que las ciudades ${ }^{4}$ puedan ser entendidas como espacios sociales contingentes, con su propia historia, alejando el foco de la linealidad evolutiva que las propuestas anteriores implicaban. Cada caso tendrá sus propias historias y complejidades, a las que habrá que aproximarse de cerca para entenderlas (Fisher y Creekmore, 2014, pp.6-7). No solo tendrán cabida las relaciones económicas y políticas, sino también las afectivas, las emocionales. Una experiencia urbana, donde se pueden dar sinergias y oportunidades para la interacción humana, desarrollándose nuevas identidades, tanto individuales como colectivas, a diferentes escalas socioespaciales.

4 Ahora ya sí en plural, en su diversidad. 
Ya situados en el caso de los procesos de urbanización de la cuenca del Mediterráneo antiguo se añade otro factor a todo lo dicho: la explicación difusionista del fenómeno urbano. Según esta concepción, se definía un eje de Oriente a Occidente, con foco original en el Egeo, desde donde se diseminaba hacia el resto. Se fijaba un modelo urbano por excelencia: el de la polis de los atenienses, que contaba como motor para esa dispersión a las migraciones de grupos egeos, conceptualizada bajo el prisma del «colonialismo" griego (Boardman, 1980 [1964]). A este modelo colonialista helenocéntrico se añade, con posterioridad, el fenicio, pues también las gentes levantinas surcan el Mediterráneo en esa dirección (Aubet, 2001); pero no deja de ser el mismo tipo de modelo conceptual difusionista oriental. Una concepción que es objeto de revisión desde la crítica poscolonial, que indica que toda esta argumentación en el fondo plasmaba una proyección hacia el pasado en busca de legitimación de las políticas coloniales e imperialistas de los modernos estados-nación europeos ${ }^{5}$ (van Dommelen, 2008), adjudicándose una misión prometeica de llevar la luz de la civilización. Además de tratarse de un modelo en el cual la agencia de las gentes locales era ninguneada, y con un tono masculino absoluto. El género activo es siempre el masculino, que será el que colonice y lleve esa llama a las gentes bárbaras; al género femenino se le deja, como mucho, parir, cocinar, limpiar o tejer.

Ahora bien, las evidencias que ha ido aportando la arqueología mediterránea en los últimos años han ido laminando todas estas premisas y construcciones teóricas. Los nuevos datos que proporcionan necrópolis, áreas santuáricas y asentamientos, lo que parecen indicar es otra cosa: que los fenómenos de urbanización que se están desarrollando en diversos lugares del Mediterráneo y de la Europa templada son más próximos en el tiempo, y se están dando de forma paralela. Se cuentan en el Egeo (Morris, 1987), la península ibérica (Sanmartí, 2014), la zona galo-germana (Fernández-Götz, 2018), y en la península italiana (Riva, 2011; Attema, et al., 2010; Alessandri, 2013). Nos muestran comunidades humanas que en su propia diversidad están transitando sus propios caminos a formas de vida

5 Es decir, se definía un sistema colonial que se formulaba desde una perspectiva moderna, como si existiera una potencia colonial griega o fenicia equivalente a las de los estados-nación colonialistas de los siglos XIX y XX. 
urbana, y que estamos más ante dinámicas panmediterráneas (Malkin, 2003; van Dommelen, 2006), que no ante procesos monodireccionales de difusión. Unas dinámicas que se están dando antes de la llegada de egeos y levantinos a tierras de Occidente, y que a su vez les afecta. Los procesos de urbanización dependen tanto de factores locales como de interacciones con otras comunidades, con lazos de interrelación que son más multidireccionales de lo que se creía. La urbanización se da antes que la ciudad esté formada, y toda explicación a partir del producto final (la ciudad del siglo IV a. C.) será teleológica. Cuando eliminamos este sesgo es cuando empezamos a ver los otros posibles caminos de urbanización, con sus líneas divergentes, e incluso abortivas.

El área centro-tirrena es un buen espacio donde ejemplificar estos cambios interpretativos que se han producido en torno a los fenómenos de urbanización mediterránea. Nos permite engarzar procesos a diferentes niveles: local (los centros urbanos), regional (Etruria y Lacio), y suprarregional (el Mediterráneo). El río Tíber delimita la frontera que separa y une estas dos regiones vecinas: en la ribera norte la Etruria meridional, y en la sur el Latium vetus (figuras 1 y 2). Una vecindad que ha favorecido interacciones culturales y económicas a lo largo del tiempo entre las gentes que las han habitado. Se trata de dos regiones con morfologías similares, pero con sus propias singularidades distintivas. Comparten un mismo clima mediterráneo, con veranos secos e inviernos moderadamente fríos, que hace que la actividad agropecuaria se ajuste a sus ritmos anuales, como las prácticas de trashumancia de rebaños ovinos y caprinos. Esta práctica se constata en la zona desde los inicios de la Edad del Bronce, con rutas de las pasturas montañosas de los Apeninos en verano hacia las tierras bajas en invierno, siguiendo los cursos fluviales. Una tradición trashumante ${ }^{6}$ que favorece un continuo contacto y comunicación entre las gentes de la costa y las del interior.

La Etruria meridional se caracteriza por la presencia de un antiguo sistema volcánico que conforma un paisaje con montículos elevados de toba aislados y lagos en algunos de sus extintos cráteres, como el Bolse-

6 Una movilidad que se suele ignorar una vez se empieza a hablar de la aparición de núcleos urbanizados, como si la urbanización terminara con estas prácticas. 


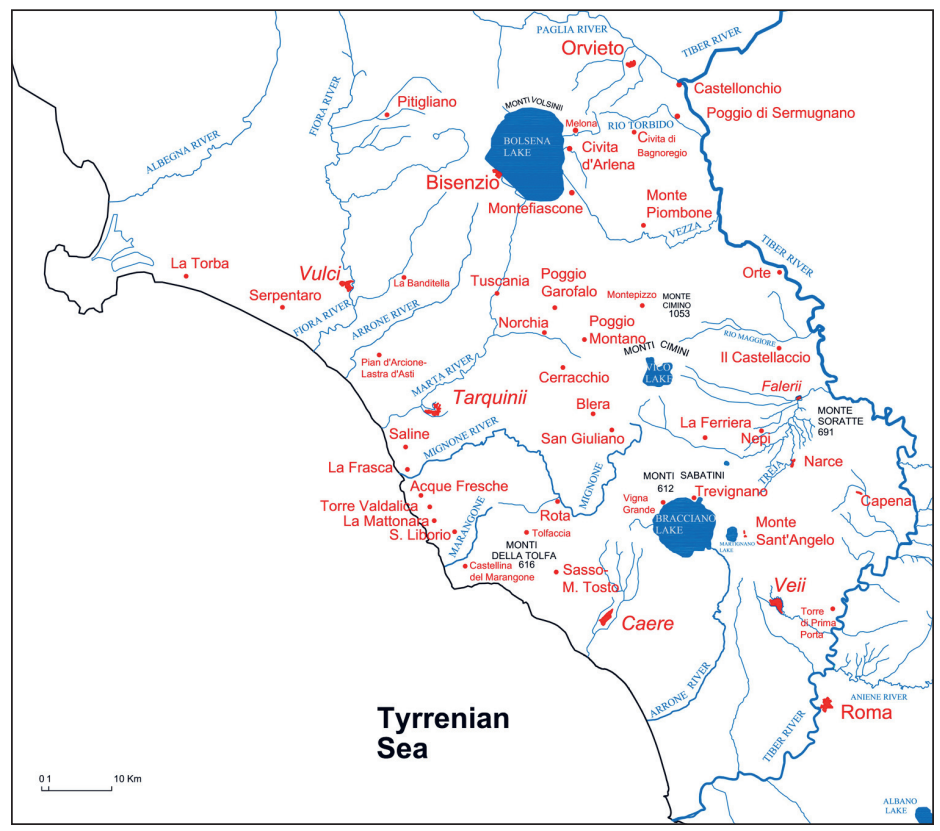

Fig. 1. Etruria Meridional (Amoroso, 2016, p.87).

na, el Vico y el Bracciano. Múltiples ríos cruzan su extensión de este a oeste, destacándose el Arno y el Tíber como los principales, todos ellos dan una capacidad hidrográfica considerable a sus tierras. Un territorio bastante homogéneo en cuanto al acceso a sus recursos y capacidad de comunicaciones. El Latium vetus también cuenta en su parte septentrional con un antiguo sistema volcánico, concentrado en el área de las montañas Albanas, que forman su elemento geográfico de referencia, y que, a su vez, ocupan una posición central; si bien, están separadas de las dos principales rutas fluviales que abren las vías de comunicación hacia otras regiones de la península. Sus dos principales ríos, el Tíber y el Aniene, se concentran en la parte septentrional, y se unen cerca de Roma. El otro gran sistema fluvial lo componen los ríos Sacco, Liri y Garigliano (este último ya en el Latium adiectum), regando la zona que conecta con la Campania, al sur. Las zonas costeras están alejadas de estos sistemas, tanto del albano, como de los fluviales. Por tanto, parecen ser las zonas más externas las que se encuentran 


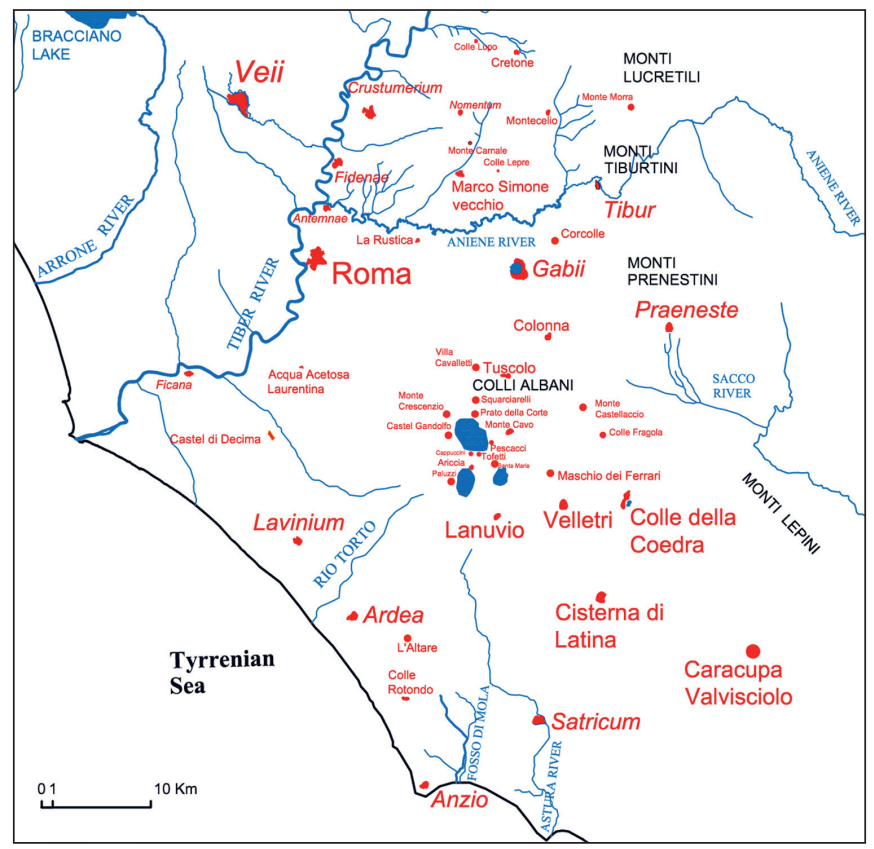

Fig. 2. Latium Vetus (Amoroso, 2016, p.87).

en mejores condiciones para establecer contactos con otras regiones: por un lado a través del Tíber con Etruria, y por otro del Sacco con Campania, y con la zona central de la península a través del Aniene. Hay autores que ven en estas diferencias de comunicación inter e intrarregionales del Lacio respecto a Etruria una explicación de los diferentes caminos urbanos que se desarrollan en ellos (Bietti-Sestieri, 1992; Pacciarelli, 2001). Aunque sea una explicación que puede pecar de un cierto determinismo geográfico, se puede destacar de la misma la importancia que da a las relaciones de interconexión de los diferentes grupos humanos en los cambios que los llevan a formas de vida urbana.

Tanto en Etruria como en Lacio las comunidades humanas que las poblaron durante la Edad del Bronce parece ser que estaban diseminadas por el territorio, en pequeños grupos, con economías de subsistencia agropecuaria. Un paisaje humano capilar en el territorio, que conformaban 
sistemas de aldeas de amplitud variable, de entre 1-5 hectáreas de tamaño en su mayoría, con casos excepcionales de 15-20 hectáreas. Pequeños asentamientos que también eran variables en cuanto a su estabilidad temporal, y que, en algunos casos, podían tener un cierto grado de integración jerárquica entre ellos, aunque con una gran autonomía (Pacciarelli, 2016, p.173). Será ya en las fases finales del Bronce (Bronce Final II y III, entre los siglos XII y X a. C.) cuando se empiece a observar cambios en este tipo de paisaje humano y se formen nuevos tipos de organización social, económica y territorial. A inicios de la Edad del Hierro los asentamientos se hacen más estables en su duración temporal, y tienden a escogerse lugares con buenas posibilidades defensivas, con cercanía a ríos y fuentes de agua, constatándose, además, un incremento en su extensión.

El registro arqueológico empieza a dar muestras de un incremento de la cantidad, y calidad, de las manufacturas, tanto locales como importadas de otros lugares. De una facies más o menos homogénea (apenínica) se pasa a una mayor variedad (villanoviana, lacial). Los objetos de las necrópolis indican un incremento de la riqueza de los ajuares, pasando de meros adornos personales a deposiciones más ricas en las que destacan objetos como fíbulas, armas, piezas de armadura, joyas, o husos para tejer. Este incremento de los utensilios, y su riqueza tanto material como simbólica, presente en algunos de los enterramientos, pero no en todos, nos hace vislumbrar unas sociedades con mayores cotas de diferencias sociales. Son algunos miembros de la comunidad los que parecen acaparar mayor estatus, significado en los objetos con los que se entierran. Para algunas autoras esto es muestra de la posible emergencia de una élite aristocrática ${ }^{7}$, que incorpora también una fuerte distinción de género, que se puede visualizar en las llamadas tumbas principescas (Bartoloni, 2003; Fulminante, 2003).

Así pues, hay indicios que es justo durante esta transición del Bronce al Hierro cuando se empiezan a dar importantes cambios en la forma que las comunidades de Etruria se distribuyen por el territorio. Los asentamientos en zonas defensivas altas, algunos ya ocupados en fases previas, se tornan en la forma predominante del paisaje poblado humano, dándose

7 Aunque hablar de aristocracia es algo que tiene su propia problemática (Bradley, 2015). 
un abandono de otros poblados pequeños en su favor. De unos cincuenta asentamientos detectados en el siglo X en el sur de Etruria, diseminados a intervalos de separación de unos cuantos kilómetros, y con una extensión de entre una y quince hectáreas, se pasa en el siglo IX a una concentración en menos lugares. Son centros que se destacan y controlan más territorio de sus alrededores. Son estos agrandados asentamientos villanovianos (hasta diez veces mayores que sus precedentes) del siglo IX, los que formarán la base de las posteriores ciudades etruscas de Veyes, Cerveteri, Tarquinia, Vulci, Bisenzio y Orvieto. Las comunidades humanas de este período se están agrupando en grupos de mayor extensión, y en algunos espacios privilegiados respecto a otros. Se produce una clara transición en la forma de distribución sobre el territorio.

La selección de estos enclaves concretos respecto a otros, en esta transición en la Etruria meridional de una capilaridad de asentamientos dispersos a una concentración en unos pocos, para algunos autores es fruto de un súbito proceso de aglutinación premeditado, que se remarca como la principal característica de la urbanización en Etruria, una svolta protourbana (Pacciarelli, 2001). Se perfila como un camino particular hacia la urbanización que se contrasta con el que se propone para el Egeo, que se dibuja más paulatino, fruto de procesos de sinecismo de pequeños centros vecinos. Para Etruria se propone un movimiento deliberado con abandono de gran parte de los asentamientos anteriores, que para algunos autores delata hasta un cierto grado de planificación (Pacciarelli, 2016). Si bien, otros autores no lo ven tan rápido, sino como algo más paulatino, de crecimiento en etapas (Vanzetti, 2004). Puede que esta concentración se debiera a un incremento de competencia por los recursos, en una dinámica que favorecía a los centros más grandes (Attema, et al., 2010), o que fuera un cambio producido por un incremento de prácticas de guerra y violencia colectiva, habida cuenta que las posibilidades de defensa son un elemento clave de los nuevos centros, y que en la cultura material hay una evidente ideología guerrera (Martinelli, 2004).

El resultado de toda esta concentración llevó a la cristalización de lo que conocemos como centros protourbanos de Etruria. Aunque no se trata de un único modelo, pues cada centro tendrá sus propias características particulares, ya sean por su cercanía a las costas, al sistema apenínico o a centros metalíferos (Marino, 2015). Buena parte de la arqueología italia- 
na veía en estos centros protourbanos de Etruria el germen de todos los procesos urbanizantes de la península. Una autoctonía que parecía terminar con la visión del difusionismo oriental, pero que en el fondo era una reformulación bajo parámetros italianos. Al tratar de dilucidar cuándo se formaban las primeras ciudades de Italia, ${ }^{8}$ se dibujaba un nuevo modelo: el villanoviano/etrusco, del cual se hacía emerger el resto (Fulminante y Stoddart, 2013). Las cronologías iniciales respecto a los asentamientos protourbanos laciales parecían favorecer esa ventaja inicial de Etruria, y se proponían modelos de dispersión del fenómeno urbano como el de Colin Renfrew de peer polity interaction. Según estas visiones, la extensión de la urbanización desde Etruria hacia el Latium vetus seguía un vector directo, que daba ventaja a Roma respecto a los otros centros latinos más meridionales (Bettelli, 1997), que seguirían la estela urbana con posterioridad. Pero los datos aportados recientemente quiebran ese modelo tan lineal, y muestran unos procesos paralelos más próximos en el tiempo entre las dos riberas del Tíber de lo asumido con anterioridad (Alessandri, 2013; Fulminante, 2014).

Los cambios que se dan a nivel del paisaje de asentamiento de los grupos humanos en el Lacio parecen ser menos radicales que los vistos en Etruria meridional, pero su desarrollo durante los inicios de la Edad del Hierro parece mostrar una trayectoria similar a los de su vecina. Es decir, se constatan también claros indicios de un incremento de la complejidad y jerarquización social de sus comunidades; desarrollo económico y producción artesana, que tiene su reflejo en la forma de asentarse en el territorio. Pero, no se detecta ese súbito abandono de múltiples asentamientos de la Edad del Bronce Final, en favor de unos pocos centros. Sí que hay un incremento en su número, con un énfasis en el emplazamiento en lugares de fácil defensa (Alessandri, 2013; Fulminante, 2014). En contraste, el tamaño de estos asentamientos del Lacio suele ser, en general, menor que los de Etruria, con la excepción del de Roma. Esta variación en cuanto al número y tamaño se destaca cuando comparamos las dimensiones relativas de ambas regiones. El territorio de la Etruria meridional

8 El congreso sostenido en Roma en el año 1977: La formazione della città nel Lazio, supuso el inicio de un fuerte debate que enfrentaba posiciones autoctonistas y orientalistas (egeo-levantinas). 
consta de unos 6.800 kilómetros cuadrados, una superficie que quedará controlada por ese reducido número de centros (Veyes, Cerveteri, Tarquinia, Vulci, Bisenzio y Orvieto), en un esquema jerarquizado donde el resto de los asentamientos orbitan sobre ellos. En cambio, el Latium vetus que cuenta con una extensión menor, de unos 2.700 kilómetros cuadrados, dispone de no menos de dieciocho asentamientos, de gran variedad en tamaño. Todos ellos posicionándose en zonas que permiten controlar las principales vías de comunicaciones. Centros que se mantendrán con posterioridad, conformando el mismo patrón territorial que tendrán las ciudades latinas de los siglos VII y VI a. C. (Amoroso, 2016). De este modo, la mayor variedad en cuanto a la posición en el territorio y el tamaño de los centros en urbanización parece indicar que se trata de otro tipo de red urbana.

En el Latium vetus se mantienen muchos de los asentamientos habitados desde el Bronce Final, de los cuales los más antiguos son los de las colinas albanas y sus pequeños lagos de origen volcánico, algo que la tradición latina parece recordar. ${ }^{9}$ Durante las primeras fases de la Edad del Hierro van cobrando fuerza en diferentes zonas estratégicas del Latium vetus otros asentamientos, que ya podían estar ocupados en fases previas - normalmente en planicies en altura- del Bronce, o son de nueva formación. Centros como: Lavinium, Ardea y Anzio, que se encuentran en zonas próximas a la costa tirrena. Cerca de la llanura pontina, se detecta un cambio en el modelo de asentamiento, de una red de tipo perilagunar se pasa a otra que se concentra en las mesetas de colinas interiores (Attema, et al., 2010), que, además, van ganando tamaño con el tiempo. Otros asentamientos se encuentran en valles fluviales, como el del Tíber, en puntos estratégicos que permiten controlar los vados del río, como Fidenae, Crustumerium o la misma Roma. Situada en la ribera del lago Castiglione, Gabii crece de tamaño y amplía su red defensiva, y se perfila como un asentamiento que permite controlar la ruta de conexión entre Etruria y la Campania a través de los valles del Sacco y el Liri. De la misma forma que Tibur permite controlar el valle del Aniene; y Praeneste el del Sacco (Amoroso, 2016).

9 Por ejemplo, la mítica Alba Longa. 
Todos estos centros de Etruria y Latium vetus se conceptualizan como lugares centrales en cuanto a explotación del territorio circundante y de densidad de población, y se les denomina proturbanos por estar todavía en una fase temprana de los procesos de urbanización. Es decir, que su extensión y cantidad de gente que vive en los mismos les hace capaces de controlar su ager, y de permitir el desarrollo de relaciones sociales más complejas que expliquen su posterior devenir. Mas, dentro de la variabilidad de asentamientos que se detectan en estas dos regiones se hace difícil establecer el límite o el modelo que los defina a todos. Al tratar de determinar la extensión de sus territorios — ager — bajo control, y generar modelos que permitan definir dichos centros proturbanos, parece que todavía se continúe muy lastrado por una visión de la ciudad antigua jerarquizada, de arriba abajo, en la que el núcleo urbano supedita a todo el entorno rural, y que, a su vez, toda su población se supedita a sus élites. Es decir, se mantiene esa visión binomial junto al Estado, en que la urbanización solo puede explicarse mediante esas relaciones de poder, en un claro eje de progresión lineal de complejidad política. De este modo, se puede ver como no casual la distinción entre centros protourbanos respecto a los auténticos centros urbanos, ${ }^{10}$ pues a los primeros les faltaría algo para llegar a ser urbanos en plenitud de su telos: les falta esa distinción de centros económicos y políticos weberianos, con sus instituciones y monumentalidad que las materializa y hace visibles.

Justo en la variabilidad local es donde se puede observar que los procesos de urbanización no son algo tan simple, lineal y jerarquizado (de arriba abajo); por ejemplo, la vida urbana no es una cosa exclusiva del asentamiento urbano, también forman parte de esta el elemento rural. No hay unas gentes del campo supeditadas a unas élites urbanas, ni unas gentes urbanas que se hacen dependientes de la producción rural, sino que en su conjunto van transitando en la forma de encajar en un mundo en cambio que se va haciendo más complejo. Esto nos demuestra que hace falta incorporar otras perspectivas más heterárquicas, y de abajo a arriba para integrar todos los datos. Hay todavía campo para interpretar mejor esos fenómenos locales.

10 Es de interés la reflexión crítica de Adam Ziółkowski sobre el uso del término protourbano (Ziółkowski, 2005). 
Que dos zonas limítrofes, en contacto e influenciadas mutuamente, tengan caminos propios de urbanización significa que hay factores contingentes en su desarrollo. Las gentes de ambas regiones desarrollan estilos de vida urbana, con sus propias características, con existencia e historia continuada en el tiempo. En esa historia se da la emergencia y consolidación de una fuerte identidad cultural, que pudo haber jugado un papel determinante en la preservación de la autonomía de cada región. Esto es, que justo en el momento que empiezan a mostrarse estos iniciales procesos de urbanización en diferentes puntos de la península se empiezan a dar también en su seno los procesos de etnogénesis, que se terminaran de construir más adelante (Cifani y Stoddart, 2012); sin que todas las identidades étnicas de la Italia preromana tengan que terminar en sociedades urbanas (Farney y Bradley, 2018). De este modo, se puede ver que hay variaciones en la forma en que las comunidades de Etruria y el Latium vetus van caminando, en paralelo, hacia un nuevo tipo de vida: la urbana. Cada centro tiene sus propias particularidades, y a nivel regional se puede establecer unas tendencias o redes urbanas, con sus variaciones locales intrínsecas.

En la Etruria meridional parece que hay una tendencia a una mayor integración jerárquica de los diferentes asentamientos en torno a los seis grandes centros. El paisaje humano se articularía en torno a ellos, emergiendo como los nuevos nodos de integración social. Por otro lado, en el Latium vetus la red urbana se manifiesta algo más policéntrica, puesto que no hay grandes centros que absorban a los más pequeños, quienes deben establecer un mayor número de lazos de interrelación, probablemente para formar alianzas militares defensivas (Pacciarelli, 2016). La urbanización en ambos casos es la respuesta a cambios y presiones sociales, tanto internas como externas, y esto tiene un reflejo en el paisaje humano. A nivel regional parece que lo hagan a través de dos caminos parecidos pero diversos, como si se formaran dos redes urbanas diferentes en la Italia centro-tirrena de los siglos X-IX antes de nuestra era, separadas por el Tíber. Y a nivel local, las gentes de ambas orillas fueron agentes activos en las transformaciones que las llevaron a nuevos tipos de estructuración social y forma de situarse en el territorio, adaptándose a sus propias circunstancias.

El inicio de la urbanización en la Italia centro-tirrena parece que empieza en diferentes puntos, no hay un único foco. $Y$, aunque el detonante $y$ desarrollo de cada caso deba buscarse en el espacio local, el caldo de cultivo 
que permite hacer brotar los fenómenos urbanos debe analizarse desde una mayor perspectiva espacial y temporal. La transición urbana es un camino de largo recorrido, que no influye en un único espacio y grupo humano, la interrelación de diversas redes humanas es la que al final nos lleva a poder observar la formación de redes urbanas. Las ciudades se forman antes que se puedan ver con claridad en el registro; los procesos de urbanización son un trasfondo que puede ser menos visible de lo esperado. Al poner en el foco las ciudades antiguas del período clásico se pasaba por alto todo el largo periplo que las precedía. Si más que en las ciudades se focaliza en la urbanización esto permite integrar la variable de espacios vividos y, por tanto, contingentes y mutables.

En esta visión de mayor espectro temporal y espacial podemos incorporar esas fases finales de la urbanización mediterránea antigua, la de los siglos VII-VI antes de nuestra era. Es en este momento cuando factores externos pueden entrar en acción, como la llegada de gentes egeas y levantinas en la parte Occidental. Las formas de vida urbana ya han florecido en diversos lugares, con sus propios caminos de centralización de poder social y generación de identidades. Diferentes contextos urbanizantes que se pueden influenciar recíprocamente al entrar en contacto. Un contacto activo en el que las gentes que lo protagonizan pueden adaptar, seleccionar e integrar nuevas ideas y productos. Las diversas trayectorias locales de nucleación y centralización están insertadas en un contexto más amplio de conexiones a nivel mediterráneo y continental. El ambiente mediterráneo (un gran espacio de interconexión de personas e ideas) puede ser uno de los catalizadores para el cambio de estos modelos locales hacia uno más global, fruto de intercambios multidireccionales. Esto nos permite ver el Mediterráneo como un gran escenario de contactos, donde no cabe menospreciar los elementos locales, sino la necesidad de integrarlos como parte sustancial.

\section{Bibliografía}

Alessandri, L., 2013. Latium Vetus in the Bronze Age and Early Iron Age/Il Latium Vetus nell'età del Bronzo e nella prima età del Ferro. Oxford: British Archeological Reports. 
Amoroso, A., 2016. Settlement patterns in South Etruria and Latium Vetus. En: P. Attema, J. Seubers y S. Willensen, eds. Early states, territories and settlements in protohistoric Central Italy. Groningen: University of Groningen, pp.83-99.

Attema, P., Burgers, G.-J. y van Leusen, P. M., 2010. Regional Pathways to Complexity. Settlement and land-use dynamics in Early Italy from the Bronze Age to the Republican period. Amsterdam: Amsterdam University Press.

Aubet, M. E., 2001. The Phoenicians and the West. Cambridge: Cambridge University Press.

Bartoloni, G., 2003. Le società dell'Italia primitive. Lo studio delle necropoli e la nascita delle aristocrazie. Roma: Carocci.

Bettelli, M., 1997. Roma, la città prima della città: i tempi di una nascita. Roma: L'Erma.

Bietti-Sestieri, A. M., 1992. The Iron Age community of Osteria dell'Osa. A study of socio-political development in central Tyrrhenian Italy. Cambridge: Cambridge University Press.

Boardman, J., 1980 [1964]. The Greeks Overseas: Their Early Colonies and Trade. London: Thames \& Hudson.

Bourdieu, P., 1977 [1972]. Outline of a Theory of Practice. Cambridge: Cambridge University Press.

Bradley, G., 2015. Investigating Aristocracy in Archaic Rome and Central Italy: Social mobility, ideology and cultural influences. En: N. Fisher y H. van Wees, eds. Aristocracy in Antiquity. Swansea: Classical Press of Wales, pp.85124.

Childe, V. G., 1950. The Urban Revolution. The Town Planning Review, 21(1), pp.3-17.

Cifani, G. y Stoddart, S., 2012. Landscape, Ethnicity and Identity in the Archaic Mediterranean Area. Oxford: Oxbow.

Cowgill, G. L., 2004. Origins and development of urbanism: archeological perspectives. Annual Review of Antrhopology, Volumen 33, pp.525-549.

Engels, F., 2008 [1884/1891]. El origen de la familia, la propiedad privada y el Estado. Madrid: Alianza.

Farney, G. D. y Bradley, G., 2018. The Peoples of Ancient Italy. Berlin: De Gruyter. Fernández-Götz, M., 2018. Urbanization in Iron Age Europe: Trajectories, Patterns, and Social Dynamics. Journal of Archaeological Research, 26(2), pp.117-162.

Finley, M. I., 1977. The Ancient City: From Fustel de Coulanges to Max Weber and beyond. Comparative Studies in Society and History, 19(3), pp.305-327.

Finley, M. I., 1999 [1973]. The Ancient Economy. Updated Edition with a Foreword by Ian Morris. Berkeley: University of California Press.

Fisher, K. D. y Creekmore, A. T., 2014. Making Ancient Cities. Space and Place in Early Urban Societies. Cambridge: Cambridge University Press. 
Foucault, M., 1977 [1975]. Discipline and Punish: The Birth of the Prison. New York: Vintage Books.

Fulminante, F., 2003. Le sepulture principesche nel Latium Vetus. Roma: L'Erma. Fulminante, F., 2014. The Urbanisation of Rome and Latium Vetus. Cambridge: Cambridge University Press.

Fulminante, F. y Stoddart, S., 2013. Indigenous politcal dynamics and identity from a comparative perspective: Etruria and Latium Vetus. En: M. E. Alberti y S. Sabatini, eds. Exchange Networks and Local Transformations, Interaction and local change in Europe and the Mediterranean from the Bronze Age to the Iron Age. Oxford: Oxbow, pp.117-133.

Fustel de Coulanges, N. D., 2009 [1866]. La Cité Antique. Étude sur le Culte, le Droit, les Institutions de la Grèce et de Rome. Cambridge: Cambridge University Press.

Lefebvre, H., 1991 [1974]. The Production of Space. Oxford: Blackwell.

Malkin, I., 2003. Networks and the Emergence of Greek Identity. Mediterranean Historical Review, pp.56-74.

Marino, T., 2015. Aspetti e fassi del processo formativo delle città in Etruria meridionale costiera. En: M. Rendeli, ed. Le città visibili. Archaeologia dei processi di formazione urbana. Roma: Officina Edizioni, pp.97-141.

Martinelli, M., 2004. La Lancia, la spada, il cavallo. Il fenomeno guerra nell'Etruria e nell'Itallia centrale tra età del bronzo ed età del ferro. Firenze: Regione Toscana.

Morris, I., 1987. Burial and ancient society. The Rise of the Greek city-state. Cambridge: Cambridge University Press.

Mumford, L., 1961. The City in History. Its Origins, Its Transformations, and Its Prospects. New York: Harcourt Brace Jovanovich.

Pacciarelli, M., 2001. Dal villaggio alla città. La svolta protourbana del 1000 a. C. nell'Italia tirrenica. Firenze: All'Insegna del Giglio.

Pacciarelli, M., 2016. The earliest processes toward City-States, political power and social stratification in middle Tyrrhenian Italy. Origini, 39, pp.169-207.

Riva, C., 2011. La urbanización de Etruria. Prácticas funerarias y cambio social, 700-600 a. C. Barcelona: Bellaterra.

Sanmartí, J., 2014. Long-Term Social Change in Iron Age Northern Iberia (C:A: 700-200 BC). En: B. Knapp y P. van Dommelen, eds. The Cambridge Prehistory of the Bronze and Iron Age Mediterranean. Cambridge: Cambridge University Press, pp.454-470.

Soja, E., 2000. Postmetropolis. Oxford: Blackwell.

van Dommelen, P., 2006. The Orientalizing Phenomenon: Hybridity and Material Culture in the Western Mediterranean. En: C. Riva y N. C. Vella, eds. Debating Orientalization. Multidisciplinary Approaches to Change in the Ancient Mediterranean. London: Equinox, pp.135-152. 
van Dommelen, P., 2008. Colonialismo: pasado y presente. Perspectivas poscoloniales y arqueológicas de contextos coloniales. En: G. Cano y A. Delgado, eds. De Tartesos a Manila. Siete estudios coloniales y poscoloniales. Valencia: Universitat de Valencia, pp.51-90.

Vanzetti, A., 2004. Risultati e problemi di alcune prospettive di studio della centralizzazione e urbanizzazione di fase protostorica in Italia. En: P. Attema, ed. Centralization, early urbanization and colonization in first millennium $B C$ Italy and Greece, Part 1: Italy. Leuven: Peeters, pp.1-28.

Weber, M., 1958 [1921]. The City. New York: Free Press.

Weber, M., 2013 [1909]. The Agrarian Sociology of Ancient Civilizations. London: Verso.

Ziółkowski, A., 2005. The aggeres and the rise of urban communities in Early Iron Age Latium. Archeologia, 56, pp.31-51. 


\section{LIMITACIONES, DIFICULTADES Y CLAVES PARA EL ESTUDIO DEL ESTATUS DE LOS ANIMALES EN EL PENSAMIENTO GRIEGO ANTIGUO}

\section{Limitations, difficulties and keys for the study of the status of animals in ancient Greek thought}

Leire Morrás AranoA ${ }^{1}$

Resumen: Este trabajo ofrece un análisis y reflexión sobre el estado actual de la disciplina emergente de los estudios animales aplicados al campo de la historia del pensamiento griego antiguo. A partir de una serie de ejemplos procedentes de las fuentes griegas que conservamos, se trata de definir algunas dificultades, retos y aspectos a tener en cuenta a la hora de estudiar el estatus moral de los animales, así como el propio concepto de la animalidad en la Antigüedad. Nuestro análisis de la figura de los animales está influido por problemáticas de diversa índole, como las limitaciones de las fuentes disponibles o las diferencias conceptuales, culturales y filosóficas que nos separan de los pensadores griegos.

Palabras clave: animalidad, humanidad, estatus moral, pensamiento griego, vegetarianismo, antropocentrismo.

Abstract: This paper offers an analysis and reflection about the current state of the emergent discipline of animal studies, applied to the history of ancient Greek thought. Based on a series of examples from the Greek fonts we preserve, the aim is to define some difficulties, challenges and

1 Estudiante del Programa de Doctorado Interuniversitario en Ciencias de la Antigüedad en la Universidad del País Vasco/Euskal Herriko Unibertsitatea. Correo electrónico:1morras001@ikasle.ehu.eus. 
aspects to keep in mind while studying the moral status of animals and the concept of animality in Antiquity. Our analysis of the figure of animals can be influenced by problems of different nature, like the limitations of the available fonts themselves or the conceptual, cultural and philosophical differences between us and the Greek thinkers.

Keywords: animality, humanity, moral status, Greek thought, vegetarianism, anthropocentrism.

Especialmente a partir de la década de los años 70 del siglo pasado y a raíz de la creciente preocupación social por las relaciones entre la humanidad y los animales, los debates sobre el estatus moral de estos últimos están cobrando cada vez un papel más central en todos los ámbitos de nuestra sociedad. Desde que pensadores como Singer (1975), Midgley (1979), Regan (1983) o Adams (1990) comenzaron a establecer las bases teóricas de la emergente disciplina de los animal studies, han proliferado los trabajos de todas las ramas del conocimiento que analizan la figura y el papel de los animales desde un punto de partida alejado del antropocentrismo ético. Esto se aplica también a los estudios clásicos. En el caso de la historia del pensamiento griego antiguo, disciplina en la que se centra el presente artículo, en las últimas décadas se han hecho destacables aportaciones de estudiosos como Dombrowski (1984), Sorabji (1993), Gilhus (2006), Steiner (2010) o Newmyer (2011), entre muchos otros. Se trata de una línea de trabajo que está atravesando, sin duda, momentos de gran ebullición y que proporciona interesantes herramientas de análisis de las relaciones que se dan entre los humanos y los animales, así como de otras muchas problemáticas circundantes.

Los objetivos del presente artículo son tanto revisar algunas de las claves teóricas que pueden resultar útiles para investigar sobre dichas cuestiones, como señalar las principales dificultades y obstáculos que surgen en el proceso. La intención es que pueda servir como una primera introducción a los estudios sobre el estatus moral de los animales en la Antigüedad. Para ello se hablará, en primer lugar, de dos nociones frecuentemente empleadas en la corriente de los estudios animales y que son parte esencial del marco teórico de toda investigación de dicha línea: el concepto de la animalidad y el del antropocentrismo ético. Seguidamente, se tratarán al- 
gunas características y limitaciones que presentan las fuentes antiguas que conservamos. Por otro lado, se harán algunos apuntes sobre la importancia y la complejidad del debate acerca de la capacidad racional de los animales en la Antigüedad, así como de la doctrina de la metempsícosis en los autores de tendencias órfico-pitagóricas, platónicas y neoplatónicas. Por último, se finalizará con una reflexión sobre los términos «vegetarianismo» y «abstinencia de la carne» y su posible aplicación a los autores antiguos. Se quiere recalcar, sin embargo, el carácter hipotético de los planteamientos que se ofrecen en este trabajo. Por las limitaciones de las fuentes y otros factores que se describen más adelante, llegar a conclusiones firmes es complicado o, en algunos casos, imposible. Por este motivo, nos ceñiremos a presentar algunas posibilidades de interpretación de esas fuentes.

Como ya se adelantaba, una de las tendencias de los trabajos pertenecientes a la disciplina que nos ocupa es estudiar la noción de la animalidad, entendida como un conjunto de características que se atribuyen a la categoría de «animal» en un sentido abstracto y homogeneizante, en oposición a la humanidad, sin tener en cuenta los rasgos propios y diferenciadores de cada una de las especies que la conforman. Es decir, el objetivo no suele ser el análisis de animales concretos, sino, más bien, de tipos de animales (domesticados, salvajes, víctimas sacrificiales, etc.) o del propio concepto de «lo animal». Además, estas investigaciones parten de la base de que esta noción es variable y, en gran medida, dependiente del contexto sociocultural. Muestra de ello es que los conflictos y problemáticas que se dan en la actualidad a raíz del estatus moral que brindamos a los animales son diferentes a los que surgían en la Antigüedad, por lo que el marco de los debates subsiguientes también cambia notablemente. Como expresa Bodson (1983, p.313): «the relationship between man and animal in the Classical antiquity cannot be isolated from what influenced it most: the philosophers' and moralists' views and the religious beliefs and rites». Las creencias religiosas y los ritos no solo son relevantes por el ya mencionado sacrificio animal, sino que, en el caso de algunas escuelas filosóficas influenciadas por la tradición órfico-pitagórica, son un factor determinante, como se señalará a lo largo del trabajo.

De la mano del concepto de animalidad, otra herramienta útil de análisis que nos proporciona la disciplina de los estudios animales es la del antropocentrismo ético, fundamental a la hora de estudiar las relaciones 
entre especies. Se entiende por antropocentrismo ético la postura ideológica, en todas sus manifestaciones, que sitúa a la especie humana en el centro del entorno en el que se desarrolla, justificando la preeminencia de los intereses del ser humano sobre los de los animales y sobre la propia naturaleza. Según esta cosmovisión antropocentrista, el fin de los recursos naturales y de los animales es la satisfacción de las necesidades humanas. Es decir, el ser humano se establece como sujeto central, mientras que las identidades no humanas quedan relegadas a la alteridad. Como consecuencia, las capacidades propias de la humanidad se estiman inherentemente superiores y son el parámetro del valor intrínseco de todos los seres vivos. Definir esta mentalidad antropocentrista, que ha sido la visión dominante desde los orígenes del pensamiento occidental, es esencial para contextualizar el debate sobre los derechos de los animales, pero no solo resulta útil en la actualidad, sino que es igual de valioso para desentrañar los testimonios de los autores antiguos.

Una vez definidas dos de las claves teóricas de las que pueden partir las investigaciones acerca de la concepción de la animalidad y otras cuestiones relativas a ella en los pensadores griegos, se tratarán algunas de las dificultades que se ocasionan en el proceso. Antes de nada, se ha de señalar un problema evidente: el estudio del estatus moral que los filósofos de las diversas épocas y corrientes atribuyen a los animales se ve, la mayoría de las veces, condicionado por las propias limitaciones de las fuentes que conocemos, que ofrecen un abanico de testimonios enormemente rico y variado. La gran diversidad en la naturaleza de los testimonios, la tradición de pensamiento de sus autores, el estado de conservación o las singularidades de algunas de ellas son aspectos fundamentales a tener en cuenta a la hora de adaptar la metodología a cada uno de los textos. El estado fragmentario de las fuentes es sobre todo problemático al intentar trazar hipótesis sobre la concepción de la animalidad de los autores presocráticos, como sucede con muchos otros temas. A pesar de ello, varios estudiosos tratan de dilucidar la postura de algunos de estos filósofos. Debido a la doctrina de la transmigración de las almas y a la abstinencia de la carne propia de la tradición órfico-pitagórica, resultan especialmente interesantes los fragmentos de Empédocles respecto al sacrificio animal (DK 31 B 117, 128, 136), así como el estudio sobre el pitagorismo antiguo. Hay indicios de que varios de los pensadores presocráticos atribuían cierto grado de racionalidad a los animales, al no diferenciar entre el intelecto y la percepción u otros 
elementos del alma (Ar., DA, 404b; Metaph., 4.5; Thphr., Sens., 23) y esta parece una hipótesis generalmente aceptada por los estudiosos.

En el caso de los filósofos de época clásica y posterior, no es tanto el estado de conservación de los textos el factor que obstaculiza la investigación, sino, más bien, cuestiones de otra índole. Hay una minoría de filósofos que explicitan sus ideas sobre la animalidad y que dedican obras exclusivamente a defender su postura respecto al estatus moral de los animales. Se ha de destacar especialmente a Plutarco y a Porfirio, ambos autores de tratados en los que se debaten cuestiones relacionadas con este tema. El De Abstinentia de Porfirio es el texto antiguo más extenso y detallado sobre la abstinencia de la carne que conocemos, por lo que se trata de una fuente de inestimable valor para nuestro estudio. Del mismo modo, se han de resaltar las obras de Aristóteles en las que habla de cuestiones zoológicas, aunque resultan especialmente reveladoras, por sus implicaciones hacia los animales, las ideas sobre la racionalidad del alma que el filósofo expresa en otras de sus obras (por ejemplo, DA, 404b; EE, 1224a; Pol., 1332b5).

En muchos otros casos, sin embargo, los pensadores no manifiestan de manera explícita el grado o las características del estatus moral que conceden a los animales, aunque no por ello dejan de ser fuentes valiosas que pueden aportar información interesante. Platón, por ejemplo, no aborda de manera directa este problema en su obra y el espacio que ocupa en su pensamiento es muy secundario. Podría decirse que esto se debe a que, dentro de su sistema filosófico, la animalidad es colateral a la humanidad, no es un fin en sí mismo. Una muestra de ello es la visión del filósofo sobre la jerarquía de especies en el ciclo de reencarnaciones y, en general, su psicología animal, de carácter poco estable y en ocasiones contradictorio. Por citar algunos ejemplos, en Leyes se les atribuye intelecto a los animales (961d), a pesar de que en otro pasaje de la misma obra se expresa lo contrario (963e). Por otro lado, en la República se afirma que los perros tienen capacidad de hacer juicios y ser amantes del conocimiento (376b). Sin embargo, en otras obras como el Simposio, Crátilo, Laques y otros pasajes de la República, se niega la capacidad de razonar a los animales. Puede comprobarse, pues, que las ideas del filósofo acerca de los animales y sus capacidades no son demasiado consistentes. Es también incierta la opinión de Platón sobre la abstinencia de la carne y sus posibles implicaciones morales, aunque parece ser que considera dicha dieta como parte de una sociedad 
utópica, como explica detalladamente Dombrowski (1984b, pp.7-8).

El tema de la racionalidad es uno de los ejes centrales en los debates antiguos sobre los animales. Hay que tener en cuenta que, a pesar de que en la actualidad la carencia de la capacidad racional de estos es uno de los fundamentos sobre los que se construye la barrera conceptual entre la especie humana y el resto de las especies (así como las relaciones jerarquizadas que esto implica), no todos los autores antiguos consideraron que los animales eran del todo irracionales. A este respecto, pueden diferenciarse dos fases en la historia del pensamiento griego: una, la más antigua, en la que la capacidad racional de los animales no se negaba de manera tajante ni cobraba gran relevancia en las discusiones filosóficas (esta fase engloba a los pensadores griegos previos a Aristóteles) y una segunda en la que la racionalidad de los animales se establece como un problema y se termina de asentar y popularizar como tema de debate de forma explícita.

Esta alteración fue provocada por lo que Sorabji (1993, pp.7-16) definió como una crisis para la filosofía de la mente y las teorías morales, surgida a raíz de que Aristóteles considerase de manera rotunda, por primera vez en la historia del pensamiento griego, que los animales carecían de capacidad racional. Esta noción gozó de gran popularidad en la filosofía posterior, especialmente entre los estoicos y los peripatéticos, a cuyos argumentos se opusieron otros pensadores influidos por el platonismo, como Plutarco y Porfirio, así como los cínicos. La negación de la racionalidad de los animales supuso un cambio sustancial en el marco de los debates sobre el estatus moral de estos últimos, por todas las implicaciones morales que para los filósofos griegos conlleva la ausencia de la razón. Este es el motivo por el que los tratados helenísticos y posteriores en defensa de los animales hacen hincapié en demostrar lo contrario. Es decir, el impacto de esta aportación aristotélica en las visiones filosóficas de la animalidad no solo fue notable por la fortuna de la que gozó entre sus sucesores (y en la mayor parte de la historia del pensamiento occidental posterior), sino porque incluso aquellos autores que estaban en desacuerdo se veían obligados a debatir en torno a ella para defender sus posturas favorables hacia los animales.

Se ha de resaltar que ya desde antes del peripatético puede identificarse una noción de correspondencia entre el nivel de racionalidad de un ser y su valor intrínseco. Como señala Stainton (2001, p.452), esta idea 
más desarrollada posteriormente por Aristóteles y fuertemente arraigada en la tradición del pensamiento occidental proviene en gran medida de la filosofía de Platón. El estudioso afirma que, en el ciclo de reencarnaciones presentado por este último, se percibe una especie de teoría darwinista invertida, según la cual las especies de animales son fruto de una degeneración de la humanidad. En Timeo aparece una jerarquía de reencarnaciones (Ti., 90e-92c), en la que se establece que los hombres que no viven una vida justa y moderada se reencarnan en mujeres, pájaros, animales cuadrúpedos, reptiles, gusanos, moluscos y peces. Es destacable, además, que las mujeres se sitúan más cerca de la animalidad que los hombres o, expresado de otra manera, más alejadas del sujeto antropocentrista por excelencia (el varón griego libre, en este caso).

Siguiendo con el ejemplo de Platón, esta adaptación de la doctrina órfico-pitagórica de la metempsícosis o transmigración de las almas puede dar lugar a un conflicto importante. Si el alma que dio vida a un ser humano racional puede reencarnarse después en un animal, ¿implica esto que los animales poseen racionalidad o, por el contrario, el alma pierde dicha facultad al unirse a un cuerpo que no es humano? Ya hemos visto que, aunque pueden deducirse algunas de sus ideas al respecto, Platón no aborda este tema de forma directa, lo cual se explica porque aún no había sido problematizado por Aristóteles. Sin embargo, otros pensadores neoplatónicos sí se preocupan de resolver dicho conflicto. Este es el caso

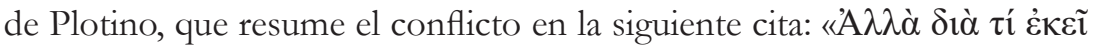

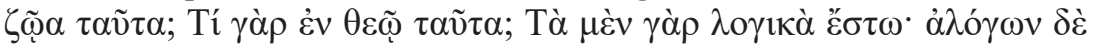

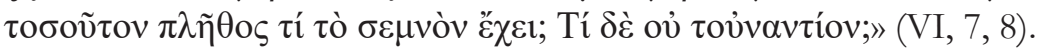

Plotino adopta de Platón sus ideas sobre la transmigración de las almas y concibe el ciclo de reencarnaciones como una manera de ajusticiar a aquellos individuos que no recibieron su merecida condena en vida. Igual que para Platón, las acciones llevadas a cabo a lo largo de la vida determinan el destino de la próxima reencarnación (III, 2, 13; IV, 7, 14) y convertirse en animal o, en este caso también en vegetal, es percibido como una denigración. Por tanto, para el filósofo explicar por qué los animales participan de un alma universal que también comparten los hombres racionales (VI, 4, 16) supone un problema, pues la animalidad y la humanidad entran en conflicto. A diferencia de Platón, Plotino evidencia este asunto y busca una manera de reconciliar la metempsícosis con su creencia de 
que los animales no son racionales. Encuentra, para ello, una solución que encaja de manera perfecta en su sistema filosófico y que tiene que ver con el carácter universal que posee el alma antes de que se una a un cuerpo, momento en el que se vuelve particular. Es decir, el alma de un animal es semejante a la de un humano y está compuesta por los mismos elementos, pero su parte intelectiva queda en estado latente de manera circunstancial, mientras está unida a un cuerpo animal.

Lo que se ha querido mostrar a través de estos ejemplos es, por un lado, la complejidad y la riqueza de perspectivas que se dieron en la Antigüedad sobre el tema de la capacidad racional de los animales y, por otro lado, el interés del estudio de la metempsícosis en los autores de tendencia órfico-pitagórica, platónica, neoplatónica y neopitagórica. La idea de la transmigración de las almas reaparece a lo largo de los siglos en diversos autores griegos, manteniendo algunos aspectos y reformulando o añadiendo otros, pero, en cualquier caso, constituye una fuente de gran interés para el estudio de la concepción de la animalidad, puesto que establece un vínculo especial entre los animales de diversas especies al presuponer una semejanza en el alma de todas ellas, incluyendo al ser humano. Esta puede considerarse, pues, una de las claves para el estudio del estatus moral de los animales en algunos de los autores antiguos.

Otro de los aspectos interesantes a analizar para comprender mejor algunas dimensiones de las relaciones entre los animales y los humanos son las prácticas alimenticias de estos últimos, motivo por el que existe una cierta tendencia a orientar la investigación desde la idea del vegetarianismo. Esta puede resultar una herramienta útil, pues, en ocasiones, revela información sobre la relación entre los autores de ciertas corrientes de pensamiento y los animales, pero requiere cautela. Podría considerarse que el término «vegetarianismo», sobre todo a partir del movimiento por los derechos de los animales al que se ha aludido anteriormente, ha adquirido connotaciones o dimensiones políticas que no siempre se dan en los pensadores griegos que se abstienen del consumo de la carne, por lo que un empleo descuidado de la palabra puede llevar a conclusiones equivocadas o engañosas. Esto es especialmente relevante en cuanto a autores cuyas ideas sobre la abstinencia de la carne no conocemos con total certeza, como en el caso de Pitágoras, a quien habitualmente se considera vegetariano. 
A la hora de definir la abstinencia de la carne en los autores antiguos, Mauro (2017, p.14) identifica cuatro de los tipos de argumentos fundamentales que estos suelen presentar para defender su postura. Pueden resumirse en los siguientes grupos: el argumento de carácter ascético-religioso; la apelación a la afinidad biopsicológica de todos los seres vivientes; la dignidad y el valor del mundo animal y, por último, la elevación y la purificación del alma. El tratado De Abstinentia de Porfirio, fuente esencial, ofrece numerosos ejemplos de todos ellos, así como el De Esu Carnium, el De Sollertia Animalium y el Bruta Animalia Ratione Uti de Plutarco. Sin duda, algunos de estos argumentos continúan manteniendo su relevancia en los debates actuales sobre el estatus moral de los animales, sobre todo en lo que concierne a la afinidad biopsicológica de todos los seres vivientes y a la dignidad y el valor del mundo animal. Los argumentos sobre la elevación y purificación del alma y sobre el ascetismo característicos de la tradición órfico-pitagórica, sin embargo, ocupan un espacio central para los pensadores griegos, pero probablemente no para el lector actual interesado en los derechos de los animales y en el vegetarianismo. Es por estas razones que se ha de tener cuidado para evitar cualquier tipo de anacronismo al emplear el término, que, en cualquier caso, puede sustituirse por el de «abstinencia de la carne», carente de connotaciones problemáticas.

Como conclusión, los testimonios antiguos sobre las relaciones entre los humanos y los animales presentan una gran complejidad que puede analizarse desde diferentes puntos de vista y según criterios variados. La disciplina de los estudios animales aporta herramientas teóricas que resultan fundamentales para llevar a cabo una investigación alejada de los sesgos del antropocentrismo, lo que da lugar a lecturas alternativas y muy enriquecedoras de las fuentes. Sin embargo, como también se ha señalado, es necesario aplicar los conceptos teniendo en cuenta las divergencias socioculturales que se dan entre la Antigüedad y la sociedad contemporánea. Las características definitorias de la animalidad, que, como se ha comentado anteriormente, no es un concepto inmutable, varían dependiendo de la época y de las corrientes de pensamiento. Así, mientras nuestra idea de la racionalidad excluye generalmente a todas o a la mayoría de las especies no humanas, siendo esta probablemente la mayor barrera diferenciadora que percibimos entre estas y nosotros mismos, hemos podido comprobar que en la Antigüedad no siempre fue así. Esto es relevante, sobre todo, para el estudio de los autores prearistotélicos y los demás pensadores posteriores 
que defendieron la racionalidad de los animales.

\section{Bibliografía}

\section{Autores clásicos}

Aristóteles. Acerca del alma. Traducción de T. Calvo Martínez, 2014. Madrid: Gredos. Aristóteles. Metafisica. Traducción de T. Calvo Martínez, 1994. Madrid: Gredos. Aristóteles. Ética eudemia. Traducción de J. Pallí Bonet, 1993. Madrid: Gredos. Aristóteles. Política. Traducción de M. García Valdés, 1988. Madrid: Gredos. Empédocles. Dier fragmente der vorsokratiker. Edición de H. A. Diels y W. Kranz, 1992. Berlin: Weidmannsche Verlagsbuchhandlung. Platón. Leyes. Traducción de F. Lisi, 1999. Madrid: Gredos.

Platón. República. Traducción de C. Eggers Lan, 1988. Madrid: Gredos.

Platón. Banquete. Traducción de M. Martínez Hernández, 1986. Madrid: Gredos. Platón. Crátilo. Traducción de J. L. Calvo, 1983. Madrid: Gredos.

Platón. Laques. Traducción de C. García Gual, 1981. Madrid: Gredos.

Platón. Timeo. Traducción de M. López Salvá, 1992. Madrid: Gredos.

Plotino. Enéadas V-VI. Traducción de J. Igal, 1998. Madrid: Gredos.

Plotino. Plotini opera. Edición de P. Henry y H. R. Schwyzer, 1951-1973. Paris: Desclée de Brouwer.

Plutarco. Obras morales y de costumbres IX. Traducción de J. Bergua Cavero y V. Ramón Palerm, 2002. Madrid: Gredos.

Porfirio. Sobre la abstinencia. Traducción de M. Periago Lorente, 1984. Madrid: Gredos.

Teofrasto. Sobre las sensaciones. Traducción de J. Solana, 2006. Barcelona: Anthropos.

\section{Bibliografía contemporánea}

Adams, C. J., 1990. The sexual politics of meat: a feminist-vegetarian critical theory. New York: Continuum International.

Bodson, L., 1983. Attitudes toward animals in Greco-Roman Antiquity. International Journal for the Study of Animal Problems, 4(4), pp.312-320.

Carter, J., 2019. Aristotle on earlier Greek psychology: the science of soul. Cambridge: Cambridge University Press.

Dombrowski, D., 1984a. The philosophy of vegetarianism, Massachusetts: University of Massachusetss Press. 
Dombrowski, D., 1984b. Was Plato a vegetarian? Apeiron, 18(1), pp.1-9.

Edwards. G. F., 2018. Reincarnation, rationality and temperance. Platonists on not eating animals. En: P. Adamson y G. F. Edwards, ed. 2018. Animals: a history. New York: Oxford University Press. Ch. 2.

Gilhus, I. S., 2006. Animals, gods and humans: changing attitudes to animals in Greek, Roman and early christian ideas. London: Routledge.

Guthrie, W. K. C., 1984. Historia de la filosofía griega I. Los primeros presocráticos y los pitagóricos, Madrid: Gredos.

Kleczkowska, K, 2014. Those who cannot speak. Animals as others in ancient Greek thought. Maska, 24, pp.97-108.

Llored, P., 2018. El pensamiento animal en Empédocles. En: L. Flores y J. Linares, coord. 2018. Los filósofos ante los animales. Ciudad de México: Almadía. pp.75103.

Mauro, L., 2017. The philosophical origins of vegetarianism. Relations beyond anthropocentrism, 5(1), pp.13-26.

Midgley, M., 1979. Beast and man. The roots of buman nature. Hassocks: The Harvester Press.

Newmyer, S. T., 2011. Animals in Greek and Roman thought. A sourcebook. London: Routledge.

Portmess, L. y Walters, K. S. eds, 1999. Ethical vegetarianism: from Pythagoras to Peter Singer. New York: SUNY Press.

Preece, R., 2008. Sins of the flesh: a history of ethical vegetarian thought. Vancouver: UBC Press.

Regan, T., 1983. The case for animal rights. Oakland: University of California Press.

Singer, P., 1976. Animal liberation. London: Jonathan Cape.

Sorabji, R., 1993. Animal minds and human morals: the origins of the western debate. London: Gerald Duckworth \& Co.

Stainton, T., 2001. Reason and value: the thought of Plato and Aristotle and the construction of intellectual disability. American Journal on Intellectual and Developmental Disabilities, 39(6), pp.452-460.

Steiner, G., 2010. Anthropocentrism and its discontents: the moral status of animals in the history of western philosophy. Pittsburgh: University of Pittsburgh Press. 



\title{
BELLAS ATROCES. FIGURAS FEMENINAS MONSTRUOSAS EN LA ANTIGUA GRECIA: UNA APROXIMACIÓN AL ESTADO ACTUAL DE LA INVESTIGACIÓN
}

\author{
Atrocious beauties. Monstrous femenine figures in \\ Ancient Greece: an approach to the current state of \\ investigation
}

\section{Paula Arbeloa Borbón ${ }^{1}$}

Resumen: El propósito del presente trabajo es ofrecer una aproximación al estado actual de la investigación sobre tres figuras femeninas monstruosas de la Antigua Grecia: Medusa, Esfinges y Sirenas. Éstas, como especializaciones de las Keres, son demones funerarios que arrancan a las personas de la vida, pero, a su vez, las conducen al Más Allá. En conjunto, son entes sobrenaturales y malignos que por su naturaleza híbrida y ambigua se constituyen como figuras de alteridad y provocan dos sentimientos contrapuestos: atracción y repulsión.

Palabras clave: Grecia; Medusa, Esfinges, Sirenas, Keres, alteridad.

Abstract: The aim of this paper is to offer an approach to the current state of investigation about three monstrous female figures in Ancient Greece: Medusa, Sphinxes and Sirens. As specializations of the Keres, they are funerary demons which strip people from life, but, at the same time, lead them to the afterlife. Altogether, they are sobrenatural and

1 Estudiante de Máster. Universidad de Zaragoza. Correo electrónico: paula22zgz@ gmail.com. 
evil beings that by their hybrid and ambiguous nature are considered as figures of otherness and cause two opposite feelings: attraction and repulsion.

Keywords: Greece, Medusa, Sphinxes, Sirens, Keres, otherness.

\section{INTRODUCCIÓN}

El presente estudio abarca el periodo histórico de la Antigua Grecia desde el final de los Siglos Oscuros hasta la época helenística incluida (900 a. C. - 30 a. C.). El objetivo es realizar una aproximación al estado actual de la investigación de tres figuras femeninas monstruosas griegas: Medusa, Esfinges y Sirenas. Para ello, es necesario utilizar fuentes literarias clásicas griegas y, en algún caso, también romanas, cuya información debe ser completada con el estudio de bibliografía moderna sobre el tema. Por último, de suma relevancia es el manejo de fuentes iconográficas, que sirven de apoyo para las diferentes hipótesis que se plantean y que, al mismo tiempo, facilitan su comprensión.

Bajo la denominación de figuras femeninas monstruosas griegas he agrupado a una serie de entidades sobrenaturales que formaban parte importante del imaginario griego y ejercían una gran influencia en él. Éstas poseen elementos comunes, tales como su carácter híbrido y su naturaleza ambigua, su conexión con la muerte y dos sentimientos que provocan a todo aquel con quien entran en contacto: seducción y terror. Estas son algunas características por las que las he denominado bellas atroces.

La primera investigadora que realiza un estudio en conjunto de estas figuras es Jane Harrison (1903). Su obra constituye un punto de inflexión en el estudio de estos seres dado que considera que son especializaciones de las Keres, espíritus femeninos de la muerte, existiendo, en consecuencia, la Ker en la manifestación de Gorgona, de Esfinge, y de Sirena. Aunque considero muy acertada su tesis puesto que son entes que arrancan a las personas del Aquende y las trasladan al Allende, ha sido criticada por Vernant (1986, p.48) porque, en su opinión, dichas figuras no tienen demasiados elementos en común. 


\section{MedusA}

Medusa, que en griego significa «Dominadora», es una de las tres hermanas Gorgonas, ${ }^{2}$ pero la única de ellas que tiene una historia mítica autónoma, que es mortal y que puede albergar vida en su seno. De ellas, es la única que ha pasado a la posteridad, por lo que es considerada la Gorgona por antonomasia y, en consecuencia, es habitual encontrar el nombre propio de Gorgo para referirse a Medusa.

Es una verdadera figura monstruosa porque encarna la figura de la alteridad por excelencia debido a su cuerpo híbrido, que produce tanto fascinación, como terror. En este sentido, no existe unanimidad entre los autores antiguos sobre si Medusa sufrió una metamorfosis motivada por su comportamiento, o si nació con rasgos híbridos, ${ }^{3}$ aunque cabe la posibilidad de que, desde un primer momento, se concibiera a esta figura como un ser híbrido y monstruoso, y que fuera a posteriori cuando surgiera el mitema del castigo de Atenea (Martín, 2012, p.176).

En primer lugar, a su cuerpo se agregan una serie de elementos que suelen aparecer separados y que, en conjunto, son irremediablemente incomprensibles puesto que no son concebibles en un mismo cuerpo. Así, aunque la forma de su cabeza esté distorsionada en determinadas ocasiones, es humanoide. Comparte rasgos masculinos, ya que a veces posee barba, con un cuerpo femenino, que se entremezclan con partes propias de diferentes animales: su cabello está conformado por serpientes, ${ }^{4}$ que pueden aparecer también en la cintura; además, posee las defensas propias

2 Medusa, Esteno y Euríale son hijas de Forcis y Ceto, dos dioses marinos primordiales, por tanto, hermanas de las Grayas y residen en los confines occidentales del mundo, en las Hespérides (Hes. Th. vv. 270-276), aunque Píndaro (P. IX. vv.29-48), por su parte, las sitúa en las regiones de los hiperbóreos.

3 Mientras que Hesíodo (Th. vv. 270-276) no da cuenta de su naturaleza híbrida, Ovidio (Met. IV. vv.799-800) sostiene que la belleza de Medusa atrajo tanto a Poseidón, que la violó ante un templo de Atenea, quién como castigo transformó el cabello de Gorgo en serpientes con la finalidad de que Poseidón se alejara para siempre de ella.

4 El hecho de que su cabellera esté compuesta de serpientes, animales relacionados con la Tierra y los dioses del Inframundo, en vez de por cabello humano, conecta a Gorgona con el mundo ctónico, ya que el principal animal de dicho ámbito no es sino la serpiente. 
de los jabalíes (fig. 1) e, incluso, puede tener partes de ave - rasgo que comparte con las Sirenas - cuando es representada de cuerpo entero, o bien de caballo, como cuando es representada como un centauro. Y, en segundo lugar, su cabeza es per se una excelente imagen de alteridad, ya que en ella convergen elementos masculinos y femeninos, de la juventud y de la vejez, de la belleza y de la fealdad, así como de la bestialidad y la humanidad. De su rostro, lo más desmesurado es su extraña y ambigua sonrisa, que llega a considerarse como una máscara que atemoriza a quien la mira.

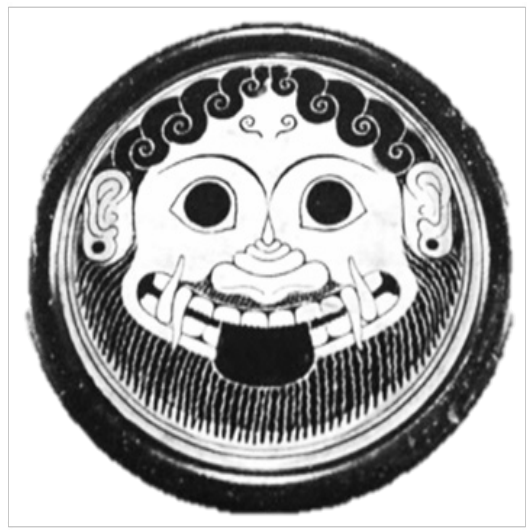

Fig. 1. Gorgoneion con barba y colmillos pintado sobre un vaso ático de figuras negras, ca. 560 a. C. Museo Metropolitano de Arte, Nueva York (Martín, 2012, p.164).

La mayoría de los seres híbridos griegos tienen antecedentes iconográficos orientales, ${ }^{5}$ y tal es el caso de Gorgona. Los modelos que mayor influencia ejercieron en la configuración de Medusa en el mundo griego fueron el dios egipcio Bes y el monstruo mesopotámico Humbaba. En cuanto a Medusa y Bes, ambos son representados frontalmente, con rasgos animales — melena, barba y grandes orejas—, y enseñando la lengua, pero no existe paralelo mítico entre ambos. Mayores similitudes presenta Gorgo con Humbaba, ya que ambos se representan la mayoría de las veces sin cuerpo, tan solo como un rostro frontal, con enormes dientes y arrugas, y cuando son representados de cuerpo entero ambos visten una corta falda. Por otro lado, aunque no se encuentran paralelos iconográficos en el caso de las serpientes en el cabello, sí se han identificado en el de las alas, elemento que comparte con el demonio oriental Pazuzu. No obstante, aunque Medusa tiene antecedentes iconográficos, se presenta en la cosmovisión griega como un ente nuevo fundamentalmente porque es concebida

5 En las culturas del Próximo Oriente Antiguo, de igual modo que en la griega, este tipo de representaciones que calificamos como monstruosas constituyen arquetipos de terror y fealdad, en los que el ser humano ha ido proyectando sus diferentes temores. 


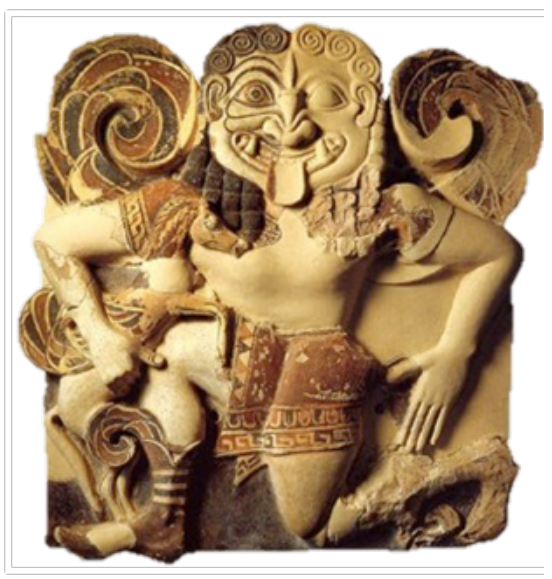

Fig. 2. Acroterion del Templo de Atenea en Siracusa, realizado en terracota policromada, del s. VII a. C. Museo de Siracusa (Martín, 2012, p.166).

como una figura femenina, frente a los seres sobrehumanos masculinos mencionados anteriormente.

Acertó Furtwängler (18841890 , pp. 1695-1717) estableciendo una división de la iconografía medusina en el arte griego en tres etapas: primero, la denominada "Gorgona Arcaica», VIII a. C. - siglo V a. C.; segundo, la "Gorgona de Transición o media», desde finales del siglo VI a. C. hasta el siglo II a. C.; y la «Gorgona Hermosa o tardía", a partir del siglo IV a. C., solapándose estas dos últimas fases. A través de dicha evolución se observan diferentes

concepciones de Medusa, pasando de ser representada como monstruosa en la primera etapa a la imagen de una bella doncella cuya muerte obedece a los designios divinos, concretamente de Atenea.

Aunque tres son los elementos principales en las representaciones de Medusa en la primera fase ${ }^{6}$ — arcaísmo, exaltación de rasgos híbridos y aparición como una máscara-, observamos que en este momento no había una imagen canónica de esta figura, probablemente porque tanto el mito como sus características estaban aún formándose. De este modo, aunque la imagen más frecuente es la de Medusa de perfil y corriendo, con una cabeza unida al cuerpo sin cuello (fig.2), encontramos representaciones excepcionales, como un pithos de arcilla beocio de $c a .670$ a. C., en el que es representada como un centauro, evidenciando así su relación con Poseidón, que además de ser el dios del mar, lo es también de los caballos (Frottingham, 1911, pp.373-376).

6 Antes del siglo VII a. C., en el imaginario griego, tan solo se conocía la existencia de la cabeza de Gorgo, a la cual, durante la última mitad de dicho siglo, se le añade la representación de su cuerpo (Hopkins, 1934, pp.341-345). 


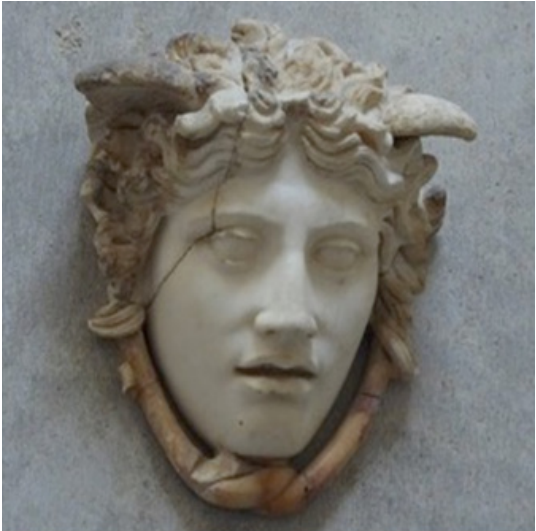

Fig. 3. Copia romana de la «Medusa Rondanini» del siglo $\mathrm{V}$ a. C., cuyo original se atribuye a Fidias. Gliptoteca de Múnich (Mayor, 2012, p.42).
La principal innovación de la segunda etapa es la unión de la cabeza de Medusa a su cuerpo mediante el cuello. Asimismo, va adquiriendo progresivamente rasgos antropomorfos, aunque sin perder su ferocidad. En la tercera fase vemos a una Gorgona representada como una joven con el pelo serpentino, en la que han desaparecido sus rasgos más horripilantes y animalescos, y que se ha convertido en una persona humana, víctima de los designios divinos de Atenea. Además, en esta fase, en lugar de su tradicional rostro frontal, es común encontrarla representada con la cabeza de perfil, cuyo máximo exponente es la denominada «Medusa Rondanini» (fig.3).

Medusa es una potencia sobrenatural convertida en mascara, cuyas principales características son la monstruosidad y la frontalidad. Su fuerza se concentra en su cabeza desde el momento en el que Perseo se la corta y ofrece como presente a la diosa Atenea; en otras palabras, se puede decir que la leyenda de Perseo sirve para evidenciar la fuerza de la cabeza de Gorgo. La cabeza de esta figura es tan importante porque el horror que infunde la convierte en un elemento apotropaico: a mayor monstruosidad de la cara, mayor protección (del Hoyo y Vázquez, 1990, p.119). Dado que los griegos, como otras sociedades antiguas, pensaban que el poder de una figura se transmitía al objeto o lugar en el que se representaba, la cabeza de Gorgona se convirtió en un amuleto. Por ello, fue un motivo muy utilizado en los escudos con el objetivo de aterrorizar a los enemigos, pues con solo mirarlo se convertían en piedra y, además, recordaban así la muerte de Medusa por el propio Perseo ayudado por el escudo de bronce, según Apolodoro (II. vv.42) y Ovidio (Met. IV. vv.782).

De igual modo, por su valencia como elemento apotropaico fue una imagen colocada como motivo decorativo en diversas partes de los templos, como las metopas, las antefijas, los frontones, las acróteras, etc. 
Además, es frecuente encontrar el rostro de Medusa representado sobre elementos de la vajilla, principalmente, copas, cumpliendo una función simbólica. Al representar su rostro en el fondo de un vaso que va a ser llenado de líquido -fundamentalmente de vino- se representan los confines del mar y/o la geografía liminal del Allende, donde moran las Gorgonas y otra serie de monstruos híbridos. De este modo, al beber el líquido del vaso se accede al Más Allá, siendo una manera de mirar a la vez los ojos de la muerte y de conjurar el miedo

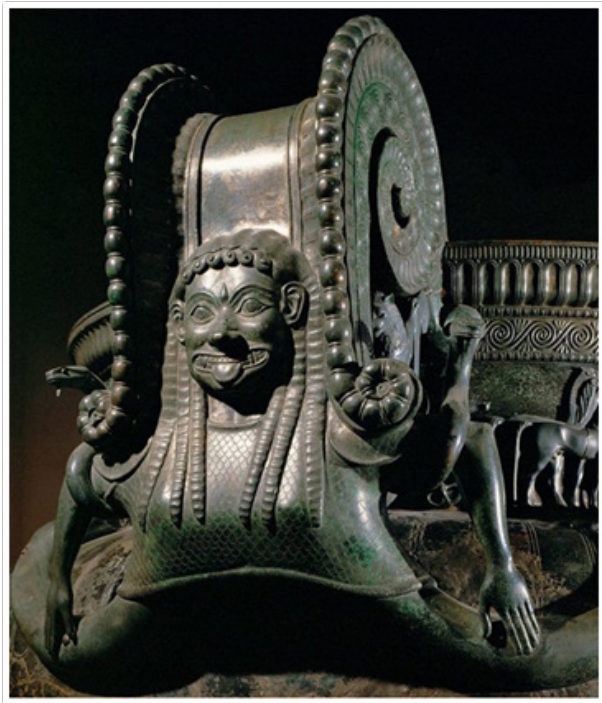

Fig. 4. Gorgona representada en la crátera aparecida en la tumba de Vix, siglo V a. C. Museo del Louvre, París (Mclerney, 2018, p.146).

(Díez de Velasco, 1995, p.99). También es representada en el exterior de los soportes vasculares por su valencia como amuleto visual contra el mal de ojo debido a sus rasgos grotescos - ojos muy abiertos, lengua afuera y dientes grandes - (fig.4) (del Hoyo y Vázquez, 1990, pp.149-150). Por otro lado, como el fuego era un elemento que causaba temor, igualmente fue una imagen colocada en los hornos como elemento profiláctico (Harrison, 1960, p.189).

Además de ser una máscara de la muerte, Gorgo es, al mismo tiempo, el sexo hecho máscara. Por ello se le compara con Baubo, una figura femenina impúdica que consiguió terminar con el duelo de Deméter, causado por el rapto de su hija Perséfone, cuando levantó su falda y mostró su vulva. Gorgo, al sacar la lengua, un elemento que debe quedar oculto y que evoca al falo, estaría representando igualmente tanto lo inquietante como lo grotesco del sexo (del Hoyo y Vázquez, 1990, pp.149-150). De ahí que esta imagen se convierta también en un elemento apotropaico, pues la lengua evoca al elemento masculino por antonomasia, el falo, que era un amuleto contra diversos peligros sobrenaturales como el mal de ojo. 


\section{EsFINGES}

El primer relato sobre el nacimiento de la Esfinge griega lo encontramos en Hesíodo (Th. vv.327-328), quien afirma que es hija de Quimera y Orto, pero otros autores como Apolodoro (III, 6, 8), Eurípides (Ph. vv. 1020-1021) y Pausanias (IX, 26, vv. 2-4) también ofrecen detalles sobre su origen. Retomando los versos de Hesíodo (Th. vv. 327-328), es importante señalar que él no la denomina «Esfinge» sino que la denomina Phix. Dicho nombre cambia a Sphinx, seguramente como consecuencia de una etimología popular que pone en relación su nombre con el verbo sphingo, "ahogar», elaborando así un nombre parlante que evoca su amenazadora acción, pues su mismo nombre significa "la que aprieta», "la que oprime», «la que ahoga».

En la mayoría de ocasiones fue concebida como un ser mixto, pues tenía rostro de mujer, pecho, patas y cola de león, y alas de pájaro, según Apolodoro (III, 6, 8). A pesar de su naturaleza híbrida, su femineidad fue acentuada dotándola de enormes pechos, como si acabara de parir. Estas características la convierten en una figura monstruosa femenina ambigua, atrayente y repelente al mismo tiempo, y cuya presencia causa siempre inquietud en la mente humana, al igual que sucede con el resto de seres híbridos, como Medusa y las Sirenas.

La Esfinge es un demon funerario, que arrancaba a las personas del mundo de los vivos, pero también las protegía en su tránsito al Más Allá, faceta que se mantiene inalterable a lo largo de la Grecia Antigua (fig.5). Prueba de ello es su presencia en los espacios funerarios ya desde época micénica, donde posee una triple función: señalar y proteger las tumbas, como las Sirenas, situándose sobre una estela o pilar sepulcral; transportar el alma de las personas fallecidas,

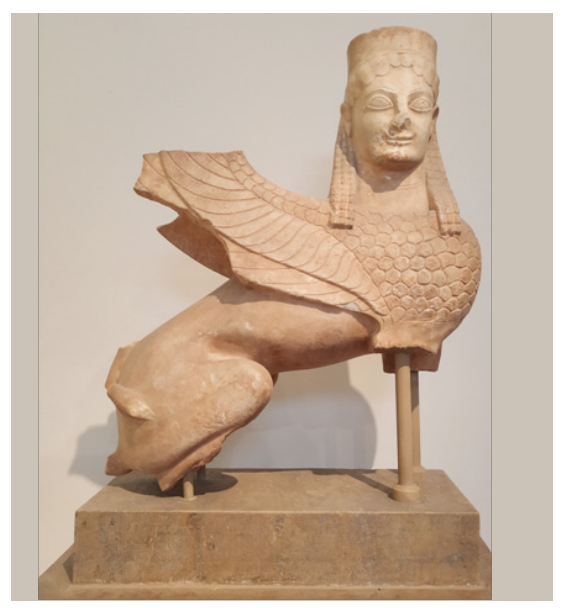

Fig. 5. Esfinge de Spata. 570-550 a. C. Museo Arqueológico Nacional, Atenas. Fotografía de la autora. 
como demon psicopompo; y simbolizar la renovación de la vida en el Más Allá (Iriarte, 1990). Por su condición funeraria también aparece representada en los vestidos utilizados por los atenienses en el momento del duelo, junto con el caballo funerario y la plañidera. Incluso es considerada como el equivalente femenino de Cerbero, carcelera del Hades (Vermeule, 1984, pp.283-284). Además, su caracterización como genio fúnebre se refuerza por su identificación como una Ker en Esquilo (Th. vv.775-776), y por su asociación con las Erinias en

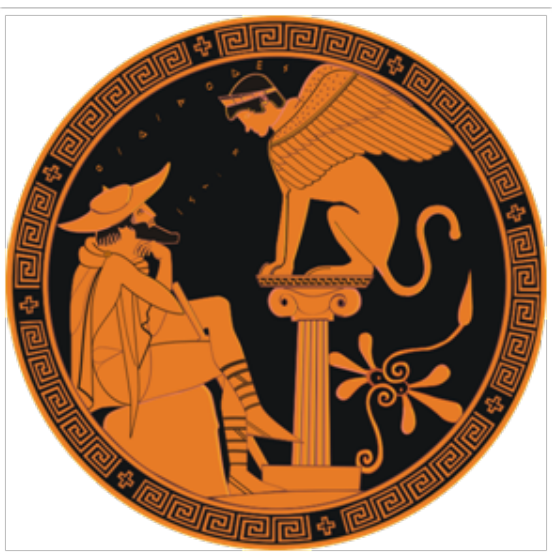

Fig. 6. Edipo y la Esfinge en una kylix ática del Pintor de Edipo, ca. 470 a. C., Vulci. Museo Gregoriano Etrusco, Roma (Iriarte, 1990, p.147). Eurípides (Ph. vv.1026-1030).

Por otro lado, la Esfinge de Tebas es la más famosa de todas las esfinges griegas ya que desempeña un papel fundamental en el mito de Edipo, que ha pervivido en el imaginario occidental (fig. 6). Desde su llegada al monte Ficio, la Esfinge sometió a la población tebana a un régimen de terror por su fuerza física destructora y porque con ella solo podía salir vivo uno de los dos contrincantes: el humano o la propia Esfinge. Diversos investigadores, como Pérez de Tudela (2012, p.59), sostienen que todos los mitos se racionalizan con el tiempo, y ello es lo que le habría sucedido al de Edipo y la Esfinge, ya que, en su opinión, solo en una fase ulterior la fuerza de la Esfinge residiría más en su inteligencia, portando el famoso enigma recibido de las Musas, que en su fuerza.

La versión más moderna, de hecho, es la que alude a la resolución del enigma como único modo posible de acabar con la dominación de Esfinge. El salvajismo de esta figura no radicaba tanto en sus garras animalescas como en su gran boca, con la cual podía tanto proponer el enigma como matar a quien no formulara la respuesta correcta. Durante su adolescencia, Edipo consultó el oráculo de Delfos, que le vaticinó que mataría a su padre y acto seguido contraería nupcias con su madre. Ante semejante 
aberración, decidió huir de Corinto para escapar de su sino y se dirigió a Tebas. Durante el camino tuvo una disputa con Layo, a quien da muerte, cumpliendo así la profecía (Pedraza, 1991, pp.55-56). Al llegar a Tebas, Edipo recibió la noticia de que la Esfinge estaba asolando dicha ciudad, y que ante tal problema, la reina Yocasta había prometido su mano a quien consiguiera dar muerte al monstruo. Edipo consiguió adivinar el secreto del enigma en un agon y, en consecuencia, casarse con Yocasta, su propia madre.

Por otro lado, quisiera aludir al aspecto sonoro de la Esfinge. Su canto enigmático, que es una de sus mayores cualidades, es una muestra de enorme ferocidad, de ahí que se la denomine "cruel cantora», "la perra cantora» y "la profetisa de corvas garras» en Sófocles (OT. vv.37, 393, y 1200). Pero su voz carece de armonía, lo que acentúa aun más, si cabe, su naturaleza salvaje y violenta. Así, su enigma es calificado como «el más disonante de los cantos», amousótatos odôn, y como un canto despojado de la mesura de la lira, ályros mô̂sa, cuyo objetivo es la interrupción de la comunicación; pero también es mayoritariamente calificado como aoidé, término que designa al sonido musical provisto de sentido, es decir, al canto poético (Iriarte, 1990, p.138). Además, el enigma sonoro que planteaba la Esfinge tenía el mismo efecto que el canto de las Sirenas, pues atraía y seducía tanto que causaba un efecto paralizante en aquel que lo escuchaba (Iriarte, 1990, p.137). De hecho, para la población tebana la Esfinge simbolizó la encarnación del rapto violento y súbito que ocasionaba la muerte, emparentándose así con las Harpías, según Eurípides (Ph. v.1021), y que incluía formas violentas de posesión sexual.

En cuanto al secreto de su enigma, existen alusiones a este en la literatura de inicios del siglo $\mathrm{V}$ a. C., pero no es hasta el siglo IV a. C. cuando contamos con el relato completo, proporcionado por el historiador Asclepíades de Trágilo - transmitido a través de un escolio al verso 50 de las Fenicias de Eurípides_- quien apuntó que para resolver el enigma había que adivinar cuál es el ser bípedo, cuadrúpedo y trípedo que cambia de figura y camina más despacio a medida que le aumentan las patas en que se apoya.

En este sentido, observamos elementos que identifican la palabra de la Esfinge como profética; de hecho, se emplea el término khresmós en Sófocles (OT. v.1200), para designar tanto su canto, como la respuesta délfica 
(OT. v.712): su carácter enigmático, y la exposición del pasado, presente y futuro de la persona a la que se está dirigiendo (Iriarte, 1990, p.140). A ello se le añaden versiones de autores clásicos que resaltan el carácter profético del monstruo: la primera procede del escoliasta de Eurípides (comentario al verso 1760 de las Fenicias), quien señala la condición de la Esfinge como una profetisa (khresmológos) cuya función era formular enigmas a la población tebana y acabar con quienes no los acertaran; y la segunda afirma que su enigma era un «oráculo» de Delfos, según Pausanias (IX, 26. vv.3-4).

Aunque es aceptable que la Esfinge sea nombrada profetisa porque su conocimiento es sobrehumano, ella se diferencia del resto de los intermediarios de Apolo porque su cometido es constatar la incapacidad del conocimiento humano, mientras que los otros intermediarios tienen como función transmitir un saber a las personas. ¿Qué sentido tiene el enigma? La Esfinge con su canto alude al apotegma enigmático que se encontraba en la entrada del santuario de Apolo en Delfos, y que evidencia la limitación del ser humano, gnôthi seautón, «conócete a ti mismo».

La figura de la Esfinge nace en Egipto, donde simboliza al faraón desde el Imperio Antiguo hasta el Imperio Nuevo. Durante el reinado de Hatshepsut (siglo XV a. C.), aparece la llamada «Esfinge femenina», que

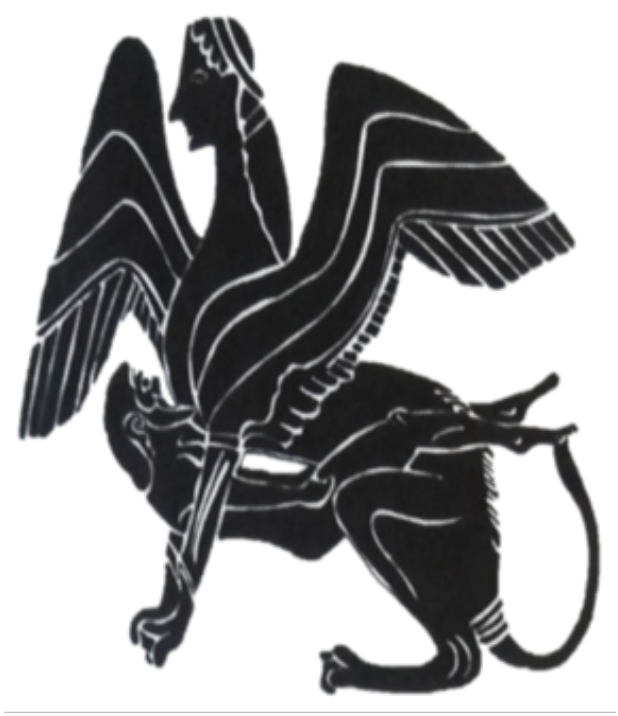
posee brazos humanos en vez de patas. En el mundo micénico se representan dos tipos de esfinges, las femeninas y las masculinas, generalmente protegiendo al árbol sagrado, o una columna o un altar (Bermejo, 1982, pp.54-56).

Esta figura sufre una evolución iconográfica, pudiéndose establecer dos etapas: desde época arcaica, prima su naturaleza salvaje y violenta, pero a partir del 490/480 a.

Fig. 7. Dibujo de una Esfinge representada en una copa ática del 560 a. C. (Cabrera, 2012, p.28). 
C. su imagen se dulcifica. En la primera etapa predominan las escenas de persecución o de rapto, en las que la Esfinge es representada persiguiendo, raptando, o copulando con jóvenes víctimas varones, que son representados huyendo aterrorizados ante la persecución de la Esfinge, o inmóviles y apresados bajo sus garras (fig. 7). En la segunda, la escena de rapto es menos frecuente y se generaliza la imagen de la Esfinge hierática, sentada sobre una roca o en una columna, y dispuesta frente a Edipo o un grupo de tebanos (cf. fig. 6. Iriarte, 1990, p.135).

Me parece interesante prestar atención a las «escenas de rapto» características de la época arcaica griega, en las que la Esfinge es una raptora de hombres como las Sirenas y las Harpías, quienes al igual que la Esfinge reciben el adjetivo de parthénos o Koré, "virgen», calificativo que señala tanto su pureza como su marginalidad social. La Esfinge tiene una doble naturaleza: psicológica, porque se convierte en una pesadilla erótica que atormenta a la persona que duerme, pero también religiosa, porque simboliza el alma de los fallecidos y su tránsito al Más Allá. En tanto que pesadilla erótica, la Esfinge se relaciona con las llamadas Damas del Mediodía, espíritus femeninos que se aparecen a los durmientes y les oprimen con preguntas difíciles, les acarician, les fuerzan a mantener relaciones sexuales e incluso pueden causarles la muerte. Todos estos jóvenes muestran una actitud pasiva, que contrasta con la de la Esfinge, situada encima y ejerciendo una posición dominante que conlleva la inversión de los roles —eróticos y de poder - de género tradicionales al tratarse de una violación realizada por una mujer (Delcourt, 1944).

El hecho de que siempre rapte a hombres jóvenes y se sitúe en una posición dominante propia del rol masculino evidencia su avidez erótica, deseante tanto de placer sexual como de sangre, y que comporta también una pulsión de muerte. De hecho, acaba con la vida de sus víctimas mediante un abrazo en el que despliega todo su cuerpo sobre el del varón con tanta fuerza que lo ahoga, de modo que la Esfinge es un íncubo femenino que da muerte mediante un abrazo amoroso sofocante, capacidad que ya expresa la etimología de su nombre. El amor y la muerte son, por tanto, dos aspectos del poder de la Esfinge, plasmados en las «escenas de rapto». Una vez explicada la relación entre su naturaleza funeraria y erótica, se puede decir que para la Esfinge los muertos son, al mismo tiempo, sus amantes y sus víctimas. 
Pero, además, la Esfinge, al igual que Gorgona, fue utilizada como elemento apotropaico y representada en cascos y escudos para causar un efecto paralizante en los enemigos; de hecho, es significativo que ambas figuras con ese fin aparezcan representadas en la armadura que Tetis le regaló a su hijo Aquiles, como recoge Eurípides ( $P h$. vv.470-472).

\section{SIRENAS}

La versión más famosa es la que atribuye la paternidad de las Sirenas a una Musa - ya sea Terpsícore, Melpómene o Calíope- y al dios-río Aqueloo. De este modo, por vía paterna heredan tanto su condición híbrida como su gusto por el mar, y por vía materna su habilidad para el canto. Existe una variante de esta versión, en la que Aqueloo y Estérope, hija del rey de Etolia, habrían concebido a las Sirenas, según Apolodoro de Rodas $(I, 7,10)$, y es probable que esta versión fuese antigua e incluso que estuviese ya recogida en el Catálogo de las mujeres de Hesíodo, aunque no tuviese gran aceptación (Jiménez, 2012, pp.119-120).

Homero (Od. XII. vv.37-164) no menciona su nombre, sino que usa el plural para referirse a ellas. Además, los escoliastas del poeta tienen opiniones diferentes pues, por un lado, en un escolio a Homero $(\mathrm{Od}$. XII. v.39) se da el nombre de dos Sirenas, Aglaofame y Telxiepia y, por otro lado, en otro escolio diferente al mismo verso se cita a cuatro Sirenas que reciben el nombre de Aglaofeme, Telxiepia, Pisíone y Ligia.

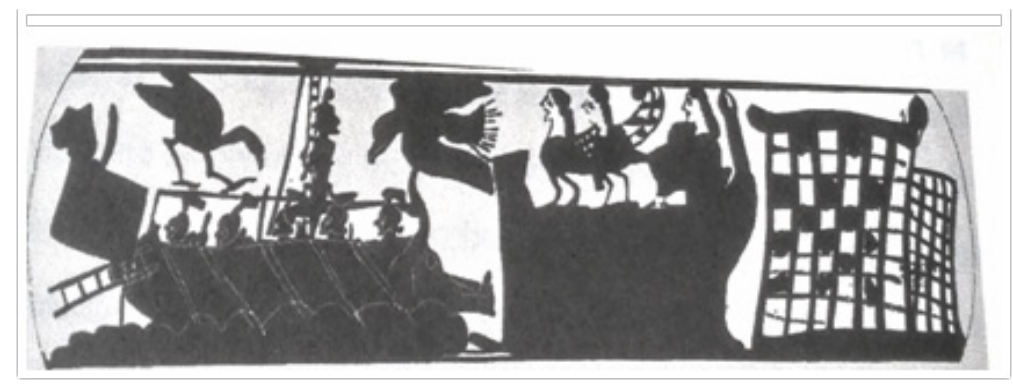

Fig. 8. Escena de la Odisea pintada sobre un aríbalo corintio, en la que aparece Odiseo entre dos pájaros carroñeros como alegoría de las Sirenas, dos Sirenas en una roca, una figura femenina, y las puertas del Hades, ca. 560 a. C., Museo de Bellas Artes, Boston (García, 2014, p.18). 
El hecho de que aparezcan siempre en plural y nunca en singular da a entender que siempre actúan en grupo, de dos a cuatro generalmente. Se trata, casi en su totalidad, de nombres parlantes que evocan su principal facultad. Así pues, Aglaofeme es «la de espléndida fama»; Pisíone es «la que persuade la mente»; Telxiepia es «la que encanta con las palabras»; y Ligia, «la sonora».

En el mundo grecolatino, las Sirenas eran concebidas como seres con rostro y tronco humano y extremidades propias de las aves. El documento escrito más antiguo en Grecia que menciona a estos seres son tres tablillas de Pilo que datan de época micénica (1900-1200 a. C.). En ellas se incluye la expresión "con cabeza(s) de Sirena» al describir las piezas de marfil y oro que decoran un sillón. Este testimonio permite pensar que si las cabezas de las Sirenas no se diferencian de las humanas en la tradición posterior, sí que debían diferenciarse en el mundo micénico, pudiendo ser similares a las de las Esfinges o que también llevaran adornos en la cabeza como el polos, un tipo de gorro (Jiménez 2012, pp.122-123). Sin embargo, no es hasta el siglo III a. C. cuando Apolodoro de Rodas (IV. vv.897-899), alude a su condición híbrida, y al hecho de que habían sufrido una metamorfosis, que Ovidio (Met. V. vv.552-563) sitúa cuando Proserpina fue raptada por Venus, mientras que los griegos piensan que se debe a un enfado de Afrodita, quien las habría castigado por permanecer vírgenes.

El encuentro de Odiseo con las Sirenas (Od. XII. vv.27-164) es el más conocido en el imaginario occidental (fig.8). Son seres cuyo encuentro constituye una de las aventuras que marcan el regreso de Odiseo a su patria, a Ítaca. Se trata de un episodio breve, sin muchos detalles, pues Homero, que bebe de la tradición oral, da por supuesto su conocimiento. En primer lugar, la maga $\mathrm{Circe}^{7}$ previene a Ulises, tras su regreso del Hades, y a su tripulación del encuentro con las Sirenas, quienes recitaron su armonioso canto, éntynon aoidén, que tuvo lugar en un prado florido ausente de brisa (37-52).

7 Es solo a través de las palabras de Circe por las que conocemos la existencia del montón de huesos corruptos que rodean a estos seres, quienes no eran devorados por las Sirenas sino que morían por extenuación dado que el hechizo provocaba que se olvidaran de su propia existencia. 
El peligro de estos seres reside en su canto ardiente, que era temido por el hechizo que producía y cuyo final era la muerte. Dado que su peligro está relacionado con el aspecto auditivo, no se detalla su fisionomía. El canto que le ofrecieron a Ulises era un espejo de su gloria, y de hecho fue compuesto para él: para ello utilizaron una formula idéntica a la que expresa Agamenón cuando le rinde homenaje a Ulises, según Homero (Il. IX. v. 673). El objetivo era encantarle aludiendo a su pasado glorioso, a la guerra entre argivos y troyanos, mediante esa canción seductora que le identifica más con el guerrero troyano que con el marinero.

Por su condición ctónica, eran poseedoras de un conocimiento sobrehumano, cuya seducción es similar a la producida por el Gorgoneion, por lo que le podían relatar a Odiseo desde la guerra troyana hasta todos los acontecimientos que tienen lugar en la tierra. Era muy atractiva la propuesta de las Sirenas puesto que el que las escuchaba era testigo, siendo mortal, de su heroicidad, pero el final de su canto conllevaba, a su vez, la muerte del oyente. Es muy relevante constatar que la atracción que producían no era erótica sino de conocimiento, y para el hombre primitivo el deseo de saber, equiparándose con los dioses, era el deseo fatal.

Por otro lado, Odiseo no fue el único héroe que pudo deshacerse del encanto de las Sirenas, sino que, con anterioridad, Orfeo y los Argonautas que habían ido en busca del vellocino de oro también logaron escapar, a excepción de Butes, que se precipitó al mar. Este episodio mítico es ya representado en un lecito ático de figuras negras del 570 a. C., pero no es narrado por completo hasta el siglo IV a. C. por Apolodoro de Rodas (IV, vv.891-920). Es significativo que ni Homero ni Apolonio de Rodas narran la muerte de las Sirenas tras su derrota frente a Odiseo y Orfeo, respectivamente, pero que sí aparezca representada en un stamnos ático de figuras rojas del siglo $\mathrm{V}$ a. C. encontrado en Vulci. No obstante, Licofrón (Alex. vv.712-716) conecta el suicidio de las Sirenas con una tradición profética.

Es notable la distinción entre, por un lado, las Sirenas representadas literariamente como cantantes de Odiseo y Orfeo y, por otro lado, las imágenes de ellas colocadas sobre las tumbas y formando parte de los ajuares funerarios, especialmente en época helenística, y cuya función es claramente apotropaica y psicopompa. De estas segundas Sirenas funerarias cabe mencionar las figuras realizadas en terracota que tienen cabeza humana y forma de pájaro, y portan un cestillo (kalathos) en la cabeza, que 
se depositan en los templos de Hera y Perséfone así como en las tumbas; los vasos decorados con Sirenas que portan una figura en sus brazos, que se ha interpretado como un alma o que participan en el banquete de los bienaventurados; las Sirenas en forma de askos colocadas en el ajuar funerario; las representadas en lecitos, vasos específicamente funerarios y las colocadas sobre tumbas, ejerciendo como seres protectores de las mismas (fig. 9).

No obstante, en el relato homérico se ofrecen diversos detalles a través de los cuales se pueden relacionar a las Sirenas con el Allende: el emplazamiento occidental de las mismas, que indica que

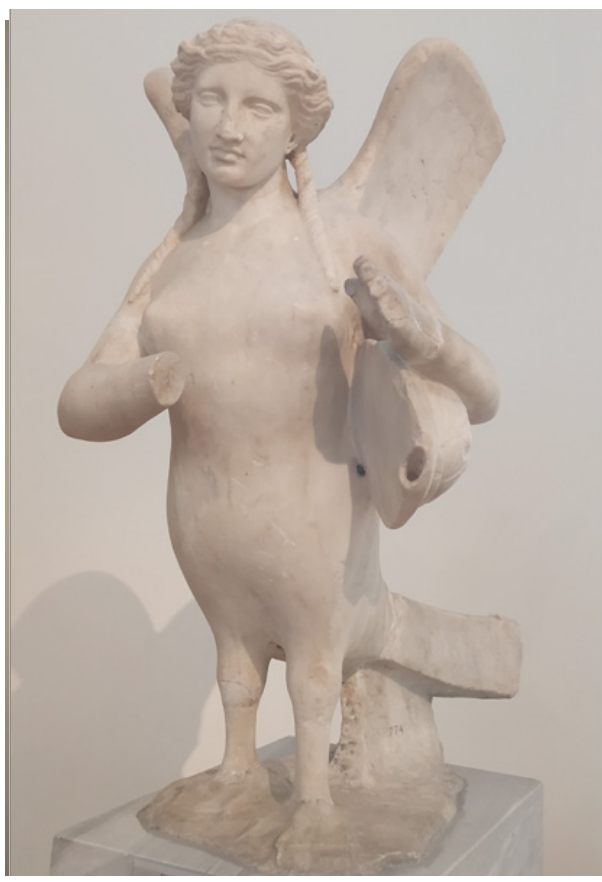

Fig. 9. Estatua de una Sirena con una lira hecha de concha de tortuga, datada en el 370 a. C. y procedente del Cerámico de Atenas. Museo Arqueológico Nacional, Atenas. Fotografía de la autora. son seres intermedios entre la vida y la muerte; el hecho de que el encuentro con ellas tenga lugar tras el regreso de Odiseo al Hades; y su ubicación en un prado lleno de huesos. Existen dos obras literarias griegas que muestran la conexión de las Sirenas con el Más Allá. Por un lado, Eurípides (Hel. vv.169-178), las muestra como ayudantes del lamento de Helena, pues son seres que cantan en el mundo infernal a los muertos. Por otro lado, Sófocles (fr. 861 Radt), las considera cantoras del Hades. Tras analizar estos pasajes, podemos concluir que son criaturas psicopompas, que recogen las almas de los fallecidos y con sus cantos las transportan al Más Allá. A ello se le añade que sean consideradas por Apolodoro de Rodas (IV, vv.896-90), como parte del cortejo de Perséfone antes de su rapto por Hades, siendo así mediadoras entre ambos mundos, y que el olvido que produce su canto está ligado al Más Allá en el mundo griego. 
Una consecuencia de su conexión con el mundo funerario es que han sido interpretadas como almas aladas de los muertos; por ello y por su fisionomía han sido consideradas como descendientes mitológicos del $\mathrm{Ba}$ egipcio, el alma del difunto cuando muere (Iriarte, 2002, p.53). Aunque ello no implica que los griegos las consideraran de este modo, sino más bien como demones funerarios tales como las Gorgonas, las Esfinges y las Harpías. Tras analizar ambas interpretaciones de las Sirenas, cabe decir que no son excluyentes, sino complementarias.

\section{Conclusiones}

Todas las figuras analizadas son seres híbridos que ocupan un lugar central en el imaginario griego, poblando tanto los relatos literarios como las representaciones iconográficas. Son seres que por su condición monstruosa, en la que combinan la naturaleza humana y animal, pueblan lo que en griego se denomina la eschatiá, el espacio de frontera, constituyéndose así como figuras de la alteridad, y es que, de hecho, el reino que tanto frecuentan, el de la Muerte, es el ámbito por excelencia de la otredad. Son, en conjunto, bellas atroces, totalmente ambiguas, liminales, que invierten algunos roles de género tradicionales, produciendo, por todo ello, dos sentimientos contradictorios: atracción y repulsión.

En realidad, se trata de una lucha entre el Bien, que está asociado al hombre, y el Mal, que es encarnado por la mujer. Es más, son las propias mujeres - en este caso como figuras híbridas - las que poseen como objetivo buscar la ruina a los hombres, que generalmente son héroes, caso de Perseo, Edipo y Ulises, o personajes ilustres de la talla de Orfeo, o personas anónimas. En definitiva, es un arquetipo que se ha ido gestando a lo largo de la Historia, al que han contribuido tanto el arte como la religión, y que se ha convertido en una figura imaginaria sobre la que la masculinidad ha proyectado un discurso misógino.

Es por ello por lo que no sería justo que la figura de la Esfinge fuera reducida a su encuentro fatal con Edipo, sino que fuera vista, al mismo tiempo, como un demonio funerario, protector de tumbas, psicopompo y como una potencia, opuesta a Apolo, encargada de evidenciar la incapacidad del conocimiento humano. Y lo mismo sucede con Gorgo, quien 
ha pasado a la posteridad por presidir la égida o escudo de Atenea, pero que, en mi opinión, debe ser valorada verdaderamente por la funcionalidad por la que está presente en tantas representaciones: porque es un talismán que protege a quien lo porta, ya sea en escudo, en una cerámica o en un horno. En la misma línea, habría que destacar no el canto de las Sirenas como tal, sino lo que este puede expresar, un conocimiento sobrehumano.

Finalmente, estudiar en conjunto a estos entes sobrenaturales permite establecer conexiones más allá de la tesis de Harrison, puesto que las acciones de algunas de ellas producen el mismo efecto, como la atracción que desencadenan el Gorgoneion, el canto de las Sirenas y el enigma de la Esfinge de Tebas.

\section{BibliografíA}

\section{Autores clásicos}

Apolodoro de Atenas. Biblioteca. Edición de M. Rodríguez, 1985. Madrid: Gredos.

Eurípides. Tragedias. III. Edición de C. García y L. A. De Cuenca, 1979. Madrid: Gredos.

Hesíodo. Obras y fragmentos. Edición de A. Pérez y A. Martínez, 1983. Madrid: Gredos.

Homero. Odisea. Edición de J. M. Pabón, 1982. Madrid: Gredos.

Homero. Ilíada. Edición de E. Crespo, 1991. Madrid: Gredos.

Ovidio. Metamorfosis. Edición de J. C. Fernández y J. Cantó, 2008. Madrid: Gredos.

\section{Bibliografía contemporánea}

Bermejo, J., 1982. Mitología y mitos de la Hispania prerromana. Madrid: Akal. Cabrera, P., 2012. Los seres híbridos. Imágenes de la alteridad en la Grecia clásica. En: A. Bernabé, J. Pérez de Tudela, eds. Seres híbridos en la mitología griega. Madrid: Ediciones Pensamiento, pp.13-48.

Delcourt, M., (1944). Edipe ou la légende du conquérant. Paris: Les Belles Lettres. 
Del Hoyo, J. y Vázquez, A., 1990. La Gorgona y su triple poder mágico (aproximación a la magia, la brujería y la superstición II), Espacio, Tiempo y Forma, Serie II, Historia Antigua (3), pp.117-182.

Díez de Velasco, F., 1995. Los caminos de la muerte: religión, rito e iconografía del paso del más allá en la Grecia antigua. Madrid: Editorial Trotta.

Frothingham, A. L., 1911. Medusa, Apollo, and the Great Mother. AJA, 15 (3), pp.349-377.

Furtwängler, A., 1884-1890. Gorgo. En: W. Roscher. Ausführliches Lexikon der Griechischen und Römischen Mythologie, Hildesheim: Georg Olms Verlag, pp.1695-1717.

García, C., 2014. Sirenas. Seducciones y metamorfosis. Madrid: Turner.

Harrison, J., 1960. Prolegomena to the Study of Greek Religion. New York: Meridian Books.

Hopkins, C., 1934. Assyrian Elements in the Perseus-Gorgon Story. AJA, 38 (3), pp.341-358.

Iriarte, A., 1990. Las redes del enigma. Voces femeninas en el pensamiento griego. Madrid: Taurus.

Jiménez, A. I., 2012. Las Sirenas. En: A. Bernabé, J. Pérez de Tudela, eds. Seres híbridos en la mitología griega. Madrid: Ediciones Pensamiento, pp.115-151.

Martín, R., 2012. Medusa y las Gorgonas. En: A. Bernabé, J. Pérez de Tudela, eds. Seres híbridos en la mitología griega. Madrid: Ediciones Pensamiento, pp.155-185.

Mayor, Ma, T., 2012. Monstruos femeninos en la mitología griega, Revista de Claseshistoria, 287, pp.1-44.

Mclerney, J., 2018. Greece in the Ancient World. Greece: Thames \& Hudson.

Pedraza, P., 1991. La Bella, enigma y pesadilla (Esfinge, Medusa, Pantera). Barcelona: Tusquets.

Pérez de Tudela, J., 2012. La Esfinge de Tebas. En: A. Bernabé, J. Pérez de Tudela, eds. Seres híbridos en la mitología griega. Madrid: Ediciones Pensamiento, pp.51-71.

Vermeule, E., 1984. La muerte en la poesía y en el arte de Grecia. México: Fondo de Cultura Económica.

Vernant, J-P., 1986. La muerte en los ojos. Figuras del Otro en la antigua Grecia. Barcelona: Gedisa. 



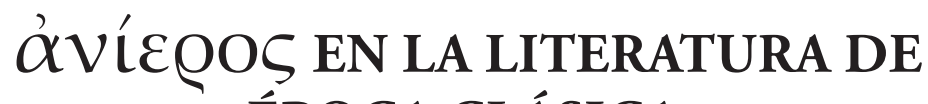 ÉPOCA CLÁSICA
}

\section{aviegos in the literature of the classical period}

\author{
Silvita Vergara Recreo ${ }^{\mathrm{I}}$
}

Resumen: En el presente trabajo pretendemos delimitar la esfera léxico-semántica del étimo irreligioso àvícoos en la literatura de época clásica, adjetivo antónimo de íøós ('sagrado') que aparece puntualmente en los textos literarios con el propósito de subrayar la condición sacrílega de un individuo que osa trasgredir los límites de lo sagrado. clásica.

Palabras clave: Irreligiosidad, ảvízoos, į́oós, literatura griega, época

Abstract: In this work we intent to specify the lexical-semantic sphere of the irreligious word dxvizoos in the literature of the Classical period, an adjective oppossed to į́ós ('sacred'), which appears in isolated cases emphasizing the sinful condition of whom dares to break the religious boundaries. riod.

Keywords: Irreligiosity, àvíєoos, į́oós, Greek literature, Classical pe-

1 Doctoranda. Universidad de Zaragoza. Correo electrónico: svergara@unizar.es. 
A finales del siglo $\mathrm{V}$ a.C. Atenas se encontraba sumida en una profunda crisis social que tuvo serias repercusiones en la moralidad y el pensamiento religioso de aquella época. Los continuos infortunios acontecidos durante la Guerra del Peloponeso y los rápidos cambios socioculturales, causados principalmente por la irrupción de nuevas teorías científico-filosóficas en la ciudad, propiciaron la gestación de un estado de nerviosismo y miedo ante lo que parecía amenazar los preceptos morales y religiosos. ${ }^{2}$ Todos estos eventos abrumadores crearon el perfecto caldo de cultivo para la aparición de un nuevo léxico de naturaleza irreligiosa que definía las conductas y las acciones contrarias a la moral y a la religión tradicionales.

Uno de los términos testimoniados por vez primera en época clásica es àvícoos, el cual aparece de forma ocasional en los textos literarios y posee un potente valor irreligioso. Durante este período, fue usado en varias ocasiones por los tragediógrafos y posteriormente fue adoptado por Platón. Sin embargo, en el ocaso del siglo IV a.C. encontramos una ausencia significativa de àvíreos en las fuentes literarias, desconociendo su empleo y operatividad precisos hasta casi cuatro siglos después, cuando Plutarco de Queronea vuelve a utilizarlo en distintas obras de su vasta producción literaria. ${ }^{3}$ Este vocablo es la forma opuesta al adjetivo íøós, ampliamente documentado en la literatura griega y comúnmente traducido como 'sagrado'. En cuanto a la concreción semántica de esta voz irreligiosa, si atendemos a estudios recientes como el de Sorel (2015, pp.419-420), observamos que į́œó es definido como aquello perteneciente a los dioses o que se encuentra inserto dentro de los límites de lo sagrado, integrando así tanto objetos como lugares, cultos y rituales. De este modo, àvíeoos remitiría a los gestos sacrílegos que violan los espacios y elementos inherentes a la divinidad.

Así las cosas, en esta contribución pretendemos realizar un estudio sincrónico con la intención de delimitar la esfera léxico-semántica del vocablo àvízoo a través del estudio de sus cinco únicas comparecencias en las manifestaciones literarias datadas entre los siglos V y IV a.C., apareciendo

2 Para una exposición pormenorizada sobre las dificultades afrontadas por Atenas durante los últimos años del siglo V a.C., cf. Rubel, 2014.

3 TLG, II, p.797 s.v. ávícoos. 
en dos ocasiones en el Agamenón de Esquilo y una sola vez en el resto de los casos: en las Suplicantes de Esquilo, en el Hipólito de Eurípides y en la República de Platón. Hemos de señalar que obviamos en este trabajo el análisis de la lítote oủx í@ós, giro retórico cuyo sentido irreligioso consideramos más flexible que àvíreos, debido a la naturaleza polisémica adquirida por el término ícoós según el contexto en que se inserta.

A. Supp. vv. 748-759. El siguiente pasaje es un ejemplo excepcional con el que comprobar la profusión de nociones religiosas e irreligiosas utilizadas por Esquilo en esta tragedia para marcar las tensiones existentes entre el comportamiento piadoso de las Danaides y el carácter impío de sus enemigos. Concretamente, el Coro presenta a los hijos de Egipto sirviéndose de un amplio abanico de términos de índole irreligiosa, los cuales le permiten insistir en su condición desafiante y transgresora (Calderón Dorda, 2013, p.304; Vicente Sánchez, 2018, p.70):

«CO. No me dejes sola, te lo ruego, padre. Una mujer no es nada cuando permanece sola, pues Ares no reside en ella. Malvados, mentirosos, de actitudes impuras, iguales que los cuervos, de ningún modo respetan los altares.

DA. Sin duda nos ayudaría esto, hijas, que fueran odiados por ti y por los dioses.

CO. Pero no alejarán sus manos de nosotras, padre, porque no tienen miedo de estos tridentes ni de desobedecer a los dioses.

Orgullosos en exceso, con una actitud sacrílega, enfurecidos descomunalmente, arrogantes como perros, de ningún modo escuchan a los dioses.» ${ }^{4}$

La vileza de los egipcios se describe usando expresiones que apuntan a su maldad (v. 750: «oủ

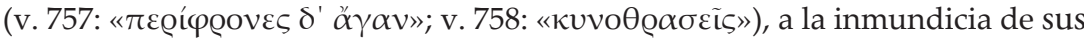

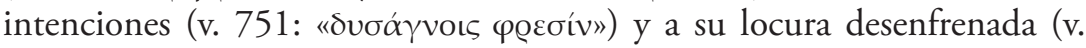

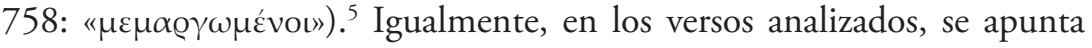

4 Las traducciones aportadas en esta contribución, salvo citación expresa, son personales.

5 El vocabulario empleado en estos versos es realmente llamativo: por un lado, oủ mera vez atestiguado en época clásica en esta tragedia, y no volverá a comparecer hasta la 
ya al carácter impío de estos personajes cuando una de las Danaides nos advierte sobre la gravedad de su ofensa, pues desean llevárselas a la fuerza de vuelta a Egipto sin amedrentarse ante la autoridad divina (vv. 755-756:

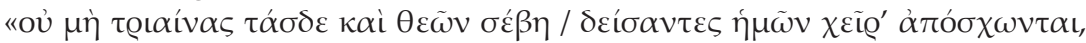

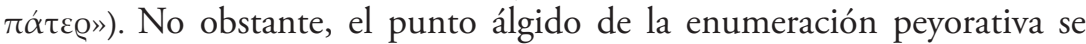
alcanza al definir la actitud de los egipcios con el adjetivo ḋvícoos (v. 758:

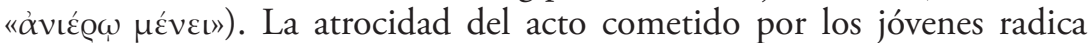
en el intento de expulsar de los templos a suplicantes amparados bajo la protección de la divinidad, lo cual suponía un enorme atentado contra

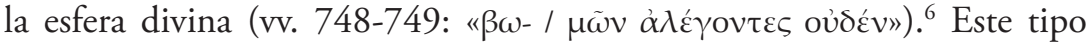
de conductas acaban suscitando un sentimiento de aversión hostil no solo entre los hombres, sino también entre los mismísimos dioses, aquí

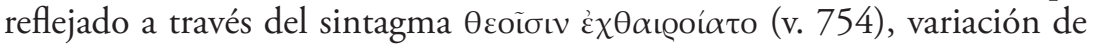

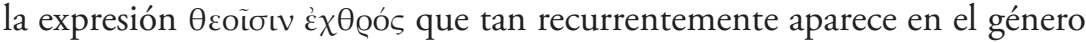
trágico (Vicente Sánchez, 2018, pp.70-71).

A. Ag. vv. 206-233. El nudo de Agamenón —el cual se dilata argumentalmente hasta la última tragedia de la trilogía esquílea- trasluce el tema de la contaminación impía desatada por la concatenación de homicidios dentro de la casa atrida, acciones terribles que necesitaban ser expiadas con una nueva víctima para vengar la muerte del difunto. El presente pasaje narra los antiguos sacrilegios cometidos por Agamenón, los cuales, al final de la tragedia, le conducirán a su funesto final (vv. 206-223):

«CO. "Dolor siento en mi corazón por no obedecer, y dolor sentiré si mato a mi hija, delicia de mi casa, contaminando mis manos de padre con los borbotones de sangre que brotan de la joven sacrificada junto al altar. ¿Qué hay lejos de estas desgracias? ¿Cómo voy a traicionar a la flota, fallando a los aliados? En efecto, es lícito desear con pasión desenfrenada ofrecer como sacrificio la sangre de una muchacha para aplacar los vientos. Pues que así sea”.

Y cuando lo invadió el yugo de la necesidad con un soplo de viento cambiante que brotaba desde su interior, impío, impuro y sacrílego, desde entonces decidió tomar decisiones completamente audaces, pues a los mortales los hace insensatos la penosa locura de vergonzosos pensamientos, primera causa de desgracias.»

literatura tardía; por otro lado, $\pi \varepsilon \varrho i ́(\varphi \varrho \omega v$ aparece generalmente en contextos positivos. Cf. Petrovic y Petrovic, 2016, p.173.

6 Cf. Parker, 1996, p.146. 
El Coro nos presenta a un Agamenón atribulado a causa de una auténtica encrucijada moral: si no acata las órdenes de Ártemis, quien demanda el sacrificio de la joven Ifigenia, cometerá una impiedad contra la diosa; en cambio, si degüella a su hija, este crimen desatará la ira y la

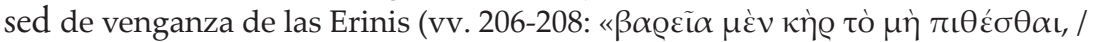

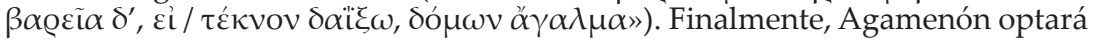

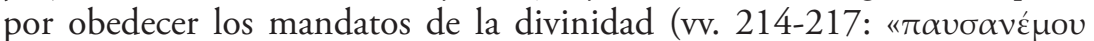

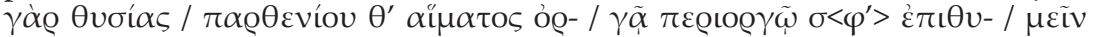

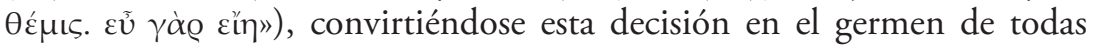
las desgracias que arruinarán a la familia atrida (Petrovic y Petrovic 2016, pp.136-137). ${ }^{7}$

En lo que atañe estrictamente al léxico irreligioso, en este fragmento se utilizan términos cercanos al campo de la contaminación para evidenciar la gravedad que suponía asesinar a un miembro de la familia. Así, se alude simbólicamente a la sangre que emana del cuerpo de Ifigenia manchando las manos de su verdugo mediante la voz irreligiosa $\mu \iota \alpha i ́ v \omega$, verbo que incide en la contaminación impía que recae sobre el homicida (vv. 209-

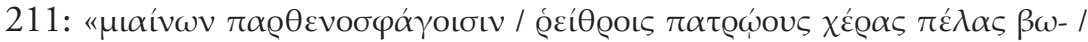

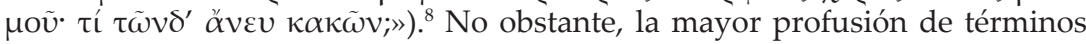
irreligiosos la encontramos inmediatamente después, cuando el Coro expone las consecuencias de la inmolación de Ifigenia con una cuidada metáfora. Mientras se serena el temporal que impedía la partida de los navíos griegos hacia Troya, vientos impíos invaden la mente de Agamenón transformándolo en un individuo que osa transgredir los ideales de la

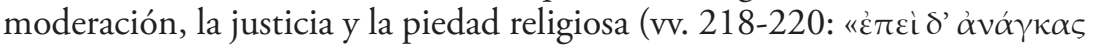

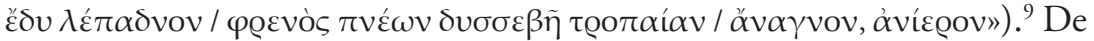
hecho, su conversión moral se enfatiza mediante la yuxtaposición de tres adjetivos de potente naturaleza irreligiosa: $\delta \sigma \sigma \varepsilon \beta \eta \dot{\zeta}$, vocablo que incide en la impiedad desencadenada por el delito de sangre (Calderón Dorda, 2013,

7 Cf. Vicente Sánchez, 2015, p.138.

8 Como indica Parker (1996, pp.104-106), en el imaginario griego se plasmaba el carácter sumamente impío del derramamiento de sangre a través de la imagen de las manos manchadas del asesino.

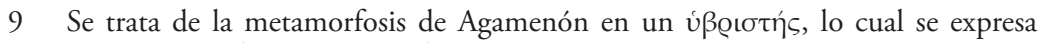

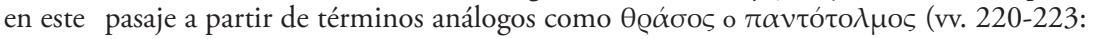

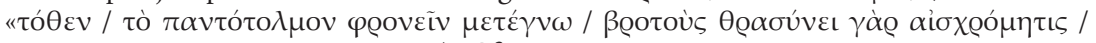

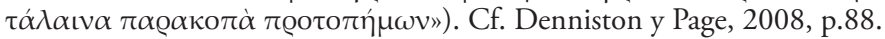


p.309); $\check{\alpha} v \alpha \gamma v o s$, adjetivo con el cual se destaca la predisposición impura de Agamenón; ${ }^{10}$ y àvíreos, un término que, como ya hemos comentado, acentúa la falta religiosa ocasionada al profanar todo aquello perteneciente a la esfera divina, en este caso, la resolución de Agamenón de ofrecer a su propia hija como víctima sacrificial.

A. Ag. vv. 758-781: en los momentos previos a la llegada de Agamenón a su hogar, el Coro entona un canto con un marcado estilo antitético a fin de recordar el hado que la divinidad reserva a los hombres piadosos y a los sacrílegos. Es lo que se deduce del siguiente parlamento del Corifeo (vv. 758-781):

«CO. Efectivamente, una acción impía engendra después muchas más, similares a su propia estirpe, mientras que el destino de las casas estrictamente justas es ser bendecidas siempre con buenos hijos.

Y la soberbia antigua suele concebir una soberbia más joven entre los mortales malvados, tarde o temprano, tras llegar el día seńalado del parto, un ente divino, invencible e imbatible, el orgullo sacrílego causado por la ceguera, perniciosa para las familias, similar a sus progenitores.

La Justicia resplandece en las casas manchadas por el humo y honra la vida recta; sin embargo, abandona las casas tachonadas de oro con una mancha en las manos, dirigiendo la vista hacia viviendas piadosas, sin guardar respeto alguno hacia el poder de la riqueza, falsamente sellado por la alabanza; pues todo lo conduce a su fin.»

Esquilo pondera la posibilidad de que los vicios y las virtudes pueden sucederse de generación en generación, de tal manera que los individuos depravados e irrespetuosos con los dioses engendrarían hijos de esta misma

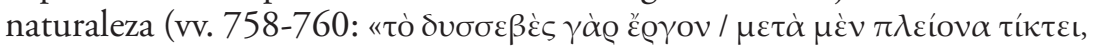

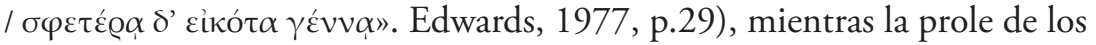
hombres honrados heredaría cualidades como la justicia, la moderación

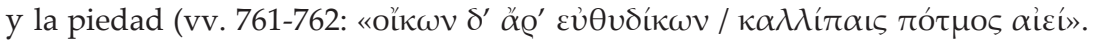
Calderón Dorda, 2013, p.310).

$10 \alpha \ddot{\alpha} v \alpha \gamma v o \varsigma$ se opone a $\alpha ́ \gamma v o ́ s$, que define la pureza necesaria para llevar a cabo una acción ritual y garantizar su eficacia. Cf. Rudhardt, 1992, pp.171-172. 
El momento culminante de esta monodia coral se alcanza en los versos 763-771, cuando se recurre a la idea arcaica de que todo acto de úßoıs genera úßoıs mediante la descripción del retońo surgido de la

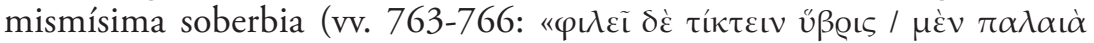

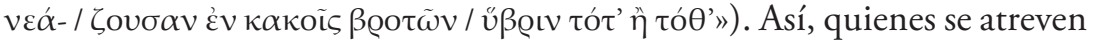
a desafiar a los dioses desarrollan un orgullo sacrílego, aquí calificado como una divinidad implacable cuya génesis ha causado ese estado de insensatez que empuja a los hombres a cometer faltas contra lo divino

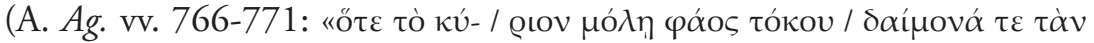

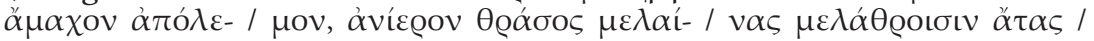

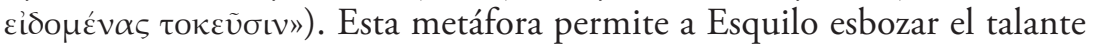
de los criminales impíos, concluyendo que, si 'Atๆ conduce a los mortales corruptos a padecer las desgracias más terribles, $\Delta$ ík prima la rectitud moral y el respeto hacia las normas estipuladas por los

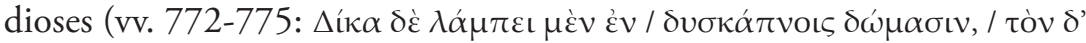

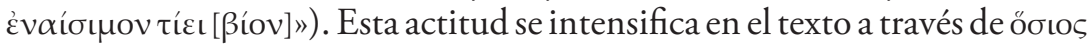

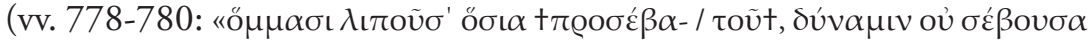

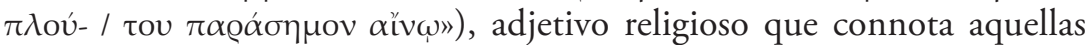
actitudes correctamente sancionadas a ojos de la divinidad (Calderón Dorda, 2013, p.306). Como apostilla final a este comentario, podemos señalar que el enfrentamiento entre estos dos tipos de comportamiento se ejemplifica gracias a la mención del humo sacrificial que tapiza los muros

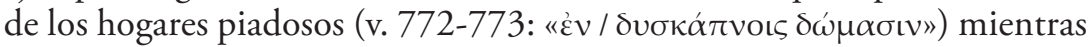
las casas corrompidas se representan manchadas por la lacra infecciosa

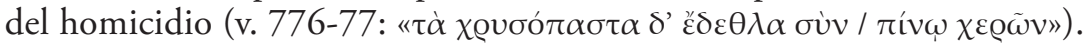

E. Hipp. vv. 129-147: este episodio narra los sufrimientos que Fedra padece a causa del estado de enamoramiento ilícito provocado por Afrodita, ultrajada por la actitud irrespetuosa de Hipólito, quien había desdeñado el culto de la diosa, tal y como se advierte en el prólogo de esta obra (vv. 11-14: «Hipólito, pupilo del inmaculado Piteo, / entre los ciudadanos de esta tierra, Trecén, solamente él / dice que soy la más infame de todas las divinidades, / rechaza los lechos y reniega de los matrimonios»). ${ }^{11}$ En este fragmento coral se detallan las características de la aflicción de la reina,

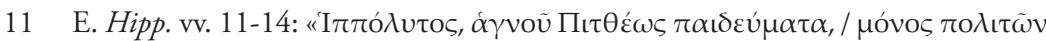

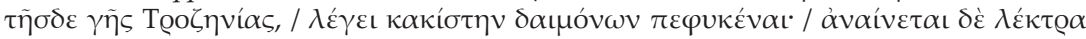

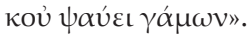


enamorada de su hijastro, siguiendo el tópico arcaico de la enfermedad de amor (vv. 129-147): ${ }^{12}$

«CO. De allí me acaba de llegar un rumor sobre la reina, que está sufriendo dentro de palacio en un lecho enfermo, y que mantos finos oscurecen su rubia cabellera.

He oído que ella lleva tres días en ayuno y que mantiene alejado su puro cuerpo del trigo de Deméter, con el deseo de dirigirse, por un sufrimiento oculto, hacia el desastroso final de la muerte.

¿Acaso, completamente poseída, muchacha, bien por el dios Pan, por Hécate, por los venerables Coribantes o por la madre de las montańas te encuentras en un estado de frenesí? ¿¿ te estás consumiendo por los fallos cometidos contra la cazadora Dictina, siendo una sacrílega por no darle como ofrenda una torta sacrificial?»

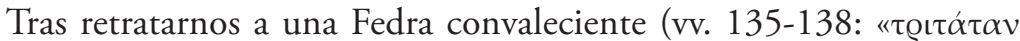

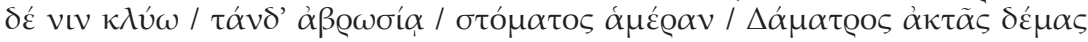
$\alpha \gamma \nu$ òv ľ $\sigma \chi \varepsilon เ v »)$, el Coro engarza una serie de preguntas retóricas con las cuales se pretende hallar el origen de la congoja de Fedra. En un primer momento, la enajenación mental se atribuye a la actuación de distintas divinidades a las que popularmente se consideraba responsables de desencadenar reacciones sintomatológicas de enfermedades concretas (vv.

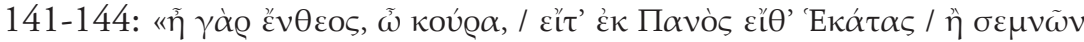

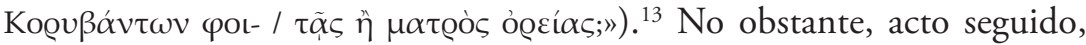
una de las posibilidades contempladas es que la reina esté compungida por haber cometido una injuria contra Ártemis (vv. 145-147: «†où $\delta$ †

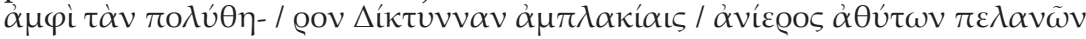

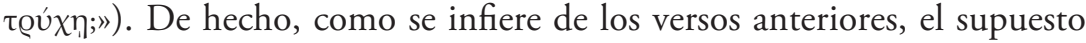
crimen de Fedra se define como àvícoos por haber despojado a la diosa de los sacrificios celebrados en su honor, lo cual se insinúa con el étimo

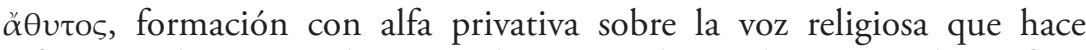
referencia al acto ritual por excelencia en el mundo griego, el sacrificio (Burkert, 2007, p.79).

Pl. R. 460E-461B: junto a las distintas medidas que Platón propone a lo largo de su obra, en este punto del tratado filosófico esboza las normas y prohibiciones consustanciales al ámbito conyugal, preceptos cívicos

12 Cf. Sapph. fr. 31 Voigt.

13 Hp. Morb. Sacr. 4. Cf. Parker, 1996, pp.244-245. 
esenciales para una buena convivencia política. Así se presenta en los parágrafos 460E-461B del diálogo platónico:

" $" P o r$ un lado, las mujeres — afirmé yo— pueden engendrar hijos en beneficio del Estado desde los veinte años incluidos hasta los cuarenta; por otro lado, los hombres, una vez que han alcanzado el momento más activo de su carrera, pueden tener descendencia para la ciudad desde ese momento hasta los cincuenta y cinco años". "Sin duda alguna - aseguró-, este es el máximo momento de desarrollo del cuerpo y del sentido común para ambos". "No obstante, si alguien más viejo o más joven que estos participa en las procreaciones públicas, sin duda, consideraremos el error impío e injusto, ya que se ha concebido para el Estado un niño que, si pasa desapercibido, será engendrado sin los sacrificios y las plegarias que las sacerdotisas, los sacerdotes y toda la ciudad realizan en cada una de las uniones conyugales para que los hijos de hombres buenos siempre sean mejores, y para que los hijos de hombres útiles sean más útiles todavía; al contrario, nacerá en la oscuridad después de una terrible irresponsabilidad”. “¿Ciertamente! —exclamó—”. "Y, en verdad, es la misma la ley si alguno de los que todavía puede tener hijos contrae nupcias con mujeres en la edad establecida sin que el arconte los haya emparejado. En ese caso consideramos que han traído a la ciudad un nińo bastardo, ilegítimo y sacrílego"».

En esta utopía política, el filósofo sugiere que el Estado debe ser el órgano encargado de gestionar y sancionar las uniones matrimoniales con el único propósito de procrear y suministrar nuevos ciudadanos

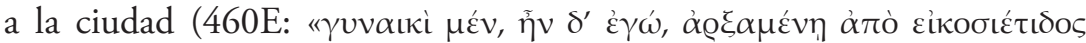

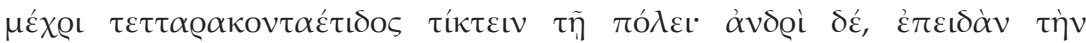

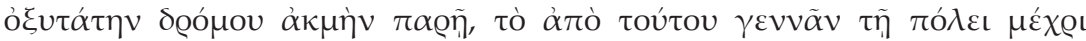
$\pi \varepsilon \nu \tau \varepsilon \kappa \alpha \iota \pi \varepsilon \nu \tau \eta \kappa о \nu \tau \alpha \varepsilon ́ \tau o u \varsigma »)$. Esto garantizaba que los ciudadanos reunieran las mejores virtudes para asegurar el funcionamiento de la polis, labor nada trivial para Platón, pues consideraba que los atributos de los padres podían transferirse genéticamente a los hijos. Así, dos progenitores honrados, piadosos y útiles para la ciudad concebirían un hijo mucho más so-

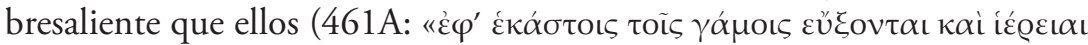

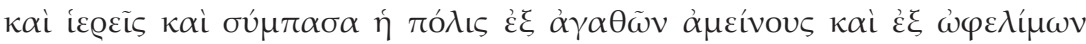

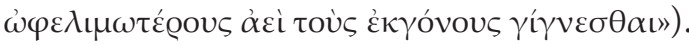

Por el contrario, las uniones clandestinas se consideraban infracciones que atentaban no solo contra las normas cívicas sino también contra la 
esfera divina. ${ }^{14}$ Las perjudiciales secuelas de un matrimonio ilícito son plasmadas a partir de una nómina de términos religiosos, como bien

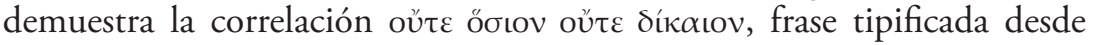
la época clásica (Frazier, 2018, pp.309-310); el sustantivo técnico tò $\alpha \dot{\alpha} \alpha \dot{\varrho} \tau \eta \mu \alpha$, el cual ya comparece en los discursos antifonteos designando yerros que debían ser expiados (Decleva Caizzi, 1969, pp.55-57); o las dos

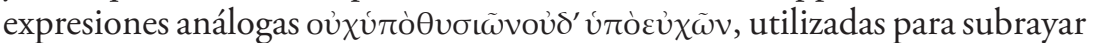
la impiedad cometida por los padres, quienes soslayaron en el pasado las

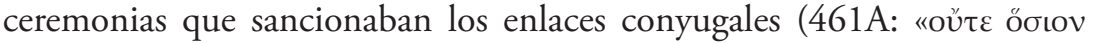

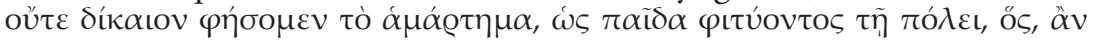

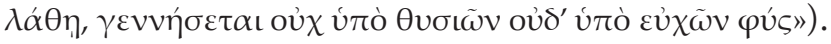

Con todo esto, Platón pretende legitimar las leyes matrimoniales diseñadas para su ciudad ideal, sometiéndolas a un proceso de ritualización, el cual se verifica mediante el léxico (ir)religioso que galvaniza la totalidad de este pasaje. Con estos términos el autor intenta persuadir a sus lectores, justificando que las nupcias eran ilegales cuando eludían las celebraciones rituales estipuladas por la ciudad, una acción peligrosa para la comunidad al perturbar y amenazar los límites religiosos. Por esta razón los niños nacidos del adulterio se consideraban fruto de un acto descontrolado (461B: « $\dot{\alpha} \lambda \lambda^{\prime}$

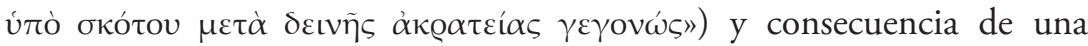

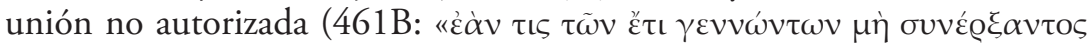

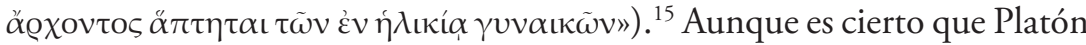
ya ha aducido pruebas suficientes para exponer el carácter sacrílego de los himeneos furtivos, remata este parágrafo utilizando el adjetivo àvícoos, recalcando que los jóvenes bastardos eran concebidos quebrantando toda

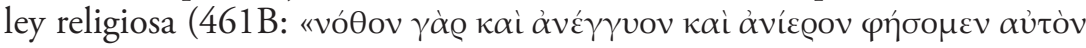

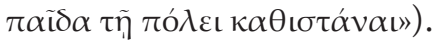

Como colofón, tras analizar y comentar los pasajes literarios donde opera esta palabra, podemos deducir las siguientes conclusiones:

14 Ya desde época clásica, los planos político, jurídico y religioso se encuentran estrechamente imbricados. Esto se comprueba con facilidad, entre otras fuentes literarias,

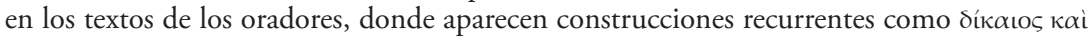
$\varepsilon \dot{v} \sigma \varepsilon \beta \eta ́ s$, con la que se subraya la fuerte ligazón existente entre el respeto de las instituciones políticas, la moral tradicional y la religión.

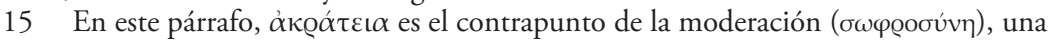

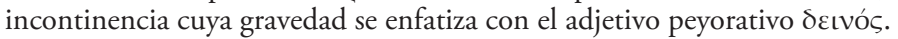


1. El uso de àvíc@os se verifica por vez primera en época clásica. El término, con potente sentido irreligioso, se atestigua de forma puntual en la literatura de este período -cinco apariciones en total-. Tal y como habíamos señalado en la introducción, el vocablo, opuesto al adjetivo iz@ós, describe las actuaciones o propensiones sacrílegas que dañan aquellos elementos connaturales al ámbito divinal. Así, en el género trágico siempre alude a acciones que trastocan los límites de lo divino; mientras que Platón, junto a una amalgama de nociones religiosas y morales, se sirve de él con el objetivo de dar más peso a su argumentación y persuadir a sus conciudadanos para que respeten las normas cívico-políticas de la ciudad.

2. En todos los textos analizados, ג̇vícoos se encuadra en pasajes donde se combinan distintas nociones (ir)religiosas e (in)morales, empleadas para marcar los comportamientos aceptados o condenados por la comunidad, lo cual nos permite precisar el sentido negativo de esta palabra estableciendo una gradación semántica entre los distintos términos recogidos en estos textos.

\section{Bibliografía}

\section{Autores clásicos}

Antifonte. Antiphontis Tetralogiae. Edición de F. Decleva Caizzi, 1969. Milano Varese: Cisalpino.

Esquilo. Aeschylus. Suppliant Women. Edición de A. J. Bowen, 2013. Oxford: Oxford Books.

Esquilo. Aeschylus. Agamemnon. Edición de J. D. Denniston y D. L. Page, 2008. Oxford: Claredon Press.

Eurípides. Euripides. Hippolytos. Edición de W. S. Barret, 1992. Oxford: Oxford Claredon Press.

Platón. Plato. Republic V. Edición de S. Halliwell, 2008. Eastbourne: Aris \& Philips.

\section{Bibliografía contemporánea}

Burkert, W., 2007. Religión griega arcaica y clásica. Madrid: Abada Editores. 
Calderón Dorda, E., 2013. El concepto de religión en Esquilo: reflexión terminológica. Emerita, 81(2), pp.295-313.

Edwards, M. W., 1977. Agamemnon's Decision: Freedom and Folly in Aeschylus. California Studies in Classical Antiquity, 10, pp.17-38.

Frazier, F., 2018. Regards grecs sur l'Athènes du Ve siecle et 'l'irreligion' de Platon à Plutarque. En: V. M. Ramón Palerm, G. Sopeña Genzor y A. C. Vicente Sánchez eds. 2018. Irreligiosidad y Literatura en la Atenas Clásica. Coimbra: Coimbra University Press, pp.305-374.

Parker, R., 1996. Miasma. Pollution and Purification in early Greek Religion. Oxford: Claredon Press.

Petrovic, A. y Petrovic, I., 2016. Inner Purity \& Pollution in Greek Religion. Volume I: Early Greek Religion. Oxford: Oxford University Press.

Rubel, A., 2014. Fear and Loathing in Ancient Athens. Religion and Politics during the Peloponnesian War. Durham: Acumen.

Rudhardt, J., 1992. Notions fondamentales de la pensée religieuse et actes constitutifs du culte dans la Grèce Classique. 2. ${ }^{a}$ ed. Paris: Picard.

Sorel, R., 2015. Dictionnaire du paganisme grec. Notions et débats autor de l'epoque classique. Paris: Les Belles Lettres.

Stephanus, H., 2008. Thesaurus Graecae Linguae (vol. 2). Napoli: La scuola di Pitagora editrice $(=1928)$.

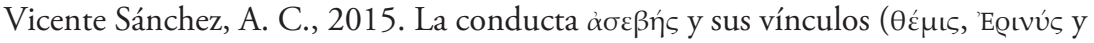
otros) en la obra de Esquilo. $C F C(G), 25$, pp.125-155.

Vicente Sánchez, A. C., 2018. Irreligiosidad y Literatura. Comentarios. Tragedia. En: V. M. Ramón Palerm, G. Sopeña Genzor y A. C. Vicente Sánchez, eds. 2018. Irreligiosidad y literatura en la Atenas Clásica. Coimbra: Coimbra University Press. pp.65-150. 


\title{
À PROPOS D'UNE «HISTOIRE CONNECTÉE» DU CULTE DE SARAPIS EN ÉGYPTE HELLÉNISTIQUE
}

\author{
About a "connected history» of Sarapis cult in \\ Hellenistic Egypt \\ Efstathia Dionysopoulou ${ }^{1}$
}

Résumé: L'objectif de cette contribution est de mettre en lumière la nécessité de mener une enquête interdisciplinaire, tant au niveau heuristique qu'analytique, dans l'étude du culte de Sarapis en Égypte hellénistique, à savoir d'un phénomène religieux qui apparaît au sein d'une société multiculturelle. Une telle démarche peut aboutir à l'élaboration d'un récit historique global et décloisonné, c'est-à-dire, une "histoire connectée», susceptible de faire émerger les logiques qui animent les échanges interculturels et la nature des articulations du phénomène en question avec les contextes micro et macro-historiques.

Mots-clés: Sarapis; Égypte hellénistique; historiographie; interdisciplinarité.

Abstract: The aim of this paper is to highlight the importance of an interdisciplinary research approach applied to the analysis and interpretation of Sarapis cult in Hellenistic Egypt, namely a religious phenomenon which appears within a multicultural society. Such an approach leads to a global

1 Doctorante en Histoire ancienne. Université de Strasbourg (UMR 7044 ArcHiMedE) - Université de Toulouse II (PLH-ERASME). Adresse électronique: edionysopoulou@unistra.fr. 
historical narrative, that is a "connected history", which could unveil the mechanisms behind multicultural interactions and the interlinkage of the studied phenomenon with micro- and macro-levels of History.

Keywords: Sarapis; Ptolemaic Egypt; Historiography; interdisciplinary approach.

\section{LE CUlTE de SARAPIS EN ÉGYPTE HELLÉNiSTIQUE ET L'HISTO- RIOGRAPHIE DU ROYAUME LAGIDE: ÉTAT DE L'ART}

L'institution du culte de Sarapis en Égypte à la fin du IV ou au tout début du $\mathrm{III}^{\mathrm{e}}$ siècle av. n.è. coïncide avec l'établissement du pouvoir des Lagides en terre égyptienne. Les raisons qui ont présidé à cette expérimentation religieuse nous échappent en grande mesure. La question de l'élaboration de ce culte a suscité de longs débats qui ont alimenté des hypothèses assez diverses. Pour plusieurs savants du XIX ${ }^{\mathrm{e}}$ siècle, la création de Sarapis visait à fusionner, sur un plan religieux, les Grecs et les Égyptiens. Johann-Gustav Droysen est l'un des premiers historiens qui a défendu cette idée dans son œuvre Geschichte des Hellenismus. Pour lui, cette expérimentation religieuse s'inscrit dans le sillon de la politique de la fusion des ethnies étrangères (Verschmelzungspolitik) initiée et encouragée par Alexandre III (Payen, 2006, p.171). Cette rencontre fusionnelle ne mettait pas toutefois les deux civilisations sur un pied d'égalité (Préaux, 1997, Vol.I, pp.8-9). L'historien allemand ne manque pas de souligner la supériorité de l'esprit grec qui travaille constamment pour s'imposer sur les cultures indigènes (Droysen, 1877, Vol.III, p.23). Pour Droysen, Sarapis était une divinité à vocation universelle, résultat d'une théocrasie à l'initiative des premiers Lagides, qui a été utilisé comme instrument d'une politique royale visant un double objectif: abaisser les barrières ethniques et culturelles entre les Grecs et les Égyptiens et attirer les derniers vers les intérêts de leurs nouveaux maîtres (Droysen, 1877, Vol.III, pp.46-47).

Au tout début du XX $\mathrm{XX}^{\mathrm{e}}$ siècle, Auguste Bouché-Leclercq a franchi un pas supplémentaire. Il entrevoit dans l'institution du culte de Sarapis la volonté royale de créer une divinité poliade, susceptible de réunir, grâce à son caractère composite gréco-égyptien tous les habitants installés dans la nouvelle capitale lagide (Bouché-Leclercq, 1902, p.8). Ainsi, «à Alexan- 
drie, Hellènes et Égyptiens purent vénérer la même divinité poliade, dont la personnalité s'accommodait de toutes les théologies [...] Le dieu alexandrin, Osiris pour les Égyptiens, fut à volonté Zeus, Pluton, Dionysos, Asklépios pour les Grecs [...]» (Bouché-Leclercq, 1902, p.29). Selon lui, la mise en place d'une société alexandrine multiculturelle nécessite l'affaiblissement de l'antagonisme religieux, par l'intermédiaire d'une figure divine dans laquelle les différents groupes ethniques reconnaissent des caractéristiques et des fonctions de leurs propres dieux (Bouché-Leclercq, 1902, p.7). La thèse de l'unification des Grecs et des Égyptiens par le truchement du culte de Sarapis prédomine, ${ }^{2}$ et ce jusqu’à la fin des années $1950 .{ }^{3}$

En 1960, Peter Marshall Fraser a publié sa fameuse étude «Two studies on the cult of Sarapis in the Hellenistic world». En s'appuyant sur les données fournies par les sources épigraphiques et papyrologiques en langue grecque, il a conclu la première partie de son enquête estimant que le rôle principal du culte de Sarapis institué sous patronage royal aurait été de faciliter le rapprochement de la population hellénophone d'Alexandrie. Pour lui, cette expérimentation religieuse visait un double objectif: donner un dieu tutélaire à la nouvelle capitale du royaume et aider à l'intégration des sujets grecs à l'État égyptien (Fraser, 1960, p.19). Sarapis a dû jouer un rôle similaire à celui d'une divinité poliade. Son culte aurait été destiné à rassembler tous les hellénophones massivement installés sur le sol égyptien, et notamment à Alexandrie. En plus, son origine assurément égyptienne, qui ramène avec insistance vers la figure de l'Osiris-Apis memphite (Fraser, 1960, pp.1-2) aurait pu créer chez les Grecs un sentiment d'appartenance à la culture égyptienne. Cette thèse, qu'on qualifierait d'intégrationniste,

2 La thèse de Youtie (1948, p.28) fait figure d'exception. Elle offre une vision qu'on qualifierait d'antagoniste. Il propose que l'établissement du culte de Sarapis ait servi à helléniser les Égyptiens et arrêter l'égyptianisation des Grecs installés en Égypte.

3 Voir par exemple, Otto, 1905-1908, Vol.I, pp.11-16, Vol.II, pp.264-269; Weinreich, 1919, pp.4-5; Wilcken, 1927, pp.84-85; Milne, 1928, p.227; Brady, 1935, p.16; Bell, 1948; Kiessling, 1949, p.318; Jouguet, 1961, pp.391-394. Bien que l'hypothèse d'un «dieu de l'entente nationale», selon l'expression employée par Quaegebeur (1983, p.303) soit abandonnée aujourd'hui, elle est encore évoquée par certains chercheurs, comme Hölbl (2001, p.99). Dans une optique similaire, Stricker (1956, pp.69-70) propose que l'institution du culte de Sarapis ait eu vocation à réunir en une seule divinité des éléments de Zeus, Osiris et Yahvé, faisant ainsi liaison parmi les trois groupes ethniques installés en terre égyptienne, à savoir les Grecs, les Égyptiens et les Juifs. 
puisqu'elle considère Sarapis comme un moyen de faciliter l'intégration des Grecs dans leur nouvelle patrie, fait actuellement la quasi-unanimité parmi les chercheurs. ${ }^{4}$ Dans une étude où il examine l'histoire et l'architecture des Sarapieia d'Égypte d'un point de vue égyptologique, Dieter Kessler (2000) conclut que le complexe monumental du temple du dieu à Alexandrie était le cadre des fêtes égyptiens de Sokar-Osiris et du Nouvel An. Ces dernières étant étroitement liées au concept du renouvellement du pouvoir pharaonique auraient permis aux Grecs de s'attacher à l'idéologie royale traditionnelle et de participer à la vie religieuse égyptienne (Kessler, 2000, pp.223-224). Cette hypothèse a mis en exergue la dimension royale du dieu et les éventuels motifs politiques derrière l'élaboration de son culte.

À partir des années 2000, les études soulignent de plus en plus la dimension dynastique du phénomène, en mettant l'accent sur les rapports qui unissaient le dieu à la maison royale (Pfeiffer, 2008a; Fassa, 2013, p.122; Legras, 2014). Cette tendance de la recherche historiographique voit dans l'introduction et la promotion de Sarapis au rang de dieu majeur sous les premiers Ptolémées quatre raisons possibles: la popularité grandissante du culte osirien dans la région memphite pendant le $\mathrm{I}^{\text {er }}$ millénaire, son patronage systématique, notamment par les pharaons de la $\mathrm{XXX}^{\mathrm{e}}$ dynastie, dont les souverains ptolémaïques se présentent comme les héritiers directs (Devauchelle, 2010; 2012; Fassa, 2013; Caneva, 2018, pp.97, 100), la volonté des Lagides d'assurer la loyauté des fonctionnaires et des mercenaires ralliés à l'État ptolémaïque (Pfeiffer, 2008a, pp.407-408) et leur souhait d'entretenir des rapports étroits avec le clergé memphite (Bergmann, 2010, p.120).

Toutes ces courants historiographiques du culte de Sarapis sont tributaires de l'actualité scientifique, et parfois même idéologique, qui condi-

4 Par exemple, Fraser, 1967; 1972, Vol.I, pp.251-252; Stambaugh, 1972, p.94; Koenen, 1993, p.44; Huß, 1994, p.65; Borgeaud et Volokhine, 2000, p.76; Quack et Paarmann, 2013, p.255; Worthington, 2016, p.198. Devauchelle (2012) propose une hypothèse légèrement différente, suivie par Caneva (2018, p.101), selon laquelle «la création de Sarapis s'explique par la volonté des souverains de nommer un dieu qui rassemble les Grecs d'Égypte, les nouveaux arrivants comme ceux qui étaient déjà installés, depuis parfois fort longtemps» (p.225). 
tionne l'évolution de l'historiographie du royaume lagide, depuis le XIX ${ }^{e}$ siècle jusqu'à nos jours.

Le concept droysenien d'une parfaite fusion d'ordre politique, culturel/religieuse et religieux entre les Grecs et les Orientaux dans les monarchies issues du partage de l'empire d'Alexandre a été critiqué plusieurs fois par la recherche moderne (Kreissig, 1982, pp.11-15; Préaux, 1997, Vol.I, pp.5-9; Vol.II, pp.545-586; Payen, 2006, p.171; 2008, pp.5-82). Premièrement, parce qu'un tel concept manque en effet de pertinence, car il est trop "généraliste». Il ne prend pas en compte les multiples formes régionales d'interaction et d'intégration. Deuxièmement, car cette vision unificatrice du monde hellénistique a été fortement influencée par les choix idéologiques de l'historien allemand. La situation politique de son époque a eu une répercussion directe sur sa conception du monde hellénistique et reflète son engagement dans le projet de l'unification et de la constitution d'un État national allemande, autour de la Prusse (Payen, 2001, pp.115-134). De plus, Droysen, qui se forme et travaille dans un milieu académique accordant trop d'importance à l'analyse minutieuse des sources philologiques, a étayé son idée de la Verschmelzungspolitik sur les écrits des auteurs anciens, notamment de Plutarque. ${ }^{5}$ Ces ouvres, bien qu'elles se prétendent être fondées sur des sources qui remontent à l'époque hellénistique, apportent des témoignages indirects et ne peuvent en aucune manière faire totalement écho de l'idéologie et des aspirations politiques d'Alexandre et des Diadoques (Colin, 2003, p.271). Quant à l'idée que l'institution du culte de Sarapis pourrait être une mesure politique destinée à fusionner Grecs et Égyptiens, il est à noter qu'elle est loin de correspondre à la «réalité du terrain». Rien ne permet de supposer que Ptolémée $\mathrm{I}^{\text {er }}$ ou un de ses successeurs cherchait à unir par fusion, au sens droysénien du terme, les Grecs et les Égyptiens sur le plan religieux. Une telle hypothèse implique, de prime abord, l'idée que la maison royale témoigne d'un certain dédain pour la religion égyptienne. Par contre, il est bien connu que les Ptolémées, tout comme les rois argéades, étaient soucieux, à des fins avant tout politiques, de manifester du respect à l'égard de

5 C'est le biographe de Chéronée qui présente, pour la première fois, l'image d'un Alexandre civilisateur visant à fusionner les Grecs et les populations orientales barbares. Voir Plut. Mor. De Alex. fort. 328 B-329 F. 
la tradition religieuse égyptienne. Une telle attitude avait une importance particulière, dans la mesure où elle assurait la collaboration étroite avec les clergés. Cela était indispensable pour que les Ptolémées s'inscrivent dans la lignée des pharaons égyptiens et légitiment leur pouvoir. Vastes programmes architecturaux de restauration et/ou de développement des sanctuaires de la chôra (Thiers, 2010; Ladynin, 2014; Caneva, 2018, pp.8996; Minas-Nerpel, 2018), restitution des objets sacrés, ${ }^{6}$ soutien financier pour l'enterrement des animaux sacrés, ${ }^{7}$ privilèges et autonomie de gestion pour les clergés (Nespoulous-Phalippou, 2015, Vol.II, p.193-194) sont des marques de l'attention particulière des premiers Lagides face au système religieux égyptien (Huß, 1994; Colin 1994b; Gorre, 2003; 2009). En contrepartie, les prêtres reconnaissaient la légitimité de leur pouvoir politique, en l'intégrant dans une tradition religieuse et politique plurimillénaire. En outre, l'interdiction des mariages mixtes, entre Grecs et Égyptiens, à Alexandrie (Legras, 2010, pp.174-180) rend la thèse «unificatrice» encore moins plausible. ${ }^{8}$

L'édition progressive de nouvelles sources, tant épigraphiques que papyrologiques en grec et en démotique, qui a été entreprise dès la fin du $\mathrm{XIX}^{\mathrm{e}}$ siècle, a eu pour effet de réviser les conceptions de Droysen. Nouvelles visions du monde hellénistique ont été apparues. L'idée de la fusion de races a été atténuée au profit du concept de l'«étanchéité culturelle» (Préaux, 1997, Vol.II, pp.545-586), qui a été nuancé, quelques années plus tard, par celui de l' "étanchéité ethnique» (Goudriaan, 1988, p.95; Colin, 1994a, pp.256, 261). En distinguant complétement les concepts de culture et d'identité ethnique, ce dernier permet d'éclairer le jeu des interactions culturelles parmi les différents groupes ethniques installés en terre égyptienne sous les Lagides. Il ne faut pas imaginer l'Égypte hellénistique comme une société sclérosée où les deux systèmes culturels en présence

6 Par exemple, la stèle du «Satrape» (Le Caire, musée égyptien CGC 22182), qui date du règne du satrape Ptolémée Ier mentionne la restitution aux sanctuaires égyptiens des effigies divines qui ont été emportées par les Perses en Asie. Voir Schäfer (2011, pp.7483).

7 Par exemple, à propos des soins rendus par la dynastie lagide à Apis mort, voir Crawford (1980, pp.8-12).

8 Par contre, dans la chôra égyptienne un certain nombre de mariages mixtes est attesté depuis le III ${ }^{e}$ s. av. n.è. Voir Legras (2004, pp.174-175). 
sont opaques, selon la conception de Claire Préaux. Bien que souvent il y ait une simple coexistence ou juxtaposition, on observe d'autre part des amorces d'interactions. L'«étanchéité ethnique» ne signifie pas que les composants ethniques de la société lagide doivent être perçus comme des entités culturelles imperméables. Rien n'empêchait leur imbrication culturelle, ce qui était néanmoins loin d'amener à une vraie fusion (Heinen, 1989, pp.110-111). C'est dans la religion qu'on peut voir le domaine par excellence des interactions les plus intenses entre les Grecs et les Égyptiens. Celles-ci ne dépendaient pas toujours de l'identité ethnique. Les Grecs pratiquaient des cultes égyptiens ${ }^{9}$ et les Égyptiens embrassaient des cultes grecs, ${ }^{10}$ tout en restant à la fois fidèles à leurs propres divinités. ${ }^{11}$

Malgré la publication systématique de la documentation démotique dès la fin du XIX ${ }^{e}$ siècle par des savants comme Wilhelm Spiegelberg et Eugène Revillout, la floraison des publications, toujours plus nombreuses, de la documentation papyrologique et épigraphique grecque et l'émergence du concept de l' «étanchéité culturelle» a poussé les historiens, au moins jusqu'à la fin des années 1960, de mener des enquêtes sur l'histoire du royaume lagide du seul point de vue des sources grecques, ce qui n'a pu qu'offrir une connaissance partielle et fragmentaire de la réalité d'Égypte hellénistique. Vers la fin des années 1970, en parallèle avec la multiplication des publications des textes démotiques, l'équipe de Pieter Willem Pestman à Leyde et celle d'Erich Lüddeckens en Allemagne ont créé les premières compilations et instruments de recherche susceptibles de faciliter l'étude des documents démotiques, mais surtout de promouvoir la collaboration entre les papyrologues hellénisants et démotisants. ${ }^{12}$ Un tel afflux a eu contribué à une compréhension renouvelée de l'évolution de la civilisation égyptienne sous les Lagides, en nous apportant de plus en

9 À titre d'exemple, on peut mentionner l'acte d'auto-consécration à Anubis d'un certain Néoptolemos, d'origine macédonienne, clérouque à Philadelphie du Fayoum, qui date en 270 av. n.è. Voir Dunand (1999, p.103).

10 Par exemple, un papyrus démotique provenant du Fayoum et daté du $\mathrm{II}^{e}$ siècle av. n.è., atteste la présence d'un Égyptien nommé Peteèsis qui fonctionnait comme prêtre de Déméter. Voir Quaegebeur (1983, p.306).

11 À ce propos, voir également Dunand (1999).

12 Par exemple, voir le Demotisches Namenbuch dont le premier volume a été paru en 1980 . 
plus des connaissances originales. Dans les années 1980, des voix se sont élevées pour signaler la nécessité d'une démarche de recherche mixte (Mischforschung), qui cherche à faire dialoguer les sources textuelles grecques et égyptiennes (Quaegebeur, 1983; Heinen, 1989, p.132). Sa mise en œuvre n'a pas été une tâche aisée. Vingt ans plus tard, Frédéric Colin (2003, p.272), dans un article concernant les interactions linguistiques et culturelles en Égypte hellénistique revient sur la question de la Mischforschung pour souligner avec fermeté la nécessité de développer une collaboration scientifique encore plus étroite entre hellénistes et égyptologues.

Une des premières conséquences de la pratique de la Mischforschung était la mise en discussion de l'idée que l'Égypte lagide était une société de type colonial (Will, 1985, pp.273-301), où le groupe dominant des colons grecs impose son autorité sur la masse dominée des Égyptiens. Cette théorie a été délaissée progressivement, à partir des années 1990 (Bagnall, 1997, pp.225-241), au profit de l'idée d'une société multiculturelle. Aux années 2000, plusieurs études ont montré qu'il n'est pas toujours facile de séparer clairement deux groupes ethniques et culturels bien délimités. Déjà dès le début de l'époque hellénistique, on constate l'interférence sociale, politique et culturelle, notamment entre les membres de l'élite grecque et égyptienne (Clarysse, 1985; Collombert, 2000; Derchain, 2000; Coulon, 2001). À ce sujet, Willy Clarysse (1995, p.19) écrit:

«dans la région de la Thébaïde des immigrants grecs ont été alliés, pour des raisons professionnelles ou par mariage à la classe cultivée égyptienne [...] Depuis le III ${ }^{e}$ siècle av. n.è., les scribes égyptiens se mirent à apprendre le grec et mariaient leurs filles et leurs fils à des immigrants, de sort qu’à la fin de la période ptolémaïque, la classe supérieure parlant grec, du point de vue ethnique, était entièrement confondue avec les familles indigènes. Du point de vue culturel, ils pouvaient être actifs de deux façons selon les circonstances: comme Grecs dans l'administration, l'armée et au gymnase, comme Égyptiens dans le temple et dans la vie privée». ${ }^{13}$

Les différentes facettes de l'identité de ces personnes, qui étaient le plus souvent agents du pouvoir lagide, comme le célèbre diocète Dios-

13 Traduction de Derchain (2000, p.15). 
couridès (Collombert, 2000), et qui apparaissent sous des traits helléniques dans les sources grecques et sous des traits égyptiens dans les sources égyptiennes, soulignent, encore une fois, le besoin impératif de croiser les sources disponibles (Veïsse, 2012, p.21). Ce n'étaient pas seulement les élites qui construisaient des identités à des appartenances multiples. Il en va de même pour les souverains du pays du Nil. Les travaux de Ludwig Koenen (1993) et de Stefan Pfeiffer (2008b) ont fait ressortir la dualité de l'identité politique de la dynastie lagide. Le «double» visage de leur royauté leur permettait d'agir tantôt comme rois hellénistiques, tantôt comme pharaons, selon les besoins et les contextes. Le concept donc d'identités composées d'appartenances différentes pourrait nous amener à adopter une position plus nuancée face à la thèse intégrationniste, évoquée ci-dessus, selon laquelle, l'institution du culte de Sarapis visait, d'une part, à satisfaire les besoins religieux des Grecs d'Alexandrie et, d'autre part, à créer un lien fédérateur entre eux. Cette hypothèse, fondée sur les conclusions des enquêtes de Fraser (1960, p.9; 1972, Vol.I, p.251), qui sont essentiellement appuyées sur la documentation grecque de l'époque hellénistique, a mis en évidence que le culte touchait principalement les hautes couches de la société lagide et les membres de la Cour royale. Comment peut-on être sûr que tous les dédicants sont d'origine grecque, notamment quand le prénom et/ou le patronyme ne sont pas complétés par l'ethnique ? À la lumière de toutes ces considérations de l'historiographie actuelle, à quel point est-il pertinent d'étayer une hypothèse destinée à expliquer l'apparition du culte de Sarapis en s'appuyant exclusivement sur l'identité ethnique de ses dévots?

On constate donc que l'historiographie du culte de Sarapis n'a pas échappé à la tendance générale de l'historiographie de l'Égypte hellénistique qu'on a esquissée ci-dessus. Les études de Fraser parues aux années 1960-1970, malgré leur rôle fondamental dans la question des débuts du culte du dieu, étaient menées uniquement du seul point de vue des sources grecques. Cela ne peut qu'amener à une connaissance fragmentaire et hachée de ce qui était Sarapis en Égypte hellénistique. Il en va de même pour tous les travaux relatifs à cette question, et c'est jusqu'à la fin des années 1990. Au début des années 2000, Laurent Bricault (2000, pp.193-194) signale la nécessité de mener une recherche mixte sur le culte du dieu, en conjuguant avec un soin égal les sources grecques et démotiques, afin d'approfondir les pistes tracées par les travaux de Fraser. La contribution 
de Philippe Borgeaud et Youri Volokhine, parue en 2000 (Borgeaud et Volokhine, 2000, p.38) est une première tentative de rapprocher les récits postérieurs des auteurs anciens, analysés à maintes reprises par les savants du XIX ${ }^{e}$ siècle, avec des données égyptiennes et grecques. L'analyse décloisonnée qu'ils proposent a mis en exergue les avantages d'une Mischforschung pour l'étude du culte du dieu en Égypte hellénistique. L'approche transculturelle de leur travail a fait ressortir l'ancrage des récits de Tacite et Plutarque dans la tradition littéraire gréco-romaine et égyptienne, et elle a cerné les différentes traditions qui ont pu contribuer à la fabrique du dieu en terre égyptienne sous les premiers Lagides. Dans une optique similaire, les analyses de Stefan Pfeiffer (2008a), Eleni Fassa (2013), Joachim Quack et Björn Paarmann (2013) ont essayé de mobiliser un grand nombre de sources littéraires et documentaires en langues grecque et égyptienne, dans le but de décloisonner l'étude du culte du dieu et sortir de l'impasse du clivage Grec/non-Grec. En parallèle, ces dernières années ont été parus des travaux qui ont tenté d'étudier Sarapis d'un œil surtout égyptien. On songe notamment aux études de Didier Devauchelle (2010; 2012), Nicolas Cacace (2017) et Mark Smith (2017, pp.390-414), qui mobilisent surtout des sources textuelles bilingues et égyptiennes. Ce choix méthodologique s'explique par l'objectif principal de ces travaux, qui consiste à déchiffrer et analyser les relations que Sarapis entretenait avec les différentes hypostases osiriennes.

Outre le problème de la langue des sources mobilisées, l'historiographie du culte de Sarapis en Égypte hellénistique pose aussi la question du type des sources mises en œuvre. Un bon nombre d'études sont fondées principalement sur un seul type de sources, à savoir littéraire (p.ex. Belayche, 2011; Paarmann, 2011), épigraphique-papyrologique (p.ex. Fassa, 2013), iconographique (p.ex. Hornbostel, 1973; Castiglione, 1958; 1978) ou architecturale (p.ex., McKenzie, et al., 2004; Sabottka, 2008). Dans le cadre de ces travaux, qui se concentrent plutôt sur l'analyse d'un aspect particulier du culte du dieu, les autres types de sources occupent une place secondaire. Une telle approche heuristique unilatérale ne permet pas toutefois d'appréhender le caractère multidimensionnel et complexe de ce phénomène religieux. Jan Quaegebeur (1983), lors d'un colloque international tenu à Louvain, a démontré, à l'aide de cas concrets, comment une démarche interdisciplinaire, visant à l'exploitation conjointe de toutes les sources disponibles, qu'elles relèvent de la sphère culturelle égyptienne 
ou grecque, de l'archéologie, de l'épigraphie ou de la papyrologie peut éclairer, d'un jour nouveau, diverses questions concernant la coexistence, la transformation et l'interpénétration des cultes égyptiens et grecs en terre nilotique sous les Ptolémée. Les avantages de cette méthode interdisciplinaire ont été mis en évidence également dans le cadre du travail de Ludwig Koenen (1993) portant sur la dimension religieuse du roi ptolémaïque. Croisant et comparant la diversité des sources relatives à son sujet, il a réussi à analyser dans un sens dual, grec et égyptien, la question de l'interaction royauté-divinité en Égypte hellénistique.

\section{VERS UNE «HISTOIRE CONNECTÉE» DU CULTE DE SARAPIS EN ÉGYPTE HELLÉNISTIQUE}

Privilégier donc une même approche interdisciplinaire dans l'étude du culte de Sarapis en Égypte hellénistique peut jouer un rôle essentiel dans l'appréhension globale du phénomène de l'élaboration du culte du dieu. L'analyse croisée de l'ensemble, suffisamment ample et varié de toutes les sources disponibles d'origine et de types différents peut autoriser des conclusions solides sur l'élaboration et l'évolution de la personnalité du dieu en Égypte hellénistique, tout en offrant à la fois de nouvelles perspectives sur la question des dynamiques interculturelles en Égypte lagide.

La conquête de la vallée du Nil par les troupes gréco-macédoniennes a entrâné l'émergence d'un terreau particulièrement riche en interactions, où identités ethniques et sociales, individuelles ou collectives, ainsi que traits culturels d'origines diverses se mélangent, en même temps qu'ils coexistent. C'est cette complexité qui nous invite à préconiser une approche heuristique interdisciplinaire qui a une double vocation: tout d'abord, réunir et faire dialoguer toutes les sources disponibles en grec et/ou en égyptien concernant le thème analysé. Pour que cette démarche soit efficace, il est absolument nécessaire de procéder pour chaque document à une "critique historique adaptée» (Colin, 2003, pp.687-690). Cela veut dire que leur interprétation exige de prendre en compte les logiques propres du contexte (multi)culturel dont ils proviennent. Ensuite, cette démarche heuristique doit se compléter par la mise en œuvre de sources de toute nature —inscriptions, papyri, textes littéraires, monnaies, vestiges archi- 
tecturaux et représentations figurées - dans le but d'aboutir à une étude globale et totalement décloisonnée, qui se propose d'offrir une «biographie divine» du dieu en terre nilotique sous les Lagides. Le foisonnant matériel qui nous est fourni par cette démarche permet d'aborder la question de la genèse du dieu, du rôle, et de sa place dans l'univers religieux d'Égypte hellénistique, ainsi que de la diffusion et de la réception de son culte au sein de la société lagide.

L'intérêt d'une telle analyse, totalement décloisonnée, est multiple. La pluralité des sources disponibles permet d'aborder de manière plus précise et dynamique la question des origines, des modalités et des motifs d'une telle expérimentation religieuse, en saisissant les acteurs, les contextes et toutes les différentes étapes de la fabrique du dieu. Elle donne aussi la possibilité d'éclairer l'accent, à la fois égyptien et grec décelé dans son élaboration, les aspects et les limites de sa puissance divine ainsi que les types et les raisons des relations que le dieu a nouées avec d'autres divinités du panthéon grec et égyptien, filtrées ou non à travers le prisme de l'interpretatio. De ce fait, on peut mieux saisir le dialogue que le dieu instaure avec les paysages religieux locaux et les deux systèmes théologiques majeurs en Égypte hellénistique. Une telle analyse, qui croise, compare et met en parallèle toutes les sources disponibles, de toute nature et origine sert aussi à évaluer l'emprise du culte sur la population du royaume lagide, et le degré de sa pénétration dans la piète personnelle des dévots. Il est ainsi possible de cerner le rôle que le dieu joue pour les différentes strates de la société lagide et observer comment ce rôle évolue avec le contexte géographique. De cette manière, elle permet de retracer l'ensemble du processus qui a élaboré et fait évoluer le culte du dieu dans la vallée du Nil, élucider tous les différents aspects qualitatifs de sa personnalité, et faire ressortir sa fonction religieuse, culturelle et symbolique, tout en l'articulant avec les contextes social, politique et historique. Une démarche interdisciplinaire permet également de rétablir le phénomène de l'élaboration et de la diffusion du culte du dieu dans les nouveaux paysages politique et religieux qui émergent en Égypte avec l'installation du pouvoir gréco-macédonien. Par la notion du paysage, qu'on le mobilise dans sa dimension à la fois matérielle et symbolique et on le reconnaît à trois niveaux, — «national», régional et local-- on entend l'ensemble de structures, normes et pratiques qui incarnent d'un côté, le potentiel, les aspirations et les revendications de l'autorité poli- 
tique, et de l'autre, les croyances religieuses. L'appréhension du paysage qui conditionne, en même temps qu'il reçoit, le culte de Sarapis est fondamentale pour aboutir à une analyse contextualisée du phénomène en question. ${ }^{14}$

Une fois que les paysages politique et religieux sont restitués, ils doivent être analysés afin d'apporter de l'eau au moulin de l'historien. Pour ce faire, le chercheur peut mobiliser des grilles de lecture empruntées aux sciences sociales. Il est bien connu qu'en Sciences de l'Antiquité, les chercheurs recourent souvent aux modèles développés par les domaines de la ciologie et de l'anthropologie pour analyser et interpréter leurs données. ${ }^{15}$ Dans le cas qui nous intéresse ici, une telle démarche interdisciplinaire, qu'on le qualifierait cette fois-ci d'analytique, puisqu'elle peut offrir des clés d'analyse et d'interprétation du phénomène en question, se révèle très fructueuse. La notion du paysage, telle qu'elle est définie ci-dessus, fait appel au concept du «mnémotope» proposé par le sociologue Maurice Halbwachs dans son ouvrage sur la «topographie légendaire, de la Terre sainte (Halbwachs, 1941). En étudiant la région de la Palestine comme un paysage religieux commémoratif, le sociologue français de l'école durkheimienne a essayé de faire ressortir le poids de la reconstructivité de la mémoire collective au travers du paysage, tant du point de vue matériel que symbolique. Il a montré comment les différents groupes religieux ont localisé et monumentalisé leurs souvenirs par la resémantisation des croyances religieuses et des vestiges matériels du

14 Tant du point de vue anthropologique qu'historique, la contextualisation du fait religieux est une démarche méthodologique essentielle. Quelle que soit la forme qu'il revêt, le fait religieux ne doit jamais être traité de manière autonome, comme un phénomène sui generis. Son intelligibilité est tributaire du social, du psychique et de l'historique et sa variabilité, du contexte culturel dans lequel il s'inscrit. Cette contextualisation doit s'effectuer à trois niveaux: la contextualisation du fait religieux doit être, tout d'abord, historique, puisque le cadre social et culturel de chaque système religieux est affecté par les mutations historiques (Bastide, 1997). Le deuxième type de contextualisation peut être qualifié d' «empirique», puisque elle vise à analyser les pratiques religieuses du point de vue de leur codification culturelle et de leur inscription dans les usages sociaux tandis que le troisième, dite «systémique» cherche à déchiffrer le rapport du fait religieux avec les autres systèmes de la vie sociale et culturelle, tels que la politique, l'économie, l'art, etc.

15 À ce sujet, voir Bengtson, 1959, pp.45-61; Braudel, 1969, pp.97-121; Veyne, 1971, pp.339-343; Colin, 1994a. 
passé, de sorte qu'ils soient adaptés aux besoins du présent. Le paysage devient ainsi un médium pour la construction de la mémoire culturelle. La restitution donc des paysages religieux et politique qui conditionnent l'élaboration et la diffusion du culte du dieu en terre égyptienne sous les Lagides fournit, grâce à l'interdisciplinarité heuristique, de données riches et variées. Celles-ci, interprétées, dans une démarche d'interdisciplinarité analytique, et à la lumière du concept du «mnémotope», pourraient apporter des éclairages appréciables sur le dialogue que le dieu instaure avec les traditions grecques et égyptiennes antérieures, et sur la place de son culte dans la construction de la mémoire culturelle du royaume lagide.

Le résultat obtenu par la combinaison d'une approche interdisciplinaire heuristique et analytique est d'aboutir à une histoire "connectée» du culte du dieu en Égypte hellénistique. Ce concept, emprunté à l'œuvre de l'historien de la première modernité (XVe-XIX ${ }^{\mathrm{e}}$ siècles) Sanjay Subrahmanyam (1997; 2005) désigne le récit historique globale qui dérive de l'analyse stéréoscopique des relations des cultures différentes par l'étude croisée de sources d'origines et de types divers. En travaillant sur la base de documents de grande variété, tant typologique que linguistique, l'historien cherche à saisir les logiques qui animent les interactions et les transferts culturels entre les différentes entités ethniques, ainsi que leur impact sur l'émergence des dynamiques interculturelles et l'élaboration de nouvelles identités, destinées à légitimer actions et revendications. L'histoire "connectée» est considérée comme une modalité spécifique de l'histoire globale (Douki et Minard, 2007, p.8), qui s'intéresse à l'analyse des espaces et des trajectoires biographiques des figures de l'«entre-deux». L'historien qui pratique cette approche «joue en quelque sorte le rôle de l'électricien rétablissant les connexions continentales et intercontinentales que les historiographies nationales ont escamotées en imperméabilisant leurs frontières» (Douki et Minard, 2007, p.19). Une histoire donc symétrique, du point de vue des sources mobilisées, et de va-et-vient entre les mondes grec et égyptien permet de retracer l'histoire et dresser la «biographie» d'un dieu qui oscille entre les deux cultures, tout en sortant de l'impasse des clivages ethniques et brisant les compartimentages disciplinaires. L' analyse totalement décloisonnée de la fabrique et de la diffusion de son identité divine permet également d'apporter d'éclairages appréciables sur une série de questions posées par la recherche actuelle, concernant la 
réappropriation et la resémantisation des traditions religieuses plus anciennes, les interactions et l'interpénétration des cultures grecque et égyptienne, ainsi que l'élaboration des identités et des imaginaires sociaux, au sein du pays nilotique en transition, entre la fin de la Basse Époque et la période ptolémaïque.

\section{ConClusion}

Une histoire «connectée» du culte de Sarapis en Égypte hellénistique a pour objectif de scruter l'élaboration, l'implantation et la diffusion du culte du dieu sur le sol égyptien. À travers une approche interdisciplinaire, qui vise à mobiliser et faire dialoguer l'ensemble des sources disponibles de toute nature et origine, l'analyse globale qui en dérive, souhaite examiner sa genèse, sa place dans la société et l'univers religieux de l'Égypte hellénistique, ainsi que tous les différents éléments qui composent l'identité du dieu en terre égyptienne. Le contexte multiculturel dans lequel $s^{\prime}$ inscrit cette expérimentation religieuse nous invite également à mettre en valeur la manière avec laquelle les paysages religieux locaux et certains concepts issus du monde hellénique et égyptien ont pu influer sur la fabrique du dieu. Une telle étude désire offrir une «biographie divine» qui vise un triple objectif: retracer le processus de l'élaboration et de la diffusion de ce culte sur les rives du Nil, élucider les différents aspects qualitatifs de sa personnalité et faire ressortir sa fonction religieuse, culturelle et symbolique, tout en l'articulant avec les contextes social, politique et historique de son époque.

\section{BibliographIE}

\section{Auteurs classiques}

Plutarque. Euvres morales. La fortune d'Alexandre. Édition de F. Frazier et C. Froidefond, 1990. Paris: Les Belles Lettres. 


\section{Bibliographie contemporaine}

Bagnall, R.S., 1997. Decolonizing Ptolemaic Egypt. Dans: Cartlendge, P., Garnsey, P. et Gruen, E. eds. Hellenistic Constructs. Essays in Culture, History and Historiography. Berkeley: Univ. of California Press. pp.225-241.

Bastide, R., 1997. Éléments de sociologie religieuse. $2^{\mathrm{e}}$ éd. Paris: Stock.

Belayche, N., 2011. Le possible «corps» des dieux: retour sur Sarapis. Dans: Prescendi, F. et Volokhine, Y. eds. Dans le laboratoire de l'historien des religions: mélanges offerts à Philippe Borgeaud. Genève: Labor et fides. pp.227-250.

Bell, H.I., 1948. Egypt from Alexander the Great to Arab conquest: a study in the diffusion and decay of Hellenism. Oxford: Clarendon Press.

Bengtson, H., 1959. Einführung in die alte Geschichte. München: C. H. Beck'sche Verlagsbuch. Bergmann, M., 2010. Sarapis im 3. Jahrhundert v. Chr. Dans: Weber, G. ed. Alexandreia und das ptolemäische Ägypten. Berlin: Antike. pp.109-135.

Borgeaud, P., Volokhine, Y., 2000. La formation de la légende de Sarapis: une approche transculturelle. $A f R$ 2, pp.37-76.

Bouché-Leclercq, A., 1902. La politique religieuse de Ptolemée Soter et le culte de Serapis. RHR 46, pp.1-30.

Brady, T.A., 1935. The reception of the Egyptian cults by the Greeks (330-30 B.C.). Columbia: Univ. of Missouri.

Braudel, F., 1969. Écrits sur l'histoire. Paris: Flammarion.

Bricault, L., 2000. Études isiaques: perspectives. Dans: Bricault, L. ed., De Memphis à Rome. Actes du I'r Colloque international sur les études isiaques, Poitiers - Futuroscope, 8-10 avril 1999. Leiden: Brill. pp.189-210.

Cacace, N., 2017. King Osiris and Lord Sarapis. ARG 18/19, pp.285-306.

Caneva, S., 2018. Ptolemy I: Politics, Religion and the Transition to Hellenistic Egypt. Dans: Howe, T. ed., Ptolemy I Soter. A self-made man. Oxford: Oxbow Books. pp.88-127.

Castiglione, L., 1958. La statue de culte hellénistique du Sarapieion d'Alexandrie. BMusHongr 12, pp.17-39.

Castiglione, L., 1978. Nouvelles données archéologiques concernant la genèse du culte de Sarapis. Dans: Boer, M.B. et Edridge, T.A. eds. Hommages à Maarten J. Vermaseren: recueil d'études offert par les auteurs de la série "Etudes préliminaires aux religions orientales dans l'Empire romain" à Maarten J. Vermaseren à l'occasion de son soixantième anniversaire le 7 avril 1978, Vol.I. Leiden: Brill. pp.208-232.

Clarysse, W., 1985. Greeks and Egyptians in the Ptolemaic army and administration. Aegyptus 65, pp.57-66.

Clarysse, W., 1995. Greeks in Ptolemaic Thebes. Dans: Vleeming, S.P. ed. Hundred-gated Thebes. Acts of a colloquium on Thebes and the Theban area in the 
Graeco-Roman Period (P. L. Bat. 27). Leiden: Brill. pp.1-19.

Colin, F., 1994a. Identités ethniques et interactions culturelles dans l'Antiquité. Réflexions autour de l'ouvrage «Ethnicity in Hellenistic Egypt». AC 63, pp.253-262.

Colin, F., 1994b. Compte-rendu de Huß, W., 1994. Der makedonische König und die ägyptischen Priester. Studien zur Geschichte des ptolemaischen Ägypten. Stuttgart: Franz Steiner. CdÉ 69, pp.374-378.

Colin, F., 2003. La documentation plurilingue de l'Égypte hellénistique: un laboratoire des interactions linguistiques culturelles. Dans: Le Dinahet, M.T. ed. L'Orient méditerranéen de la mort d'Alexandre au Irer siècle avant notre ère. Nantes: Éditions du Temps. pp.672-695.

Collombert, P., 2000. Religion égyptienne et culture grecque: l'exemple de Dioskouridès. $C d E ́$ 75, pp.47-63.

Coulon, L., 2001. Quand Amon parle à Platon. RdÉ 52, pp.85-125.

Crawford, D.J., 1980. Ptolemy, Ptah and Apis in Hellenistic Memphis. Dans: Crawford, D.J., et al. eds. Studies on Ptolemaic Memphis. Leuven: Peeters. pp.1-42.

Derchain, P., 2000. Les impondérables de l'hellénisation: littérature d'hiérogrammates. Turnhout: Brepols.

Devauchelle, D., 2010. Osiris, Apis, Sarapis et les autres. Remarques sur les Osiris memphites au Ier millénaire av. J.-C. Dans: Coulon, L. ed. Le culte d'Osiris au Ier millénaire av. J.-C. Découvertes et travaux récents. Actes de la table ronde internationale tenue à Lyon Maison de l'Orient et de la Méditerranée (Université Lumière-Lyon 2) les 8 et 9 juillet 2005. Le Caire: IFAO. pp.49-62.

Devauchelle, D., 2012. Pas d'Apis pour Sarapis! Dans: Gasse, A., Servajean, F. et Thiers, C. eds. Et in Ægypto et ad Ægyptum. Recueil d'études dédiées à JeanClaude Grenier. Montpellier: Université Paul Valéry. pp.213-225.

Douki, C., Minard, P., 2007. Histoire globale, histoires connectées: un changement d'échelle historiographique ?. Revue d'histoire moderne et contemporaine 54, pp.7-21.

Droysen, J.G., 1877-1878. Geschichte des Hellenismus, Vol.I-II. Gotha: F. A. Perthes.

Dunand, F., 1999. Syncrétisme ou coexistence: images du religieux dans l'Égypte tardive. Dans: Bonnet, C., Motte, A. eds. Les syncrétismes religieux dans le monde méditerranéen antique. Actes du Colloque International en l'honneur de Franz Cumont à l'occasion du cinquantième anniversaire de sa mort. Rome, Academia Belgica, 25-27 septembre 1997. Bruxelles-Brussel-Rome: Brepols Publishers, pp.97-116.

Fassa, E., 2013. Shifting Conceptions of the Divine: Sarapis as part of Ptolemaic Egypt's Social Imaginaries. Dans: Stavrianopoulou, E. ed. Shifting Social Imaginaries in the Hellenistic Period: Narrations, practices and Images. Leiden: Brill. pp.115-139. 
Fraser, P.M., 1960. Two studies on the cult of Sarapis in the Hellenistic world. OpuscAthen 3, pp.1-54.

Fraser, P.M., 1967. Current problems concerning the early history of the cult of Sarapis. OpuscAthen 7, pp.23-45.

Fraser, P.M., 1972. Ptolemaic Alexandria. Vol.I-III. Oxford: Clarendon press.

Gorre, G., 2003. Les relations du clergé égyptien et des Lagides d'après la documentation privée. Cahiers du Centre Gustave Glotz 14, pp.23-43.

Gorre, G., 2009. Les relations du clergé égyptien et des lagides d'après les sources privées. Leuven: Peeters.

Goudriaan, K., 1988. Ethnicity in Ptolemaic Egypt. Amsterdam: J.C. Gieben.

Halbwachs, M., 1941. La topographie légendaire des Évangiles en Terre Sainte: étude de mémoire collective. Paris: Pr. Univ. de France.

Heinen, H., 1989. L'Égypte dans l'historiographie moderne du monde hellénistique. Dans: Criscuolo, L., Geraci, G. eds. Egitto e storia antica dall'ellenismo all'età araba. Bilancio di un confronto. Atti del colloquio internazionale, Bologna, 31 agosto-2 settembre 1987. Bologna: CLUEB. pp.105-135.

Hölbl, G., 2001. A history of the Ptolemaic empire. Traduit de l'allemand par T. Saavedra. London: Routledge.

Hornbostel, W., 1973. Sarapis: Studien zur Überlieferungsgeschichte, den Erscheinungsformen und Wandlungen der Gestalt eines Gottes. Leiden: Brill.

Huß, W., 1994. Der makedonische König und die ägyptischen Priester. Studien zur Geschichte des ptolemaiischen Ägypten. Stuttgart: Franz Steiner.

Jouguet, P., 1961. L'impérialisme macédonien et l'hellénisation de l'Orient. $3^{\mathrm{e}}$ ed. Paris: Albin Michel.

Kessler, D., 2000. Das hellenistische Serapeum in Alexandria und Ägypten in ägyptologischer Sicht. Dans: Görg, M., Hölbl, G. eds. Ägypten und der östliche Mittelmeerraum im 1. Jahrtausend v. Chr. Akten des Interdisziplinären Symposions am Institut für Ägyptologie der Universität München 25.-27. 10. 1996. Wiesbaden: Harrassowitz. pp.163-230.

Kiessling, E., 1949. La genèse du culte de Sarapis à Alexandrie. CdÉ 24, pp.317323.

Koenen, L., 1993. The Ptolemaic King as a Religious Figure. Dans: Bulloch, A., Gruen, E.S. et Long, A.A. eds., Images and Ideologies. Self-definition in the Hellenistic World. Berkeley: Univ. of California Press. pp.25-115.

Kreissig, H., 1978. Das Hellenismus-Kolloquium von Hartenstein 30.3.1.4.1976. Klio 60.1, p.9.

Ladynin, I.A., 2014. The Argeadai building program in Egypt in the framework of dynasties XXIX-XXX Temple Building. Dans: Grieb, V., Nawotka, K. et Wojciechowska, A. eds. Alexander the Great and Egypt: History, Art, Tradition. Wiesbaden: Harrassowitz Verlag. pp.221-240.

Legras, B. 2004. L'Égypte grecque et romaine. Paris: Armand Colin. 
Legras, B. 2010. Hommes et femmes d'Égypte (IVe s. av. n.è. - IV s. de n.è.). Droit, histoire, anthropologie. Paris: Armand Colin.

Legras, B., 2014. Sarapis, Isis et le pouvoir lagide. Dans: Bricault, L., Versluys, M.J. eds. Power, Politics and the Cults of Isis. Proceedings of the Vth International Conference of Isis Studies, Boulogne-sur-Mer, October 13-15, 2011. Leiden: Brill. pp.95-115.

McKenzie, J.S., et al., 2004. Reconstructing the Serapeum in Alexandria from the Archaeological Evidence. JRS 94, pp.73-121.

Milne, J.G., 1928. Egyptian Nationalism under Greek and Roman Rule. JEA 14, pp.226-234.

Minas-Nerpel, M., 2018. Pharaoh and temple building in the fourth century BCE. Dans: McKechnie, P., Cromwell, J. eds. Ptolemy I and the Transformation of Egypt, 404-282 BCE. Leiden: Brill. pp.120-165.

Nespoulous-Phalippou, A. 2015. Ptolémée Épiphane, Aristonikos et les prêtres d'Égypte. Le Décret de Memphis (182 a.C.). Édition commentée des stèles Caire RT 2/3/25/7 et JE 44901, Vol.I-II. Montpellier: Univ. Paul Valéry.

Otto, W.G.A., 1905-1908. Priester und tempel im hellenistischen Ägypten. Leipzig: B. G. Teubner.

Paarmann, B., 2011. Den ptolemæiske Sarapis-kult og dens grundlæggelsesmyte. Dans: Schwartz, A., Heine Nielsen, T. et Bloch, D. eds. Festskrift for Chr. Gorm Tortzen. København: Det Humanistiske Fakultet. pp.1-17.

Payen, P., 2001. Droysen, l'Histoire d'Alexandre le Grand et l'État prussien: la querelle de l'unité et la question du «modernisme». Dans: Caucanas, S., Cazals, R. et Payen, P. eds. Retrouver, imaginer, utiliser l'Antiquité: actes du Colloque international tenu à Carcassonne les 19 et 20 mai 2000. Toulouse-Carcassonne: Privat-Les Audois. pp.115-134.

Payen, P., 2006. Les «Religions Orientales» au Laboratoire de l'Hellénisme. 1. Johann Gustav Droysen. $A R G$ 8, pp.163-180.

Pfeiffer, S., 2008a. The God Serapis, his Cult and the Beginnings of the Ruler Cult in Ptolemaic Egypt. Dans: McKechnie, P. et Guillaume, P. eds. Ptolemy II Philadelphus and his World. Leiden: Brill. pp.387-408.

Pfeiffer, S., 2008b. Herrscher- und Dynastiekulte im Ptolemäerreich: Systematik und Einordnung der Kulfformen. München: C.H. Beck.

Préaux, C., 1997. Le monde hellénistique. Vol.I-II. $4^{e}$ ed. Paris: Pr. Univ. de France.

Quack, J.F., Paarmann, B., 2013. Sarapis: ein Gott zwischen griechischer und ägyptischer Religion. Bemerkungen aus der Sicht eines Ägyptologen / The Ptolemaic Sarapis-cult and its foundation myths. Dans: Zenzen, N., Hölscher, T. et Trampedach, K. eds. Aneignung und Abgrenzung: Wechselnde perspektiven auf die antithese von "Ost» und "West» in der Griechischen Antike. Heidelberg: Verlag Antike, pp.229-255.

Quaegebeur, J., 1983. Cultes égyptiens et grecs en Égypte hellénistique. L'exploi- 
tation des sources. Dans: Van't Dack, E. et van Dessel, P. eds., Egypt and the Hellenistic World. Proceedings of the international colloquium, Leuven, 24-26 May 1982. Leuven: Peeters. pp.303-324.

Sabottka, M., 2008. Das Serapeum in Alexandria: Untersuchungen zur Architektur und Baugeschichte des Heiligtums von der frühen ptolemäischen Zeit bis zur Zerstörung 391 n. Chr. Le Caire: IFAO.

Schäfer, D., 2011. Makedonische Pharaonen und hieroglyphische Stelen. Historische untersuchungen zur satrapenstele und verwandten denkmälern. Leuven-ParisWalpole: Peeters.

Smith, M., 2017. Following Osiris: perspectives on the Osirian afterlife from four millennia. Oxford: Oxford University Press.

Stambaugh, J.E., 1972. Sarapis under the early Ptolemies. Leiden: Brill.

Stricker, B.H., 1956. De Brief van Aristeas de hellenistiche codificaties der praehelleense Godsdiensten. Amsterdam.

Subrahmanyam, S., 1997. Connected Histories: Notes towards a Reconfiguration of Early Modern Eurasia. Modern Asian Studies 31, pp.735-762.

Subrahmanyam, S., 2005. From the Tagus to the Ganges. New Delhi-Oxford-New York: Oxford Univ. Press

Thiers, C., 2010. Membra disiecta ptolemaica. Cahiers de Karnak 13, pp.373-399.

Veïsse, A.E., 2012. Être Grec, être Égyptien dans l'Égypte ptolémaïque. Dans: Brizay, F. ed. Les formes de l'échange. Communiquer, diffuser, informer, de l'Antiquité au XVIII siècle. Rennes: Presses Univ. Rennes. pp.19-30.

Veyne, P., 1971. Comment on écrit l'histoire. Essai d'épistémologie. Paris: Éd. du Seuil.

Weinreich, O., 1919. Neue Urkunden zur Sarapis-Religion. Tübingen: J.C.B. Mohr. Wilcken, U., 1927. Urkunden der Ptolermäerzeit. Berlin: W. de Gruyter.

Will, E., 1985. Pour une "anthropologie coloniale» du monde hellénistique. Dans: Eadie, J.W. et Ober, J. eds. The Craft of Ancient Historian. Essays in Honour of Chester G. Starr. London: Lanham. pp.273-301.

Worthington., I., 2016. Ptolemy I: king and pharaoh of Egypt. New York: Oxford University Press. 


\section{LOS TEMPLOS DE ÉPOCA PTOLEMAICA EN EL ALTO EGIPTO: ¿LUGARES DE ACCIÓN REAL O DE FALSAS APARIENCIAS?}

\section{Ptolemaic temples of the Upper Egypt: Real action places or false appearances?}

Sergio Sistac Marina ${ }^{1}$

Resumen: El período ptolemaico en Egipto se ha visto tradicionalmente como una época de decadencia y declive del Estado faraónico egipcio. Sin embargo, aunque es cierto que los Ptolomeos gobernaron desde Alejandría como unos auténticos soberanos griegos, en seguida se darían cuenta de que su vínculo con el clero tradicional indígena iba a marcar el futuro de su dinastía. Estas relaciones cobrarían una especial importancia en el Alto Egipto, una zona tradicionalmente propensa a las rebeliones en contra del faraón y de su tendencia durante muchos momentos de la Historia de Egipto a centralizar su poder en el norte del país.

Palabras clave: Egipto, época ptolemaica, templos, clero indígena.

Abstract: Ptolemaic Period in Egypt has traditionally been seen as a decline and decay era of the Pharaonic Egyptian State. Although it is true that Ptolemies ruled from Alexandria like real Greek rulers, they soon realized that their link with the traditional indigenous priesthood was going to mark the future of the dynasty. These relationships had a special importance in Upper Egypt, an area prone to rebel against Pharaoh and his

1 Doctorando. Universidad de Málaga. Correo electrónico: sergiosistac@uma.es. 
inclination to centralize his power in the north of the country for many times of the Egyptian history.

Keywords: Egypt, Ptolemaic Period, temples, indigenous priesthood.

Unos de los elementos patrimoniales más importantes y característicos que conservamos hoy en día acerca del periodo helenístico en Egipto son los grandes templos construidos o renovados por los Ptolomeos durante el reinado de su dinastía. Por la información que ha llegado a nosotros, sabemos que muchos de estos lugares alcanzaron un gran poder y prestigio en esta época debido, fundamentalmente, a la necesidad imperiosa de estos nuevos monarcas de origen extranjero de hacerse ver, ante la población indígena, como los verdaderos sucesores de los antiguos faraones. Por lo tanto, nuestro objetivo a continuación va a ser el de acercarnos a conocer cómo fueron estas relaciones que se establecieron entre el clero de dichos templos y los nuevos monarcas lágidas, así como entender también la importancia que podían tener estos lugares dentro del programa político creado y llevado a cabo por los últimos faraones de la historia de Egipto.

Para empezar, nos vemos en la obligación de mencionar que la historiografía que ha tratado hasta ahora estas relaciones entre el clero egipcio y los Lágidas ha ido sufriendo una evolución significativa en sus teorías, que se entiende lógicamente por la aparición continua de nuevo material arqueológico y del estudio de fuentes papirológicas descubiertas o publicadas recientemente. En un primer momento, la tendencia historiográfica planteaba este asunto como un antagonismo claro entre los templos indígenas, últimos representes de la identidad egipcia, y estos nuevos soberanos de origen extranjero. Este pulso continuo haría imposible la colaboración entre ambas esferas de poder y acabaría resultando en un fracaso para los Ptolomeos, puesto que su hegemonía se fue debilitando progresivamente conforme se multiplicaban las concesiones al clero "nacionalista" del Alto Egipto, debido al período de crisis social y política en el que la dinastía se vio envuelta desde finales del siglo III a. C., en adelante.

Sin embargo, esta interpretación de las relaciones en un contexto de rivalidad nacional fue refutada posteriormente por la papiróloga francesa Claire Préaux (1984) quien, a través de su estudio de las insurrecciones egipcias, con las que parece surgir el origen de las dificultades de los Lági- 
das, llegó a la conclusión de que el clero egipcio formó parte efectiva del sistema económico y político ptolemaico y, en consecuencia, se vio tan afectado como la casa real con estas revueltas que tuvieron identidad y autoría propias, ajenas en su mayor parte a la voluntad del clero. La autora citada también defiende que el origen esencial de este problema residió en la estructura económica dominante, que conforme a la tradición egipcia se basaba en la idea de que la tierra y sus productos pertenecían al faraón, como heredero de los dioses, y a los templos por concesión del primero. Esta también es la opinión de Willy Clarysse (2000) para quien no podría existir una oposición nacionalista por parte de aquellos hombres que servían a la "Iglesia" y al Estado al mismo tiempo.

Para otros autores posteriores que siguen esta tendencia, como Michel Chauveau (1997), la heterogeneidad del clero sería también un hecho remarcable que vendría incrementado por las posibles interrelaciones con el Estado, por lo que el sacerdocio indígena no formaría un bloque monolítico frente a los Ptolomeos y los intereses y relaciones con el Estado Lágida podrían variar según el clero de cada templo.

La aportación más reciente en el panorama historiográfico sobre este tema es el representado por Gilles Gorre (2009). Su investigación acerca del tema le ha llevado a argumentar que, en líneas generales, parece existir una estrecha relación entre el Estado y los templos egipcios, ya que los Ptolomeos optaron desde un primer momento por una política de compromiso e integración del clero con el Estado. Según este autor, este entretejido hace que sea inexacto considerar las relaciones del clero egipcio y los Lágidas como una ilustración del conflicto entre el poder temporal y el poder espiritual. En Egipto, las personas que trabajan en templos estarían, por tanto, doblemente conectadas a la esfera del Estado y, de hecho, la acumulación de cargos civiles y religiosos sería la regla. De esta manera, no deberíamos creer que los templos se beneficiaron de las crisis de la dinastía sino que, por el contrario, fueron también víctimas de ésta.

Todos estos historiadores que acabamos de mencionar han tenido que hacer frente a la dificultad inherente al estudio de las fuentes de información sobre el mundo helenístico. Incluso si nos centramos en Egipto, nos encontramos con que estas no son especialmente abundantes y, además, están muy desigualmente repartidas (Rostovtzeff, 1967, p.260). Este hecho, como vamos a ver en seguida, pone de manifiesto la importancia que 
tiene la interdisciplinariedad en las investigaciones sobre este período de la historia de Egipto.

En el caso concreto que nos atañe, el Egipto helenístico, contamos, por un lado, con las fuentes literarias antiguas que nos relatan los episodios acaecidos en este lugar durante dicha época. Estas obras antiguas nos brindan, en esencia, una información histórica y topográfica muy valiosa. Entre estos autores podemos destacar principalmente a Heródoto de Halicarnaso, Hecateo de Mileto, Hecateo de Abdera, Manetón, Diodoro Sículo, Flavio Josefo, Estrabón y Plutarco. Sin embargo, estos testimonios, aunque nos aportan un relato de los acontecimientos que suelen resultar esenciales para establecer un marco cronológico, no dejan de ser insuficientes por si solos.

Por suerte, podemos completar la información aportada por todos estos historiadores de la Antigüedad con otro tipo de testimonios históricos que permiten a los investigadores obtener una visión mucho más completa del período. El hallazgo de estas nuevas fuentes de información se lo debemos en gran medida a la arqueología y, gracias al incremento regular en la cantidad de tales testimonios, la historia de este período se encuentra en constantemente actualización, a medida que la disponibilidad de nueva información induce a revisar viejas hipótesis y a plantear algunas nuevas. Al respecto de este hecho, son muy esclarecedoras las palabras del historiador británico Graham Shipley, quien, además de hacer un profundo uso de las fuentes no literarias en sus investigaciones, alega lo siguiente (Shipley, 2001, p.54):

«Un rasgo sorprendente del período helenístico, en comparación con el clásico, es el número muy grande de textos no literarios que quedan, y su preponderancia sobre los datos historiográficos. Por una parte, dichas fuentes - papiros documentales, inscripciones, monedas, y restos arqueológicos- nos dan un acceso mucho más directo al período. Por otra parte, estas fuentes plantean problemas especiales de interpretación y necesitan conocimientos especializados para ser evaluadas directamente».

En cuanto a todas estas fuentes de naturaleza no literaria, en Egipto, cobran especial importancia los papiros, ya que son, debido a su proliferación, nuestra fuente principal de información, aunque estos proceden en su mayoría de la región de El Fayum, cercana al Delta. El principal problema 
de estas fuentes es que muy pocos se refieren a las condiciones generales del país o emanan del gobierno central, sino que, sobre todo, aluden a asuntos locales. Es por ello que es necesario utilizarlos con precaución, ya que el número de papiros griegos con los que contamos es enormemente superior a los escritos en demótico, por lo que las conclusiones que podemos sacar pueden estar sesgadas. Además, los que poseemos únicamente se pueden utilizar con fiabilidad para el lugar y el momento al que pertenezcan, ya que tenemos motivos para creer que las condiciones cambiaban considerablemente en cada lugar y en cada momento (Walbank, 2012, p.25). Por lo tanto, debido a la naturaleza de las fuentes papirológicas halladas hasta la fecha, cabe recalcar que el período mejor conocido es el que abarca el reinado de los primeros reyes de esta dinastía, en concreto, de Ptolomeo II Filadelfo y Ptolomeo III Evergetes. Por este mismo motivo, se conoce mucho más acerca de las actividades económicas y sociales propias de las élites helenísticas que habitaban Alejandría y la zona norte del país, que de las élites indígenas que, sin duda, tendrían un papel muy relevante en el Alto Egipto.

Por otra parte, contamos también con la información recogida en las inscripciones, cuyo estudio necesita de una técnica especial por parte del historiador. La procedencia exacta de muchas inscripciones es incierta y muchas son fragmentarias o parcialmente ilegibles. Por fortuna el estudio del vocabulario y la fraseología utilizados en diversos contextos y en distintas fechas permite al experto epigrafista sugerir restauraciones plausibles para llenar lagunas que se adviertan (Walbank, 2012, pp.22-23). Por lo general, muchas de estas inscripciones revelan la participación de los reyes en los cultos oficiales de Egipto. En numerosas ocasiones, las dedicatorias de estatuas y templos, la restauración, construcción y dotación de santuarios, la instauración de fiestas, los exvotos o los inventarios de tesoros sagrados atestiguan la persistencia de los dioses indígenas y el poder de los templos como centros económicos y religiosos del momento.

Por último, las fuentes de carácter iconográfico como las estatuas o monedas, son otro foco importante de información. Por ejemplo, en lo que respecta a los templos y su relación con los faraones, las esculturas y representaciones que allí residían tenían una gran importancia, ya que eran unos elementos muy útiles para el reconocimiento del poder y la legitimidad del faraón (Fabre, 2008, p.99). Por lo tanto, el estudio pormenorizado de la iconografía real hallada en los santuarios nos da información acerca 
de la política religiosa seguida por estos monarcas en relación con los templos y su clero.

A pesar de todas estas fuentes de información que acabamos de mencionar, lo cierto es que la documentación que poseemos acerca de los templos egipcios de época ptolemaica no es todo lo abundante que desearíamos y esto ha provocado que, hoy en día, ignoremos en gran medida, por poner un ejemplo, muchos de los aspectos relacionados con la economía de los templos. Esto se debe principalmente a que los papiros demóticos no han podido todavía arrojar suficiente luz sobre el tema debido a que muchos de ellos permanecen, todavía, inéditos, y también a que la mayoría de estos hallazgos ha tenido lugar, como ya hemos apuntado, en la región de El Fayum. No obstante, cabe también remarcar que la riqueza material de Egipto es abrumadora y que se está descubriendo un número cada vez mayor de papiros demóticos, especialmente en las excavaciones llevadas a cabo en los templos y en los recintos asociados a ellos.

De lo que sí tenemos constancia, gracias a la documentación analizada hasta ahora por los investigadores, es que estos centros religiosos y la clase sacerdotal indígena asociada a ellos, habituada a gozar de privilegios importantes, tales como la exención en el pago de los impuestos que gravaban las propiedades de los templos en beneficio del tesoro real, o la administración de sus propios bienes, entre otros, trató de mantener su estatus de poder social y económico al instaurarse la dinastía de los Lágidas en Egipto. El historiador griego Heródoto (II, 37) ya nos advierte de que, en Egipto, la herencia de los cargos sacerdotales era un hecho en el siglo V a. C., lo que supuso más adelante un quebradero de cabeza para los nuevos gobernantes lágidas.

Si contextualizamos este hecho, cabe apuntar que esta no era una situación nueva para el país, puesto que los templos egipcios fueron, desde un primer momento, importantes focos de poder político durante gran parte de la historia del Egipto faraónico. Esto se debía, fundamentalmente, al papel del clero como rector de la vida religiosa y de las doctrinas morales de la población. ${ }^{2}$

2 En esencia, la única autoridad impuesta era la del Estado, representada por el rey y sus funcionarios, aunque también, en el orden más estrictamente religioso, la de los sacer- 
Sin embargo, tenemos que tener claro que la importancia del templo en la sociedad egipcia, no se limitaba única y exclusivamente a su aspecto sagrado, sino que los dominios de los templos constituían una buena reserva de alimentos y desempeñaban una actividad industrial importante. Por ende, los templos eran poderosas instituciones económicas ya que, desde época antigua, estaban dotados de tierras que los faraones ofrecían a los dioses. A su vez, poseían talleres textiles, donde se fabricaban las más delicadas telas, obtenían regalos de los reyes para la celebración de las grandes fiestas religiosas, recibían ingresos de las aldeas que estaban bajo su ámbito de influencia, contaban con multitud de objetos y estatuas para el culto de una gran manufactura y fabricados con materiales preciosos. En definitiva, en palabras de Claire Préaux (1984, p.169), podemos argumentar que «los dioses eran ricos y sus templos, autárquicos».

Por lo tanto, en momentos de crisis o de debilidad del faraón reinante, no era de extrañar que el alto clero de los principales templos del país, fuesen protagonistas de tensiones con los miembros del Estado, en busca de un mayor poder político y de nuevas ventajas fiscales. Para esto, no dudaban en extender la idea de que «el destino del país se halla directamente determinado por la piedad o la impiedad que los reyes y los generales testimonian a la divinidad» (Pirenne, 1989, p.1531). Esta situación tuvo, probablemente, una especial importancia en el Alto Egipto, donde, desde el I milenio a. C., se había instaurado un poder teocrático independiente de facto, y alejado del control del poder real, residente en el Delta. Esta situación de anarquía política se mantuvo con la excepción del interregno de la primera y segunda invasiones persas, hasta la conquista de Egipto por Alejandro Magno en el 332 a. C. A lo largo de este período el sacerdocio intentó dotar al poder nacional de un carácter teocrático, erigiéndose en juez de la política real y creyéndose ser la única clase social capaz de dirigir a Egipto de manera que su pueblo pudiera recuperar el favor de Amón y, con él, la felicidad (Pirenne, 1989, pp.1531-1532).

Esta era la situación política y social que se encontraron los Ptolomeos al acceder al gobierno del país. Como consecuencia del papel que tenían los templos como garantes del orden social y, en cierto modo, como reduc-

dotes (Pirenne, 1989, p.1516). 
to de los últimos representantes de lo que había sido el Egipto faraónico, a los dirigentes macedonios no les quedaba más opción que entenderse con el personal de estos lugares sagrados si querían llevar a cabo la explotación rentable del país. Estos nuevos monarcas se encontraban con la problemática de que no podían permitirse prescindir de la colaboración del sacerdocio indígena, puesto que este, gracias a su control y supervisión de la población, tenía en su mano el otorgar o no legitimación a la corona (Gorre, 2003, p.24).

Es por ello que los nuevos dueños de Egipto se dedicaron desde un primer momento a construir grandes monumentos religiosos que iban en consonancia con la voluntad que tenían de afirmarse, en su relación con los templos y los servidores de los dioses, como los verdaderos continuadores de los antiguos faraones. Fueron numerosos los recursos que invirtieron los monarcas lágidas para levantar, reconstruir o ampliar toda una serie de templos al más puro estilo egipcio. Lo curioso es que todos estos templos y santuarios construidos a la manera indígena, siguiendo el estilo arquitectónico de los templos antiguos de época faraónica, fueron construidos en el Alto Egipto. Es lógico pensar que este hecho vino condicionado por la tendencia secesionista de la región sur del país, donde tuvieron lugar las revueltas sociales que agravaron notablemente la crisis de gobierno de la dinastía Lágida desde, prácticamente, el reinado de Ptolomeo IV Filopátor (221-205 a. C.). Estos sucesos alcanzaron tal importancia política que incluso llevaron a que en Tebas se estableciese, en algunos momentos del siglo II a. C., un poder independiente con sus propios faraones de origen indígena.

Las edificaciones de los templos más grandes como son los de Edfú, Dendera o Filé, cuya construcción comenzó en este periodo, ilustran claramente la prosperidad que llegaron a alcanzar los templos egipcios bajo el reinado de los Ptolomeos, así como la voluntad política que estos dirigentes tenían de favorecer a determinados colegios sacerdotales (Fabre, 2008, p.105). En la práctica totalidad de estos templos tardíos, no aparecen elementos griegos, ni siquiera en las inscripciones jeroglíficas oficiales, las cuales no guardan grandes diferencias con respecto a las halladas en los templos de los antiguos faraones, a no ser, eso sí, una mayor prolijidad de detalles. En definitiva, llama profundamente la atención que no hay ningún elemento en la iconografía oficial de estos templos en los que uno de 
los monarcas de esta dinastía sea representado como un personaje griego (Préaux, 1984, p.4).

Tal era la inspiración en la tradición egipcia que estos templos tardíos tenían que, hoy en día, muchos investigadores consideran que dichas construcciones son el mejor ejemplo para comprender los entresijos del templo egipcio tradicional (Finnestad, 2005, p.185). Además, las evidencias sugieren que el patrón general de estos templos a lo que hacemos referencia, fue desarrollado al principio ya de la dinastía ptolemaica, de manera que los constructores y artesanos que trabajaron en su construcción tuvieron muy claro lo que pretendían lograr desde un primer momento (Finnestad, 2005, p.188). Sin embargo, también es cierto que, aunque se ajustaron a la convención egipcia tradicional y no mostraron apenas ninguna influencia extranjera, estos templos poseían algunas innovaciones y pequeñas individualidades particulares. Por norma general, desde el punto de vista arquitectónico, estos templos continúan con las tradiciones básicas de construcción y disposición de las salas (Fig. 1). Tienen una gran puerta de entrada (que los griegos llamaban "pilono»), un patio, salas hipóstilas, espacios destinados a las ofrendas y pequeñas salas que servían como capillas y almacenes donde se guardaba todo el material relacionado con el culto. También poseían capillas en el techo (que se conservan únicamente en el templo de Dendera) y criptas subterrá-

Fig. 1. Plano del templo ptolemaico de Horus en Edfú. Fuente: Willems, 2000, p.111. 
neas que estaban relacionadas, sobre todo, con el culto a Osiris. Como hemos comentado recientemente, los templos tardíos se caracterizaban por tener además algunos rasgos especiales como es el caso de una entrada con columnas situada en frente de la naos del templo y que se conoce con el nombre de pronaos. Otro rasgo particular de estos templos era la disposición del santuario central, el cual consistía en una estructura separada con su propio tejado y rodeado por un corredor.

Por último, en lo que respecta a las innovaciones establecidas por los Ptolomeos en estos templos, cabe destacar la especial atención que se otorgan a los mammisi o Casas del Nacimiento. Estos pequeńos santuarios estaban destinados a celebrar el nacimiento del niño real gracias a la intervención del dios y, por lo tanto, hacía referencia a la ascendencia divina del sucesor al trono. En este pequeño templo que, desde la XXX Dinastía (380-342 a. C.), adquirió una mayor importancia, se celebraba anualmente el nacimiento del príncipe heredero y se llevaba a cabo el culto correspondiente. Debido a esto, no es de extrańar que, durante el gobierno del país de una dinastía cuya legitimidad al trono de Egipto estaba claramente cuestionada, estos lugares recibiesen una especial atención, otorgándoles, en época ptolemaica, un lugar independiente dentro de los recintos sagrados de los templos y prestando una mayor importancia a sus representaciones. En relación con esto último, la diosa Isis fue objeto de una profunda veneración en estos lugares puesto que ella era la madre del soberano, encarnado en este caso por el dios Horus-Harpócrates.

Un claro ejemplo de la importancia que adquirieron estos lugares bajo el mandato de los Lágidas lo podemos ver en el mammisi que mandó construir Cleopatra VII Filopátor en la antigua ciudad de Hermontis, en cuyo lugar se alzaba un templo dedicado al dios de la guerra Montu y cuyos orígenes se remontan a la XI Dinastía (2135-1994 a. C.). En este santuario la reina Cleopatra se hizo representar como la diosa Isis-Hathor sentada sobre un trono, amamantando a su hijo Cesarión, futuro rey de Egipto. De este hecho se deduce que Cleopatra VII no era ajena a este nuevo mecanismo de legitimación y que, mediante la asimilación de ambos con la reina Isis y el príncipe divino Horus, Cleopatra buscaba consolidar así la sucesión al trono de su hijo con Julio César (Arroyo, 2013, p.91). Además, el paralelo entre el asesinato de César y el de Osiris, padre de Horus, era claro (Goudchaux, 2001, p.136). 
En esta maniobra política de mostrarse como los sucesores legítimos de los antiguos faraones, los Ptolomeos eran también «hijos de Ra» e «imagen viva de Amón", por lo que asumían a su vez la función sacerdotal que implicaban estas relaciones (Préaux, 1984, p.60) y que los obligaba, en cierta medida, a proveer a los templos de todos los recursos necesarios para que el culto diario a los dioses pudiera seguir realizándose con éxito y mantener así el orden en el mundo, la maat. En definitiva, en palabras de D. Fabre (2008, p.105):

«Los soberanos lágidas eran plenamente conscientes de que los sacerdotes eran los únicos mediadores para facilitar las relaciones entre el poder real y el poder religioso, así como para que una autoridad extraña por su lengua, costumbres y cultura, fuese plenamente aceptada. Así pues, no tardaron en tratar de establecer relaciones armoniosas con el clero autóctono, puesto que para conseguir un dominio pleno que se prolongara en el tiempo necesitaban que el clero proclamase al nuevo faraón como hombredios, predestinado al trono por el creador, asegurando, de este modo, el reconocimiento de los dioses y la fidelidad de todo el pueblo egipcio. Por su parte, la lealtad del clero estaba garantizada por la concesión del caudal necesario para el cumplimiento de los ritos y el aprovisionamiento de los templos y de su personal».

Si ponemos nuestra mirada sobre el complejo templario de Karnak, el hogar del dios Amón de Tebas, vemos cómo, con el inicio de la época ptolemaica este lugar disfrutó de un período de renovación, pudiéndose observar los cartuchos y relieves de los monarcas lágidas alrededor de los recintos de los distintos templos y capillas, así como en muchas grandes puertas de piedra que se encuentran en los muros.

En el centro del primer patio, por ejemplo, se encuentran los restos de un gigantesco quiosco construido por Taharqa y que fue posteriormente restaurado por los Ptolomeos. Originalmente, el quiosco constaba de diez columnas grandes de papiro unidas por un pequeño muro y abierto por sus lados este y oeste. Sin embargo, hoy en día únicamente se conserva alzada una gran columna y una capilla realizada a partir de un bloque de calcita. ${ }^{3}$ Fue Ptolomeo quien intervino en este espacio, y por ello su nombre

3 Aunque la función de esta construcción se presume que era la de servir como reposadero de la barca del dios, el hecho de que esté abierto al cielo sugiere que pudo haber 
puede verse alrededor de toda la gran columna de Taharqa. Solo los muros del lado norte de este quiosco se han conservado y en ellos se pueden ver figuras representando los nomos del Bajo Egipto siendo liderados por el propio Ptolomeo hacia la divinidad que personificaba a la ciudad de Tebas, Waset. Parece evidente pensar que, si se hubieran conservado los muros del sur, en ellos aparecerían los nomos del Alto Egipto en una representación similar (Blyth, 2006, p.228). De esta manera, Ptolomeo IV hacía su aparición aquí como líder de todo el pueblo de Egipto y benefactor de la ciudad de Tebas.

En la misma Tebas también encontramos el ejemplo del pequeño templo ptolemaico de la ciudad obrera de Deir el-Medina. En dicho lugar, Ptolomeo IV mandó erigir un nuevo santuario dedicado a las diosas Hathor y Maat. Tanto la arquitectura como sus relieves demuestran una vez más la línea de continuidad que estos soberanos macedonios siguieron con respecto a la tradición faraónica. En las capillas principales del templo, aparecen representados a la manera tradicional egipcia, como faraones, tanto Ptolomeo IV como Ptolomeo VI (Fig. 2).

Por otra parte, los Ptolomeos no solo se dedicaron a construir y restaurar los antiguos templos de Egipto, sino que, si hacemos caso a algunas estelas, estas nos aportan información acerca de su participación, en ciertas ocasiones especiales, de las festividades que se siguieron celebrando en los templos indígenas durante los trescientos años de gobierno lágida. Este hecho queda reflejado en distintos documentos como es el caso de la estela hallada en el Bucheum de Hermonthis. En esta localidad de la Tebaida se adoraba a un toro llamado Buchis, el cual encarnaba el alma viviente del dios Amón-Ra. Cuando este animal fallecía era sustituido por otro en una ceremonia sagrada, ceremonia que, según esta estela, sabemos que tuvo lugar en el año 51 a. C., momento en el que Cleopatra VII Filopátor ascendió al trono de Egipto. En dicho documento se registra la participación de la reina Cleopatra VII en el festival de instalación del nuevo toro sagrado.

tenido un propósito especial en uno de los rituales asociados con el templo, posiblemente un tipo de ceremonia de "unidad con el sol», la cual sabemos que era practicada en épocas tardías en templos como el de Dendera y en algunos otros lugares (Wilkinson, 2000, p.156). 


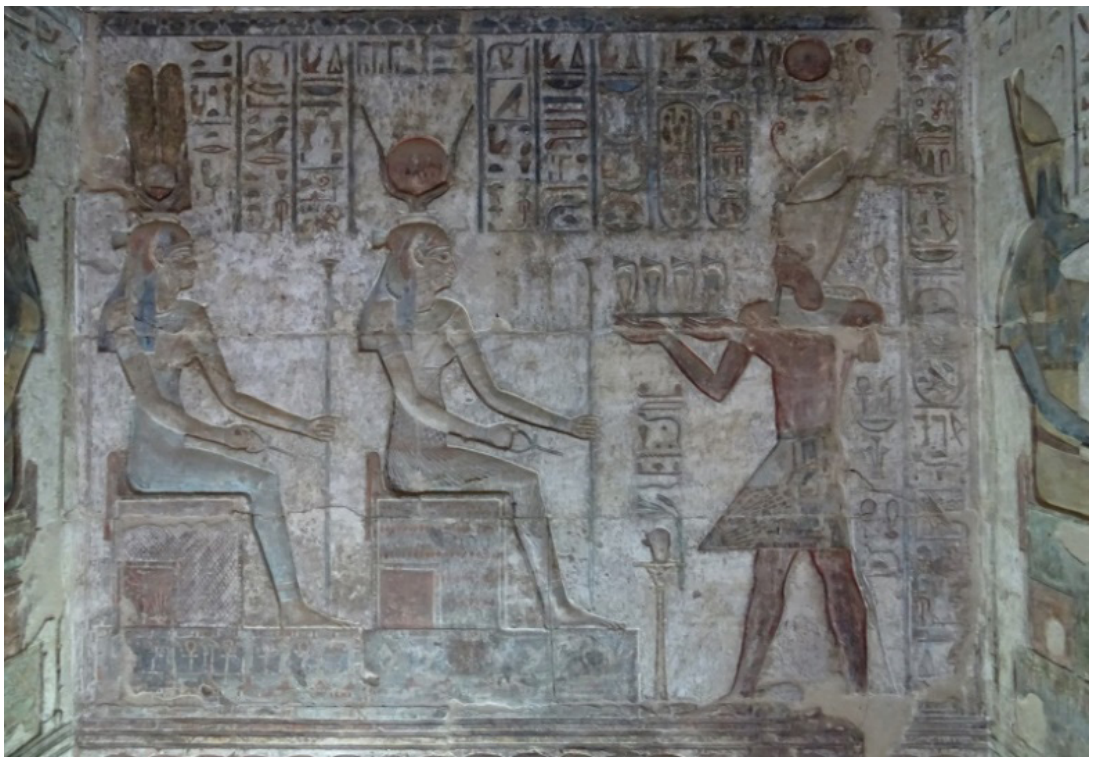

Fig. 2. Relieve de la capilla norte del templo de Hathor en Deir el-Medina. En ella se puede ver a Ptolomeo IV Filopátor realizando ofrendas a las diosas principales del santuario, Hathor y Maat, ambas sentadas sobre sus tronos. Fuente: fotografía del autor.

A su vez, cuando en el tercer año de su reinado falleció el toro Apis de Memphis, conocemos por otras fuentes que ella tomó parte directa en los gastos y expensas del culto, otorgando, además, una mesa de ofrendas y raciones diarias para todas aquellas personas encargadas de realizar los ritos relacionados con el enterramiento de este toro sagrado. Aunque la dotación económica de los ritos, como hemos apuntado anteriormente, era algo común en los Ptolomeos, «el detalle de la dotación de Cleopatra es nuevo y sugiere cierto nivel de participación personal en los cultos de toros en Egipto, que habían llegado a representar la esencia de la religión nativa» (Thompson, 1992, p.321).

Como podemos ver, la participación de Cleopatra VII en este tipo de festividades, de tradición claramente indígena, no fue un hecho aislado, sino que esta reina tuvo interés en estar presente en otros rituales propios de esta religión a lo largo de su reinado, ganándose así el respeto y la adhesión de sus súbditos, en especial, en el Alto Egipto (Puyadas Rupérez, 2016, p.44). 
En líneas generales, estamos en disposición de afirmar que los Ptolomeos intentaron guardar siempre una relación cordial con el clero indígena aunque es cierto que estas relaciones no fueron siempre idílicas. A partir del reinado de Ptolomeo IV, el imperio lágida entró en un proceso claro de decadencia que coincidió con una guerra civil prolongada, en la que el Alto Egipto se proclamó independiente del gobierno central alejandrino y, desde el $207 \mathrm{al} 186 \mathrm{a}$. C. fue gobernado por faraones independientes de ascendencia Nubia (Harmachis y Anchmachis). Estos signos de debilidad en el gobierno se pueden deber, en parte, a un sentimiento "nacionalista" de la población egipcia pero, en primera instancia, reflejan un claro desencanto social creciente que adopta las formas nacionalistas simplemente porque la élite dirigente está configurada por griegos (Walbank, 2012, p.123).

Estas agitaciones, que pueden tomar la forma de verdaderas insurrecciones, se conocen esencialmente por la documentación papirológica y los autores antiguos. Uno de estos últimos, Polibio, ya hace referencia a la división creciente que se estaba generando entre los dos pueblos, el griego y el egipcio, en época de Ptolomeo IV Filopátor y que iba a acabar desencadenando en estas revoluciones populares a las que estamos haciendo referencia. Al hablar del período inmediatamente posterior a la victoria de Ptolomeo IV sobre el rey seléucida Antíoco III en Rafia (217 a. C.), Polibio (V, 107, 1-3) nos narra lo siguiente:

«Este rey, en efecto, había armado a los egipcios para la guerra contra Antíoco: tal determinación le resultó acertada para el presente, pero equivocada para el futuro. La victoria de Rafia ensoberbeció a aquellas gentes y ya no soportaron más la autoridad. Se creían capaces de bastarse a sí mismos y se buscaron un capitoste bien figurado, cosa que acabaron por lograr, y muy pronto».

Ante esta situación, y para intentar evitar estos levantamientos populares protagonizados en su mayoría por campesinos, los distintos monarcas lágidas, desde Ptolomeo V Epífanes en adelante, se vieron todavía más obligados a realizar repetidas concesiones a los distintos cleros indígenas, entre las que destacaba, por encima de todas, la exención de impuestos. Ante estos dones que les eran otorgados a los templos, los clérigos locales solían inscribir en los muros del recinto de los santuarios o en estelas que se colocaban en el exterior de estos, las concesiones otorgadas por el monarca a ese determinado templo. De esta forma, estos escritos no solo daban se- 
guridad a los sacerdotes, sino que eran también útiles para la propaganda real, ya que daban la imagen de un soberano piadoso que se preocupaba y respetaba las prerrogativas de los dioses locales (Fabre, 2008, p.108).

Este hecho lo podemos comprobar en el gran templo ptolemaico de Edfú, el mejor preservado de esta época, cuya construcción comenzó en tiempos de Ptolomeo III Evergetes (en el 237 a. C.) y no se terminó hasta el 57 a. C., en época ya de Ptolomeo XII Neo Dioniso, ${ }^{4}$ padre de Cleopatra VII Filopátor. La construcción de dicho santuario estuvo provocada, en gran medida, por el gran clima de inestabilidad y violencia que se vivió en la región de la Tebaida durante los dos últimos siglos de gobierno macedónico en Egipto. Este templo, consagrado al dios Horus de Behdet, es, sin duda, el ejemplo más adecuado para demostrar la coherencia y la interacción de todos los componentes del templo y su importancia para la imagen pública del soberano (Finnestad, 2005, p.204). Sus textos y relieves representan al faraón como Horus, rey del universo e hijo de Ra, el Creador solar. Además, era en este templo donde tenía lugar el Festival de la Victoria, que celebraba el mito de la victoria de Horus sobre Seth y sus enemigos.

En los relieves del interior aparece el dios Horus arponeando a sus enemigos, siendo representados estos con la forma de hipopótamos y cocodrilos. Los textos que acompañan a estas imágenes muestran nuevamente que Horus y el faraón reinante se fusionaron ritualmente. Debido al trasfondo religioso que tenía este lugar sagrado, no es de extrañar que los Ptolomeos lo utilizasen para fortalecer su imagen sobre el Alto Egipto, haciéndose representar allí como los monarcas victoriosos frente a los rebeldes. Esta simbología la podemos observar también en el gran relieve del Primer Pilono, donde aparece el faraón en la clásica escena del rey golpeando a sus enemigos con una maza, en este caso, delante del Horus de Behdet.

Para finalizar, cabe destacar una de las grandes medidas religiosas impulsada por los Lágidas, con el objetivo de buscar la legitimación de su

4 En una inscripción fechada el 5 de diciembre del 57 a. C. se narra el hecho de que las puertas del templo de Edfú, hechas de madera de cedro y cubiertas de bronce, fueron ofrecidas en nombre del rey, incluso cuando éste estaba todavía exiliado en Éfeso (Goudchaux, 2001, p.132). 
dinastía y en el que iban a tener un papel principal los diversos templos y el clero tradicional egipcios. Hablamos del establecimiento de un culto a la dinastía impulsado por Ptolomeo II Filadelfo (285-246 a. C.). Dicho monarca consumó una destacable operación de propaganda a favor de la dinastía al casarse con su propia hermana Arsínoe II, cuya muerte supo explotar mediante la demostración de la naturaleza divina de la pareja real. Los sacerdotes egipcios aceptaron la significación mística de una unión que imitaba el modelo primigenio de la realeza faraónica descendiente de la pareja incestuosa formada por Isis y Osiris. Con este matrimonio se logró iniciar el culto a la dinastía, que reunió por igual a griegos y egipcios (Chauveau, 1997, pp.40-41).

Aunque Ptolomeo II ya inauguró oficialmente el culto dinástico instigando al culto de sus fallecidos padres como Theoi Soteres («dioses salvadores»), desde el 272-271 a. C., fue tanto él como su hermana-esposa, Arsínoe II, quienes se hicieron divinizar por primera vez en vida y, de esta forma, lograron que se les rindiera culto como Theoi Adelphoi («dioses hermanos»). Desde este momento, la deificación de la familia real estuvo organizada por medio del culto a los soberanos, quienes se convertían en Synnaoi Theoi («el culto a los dioses que comparten la parte más interna del templo») junto con el dios principal del templo (Fig. 3). La imagen del soberano, ya estuviera vivo o muerto, era colocada a lado de la del dios y unos sacerdotes especiales eran los encargados de cuidarla. Gracias a documentos como el Papiro de Oxirrinco (2465, frg. 2), sabemos que esto pasó con el culto a Arsínoe II, cuyas estatuas fueron adoradas en todos los templos de Egipto por mandato real.

Esto nos da una idea del control de la familia real que, de esta manera, se aseguraban la lealtad de las élites locales y la aceptación por parte del pueblo egipcio. Como relata C. Préaux (1984, p.68):

«El culto real practicado en los templos egipcios suscitó donaciones de los reyes que no sólo sirvieron para preservar la fuerza económica de estas instituciones sino que, además, permitieron iniciar o proseguir construcciones gigantescas en Edfú, Denderah, Karnak y en muchos otros santuarios».

En relación con el culto dinástico establecido en Egipto, las numerosas estatuas, de estilo tanto griego como egipcio, en las que aparecen representadas mujeres de la realeza reflejan el importante rol que estas rei- 


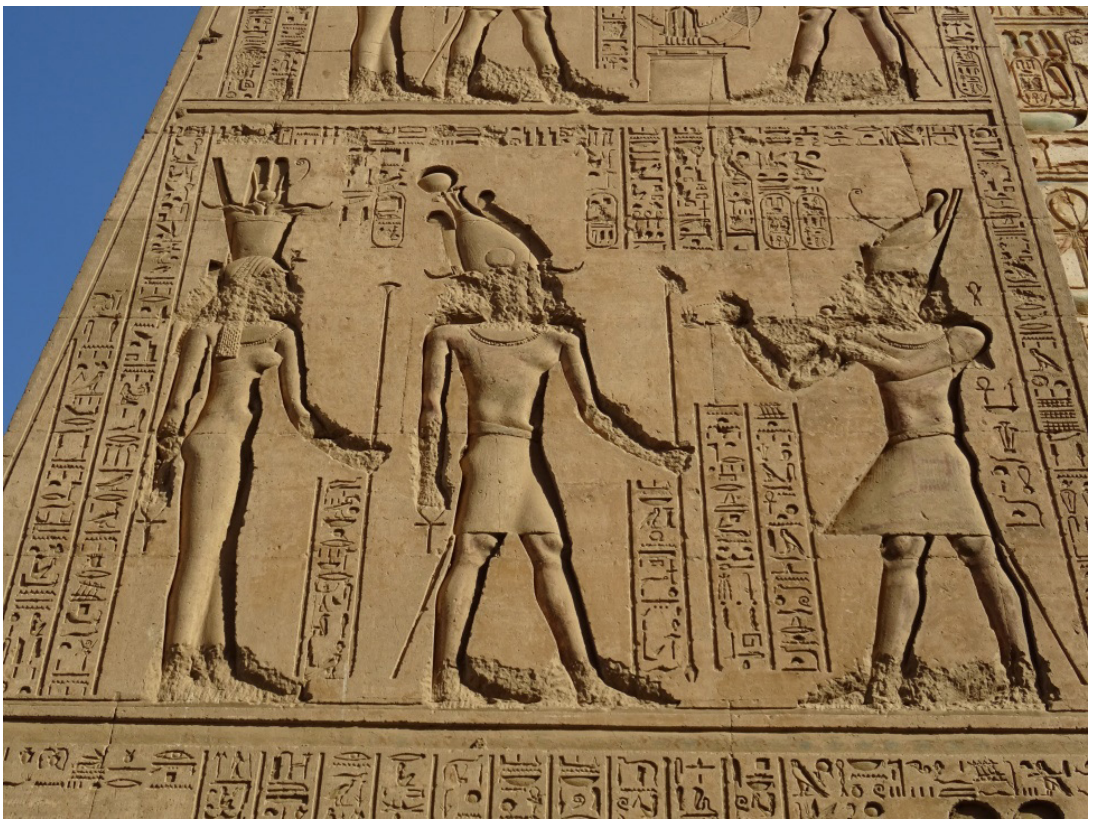

Fig. 3. Relieve de la puerta de Bab el-Amara. En esta imagen de la gran puerta que Ptolomeo III Evergetes mandó construir en las inmediaciones del templo de Jonsu, en Karnak, aparecen los Theoi Adelphoi recibiendo adoración por parte de su hijo Ptolomeo III. Fuente: fotografía del autor.

nas jugaban en los cultos religiosos de los dirigentes desde Arsínoe II. En realidad, aunque las primeras reinas como Arsínoe II pueden haber tenido influencia en lo privado, su papel público servía ante todo para reforzar las acciones y la posición de su parentela masculina (Shipley, 2001, p.98). Posteriormente, sin embargo, hubo reinas importantes que parecen haber desempeñado de modo genuino un papel independiente en las luchas dinásticas. El ejemplo más claro de esto último es, sin duda, Cleopatra VII Filopátor.

El interés de esta reina a la hora de intentar sacar partido político de su relación con el clero indígena, se demuestra una vez más en un gran relieve situado en la parte trasera del templo de Dendera (Fig. 4). Una vez más, como hemos visto ya en el mammisi de Hermonthis, la última reina de Egipto utiliza este templo para fortalecer la posición de su hijo como futuro y verdadero sucesor al trono (Puyadas Rupérez, 2016, p.55). En 


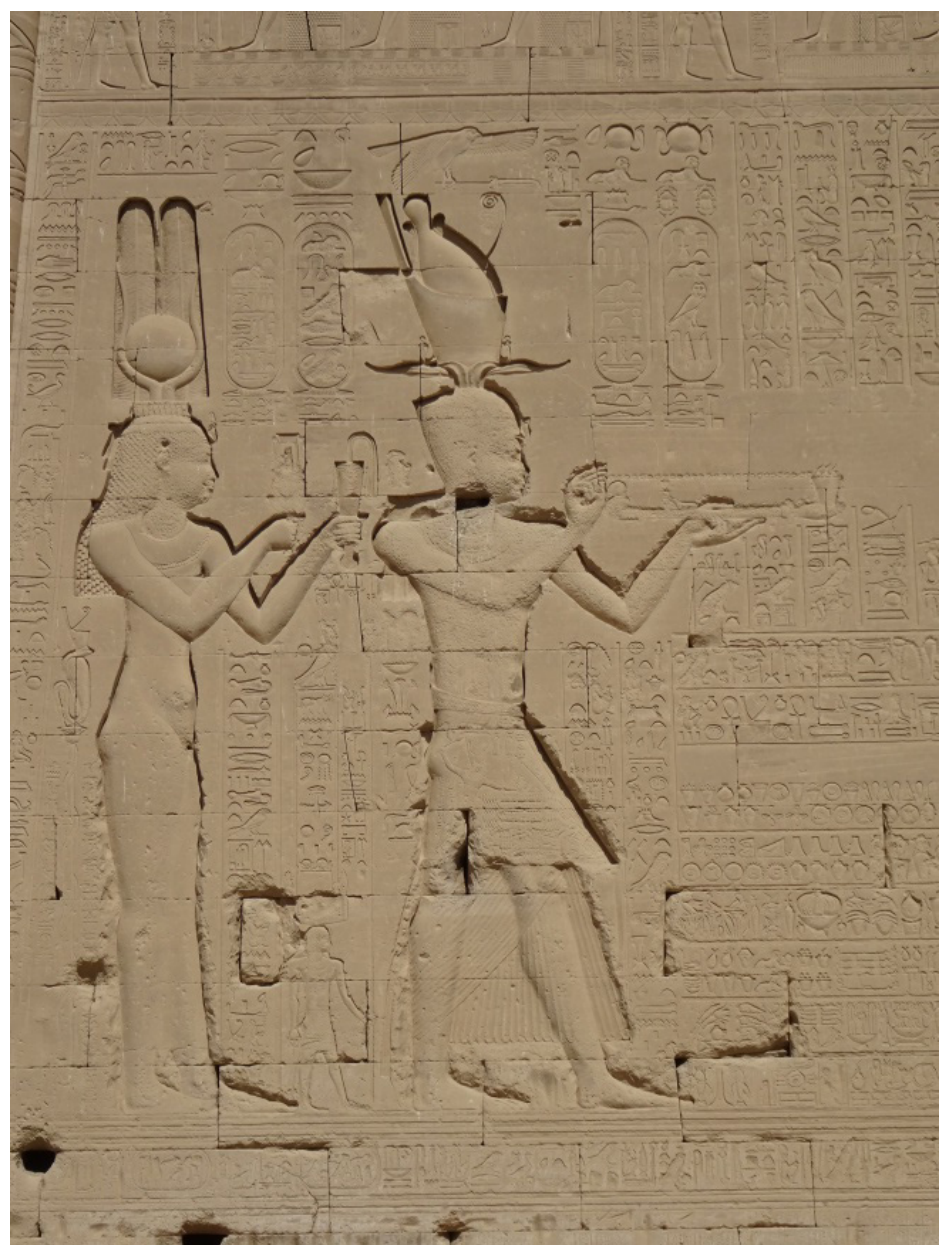

Fig. 4. Relieve de Cleopatra VII Filopátor y su hijo Cesarión en el templo de Hathor en Dendera. Fuente: fotografía del autor.

un templo dedicado a la diosa Hathor, diosa femenina con un profundo arraigo y poder en el Alto Egipto, Cleopatra aparece asimilada a dicha divinidad. Por eso adopta el tocado típico hathórico; compuesto por el disco solar con los dos cuernos de vaca; el sistro, instrumento típico del culto a esta diosa; y el collar menat. A su vez, Cesarión aparece representado con la corona del Alto y el Bajo Egipto y, debido a la asimilación de su madre 
con Hathor, este es también la encarnación de Horus, el legítimo heredero al trono de Osiris. Tampoco hay que olvidar que en este momento se había consumado ya el sincretismo religioso entre la diosa Hathor e Isis, siendo esta última todo un referente iconográfico y propagandístico para esta reina a lo largo de todo su reinado.

En definitiva, tenemos motivos para creer que la relación entre el clero egipcio y la casa real fue armoniosa y beneficiosa para ambos durante los casi tres siglos de dominación macedonia del país. Como hemos visto, los templos se beneficiaron de esta colaboración puesto que la economía egipcia en época ptolemaica desembocaba principalmente en dos polos de tesaurización: el rey y los templos. ${ }^{5}$ Los reyes lágidas otorgaron a los dioses grandes lotes de tierras y rentas durante todo este período, además de importantes sumas de dinero, destinado en muchas ocasiones a sufragar el recién instaurado culto divino a la dinastía. Es por esto que algunos autores consideran que el clero egipcio no fue el motor principal de las revueltas sociales que tuvieron lugar a partir del reinado de Ptolomeo IV Filopátor, sino que los templos fueron una víctima más y no se salvaron de los problemas que agitaban al país (Gorre, 2003, p.37).

No obstante, queremos terminar apuntando que, en conexión con las ideas de autores como G. Gorre (2003, p.25), el término «clero egipcio» abarca una categoría amplia y diversa, que varía según el rango y la naturaleza del sacerdocio y según las funciones que este pudiera llevar a cabo. Debido esta heterogeneidad, a la hora de desentrańar las posturas de los cleros de los distintos templos, tendríamos que atender a las particularidades de cada región, más aún si tenemos en cuenta el caso específico de la Tebaida en este momento. Finalmente, cabe recalcar que la labor de la interdisciplinariedad se presenta fundamental para que el investigador pueda seguir desentramando la historia de este período tan convulso de la historia de Egipto, a la luz de los nuevos hallazgos arqueológicos que, incesantemente, nos aportan nueva información proveniente de distintas fuentes egiptológicas.

5 Los grandes templos construidos en este período en el Alto Egipto, como podemos ver en Karnak, Dendera, Edfú o Kom Ombo dan buena muestra de la gran cantidad de recursos que tenía el clero indígena en este momento (Préaux, 1984, p.270). 


\section{Bibliografía}

Autores clásicos

Heródoto. Historia. Libro II. Traducción y notas de C. Schrader, 1992. Madrid: Gredos.

Polibio. Historias. Libros V-XV. Traducción y notas de M. Balasch Recort, 1981. Madrid: Gredos.

\section{Bibliografía contemporánea}

Arroyo de la Fuente, M. A., 2013. Cleopatra VII Filopátor y la legitimación del poder ptolemaico. Eikón / Imago, 2 (2), pp.69-106.

Blyth, E., 2006. Karnak: Evolution of a temple. Londres-Nueva York: Routledge. Chauveau, M., 1997. L'Egypte au temps de Cléopâtre. Paris: Hachette Littératures. Clarysse, W., 2000. Ptolémées et temples. En: D. Valbelle y J. Leclant, dir. Le Décret de Memphis. Actes du Colloque de la Fondation Singer-Polignac, Paris, $1^{e r}$ juin 1999. Paris: Diffusion De Boccard, pp.41-62.

Fabre, D., 2008. Dioses, diosas y realeza faraónica. En: F. Goddio, ed. Tesoros sumergidos de Egipto. Munich: Prestel, pp.99-145.

Finnestad, R. B., 2005. Temples of the Ptolemaic and Roman Periods: Ancient traditions in new contexts. En: B. E. Shafer, ed. Temples of Ancient Egypt. Cairo: The American University in Cairo Press, pp.185-237.

Gorre, G., 2009. Les relations du clergé égyptien et des Lagides d'après les sources privées. Lovaina: Peeters Publishers.

Gorre, G., 2003. Les relations du clergé égyptien et des Lagides d'après la documentation privée. Cahiers du Centre Gustave Glotz: Revue d'histoire ancienne, 14, pp.23-43.

Goudchaux, G. W., 2001. Cleopatra's subtle religious strategy. En: S. Walker y P. Higgs, eds. Cleopatra of Egypt: from history to the myth. Princenton: Princenton University Press, pp.128-141.

Pirenne, J., 1989. Historia del Antiguo Egipto. Volumen VI. Traducido del francés por Juan Maluquer de Motes. Barcelona: Océano.

Préaux, C., 1984. El mundo helenistico. Grecia y Oriente (323-146 a. C.). Volumen I. Traducido del francés por Juan Faci Lacasta. Barcelona: Editorial Labor.

Puyadas Rupérez, V., 2016. Cleopatra VII: La creación de una imagen. Zaragoza: Prensas de la Universidad de Zaragoza.

Rostovtzeff, M., 1967. Historia social y económica del mundo helenistico. Tomo I. Traducido del inglés por Francisco José Presedo Velo. Madrid: Espasa-Calpe. 
Shipley, G., 2001. El mundo griego después de Alejandro (323-30 a. C.). Traducido del inglés por Magdalena Chocano. Barcelona: Crítica.

Thompson, D. J., 1992. Egypt, 146-31 B.C. En: J. A. Crook, A. Lintott y E. Rawson, eds. The Cambridge Ancient History. Volumen VI, Cambridge: Cambridge University Press, pp.310-326.

Walbank, F. W., 2012. El mundo helenistico. Traducido del inglés por Francisco Javier Lomas. Madrid: Gredos.

Wilkinson, R. H., 2000. The Complete Temples of Ancient Egypt. Nueva York: Thames and Hudson.

Willems, H., 2000. Les empereurs du Nil. Lovaina: Peeters Publishers. 



\title{
LAS GUERRAS EN LA HISPANIA POSTNUMANTINA: ¿UN MEDIO DE PROMOCIÓN POLÍTICA?
}

\author{
Warfare after the Numantine War in Hispania: A \\ way to political promotion? \\ Simón Ruiz Charro ${ }^{1}$
}

Resumen: Tras las exitosas campañas de P. Cornelio Escipión Emiliano y D. Junio Bruto parecía que la situación militar en la península ibérica había quedado definitivamente resuelta y que, hasta la llegada de Q. Sertorio, los ejércitos provinciales de Roma solo tuvieron que emplearse en pequeñas escaramuzas que en absoluto pusieron en peligro su hegemonía en dicho territorio. Pero si ampliamos nuestra investigación a la esfera internacional de aquellas décadas, observaremos que Hispania fue un inmejorable punto de partida para la consolidación de una carrera política que demandaba gloria militar, ya que el contexto interno peninsular permitía una intervención que podía terminar en un triunfo.

Palabras clave: celtíberos, Hispania, lusitanos, Numancia, Sertorio, triunfo.

Abstract: After the successful campaigns of P. Cornelius Scipio Emilianus and D. Iunius Brutus it seemed that the military situation in the Iberian Peninsula had been definitively resolved and that, until the arrival of Q. Sertorius, the provincial armies of Rome only had to be employed in small skirmishes that in no way endangered its hegemony in that territory. Nevertheless, if we extend the research to the international sphere

1 Doctorando. Universidad de La Rioja. Correo electrónico: siruizc@unirioja.es. 
of those decades, we will observe that Hispania was an excellent starting point for the beginning of a political career that demanded military glory, since the peninsular context enabled an intervention that could end in a triumph.

Keywords: Celtiberians, Hispania, Lusitanians, Numantia, Sertorius, triumph.

Los cincuenta años que pasaron desde la conquista del indomable oppidum de Numancia hasta la llegada de Sertorio es una de las etapas más desconocidas y oscuras de la historia de la península ibérica. La brillante acción de Escipión Emiliano dio paso a un periodo en el que, aparentemente, Roma reafirmó su dominio en la península. ${ }^{1}$ Los años que transcurrieron entre 133 y $82^{2}$ se caracterizaron por los hechos ocurridos en la Vrbs, que desembocaron en la guerra civil entre los partidarios de Mario y los de Sila.

La conquista de la ciudad arévaca coincidió con la llegada al tribunado de la plebe de T. Sempronio Graco, un miembro de la nobilitas que, por cierto, había tenido un brillante pasado como cuestor en la Hispania Citerior (Plut. Ti.Grachh. 5-6). No entraremos a disertar acerca de la vida de uno de los personajes que más ríos de tinta han hecho correr en la historiografía romana, pero su actuación provocó un recrudecimiento de la lucha de facciones que llamó la atención de los escritores contemporáneos, alejados de los procesos históricos que acaecían en las provincias, especialmente en aquellas que supuestamente ya estaban bajo el yugo, a pesar de que, como veremos, en la práctica el dominio romano no era tan efectivo como podríamos esperar.

1 La historiografía tradicional da la conquista por finiquitada después de la caída de Numancia, a excepción de la conquista cantábrica. Tovar y Blázquez (1975, p.77) titulan "La Península sometida» a este capítulo de su obra sobre la Hispania romana. Richardson (1998, p.79) afirma que no hubo guerras de importancia. Curchin (1996, p.59) sostiene una "coexistencia pacífica de romanos y nativos». Solamente Roldán Hervás (1980, p.165) plantea que la dominación del territorio interior de la península por parte de Roma no fue efectiva.

2 Todas las fechas son a. C. 
Tras la guerra numantina llegó una comisión decenviral a la península, ${ }^{3}$ una medida que era habitual en los territorios que se incorporaban al territorio de la República como una provincia. No queda clara la misión principal de esta comisión, pero podemos intuir que entre sus funciones se encontraban el establecimiento de acuerdos con los oppida de la zona (tanto aliados como derrotados), la concreción del limes o las decisiones respecto al devenir de Numancia, que fue pasto de las llamas. Fueran cuales fuesen las acciones que dicha comisión tomara, daba la sensación de que la situación quedaba controlada y puede que así fuera durante unos años, en los que ninguna mención se hace en las fuentes clásicas sobre conflictos bélicos en la península ibérica. Solo podemos adivinar un interés constructivo en el nordeste peninsular, lo que puede estar muy relacionado con la actividad bélica desarrollada en la zona costera de la Galia transalpina, con la firme intención de unir por tierra las penínsulas itálica e ibérica. Los miliarios encontrados son la única manifestación que nos queda sobre los gobernadores romanos peninsulares en las primeras décadas del decenio que nos ocupa. ${ }^{4}$

En la década de 130-120 se había agravado el problema de la piratería, que tendrá como consecuencia la conquista de Baleares y su posterior incorporación a la Hispania Citerior. Roma había dado otro golpe sobre la mesa para afirmar su hegemonía sobre el mundo helenístico y esta vez se hizo sin necesitar a las legiones sobre el terreno. Atalo III, último monarca de Pérgamo, había dejado su reino en testamento a Roma (Livy. Per. 58). No debemos olvidar que hacía décadas que Macedonia y Grecia estaban bajo el yugo romano y solo resistían, aunque muy debilitados, los antiguos reinos de Egipto y Siria junto con una serie de recientes Estados helenísticos cuya supervivencia dependía de sus relaciones con Roma.

3 App. Hisp. 99. Salinas de Frías (1995, p.47) cree que dicha comisión habría puesto en marcha una lex provinciae para toda Hispania. Sin embargo, Pina Polo cree que, si bien esto no llegó a suceder, las medidas que impusieron los decenviros solo afectaron a los territorios anexionados (Pina Polo, 1997, p.97).

4 CIL, II, 4956; CIL, II, 4924 y CIL, II, 4925. Son miliarios fechados entre los años 124 y 114 de dos gobernadores de la Hispania Citerior llamados Mn. Sergio y Q. Fabio Labeón. Según Pina Polo (1993, p.94) hubo una política de urbanización y de construcción de carreteras desde el siglo II, ya que Roma era consciente de que la pacificación del territorio solo se lograría mediante una política urbana y un reforzamiento de las comunicaciones. 
Con la península ibérica recién organizada y África dominada tras la destrucción de Cartago, a los ambiciosos generales solo les quedaba mirar hacia las provincias occidentales para buscar los siguientes territorios donde encontrar enemigos que les dieran un triunfo. De este modo, una petición de la siempre fiel Massalia acerca del peligro de la piratería acabó afectando a las islas Baleares. La ciudad de origen focense alertó a Roma de la presencia de piratas cerca de sus territorios, lo que provocó una intervención que no solo se dio en la costa continental, sino que también afectó a Cerdeña (Morgan, 1969, p.222). El comandante que dirigió esa expedición, L. Aurelio Orestes, fue condecorado con el triunfo (Livy. Per. 60). Los piratas eran el nuevo casus belli que argumentarían los generales para intervenir y Baleares fue uno de los territorios afectados por ello.

Pudo haber una continuidad entre la piratería sarda y gala y la que se produciría en Baleares, pero es posible que las victoriosas campańas romanas en ambos lugares provocaran la huida de los enemigos de Roma al único lugar donde esta no extendía su influencia: el archipiélago balear, tal y como expone Zucca (1998, p.95). Junto a esta aparente razón, también deberíamos añadir otras, como podía ser el interés en la comunicación marítima entre las penínsulas itálica e ibérica mediante el paso por Córcega, Cerdeña y Baleares (Orfila, 2008, pp.17-18).

Según narran las fuentes clásicas la piratería aumentó en esos años en las islas, aunque no hay unanimidad en cuanto a la implicación de los nativos en las actividades piráticas. ${ }^{5}$ Sea como fuere, Roma decidió enviar a uno de los cónsules de 123, Q. Cecilio Metelo, a las islas para erradicar ese problema, algo que logró sin excesiva dificultad. Tras el éxito militar, se procedió a la fundación de dos ciudades, Palma y Pollentia, y a la llegada de tres mil romanos procedentes de Iberia, un epígrafe de Estrabón cuyo análisis no ha suscitado unanimidad entre los historiadores. ${ }^{6}$ Las islas con-

5 Str. III, 5, 1; Livy. Epit. I, 43. Estrabón defiende que los piratas actuaban sin la connivencia de la mayoría de los indígenas de Baleares, mientas que el epitomador de Livio alude a la colaboración de los isleños con los piratas.

6 Str. III, 5, 1. García Riaza y Sánchez León (2000, p.58) afirman que los tres mil romanos pudieron haber llegado en esos años, pero en su gran mayoría serían soldados que se instalarían en los pequeños acuartelamientos que se fundaron después de la conquista, 
quistadas fueron incorporadas a la Hispania Citerior. La carrera de Metelo, que desfiló como triumphator de Baleares, concluyó con el cargo de censor, para el que fue elegido en 120.

Es en el año 114 cuando tenemos la primera noticia bélica en las fuentes clásicas sobre la península ibérica desde la destrucción de $\mathrm{Nu}$ mancia. El protagonista es uno de los personajes que cambiará la historia de Roma. El gran C. Mario comenzó su carrera militar como pretor en la Hispania Ulterior, donde se enfrentó a los lusitanos. ${ }^{7}$ No se conoce que tuviera ningún triunfo ni reconocimiento por ello, pero sin duda este episodio bélico le sirvió para ganarse la confianza de Q. Cecilio Metelo, que le eligió como uno de sus legados en la guerra contra Yugurta, donde comenzó a ganarse la fama de gran militar. Su carrera posterior es ampliamente conocida.

Tras el pretorado de Mario, las fuentes clásicas nos siguen dando noticias sobre la Hispania Ulterior, lo que parece indicar que fue un decenio de gran actividad bélica. En 112, el gobernador romano en la provincia, L. Calpurnio Pisón, pierde la vida en la provincia (Cic. Verr. IV, 56). Al difunto Pisón le sustituye Sulpicio Galba (App. Hisp. 99).

La situación de hegemonía internacional que Roma disfrutó en la década anterior había cambiado completamente. Las guerras contra los pueblos itálicos y galos habían concluido, pero dos enemigos de gran calibre estaban amenazando la preeminente situación que Roma había conseguido durante el belicoso siglo II. En primer lugar, uno de los reyes más sagaces que compartían frontera con Roma había entrado en guerra contra la República por un conflicto dinástico. Yugurta, rey de Numidia y excompańero de armas de Escipión Emiliano en Numancia, mantenía una guerra contra Roma en su territorio que se alargaba demasiado para lo que la exitosa República estaba acostumbrada. En segundo lugar, la migración de una horda de germanos en busca de tierras más fértiles afectaba al territorio

entre ellos Palma y Pollentia. Mattingly (1983, p.245) también argumenta que las fundaciones de Palma y Pollentia era centros de acuartelamiento, pero los mencionados romanos arribaron tras la guerra sertoriana, momento en el que se produjo una reorganización de Hispania por parte de Metelo Pío.

7 Plut. Mar. 6. Plutarco deja claro que se trata de una campańa contra el bandidaje. 
gobernado por Roma, con lo que la ciudad italiana se tuvo que enfrentar a una numerosa horda de enemigos que impidió el refuerzo de tropas a otros frentes de guerra, como en aquel momento era la Hispania Ulterior.

Cuatro años más tarde, en 107, volvemos a tener noticias de los lusitanos, que esta vez son derrotados por un general que será condecorado, esta vez sí, con el triunfo. Q. Servilio Cepión, propretor de la Hispania Ulterior, derrotó a los lusitanos en una campaña de la que no sabemos nada más, pero le sirvió para obtener el máximo honor militar (Val. Max. VI, 9, 13). La influencia de una familia poderosa y patricia fue, sin duda, una de las razones para la obtención de un triunfo cuyas causas son completamente opacas. La actuación de Cepión en Hispania le llevó al consulado en el año siguiente, 106, desde donde partió a la Galia Narbonense para enfrentarse al enemigo del momento, los germanos, quienes se habían adentrado en la provincia romana debido a la ineficacia de los generales que hasta entonces se les habían enfrentado. Allí protagonizó uno de los desastres más famosos de la historia de Roma, cuando en el año 105, en Arausio, los ejércitos de Cepión y del cónsul C. Manlio Máximo fueron masacrados por los germanos. La historia no fue favorable para Cepión, pero si la batalla de Arausio hubiera tenido un distinto final, es muy probable que hubiera sido uno de los grandes referentes de los estudios históricos de su época, aunque su carrera militar empezó con una desconocida, pero efectiva campaña en la península ibérica.

Julio Obsecuente informa de que, en el año 105, un ejército romano fue derrotado por los lusitanos (Obseq. 42). La escueta información nos permite afirmar que la situación en la Hispania Ulterior seguía siendo crítica, aunque la gravedad de los hechos en la guerra contra los germanos impedía a la República proveer a los gobernadores de la Hispania Ulterior de los soldados que necesitaban. De hecho, la aparición de la tabula Alcantarensis (HEP, 1, 1989, 151), en la provincia de Cáceres, nos informa de la derrota de un oppidum lusitano por un gobernador llamado Lucio Cesio. En el epígrafe, de mucho valor informativo, se nos detalla las condiciones que este pueblo tuvo que firmar en su deditio, entre las que se encontraban la entrega de prisioneros y caballos para Roma y la vuelta al statu quo anterior a la intervención romana.

Hasta el momento no habíamos tenido noticias de la provincia $\mathrm{Ci}$ terior. Puede que la guerra de Numancia y los nuevos acuerdos que había 
firmado la comisión decenviral hubieran evitado nuevas tensiones, pero un enemigo asomaba en el horizonte. Los cimbros, pueblo germano que en su migración se había separado del teutón, se internaron en territorio hispano. La escasez de legiones romanas, diezmadas tras la reciente debacle en Arausio y el inicio de la revuelta de esclavos en Sicilia, hizo que fueran los celtíberos quienes derrotaran al ejército germano (Plut. Mar. 14, 1; Livy. Per. 67; App. Hisp. 99). Desconocemos el tamaño de las hordas germanas que penetraron en la península, pero resulta sorprendente que fueran los celtíberos, el tradicional enemigo de Roma en la península ibérica, quienes se enfrentaran y vencieran a los invasores. ${ }^{8}$ Es probable que los acuerdos a los que habría llegado la comisión decenviral con los hispanos hubieran provocado la actuación de los celtíberos a la hora de rechazar a los invasores, debido a los tratados de deditio entre Roma y los celtíberos (Ñaco del Hoyo, 2017, pp.21-22). Sea como fuere, no volvemos a recibir noticias de los germanos en la península, a lo que contribuyó la victoria de un general curtido en la Hispania Ulterior, C. Mario, quien derrotó a los germanos en las batallas de Aquae Sextiae y Vercellae, con lo que consiguió cercenar una de las mayores amenazas que tuvo la República desde Aníbal.

Dos años después de la marcha de los germanos, seguimos recibiendo noticias sobre los lusitanos. En el año 102, M. Mario, un familiar del cónsul de Arpino, funda una ciudad cerca de Colenda para recompensar a los auxiliares celtíberos que le habían ayudado en su lucha contra los lusitanos. ${ }^{9}$ Las intervenciones militares de los gobernadores romanos eran constantes. Tanto es así, que en el año 98 el gobernador L. Cornelio Dolabela celebró un triunfo por sus victorias contra los lusitanos $\left(C I L, \mathrm{II}^{2}, 1,177\right) .{ }^{10}$ No nos ha llegado más in-

8 No queda claro el nombre del comandante que se enfrentó a los germanos en Hispania. López Sánchez (2003, p.514) cree que se trató de M. Mario, aunque en una revisión posterior aclaró que fue Celio Caldo quien venció a los germanos en Hispania (López Sánchez, 2017, p.53).

9 App. Hisp. 100. La proporción de auxiliares y soldados romanos en Hispania estuvo siempre equilibrada (Cadiou, 2008, 114), pero en los años de la guerra címbrica es probable que la presencia de hispanos fuera aún mayor, debido a los problemas de reclutamiento que provocó este conflicto.

10 Según Sánchez Moreno (2017, p.62) la prolongada lucha de los lusitanos contra 
formación sobre la campaña ni tampoco acerca de la carrera política posterior de Dolabela.

Por razones que, una vez más, nos son desconocidas, en la década que transcurre entre los años 100 y 90 se dan cruentas campańas en ambas provincias hispanas, en un decenio en el que, eliminada la amenaza germana y reafirmada su hegemonía sobre el Mediterráneo, Roma carece de frentes de guerra en los que combatir. Los deseos de gloria de los grandes hombres de la República se ven satisfechos de nuevo en la península ibérica, territorio en teoría pacificado, pero que va a servir de nuevo para que los generales destinados allí inscriban su nombre en los Fasti triumphales.

El siguiente personaje que ha dejado rastro de su presencia en Hispania es C. Celio Caldo, homo novus muy relacionado con Mario, quien combatió en Hispania, según una moneda aparecida en época de su nieto, en la década de 60-50 (RRC, 437/2a). Sus acciones y enemigos en la península son completamente desconocidos, pero le sirvieron para alcanzar el consulado, que obtuvo en el ańo $94 .{ }^{11}$ De nuevo, podemos comprobar que, como en el caso anterior de Mario, Hispania volvía a servir como puente para el crecimiento político de personajes que no tenían una familia ni probablemente una fortuna que hiciera fácil su llegada a la magistratura de mayor rango del cursus honorum. La carrera de Caldo no acabó con su consulado, sino que desempeńó un proconsulado en las Galias entre los años 93 y 87 y ocupó los cargos de augur y XVvir sacris facundis. Fue una meritoria carrera de un hombre de antepasados totalmente desconocidos, que logró medrar en la política romana por su desempeño en la Hispania Citerior, entre otros méritos.

el poder de Roma se debió a una reacción a las incursiones que los generales romanos hacían por sus territorios, debido a la búsqueda de promoción y prestigio en el ejercicio de su imperium. La búsqueda de esa gloria fue la causa última de los graves y prolongados conflictos que tuvo Roma en este medio siglo en la península ibérica. Novillo (2010, p.211) también hace mención a la precariedad del dominio romano en Lusitania, algo que solo se solucionará hasta la llegada de César.

11 López Sánchez (2017, p.48) cree que Caldo lideró a las tropas hispanas en su guerra contra los germanos y que M. Mario también pudo haber contribuido en esa guerra. Sin embargo, Sánchez Moreno (2017, p.65) opina que Mario luchó exclusivamente contra los lusitanos. 
Como hemos visto, a pesar de la escasez de información de este conflicto en la Citerior que trató de resolver Caldo, una guerra abierta se había desencadenado en esta provincia, para la cual tuvo que acudir un cónsul para tratar de resolverla. Es el conflicto en el que más fuentes clásicas nos dan información de toda la época presertoriana, a pesar de que no tengamos ninguna mención en las fuentes históricas acerca de las razones de su comienzo. ${ }^{12}$ El hombre encargado de resolver este conflicto fue T. Didio, un experimentado general que había combatido contra los escordiscos en años anteriores y que además había sido recompensado con un triunfo. La carrera de Didio, otro homo novus que medró en esta época, no necesitaba ningún espaldarazo, con lo que su nombramiento como gobernador de la Citerior se pudo deber al estado crítico de las legiones en Hispania. El tiempo que estuvo en la provincia, entre cuatro y cinco ańos, nos hace entender que el conflicto fue duro y su alcance enorme, dados los diversos frentes en los que se combatió y las sangrientas medidas que el comandante adoptó. ${ }^{13}$ Apiano nos explica que Didio mandó matar a 20.000 arévacos, además de que trasladó al llano a los habitantes de Termessos y logró conquistar Colenda tras ocho meses de asedio. ${ }^{14}$ Pero la guerra incluso alcanzó el valle del Guadalquivir, donde uno de sus lugartenientes más destacados, Q. Sertorio, logró sofocar una revuelta antirromana en la ciudad de Castulo (Plu. Sert. 3). También tuvo Didio que destruir la ciudad fundada por M. Mario, en la que cometió una nueva masacre contra una serie de individuos que querían beneficiarse del reparto de tierras que iba a realizar el cónsul (App. Hisp. 100).

La guerra finalizó con la vuelta del general a Roma para la celebración de su segundo triunfo $\left(C I L, \mathrm{I}^{2}, 1,177\right)$, un logro enorme para un hombre que, como en el caso de Caldo y Mario, carecía de antepasados ilustres.

12 Sánchez Moreno (2017, p.65) aduce a un incumplimiento por parte de los romanos de las obligaciones que habían contraído con los celtíberos para conseguir su apoyo en la guerra contra los germanos en Hispania.

13 Evans (2005, p.10) afirma que Didio «appears to highlight a crisis, since he was the first consular proconsul here in over a decade»

14 App. Hisp. 99. La situación de Colenda es desconocida. Según López Sánchez (2010, p.177) se trata de la antigua Numancia, ya que dos campamentos numantinos son posteriores a 133. El oppidum arévaco se refundaría tras la quema de su territorio y la toma de la famosa ciudad por Didio es la razón que, según este historiador, justificaría su triunfo. 
La carrera de Didio no terminó ahí, ya que cuando estalló la guerra de los Aliados contra los aliados itálicos de Roma luchó y pereció en dicha contienda. De nuevo, podemos ver que en esta época las carreras políticas y militares de los homines novi no eran tan difíciles como en décadas anteriores, pero aun así los éxitos militares eran imprescindibles, ya que no podían contar con el respaldo de una familia poderosa.

Sin embargo, no solamente en la Citerior se desataron conflictos bélicos, sino que la Ulterior también necesitó la intervención de un cónsul, Publio Licinio Craso. En este caso se trató de un miembro de la nobilitas, elegido para la máxima magistratura en el año 97 . Estuvo en la provincia hasta 94, cuando regresó a Roma y celebró un triunfo días después que el que celebró Didio $\left(C I L, \mathrm{II}^{2}, 1,177\right)$. Las fuentes sobre este episodio bélico no detallan nada, únicamente nos han llegado anécdotas sobre su gobierno en la provincia, como la expedición que realizó a las islas Cassiterides (Str. III, 5, 11). Desconocemos por completo cualquier acción militar de Craso en Hispania y las razones por las que comenzó dicho episodio bélico. Tras su consulado en Hispania, continuó labrándose una carrera política muy destacada, puesto que combatió en la guerra social y fue elegido censor en el año 90. Su pertenencia al bando de Sila en la guerra civil que este mantuvo contra C. Mario provocó que se suicidara cuando los partidarios de este tomaron la ciudad en el año $87 . .^{15}$

A pesar de la escasa información que nos ha llegado de parte de las fuentes clásicas, podemos afirmar que la guerra que protagonizó Craso en Hispania no murió con él. Obsecuente relata que P. Cornelio Escipión Nasica, pretor de la Ulterior en el año 93, sofocó una revuelta en la que se tuvo que emplear con dureza, dado que tuvo que destruir sus ciudades (Obseq. 51). La intervención de Craso, por tanto, no fue definitiva. No tenemos noticias de Nasica y desconocemos por completo su carrera posterior.

El último general que combatió en la península antes de la llegada de Sertorio fue C. Valerio Flaco, cónsul del año 93. Ese año o el siguiente

15 Para Evans (2008, p.85) Mario ya estaba de vuelta en Roma en el año 97 y pudo haber aspirado al mando de la guerra contra los lusitanos, de modo que su enemistad contra Craso comenzaría por dicha razón. 
viajaría a la península a enfrentarse a la rebelión que se había producido en la ciudad de Belgeda, ${ }^{16}$ donde una parte del senado de la ciudad se había declarado antirromano. Apiano afirma que, del mismo modo que hizo Didio años antes, tuvo que recurrir a la represión como método de guerra, ya que mandó matar a veinte mil celtíberos (App. Hisp. 100). La llegada de un cónsul, con sus numerosas tropas, podría haberse dado por dos razones. En primer lugar, la campaña de Didio, a pesar del largo periodo que estuvo en la península, pudo haberse caracterizado por su ineficacia, puesto que estalló otra rebelión en cuanto este emprendió el camino de vuelta a Roma. En segundo lugar, esta llegada se pudo haber producido por el deseo expansionista de Roma en la cuenca del Duero. ${ }^{17}$ La carrera posterior de Flaco es una de las más desconocidas para un cónsul de la época, puesto que solo tenemos la noticia del triunfo que celebró en el año 81 sobre la Galia e Hispania (Cic. Quinct. 28). El hecho de que hayan pasado tantos años desde la guerra de Flaco hasta su triunfo es extrañísimo y solo puede responder a la situación de excepcionalidad que vivió la República romana poco después de la acción de Flaco, con una feroz escalada de la violencia provocada por la guerra de los Aliados y el enfrentamiento civil que enfrentó a los partidarios de Mario contra los de Sila.

Después de la guerra celtibérica, desconocemos totalmente a los gobernadores de las provincias hispanas hasta el nombramiento de Q. Sertorio como gobernador de la Citerior en el año 82. A pesar de que el sabino es el refugiado que más tiempo estuvo en la península y que protagonizó una de las guerras más exitosas de un rebelde contra Roma en una época saturada de ese tipo de conflictos, no es este el asunto que nos ocupa en el presente artículo. De hecho, la huida de Sertorio a Hispania no es la única que se produjo en estos años de sangrientas proscripciones, sino que hubo

16 No existe unanimidad entre los historiadores acerca de la situación de Belgeda. López Sánchez (2010, p.177) la sitúa en la antigua Segeda de Apiano, mientras que Martínez Caballero (2011, p.141) lo hace en territorios al oeste del Duero, de modo que la campańa de Flaco fue una guerra de conquista, del mismo modo que la de Didio.

17 Martínez Caballero (2011, p.120) cree que la guerra en la Hispania Citerior no fue defensiva ni respondió a provocaciones, sino que se trató de una "guerra de conquista» en la que Roma trató de anexionar nuevos espacios aún no dominados directamente. En base a acuñaciones de la época, argumenta que el dominio romano sobre los «territorios noroccidentales arévacos» solo se habría completado tras la campaña de Flaco. 
otros dos ilustres personajes que encontraron acomodo junto a personas que formaban parte de la clientela familiar. El primero de ellos fue M. Junio Bruto, un influyente personaje que se vio obligado a huir tras la entrada de Sila en Roma, dadas sus conexiones con los marianos, quienes le proveyeron de un ejército que se pasó al bando del futuro dictador. Esta circunstancia obligó a Bruto a buscar acomodo en Hispania (App. B Civ. I, 60). Después de la marcha de Sila a Oriente y la recuperación de la Vrbs por parte de Mario y L. Cornelio Cinna, Bruto regresó a Roma.

Con la ciudad en manos de los populares, esta vez eran los optimates quienes debían huir ante la ola de violencia que se desató sobre los enemigos políticos de los nuevos amos de Roma. Uno de los que tuvo que escapar fue el segundo caso que nos ocupa, M. Licinio Craso, el futuro triunviro, cuyo destino estaba claro. No hacía mucho que su padre, muerto en las proscripciones marianas (Plut. Crass. 4), había desempeñado su consulado en la Hispania Ulterior, así que dirigió sus miras hacia la península ibérica para tratar de encontrar acomodo a la espera de la vuelta de Sila a Italia. Plutarco nos cuenta en dos capítulos los problemas y las posteriores acciones de Craso en Hispania, en los que podemos comprobar la fidelidad de las clientelas provinciales, que en el caso de Craso le ayudaron a sobrevivir en un mundo dominado por la facción a la que no pertenecía (Plut. Crass. 4-6).

En el año 82 llega Q. Sertorio a la península, territorio que vuelve a gozar del protagonismo perdido en las fuentes clásicas debido a la guerra que se desató entre el rebelde sabino y las fuerzas de la República que le combatieron.

A modo de conclusión, hemos podido ver que los conflictos militares no cesaron tras la guerra de Numancia, lo que nos hace pensar que este periodo descrito tradicionalmente como pacificado no lo fue tanto. Sin embargo, sus razones no están tanto en la rebelión constante de los indígenas, sino en una búsqueda desesperada de la gloria militar por parte de los hombres que ostentaban la potestas publica que eran destinados a las provincias. Para sustentar esta hipótesis debemos incidir en que, tras la guerra de Numancia, las posibilidades de iniciar un nuevo conflicto que condujera a un triunfo a su comandante eran escasas. Hispania y África estaban totalmente pacificadas y sus limites ampliados, mientras que la zona oriental de influencia romana era un territorio que proyectaba una diferente situación. 
En el mismo año 133 moría Atalo III, último rey de Pérgamo, que había incluido en su testamento la donación de los territorios del reino a Roma. La ciudad-estado itálica reafirmaba su dominio sobre esa zona de manera abrumadora, en la que ya poseía la provincia de Macedonia y solo debía mantener a raya a Estados helenísticos muy debilitados, como eran Siria y Egipto. Sin embargo, es muy probable que siguieran siendo lugares muy apetecibles para los ambiciosos generales romanos que ansiaban un triunfo militar y, no menos importante, la adquisición de un botín de guerra que sería mucho más vasto que el que obtendrían en las provincias occidentales. Ante esta situación, nos debemos preguntar por qué en estas décadas las legiones romanas miraron hacia las provincias situadas al oeste de Roma.

La respuesta podemos hallarla en la enorme diversidad de enemigos que tenía Roma a lo largo y ancho del territorio que aspiraba a dominar. Al este de la península itálica, el territorio no controlado directamente por Roma comprendía una serie de reinos helenísticos que no solían mostrarse muy discordantes con las políticas de la República, lo cual hacía muy difícil encontrar un casus belli con el que comenzar un conflicto bélico en aquellos codiciados territorios. En el medio siglo que nos ocupa solamente se desencadenó el enfrentamiento contra Mitrídates VI del Ponto.

Por el contrario, la situación en las provincias occidentales era muy distinta. La amalgama de pueblos que habitaban cada territorio y las inestables relaciones que tenían entre ellas y hacia Roma daban más pretextos a los gobernadores provinciales para intervenir militarmente. Por esta razón Hispania era muy deseada por quienes aspiraban a ostentar el imperium en una provincia. Pero no se daba únicamente esta situación al sur de los Pirineos, sino que las legiones romanas también desenvainaron sus espadas en la Galia, una tierra de similares características. La guerra que comandó C. Domicio Enobarbo finalizó con la creación de la provincia de la Galia Narbonenense y la fundación de Narbo Martius, su capital, en 120. Enobarbo no fue el primer general que obtuvo la condecoración del triunfo sobre los diferentes pueblos galos, sino que, en la década de 130-120, otros generales que combatieron en ese territorio obtuvieron el privilegio de desfilar por las calles de la Ciudad Eterna con la corona de laurel encima de sus cabezas.

Con relación a esto último, podemos observar otra de las características que llama la atención de todo aquel que se acerca a estudiar la época 
presertoriana en Hispania: la cantidad de triunfos documentados en este medio siglo, un total de seis, en una provincia supuestamente pacificada tras las intervenciones militares de M. Junio Bruto y P. Cornelio Escipión Emiliano. Si los futuros gobernadores de los territorios bajo jurisdicción romana deseaban que les tocara una provincia del lado occidental del Mediterráneo se debía, entre otras razones, a esta circunstancia. De los seis triunfos que tenemos documentados sobre acciones militares protagonizadas en Hispania, solamente hay uno que sea sobre un territorio no dominado, el de Metelo por la conquista de las Baleares. El resto de triunfos que se celebraron sobre la provincia son sobre un territorio que ya había sido conquistado e incorporado.

Esta circunstancia, sin duda excepcional, se da por varias razones. Ante todo, debemos insistir que la falta de información que caracteriza a este periodo es, de nuevo, un gran inconveniente a la hora de extraer conclusiones, puesto que desconocemos el origen y la magnitud de las guerras, con la excepción de la protagonizada por T. Didio y por C. Valerio Flaco. En el caso de los triunfos que celebraron Cepión, Dolabela y Craso no tenemos información sobre el desempeño de los comandantes o la dificultad de estas guerras en un territorio conquistado. Cabe pensar que la exageración de la descripción de las batallas que hicieron los comandantes fue una de las razones para celebrar estos triunfos más que la dificultad de las mismas. Ya nos avisa Plutarco del tipo de enemigos a los que se enfrentó C. Mario, que estaban muy lejos de ser un ejército organizado. ${ }^{18}$ Hispania, al tener un territorio tan vasto y con tantos enemigos potenciales, algunos de renombrada fama a la hora de empuñar las armas, era un lugar idóneo para la búsqueda de un triunfo.

La época presertoriana es una de las épocas más desconocidas en la historia romana de Hispania. Las razones de este abandono son la escasez de información en las fuentes y la coincidencia con unos acontecimientos políticos que cambiaron para siempre a la República romana. Sin embargo, el medio siglo que nos ocupa fue protagonista de unos procesos históricos que modificaron la concepción de un territorio cuya historia se mezcló con la de Roma. 


\section{BIBLIOGRAFÍA}

\section{Autores clásicos}

Apiano. Historia romana. I. Traducción de A. Sancho Roy, 1980. Madrid: Gredos. Apiano. Historia romana. II. Traducción de A. Sancho Roy, 1980. Madrid: Gredos.

Estrabón. Geografía. Libros III-IV. Traducción de MJ. Meana Cubero y F. Piñero, 1992. Madrid: Gredos.

L. Anneo Floro. Epitome de la historia de Tito Livio. Traducción de G. Hinojo Andrés e I. Moreno Ferrero, 2000. Madrid: Gredos.

M. Tulio Cicerón. Discursos. III. Traducción de Jesús Aspa Cereza, 1991. Madrid: Gredos.

M. Tulio Cicerón. Discursos. Verrinas. Traducción de JM. Requejo Prieto, 2000. Madrid: Gredos.

Plutarco. Plutach's lives. X. Agis and Cleomenes, Tiberius and Gaius Gracchus, Philopoemen and Flamininus, 1921. Londres: Loeb Classical Library.

Plutarco. Vidas paralelas. IV: Arístides-Catón, Filopemén-Flaminino, Pirro-Mario. Traducción de A. Pérez Jiménez, 1985. Madrid: Gredos.

Plutarco. Vidas paralelas. V: Lisandro-Sila, Cimón-Lúculo, Nicias-Craso. Traducción de A. Pérez Jiménez, 1985. Madrid: Gredos.

Plutarco. Vidas paralelas. VI: Alejandro-César, Agesilao-Pompeyo, Sertorio-Éumenes. Traducción de A. Pérez Jiménez, 1985. Madrid: Gredos.

T. Livio. Periocas, Períocas de Oxirrinco, Fragmentos/Tito Livio. Libro de los prodigios/Julio Obsecuente. Traducción de JA. Villar Vidal, 1995. Madrid: Gredos.

Valerio Máximo. Hechos y dichos memorables. I. Traducción de S. López Moreda, 2003. Madrid: Gredos.

\section{Bibliografía contemporánea}

Cadiou, F., 2008. Hibera in terra miles. Les armées romaines et la conquête de l'Hispanie sous la République (218-45 av. J.-C.). Madrid: Casa de Velázquez.

CIL $=$ Corpus Inscriptionum Latinarum. Berlin, 1863.

Curchin, L.A., 1996. España romana. Conquista y asimilación. Leganés: Gredos.

Evans, R.J., 2005. Rome's Cimbric Wars and their impact on the Iberian Peninsula. Acta Classica, 48, pp.37-56.

Evans, R.J., 2008. Gaius and Marcus Marius in Iberia and Gaul: family affairs and provincial clients. Acta Classica, 51, pp.77-90. 
García Riaza, E. y Sánchez León, M.L., 2000. Roma y la municipalización de las Baleares. Palma: Universitat de les Illes Balears.

$H E P=$ Hispania Epigraphica. Alcalá de Henares, 1989.

López Sánchez, F., 2005. Moneda ibérica y hospitium. En C. Alfaro Asins, C.

Marcos Alonso y P. Otero Morán, coords. XIII Congreso Internacional de Nu-

mismática. Vol. 1. Madrid: Ministerio de Cultura. pp.511-516.

López Sánchez, F., 2010. Moneda ibérica y gens mariana (107-90 a.C.). Gladius, 30, pp.171-190.

López Sánchez, F., 2017. El triumphum ex Gallia de C. Coelius Caldus y la caballería hispana (101 a.C.). En: J. Principal, T. Naco del Hoyo, M. Durán y I. Mestres, coords. 2017. Roma en la península ibérica presertoriana. Escenarios de implantación militar provincial. Barcelona: Universitat de Barcelona. pp.39-59.

Martínez Caballero, S., 2011. La ciudad fundada por M. Marius, Termes y Colenda (App., Iber. 99-100). La guerra de 104-93 a.C. en territorios arévacos, vacceos y vettones. Studia historia. Historia antigua, 29, pp.119-151.

Mattingly, H.B., 1983. Roman Pollentia: Coinage and History. En A. Arribas, ed. 1963. Pollentia 3. Estudio de los materiales, I, Sa Portella, excavaciones $1957-$ 1963. Palma de Mallorca, pp.145-301.

Morgan, M.G., 1969. The Roman Conquest of the Balearic Isles. CSCA, 2, pp.217-231.

Novillo, M.A., 2010. La propretura cesariana en la Hispania Ulterior: "La II guerra lusitana”, Gerión, 28(1), pp.207-221.

Naaco del Hoyo, A., 2017. Conectividad, integración militar y "estrés bélico" en el N.E. de Hispania Citerior (c. 125-100). En: J. Principal, T. Naco del Hoyo, M. Durán y I. Mestres, coords. 2017. Roma en la península ibérica presertoriana. Escenarios de implantación militar provincial. Barcelona: Universitat de Barcelona. pp.17-38.

Orfila, M., 2008. La intervención de Q. Cecilio Metelo sobre las Baleares (123 a 121 a.C.). Condiciones previas y sus consecuencias. Pyrenae, 39(2), pp.7-45.

Pina Polo, F., 1993. ¿Existió una política romana de urbanización en el nordeste de la península ibérica? Habis, 24, pp.77-94.

Pina Polo, F., 1997. Las comisiones senatoriales para la reorganización de Hispania (App., Iber., 99-100) Dialogues d'histoire ancienne, 23(2), pp.83-104.

Pina Polo, F., 2003. ¿Por qué fue reclutada la turma Salluitana en Salduie? Gerión, 21(1), pp.197-204.

Richardson, J.S., 1998. Hispania y los romanos. Barcelona: Crítica.

Roldán Hervás, J.M., 1980. De Numancia a Sertorio. Problemas de la romanización de Hispania en la encrucijada de las guerras civiles. In VVAA. Studien zur antiken sozialgeschichte. Festschritf F. Vittinghoff. Colonia: Bölhau. pp.157-178. 
Salinas de Frías, M., 1995. El gobierno de las provincias hispanas durante la República romana (218-27 a.C.). Salamanca: Universidad de Salamanca.

Sánchez Moreno, E., 2017. Las guerras celtibérico-lusitanas (114-93 a.C.) y su dimensión geopolítica. En: J. Principal, T. Náaco del Hoyo, M. Durán y I. Mestres, coords. 2017. Roma en la peninsula ibérica presertoriana. Escenarios de implantación militar provincial. Barcelona: Universitat de Barcelona, pp.59-78.

Tovar, A. y Blázquez, J.M., 1975. Historia de la Hispania romana. Madrid: Alianza.

Zucca, R., 1998. Insulae Baliares: le isole Baleari sotto el dominio romano. Roma: Carocci Editore. 



\section{LA EXPOSICIÓN DE CADÁVERES EN LA ARQUEOLOGÍA CELTIBÉRICA: ¿UN ESPEJISMO HISTORIOGRÁFICO?}

\section{Corpses exposition to the vulturids on the celtiberian archaeology: a historiography mirror?}

Diego SuÁrez Martínez ${ }^{1}$

Resumen: Numerosos autores clásicos repararon en la práctica del ritual de la exposición de cadáveres a los buitres por parte de distintas poblaciones de la Hispania indoeuropea, principalmente entre los pueblos celtibéricos y vacceos. Este ritual funerario, también presente en multitud de pueblos a nivel global, significaría en el caso peninsular una suerte de recompensa a toda una vida marcada por el éthos agonístico. Arqueológicamente, se ha constatado su representación en distintos soportes vasculares y pétreos. En este trabajo se ofrece una reinterpretación del significado del ritual de la exposición de cadáveres a tenor de las fuentes con las que contamos para su estudio.

Palabras clave: Celtiberia, arqueología, ritualidad, mundo funerario, iconografía.

Abstract: A wide range of classical authors realized that different peoples of the Indo-European Hispania, especially the Celtiberian and Vaccean peoples, performed the ritual of the corpses' exposition to the vultures. This funerary ritual, which is also present in a lot of peoples worldwide, would

1 Estudiante de máster. Universidad Autónoma de Madrid. Correo electrónico: diego.suarezm@estudiante.uam.es. 
have meant in the peninsular case a sort of reward for the agonistic life of the individuals. Archaeologically, its representation has been acknowledged in different ceramic and petrean supports. In this paper we propose a reinterpretation of the meaning of the ritual of the corpses' exposition in the light of the sources at our disposition for its study.

Keywords: Celtiberia, archaeology, rituality, funeral, iconography.

Dentro de los estudios sobre el mundo celtibérico, uno de los campos de investigación que ha contado con más adeptos ha sido el de la religión y los ritos. En particular, aspectos tan llamativos para la mentalidad actual como el aquí tratado, la exposición de cadáveres a los buitres, han gozado de un gran interés tanto para el mundo científico como para el público más general. ${ }^{2}$ Este hecho no deja de ser sorprendente, máxime si nos atenemos a la escasa cantidad de fuentes con las que contamos para estudiar este tipo de actividades. Con el fin de entender el significado que pudo haber tenido este ritual, se han de comprender dos de sus aspectos fundamentales: la articulación guerrera de estas sociedades y su concepción del alma.

En primer lugar, de acuerdo con la información que las fuentes literarias transmiten sobre el éthos celtibérico — corroborada en parte por la arqueología - nos encontramos ante varios grupos poblacionales con una predisposición especial hacia la guerra. La guerra era entendida por estos pueblos, siempre según los autores grecorromanos, en un sentido ritual. Era la búsqueda del kalòs thánatos, la muerte bella, a partir de la cual se desarrollaron una serie de tópoi en la literatura romana como el de la feritas celtica (Ciprés, 1993, pp.89-90). Toda esta tramoya ideológica se escenificaba en el campo de batalla, en el que tenían lugar una serie de danzas y cantos previos a la batalla, y en el que primaba el combate individual por su alto carácter agonístico. Aunque, evidentemente, esta lectura se debe a una intención de desprestigiar al enemigo, el cual es mostrado como incapaz de combatir en orden y con disciplina, algo desmentido en los últimos

2 Algunas de las principales contribuciones al conocimiento del ritual de la exposición de cadáveres en el mundo celtibérico son Alfayé, 2009b y 2011; García Quintela, 1997; Marco, 2008; Sopeña y Ramón, 2002; Sopeña, 1995, 2004 y 2005. 
años (Ciprés, 1993 y 2002). Dentro de esta concepción agonística, no sorprende el relato de Floro, según el cual los numantinos recibieron la noticia de la entrega de sus armas como si les estuvieran amputando la mano (Flor. I, 34, 4), una práctica habitual en todo el Mediterráneo durante la Antigüedad (Gracia, 2015; 2017). Igualmente, en este arrojo militar se contextualizan las inutilizaciones de armas en distintas necrópolis del ámbito celtibérico, destacando especialmente Numancia (Jimeno y Chaín, 2017, p.165).

En segundo lugar, acerca de la concepción del alma para estas sociedades es poco lo que se sabe. Si en la exploración del mundo agonístico contamos con el respaldo de determinadas fuentes arqueológicas como las ya mencionadas piezas de armamento «matadas» ritualmente, no sucede lo mismo con este segundo aspecto, donde las fuentes escritas son el único acercamiento posible a la concepción del alma en las sociedades que los autores clásicos entendían como celtas. Es decir, del mundo religioso celtibérico, gran parte de la información con la que contamos es de autores grecolatinos que hablan acerca de otras sociedades entendidas antes, y ahora por gran parte de la Academia, como celtas. El alma para estos grupos poseía un carácter inmortal, superando el fallecimiento del cuerpo. En vez de producirse una metempsicosis en otro cuerpo, el alma viajaría a un Más Allá que en la mentalidad céltica podría estar situado allende del mar - lo cual podría relacionarse con la colocación de necrópolis en zonas inundables_-, bajo tierra, o en el mundo astral (Alfayé, 2011, pp.214-218).

Así pues, se entiende la exposición de cadáveres a los buitres en los ámbitos celtibérico y vacceo como una recompensa a toda una vida guerrera culminada por la muerte en el campo de batalla. El buitre en las sociedades célticas es el actor por excelencia en el ritual descarnatorio. Esto se debe a distintas facetas que convierten a este animal en predilecto. Por un lado, se trata de un animal salvaje, cualidad considerada divina para las sociedades de tradición céltica. No en vano, Cernunnos, una de sus deidades principales, es el protector principal de los animales salvajes (Green, 1992, p.233). Por otro lado, el vultúrido es un animal psicopompo, es decir, transmisor del alma. Por lo tanto, el buitre, animal divino, al deglutir el cuerpo sin vida del guerrero, está ingiriendo su alma y, posteriormente, al alzar el vuelo, la transporta al Más Allá astral mencionado líneas atrás. Siguiendo a Sopeña (1995, p.185), cabría definir la exposición de cadá- 
veres de manera genérica y sin entrar en los condicionantes propios del mundo celtibérico como el conjunto de rituales funerarios en los que se dispone el cadáver a cielo abierto con el fin de ser eliminado por acciones no antrópicas. Es un ritual descarnatorio dirigido a la limpieza ósea donde el trasfondo ideológico y no la acción en sí misma acapara la ritualidad y el protagonismo.

El ritual, al menos en su parte más denotativa y aséptica, está presente en multitud de culturas que desde la Prehistoria y hasta la actualidad han participado del mismo. En el ámbito mediterráneo, se ha logrado constatar arqueológicamente en espacios edificados ex professo para su práctica sobre las casas en el poblado de Çatal Huyuk (Mellaart, 1975, p.101). De igual manera, Gabriel Camps ha dado noticia de su práctica entre distintas tribus bereberes del Magreb desde el período Capsiense hasta el siglo XX (1961) y, quizás, un pasaje de Estrabón estaría haciendo alusión a su práctica entre los nabateos (XVI, 4, 26). Fuera del Mediterráneo, el ritual está presente entre tribus norteamericanas (Brown, 1981, p.31), aunque los pueblos de los que tenemos mayor información gracias a su cercanía temporal son los iranios y tibetanos, quienes practican la exposición en las conocidas como "torres del silencio». ${ }^{3}$ La mención de estos ejemplos se limita desde nuestro punto de vista únicamente a mostrar la variedad de grupos humanos que realizaron el ritual, sin que ello revista necesariamente ninguna otra similitud con el ritual celtibérico. Las diferencias habrían de ser abismales. Así, por ejemplo, se sabe que entre los grupos tibetanos se practica la exposición de cadáveres para facilitar la reencarnación del alma; mientras que, como se ha visto, las poblaciones célticas - y por extensión las celtibéricas - no creían en la reencarnación y sí en la inmortalidad del alma. Por último, merece la pena destacar la lectura de Carcedo y Pradales (2013) sobre la exposición de cadáveres en los grandes ciclos narrativos del norte de Europa, y concretamente en la literatura épica insular.

No pretende ser el objetivo de este trabajo pormenorizar cada una de las fuentes literarias que dan noticia de la realización de este ritual entre poblaciones celtibéricas. No obstante, a fin de facilitar la comprensión de

3 En Sopeña, 1995, passim se puede encontrar una larga lista de pueblos que han practicado este ritual. 
este trabajo procedemos a enumerar algunas de las fuentes clásicas existentes. Comenzando por territorio vacceo, Claudio Eliano ofrece una cita que no deja lugar a dudas:

«Los vacceos ultrajan a los cadáveres de los muertos por enfermedad, ya que consideran que han muerto cobarde y afeminadamente, y los entregan al fuego; pero a los que han perdido la vida en la guerra, los consideran nobles, valientes y dotados de valor $\mathrm{y}$, en consecuencia, los entregan a los buitres porque creen que éstos son animales sagrados.» (Ael. NA. X, 22). ${ }^{4}$

Si bien es cierto que Sopeña y Ramón (2002) han argumentado a favor de una lectura paralela en la que Eliano se estaría refiriendo a los arévacos y no a los vacceos, el interés de este fragmento para nuestro trabajo reside en la distinción cualitativa existente entre los muertos en combate y los que han muerto "cobarde y afeminadamente». Este discurso de alteridad entre valientes y cobardes se encuentra repetido en la obra de Silio Itálico: «Sucumbir en combate es para ellos un honor, pero consideran un crimen incinerar el cadáver de un guerrero así abatido. Creen que irán junto a los dioses en el cielo si los buitres hambrientos despedazan su cuerpo tendido.» (Sil. Pun. III, 340-343). ${ }^{5}$ En ambos autores se observa la misma lectura de alteridad ya comentada y que sirve para identificar a los celtíberos como un pueblo guerrero cuya mentalidad y acciones están encaminadas en su conjunto hacia la guerra. Es precisamente el propio Silio Itálico quien ofrece una tercera mención clara al ritual de la exposición de cadáveres de nuevo en su obra Punica. El de Campania pone en boca de Escipión las siguientes palabras:

«Oh, tú, el más noble descendiente del viejo Clauso, ninguna de mis preocupaciones (y no son pocas las que me apremian) podría superar a la tuya. En efecto, en todos los pueblos se observan diferentes costumbres de este ritual y es diversa y variada la opinión acerca de enterrar e incinerar los restos de los difuntos. Según cuentan, es costumbre inveterada en el país ibero que los repugnantes buitres devoren los cadáveres.» (Sil. Pun. XIII, 466-487). ${ }^{6}$

4 Trad. Díaz-Regañón.

5 Trad. Villalba Âlvarez.

6 Trad. Villalba Álvarez. 
Al margen de estas tres menciones de dos autores distintos, no hay otras referencias clásicas que avalen la práctica de la exposición de cadáveres a los buitres entre los celtíberos. Existen otros pasajes de Orosio (V, 7, 15-16) y Livio (XXXIX, 21, 6-8) en los que se ha querido ver una mención al ritual, pero no existe consenso al respecto (Alfayé, 2009b, p.121).

En parte debido a esta relativa escasez de información textual sobre el ritual, ${ }^{7}$ resulta más que necesario buscar indicios arqueológicos que demuestren su existencia. Iconográficamente, existen cuatro fragmentos de cerámica figurada y otras tantas estelas en las que posiblemente se haya representado este ritual. La primera de estas pruebas es la única que ha logrado crear consenso en lo que a su significado se refiere. Hacemos alusión a los dos fragmentos de una misma cerámica numantina datada recientemente, al igual que el resto de cerámica figurada numantina, en el siglo II a. C. (Liceras et al., 2012, pp.231-232) (Fig.1). La representación de aves carroñeras abalanzándose sobre el cuerpo de un guerrero sin vida que todavía esgrime su espada es clara. Sobre la escena principal de uno de estos fragmentos aparece un motivo curvo incompleto que podría estar representando el allende astral, lo cual sería lógico en base a la interpretación del ritual ya explicada líneas atrás (Sopeña, 1995, pp.221-223; Marco, 2008, pp.61-62).

Sin embargo, al margen de estos dos fragmentos numantinos, el resto de las imágenes han ofrecido lecturas dispares y en ocasiones incluso contrarias. Es ilustrativo el caso de la cerámica conocida comúnmente como «el cagón de Tiermes», hallada en la necrópolis de Tiermes y datada en el siglo I d. C. (Fig. 2). De acuerdo con Sopeña, en el centro de la imagen se situaría un guerrero herido de muerte que estaría siendo acechado por dos córvidos situados a ambos lados del individuo (1995, pp.241-243). Sin embargo, el individuo no porta armas ni ningún elemento distintivo de su estatus guerrero. Por el contrario, Alfayé analiza la imagen como una representación de una escena tan mundana y costumbrista como la de

7 En comparación con otras prácticas rituales, que haya una sobrerrepresentación de la exposición de cadáveres a los buitres no excluye, a nuestro juicio, la evidente escasez de pruebas con las que contamos sobre este ritual: cinco fuentes literarias de las cuales solo tres son claras y ocho elementos iconográficos de los que, como veremos, solo uno de ellos ha creado consenso entre los especialistas. 
un individuo defecando en un escenario campestre (Alfayé, 2009a, p.272; Alfayé, 2009b, p.119). Un tercer intento de descifrar el significado de esta pieza es el que ofrece García Quintela, para quien estaríamos presenciando un ajusticiamiento de tipo prometeico (1997). Esta última explicación implicaría una serie de connotaciones de marcada tradición foránea y de difícil demostración. Con la enumeración de las distintas explicaciones que se han ofrecido sobre el significado de una misma pieza pretendemos mostrar la dificultad de admitir esta pieza como una prueba fehaciente de la práctica del ritual expositorio en el mundo celtibérico.

En el territorio de Uxama apareció un vaso, hoy expuesto en el Museo Arqueológico Nacional, que ha sido datado en el siglo I d. C. En la cerámica aparecen representadas varias aves junto a un número igual de cabezas humanas insertas en lo que parecen ser cofres con alas (Fig. 3). Distintos autores han puesto este vaso en relación con la práctica del ritual expositorio. Según Martínez Quirce, se habría representado la deglución de un caído en combate ya en estado avanzado (1992, pp.169-170). De acuerdo con esta interpretación, las aves, que serían carroñeras, estarían portando en su vientre -identificado con las formas rectangulares y aladas - el alma de los guerreros caídos en combate, presentes en esta cerámica a través de las cabezas humanas. Una lectura en cierta forma similar a la anterior es la ofrecida por Alfayé, para quien se habría representado una metáfora del guerrero ascendiendo al allende astral (2009a, pp.375-378). Como se puede observar, ninguna de las posibilidades escapa a la controversia inherente a la identificación del arte narrativo celtibérico, lo cual no tiene por qué dar lugar necesariamente a una negación tajante de estas teorías, sino a una lectura cautelosa de las mismas.

Un último ejemplo de cerámica figurada en el que se ha pretendido leer la representación del ritual expositorio se encuentra en el yacimiento de Pintia, situado en territorio propiamente vacceo (Marco, 2008, p.62). Por lo tanto, si aceptamos la lectura del fragmento de Claudio Eliano citado anteriormente como "vacceos» y no "arévacos», estaríamos ante la segunda de las evidencias que podrían demostrar la práctica de este ritual entre poblaciones vacceas. Esta jarra ha sido datada en el siglo I d. C. y en ella se pueden observar distintas aves rodeadas de elementos astrales de difícil adscripción para nuestros parámetros actuales y en base al conocimiento del arte de estas poblaciones que atesoramos hasta el momento (Fig. 4). 
Marco (2008, p.62), entre otros, ha puesto en relación la aparición de elementos astrales y aves en una misma cerámica para señalar que se estaría representando el alma de los guerreros — identificados en las aves - ascendiendo al allende astral — significado en los distintos motivos astrales-.

Como se ha podido observar en líneas anteriores, a excepción de los ejemplos numantinos, el resto de los elementos cerámicos ofrecen una identificación excesivamente esquiva que en unas ocasiones ha dado lugar a interpretaciones de sorprendente disparidad entre ellas y, en otras ocasiones, a lecturas de gran controversia y compleja aceptación. En los soportes pétreos que enumeramos a continuación se mantiene su difícil aceptación, a lo cual se suma la falta de dataciones precisas de estas estelas, problema presente, por otro lado, en la gran mayoría de las estelas protohistóricas de la Península Ibérica.

En soportes pétreos se han reconocido hasta cinco estelas en las que pudiera haberse escenificado la exposición de cadáveres a los buitres. La primera de estas estelas es la de Zurita (Sopeña, 1995, p.240), en la actual Cantabria y en el antiguo solar cántabro, no celtibérico si asumimos la existencia de una frontera cultural claramente marcada entre ambas identidades. Es una estela discoidea de dos metros de diámetro datada entre los siglos II y I a. C. y grabada en sus dos caras (Fig. 5). En una de ellas aparecen distintos motivos geométricos identificados como astrales y enmarcados en círculos concéntricos. En su otra cara aparecen dos escenas separadas por una gruesa línea. En la escena principal se observa un caballo con jinete frente a dos guerreros armados con escudo y espada y ataviados con lo que parece ser la piel de algún animal de difícil identificación. En el margen inferior de esta cara se encuentra la posible exposición de cadáveres. Se observa un guerrero ataviado con escudo y en posición retorcida junto a un ave que podría caracterizarse como un vultúrido gracias a la forma de su pico.

En la zona de Lara de los Infantes, en la actual provincia de Burgos, aparecieron dos estelas en las que también se ha supuesto la representación de la exposición de cadáveres de guerreros caídos en combate a las aves gracias a la identificación de un ave carrońera en la primera de estas estelas y de un grifo en la segunda, abalanzándose ambos sobre un cadáver yacente en la tierra (Marco, 1978, pp.52-54) (Fig. 6). Ambas, sin contexto arqueológico claro, han sido datadas en fechas tardías, a partir del siglo I 
d. C. En la primera de las estelas, de la escena de la deglución del cadáver propiamente dicha solo se conservan los miembros inferiores y alas del ave identificada como un buitre. Mientras que, en la segunda, ocupa una posición central la imagen del grifo dirigiéndose contra un individuo de mayor tamaño que la bestia.

En El Palao, Teruel, apareció una losa que, de nuevo, carece de contexto estratigráfico, y que ha sido datada por paralelos entre los siglos II y I a. C. (Sopeña, 1995, p.243). Su rica iconografía es de gran interés y suscita multitud de lecturas, como la evidente desproporción existente entre la mano extendida que aparece en el margen superior izquierdo y el resto de las figuras, llegando incluso a superar en tamaño al jinete con brazos extendidos galopando sobre un caballo (Fig. 7). Precisamente el jinete es una de las figuras de mayor importancia para asumir la representación del ritual expositorio en esta pieza pues, presumiblemente, con su lanza y escudo habría dado muerte al infante caído. Rodeando al infante en clara posición de derrota y humillación, aparecen dos aves identificadas como buitres que estarían procediendo al consumo del cadáver. Sin embargo, no se debe desatender la presencia de dos animales terrestres carrońeros que, de igual manera, están rodeando al infante vencido, posiblemente dispuestos a participar de su descarnación. Esto confronta directamente con la tramoya ideológica celtibérica ya expuesta líneas atrás, según la cual el alma solo accede al allende a través de su deglución por parte de un buitre.

Por último, la estela de Binéfar (Fig. 8), hallada en el término municipal de Vispesa, en Huesca, es el quinto elemento pétreo en el que posiblemente se haya representado la exposición de cadáveres (Sopeña, 2005, p.226). Como se observa en la imagen, se trata de una estela enmarcada por distintos signos ibéricos hallada fuera de contexto arqueológico y datada entre los siglos II y I a. C. En una de sus caras laterales aparecen manos cortadas al igual que en la estela de El Palao; mientras que en su lateral y junto a otra sucesión de palmas de manos se observa lo que parece ser un monstruo alado devorando el cadáver de un guerrero ataviado con escudo y lanza.

Con esta enumeración hemos presentado todas las fuentes existentes y que han servido para defender en mayor o menor medida la práctica de este ritual a través de la iconografía. Igualmente, se ha pretendido demostrar su existencia a través del estudio de los lugares en los que previsiblemente se 
realizaría la exposición de cadáveres. Siguiendo fundamentalmente a Orosio y Livio, se ha defendido su posible práctica directamente en el campo de batalla, sin la necesidad de construcción alguna. Sin embargo, esta explicación ha de ser tomada con cautela, pues, tal y como hemos observado en la estela de El Palao, la deglución del cadáver por parte de distintas alimañas terrestres impediría la vehiculación del alma hacia el allende astral a través del vultúrido. En parte debido a este razonamiento, se ha propuesto la existencia de distintas estructuras sobre las que se colocaría el cadáver para evitar su consumo por parte de bestias no deseadas. Se ha teorizado acerca de distintas plataformas en materiales perecederos, algo imposible de demostrar debido a la inexistencia de fuentes documentales que atestigüen su presencia y la desaparición de su huella arqueológica.

El planteamiento que más adeptos ha granjeado entre los especialistas y en las explicaciones dirigidas a públicos más amplios es la construcción de torres circulares en piedra en cuya cima se depositaría el cadáver (Sopeña, 1995; Jimeno et al., 2004). Se han identificado como supuestas torres de exposición distintos enlosados circulares de Numancia, de Montecillo-Dulla en Burgos y de los castros de El Arenal y Zaranzano en Soria (Sopeña, 2004, p.76). ${ }^{8}$ El enlosado circular mejor conocido es uno de los trece hallados junto a la necrópolis de Numancia, identificado ya por Taracena como lugar de exposición de cadáveres (apud Sopeña, 1995). Su vecindad a la necrópolis podría sugerir a priori su relación con el mundo funerario y ritual. Frente a esta hipótesis se plantean dos grandes caveats. El primero de ellos es la aparición de cerámicas rojas y carbones bajo las piedras del enlosado (Jimeno et al., 2004, p.37), imposibilitando que estos encachados circulares sean celtibéricos. Este dato per se anularía la hipótesis planteada por Taracena y seguida hasta fechas recientes, a lo cual se añade un segundo aspecto. En ninguna de las referencias clásicas que aquí apenas hemos esbozado ni en ninguna fuente iconográfica de las aquí presentadas aparecen los cadáveres sobre torres circulares. Es decir, la interpretación de la exposición de cadáveres a las aves en el mundo celtibérico sobre torres pétreas circulares se ha producido a partir del comparativismo religioso

8 Debido al ámbito geográfico en el que hemos centrado este trabajo, excluimos de su estudio otras supuestas torres de exposición como las de la necrópolis de Pintia, en territorio vacceo. 
con otras culturas mejor conocidas en las que sí está constatada la práctica de este ritual sobre dichas torres. Nos referimos a las ya mencionadas poblaciones iranias y tibetanas, con las particulares torres del silencio de los primeros. No obstante, otros de los ejemplos aquí presentados como los altares sobre las casas de Çatal Huyuk distan mucho de seguir este modelo que, por razones difíciles de desencriptar, se ha impuesto en el estudio de la religión y ritos celtibéricos.

A modo de conclusión, consideramos necesario reunir de nuevo las fuentes arqueológicas en las que la literatura científica se ha apoyado para defender la existencia de la exposición de cadáveres en el mundo celtibérico. Cuantitativamente, nos encontramos ante un total de ocho fuentes entre cerámica figurada y estelas de piedra. De este conjunto, solo una, como hemos comprobado, no presenta problemas de lectura; mientras tanto, del resto de materiales solo seis aparecieron en territorio de la Celtiberia histórica, aunque sus problemas de lectura e interpretación son abundantes. Así pues, se observa que uno de los pilares básicos en los que se ha apoyado la tradición historiográfica para remarcar el complejo éthos agonístico que los autores grecolatinos asimilaban a los celtíberos es de difícil comprobación documental. Esta escasez de fuentes acerca de la exposición de cadáveres a los buitres en el mundo celtibérico ha dado lugar al comparativismo religioso con otros pueblos que tradicionalmente se han visto como parte integrante de un mismo complejo cultural llamado celta. A su vez, este comparativismo religioso también ha llevado a entender que el ritual se practicaría sobre torres circulares. Esto, como se ha visto, es una extrapolación directa de la práctica del rito en las poblaciones iranias, mejor conocidas documentalmente. Sin embargo, no hay ningún indicio que permita pensar acerca de la existencia de dichas torres en suelo celtibérico.

Habida cuenta del catálogo de fuentes documentales acerca de la exposición de cadáveres a los buitres en el mundo celtibérico, consideramos igualmente difíciles de abordar tanto la aceptación de su práctica como su negación. Sin embargo, estimamos plausible la reflexión acerca de su significación para las sociedades del contexto en el que supuestamente habría tenido lugar este ritual. Todas las fuentes aquí presentadas comparten un marco cronológico bastante homogéneo y que entronca directamente con un evento de trascendencia insondable para estas poblaciones: la presencia romana en suelo celtibérico. Pese a la falta de contextos arqueológicos ri- 
gurosos para las estelas de piedra expuestas, podemos inscribir todas estas piezas entre el siglo II a. C. y el I d. C. La representación de la exposición de cadáveres, hubiese tenido lugar o no, se produjo en un contexto de gran agitación tanto en el conjunto de la sociedad como en los sectores poblacionales privilegiados, viéndose estos últimos afectados particularmente. Por esto, consideramos probable que la representación del ritual, más allá de su veracidad o no, estaría encerrando un discurso de poder aristocrático. Es decir, cada una de las supuestas representaciones de la exposición de cadáveres de las que se tiene noticia no estaría recreando una escena histórica que hubiese tenido lugar, sino que nos encontramos ante una forma de legitimación de las aristocracias celtibéricas — sean nuevas o las tradicionales-, las cuales necesitan nuevos códigos de autorrepresentación hacia el resto de la sociedad debido a los enormes cambios que se habrían producido en la zona. Indefectiblemente, estas elites necesitarían de nuevos discursos que sustentaran ideológicamente su posición social. La representación de la exposición de cadáveres sería una de estas nuevas formas de legitimación del héroe honrado con el ascenso al allende astral.

Por lo tanto, habría que incluir la representación de la exposición de cadáveres a los buitres como parte de un proyecto iconográfico más ambicioso y que incluye otras formas de autorrepresentación que comienzan ahora a gestarse en el solar celtibérico, como el combate singular (García Cardiel, 2012). García Cardiel en su tesis doctoral, publicada en el año 2016, expuso los fundamentos de los discursos de poder que se dan en el mundo ibérico atendiendo a los cambios que se producen en la representación del poder. Son fundamentales sus aportaciones a la evolución de la iconografía en el horizonte de expansión romana para comprender cómo las elites, en caso de necesidad de reforzar su legitimidad, generan nuevos códigos de autorrepresentación. En el ejemplo ibérico, se observa en la iconografía vascular (García Cardiel, 2014; 2016) cómo surgen estas nuevas formas de representación del poder que tratan de vehicular una nueva legitimación en un contexto de cambios profundos como es el de la expansión romana. Es éste el modelo que se debería observar y poner en relación con la iconografía tratada en este trabajo, donde se ha pretendido mostrar el surgimiento de un nuevo motivo iconográfico, la exposición de cadáveres a los buitres, en un contexto de gran agitación social. Las lecturas que en este sentido se pueden hacer de la representación de la exposición de cadáveres son múltiples y abren líneas de investigación no tratadas anteriormente. 


\section{ILUSTRACIONES}
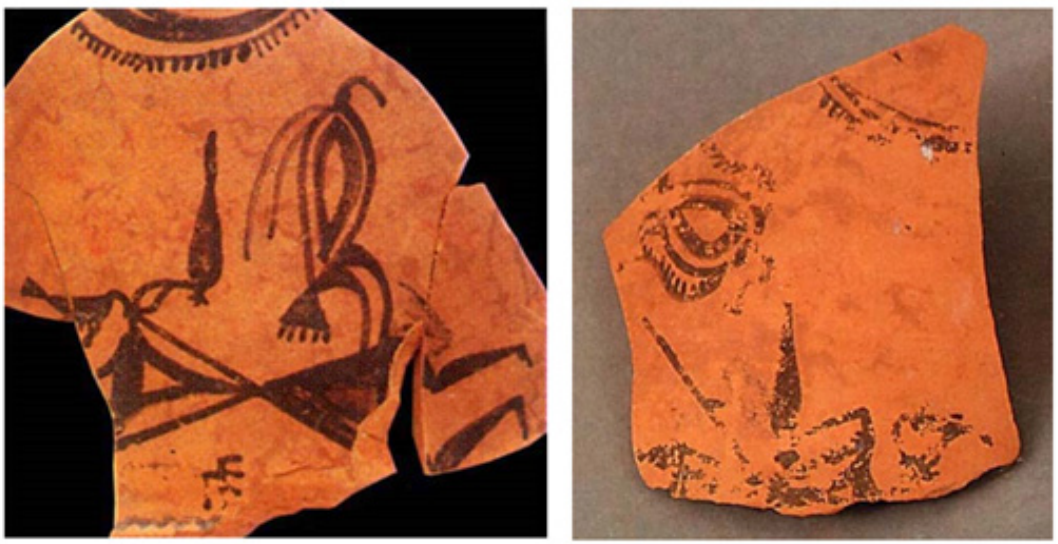

Figura 1. Sopeña, 2005, p.381. Fotografía A. Plaza

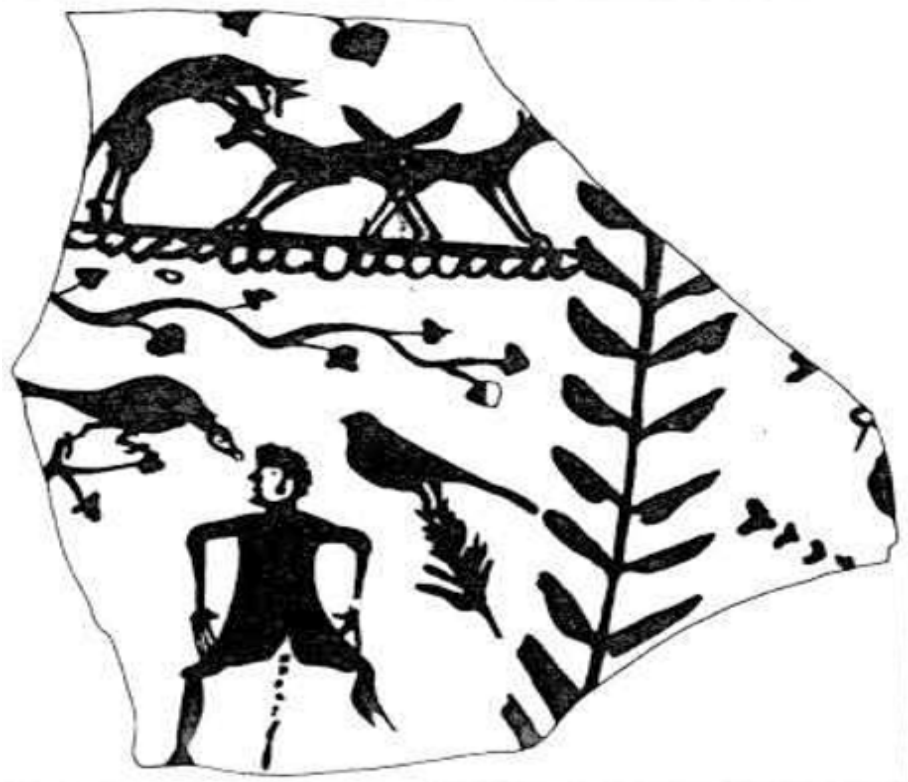

Figura 2. García Quintela, 1997, p.104 


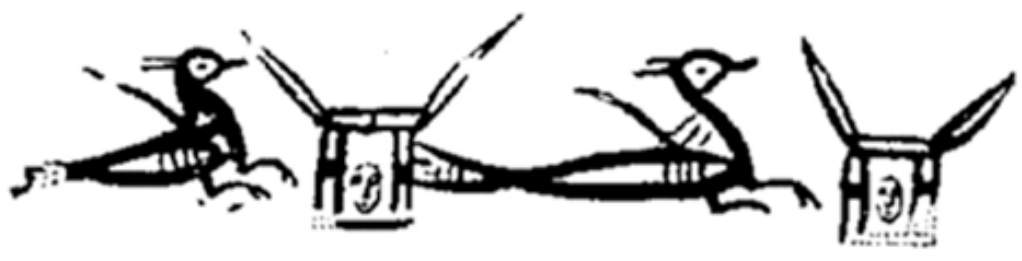

Figura 3. Alfayé, 2009b, p.119

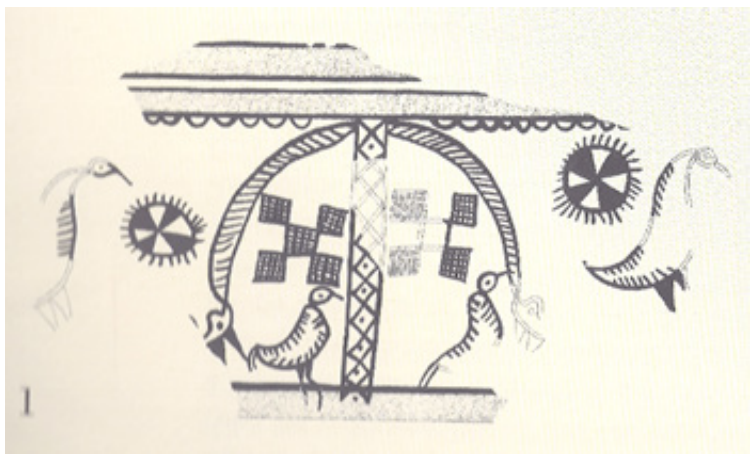

Figura 4. Sanz y Velasco, 2003, p.193

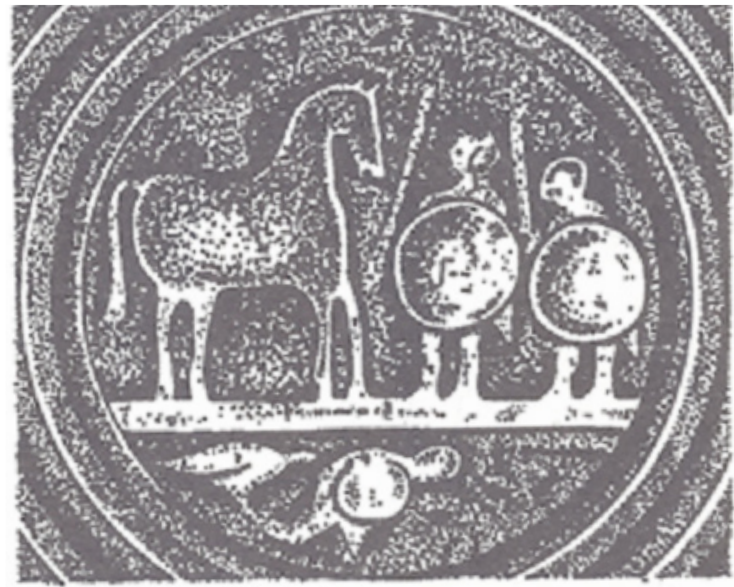

Figura 5. Sopeńa, 1995, p.305 


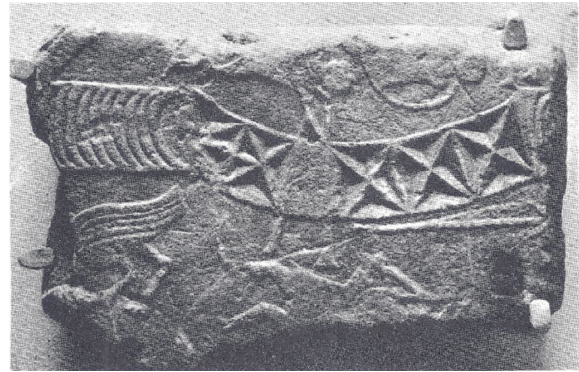

Figura 6. Abásolo, 1974, lám. LXVII, 1

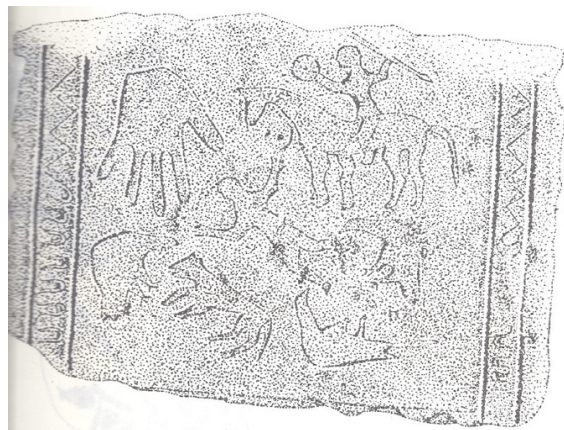

Figura 7. Desarrollo de la estela de El Palao según Marco y Baldellou (Sopeńa, 1995, p.305)

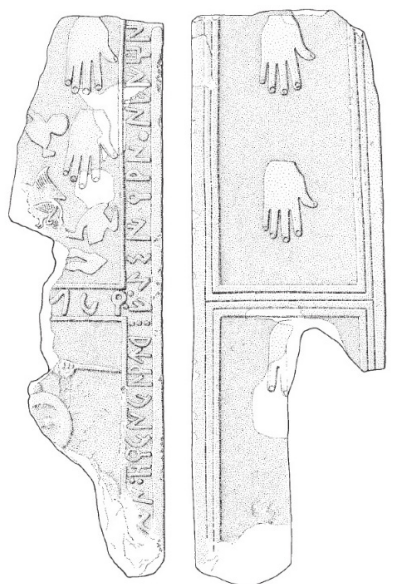

Figura 8. Dibujo de R. Álvarez (Garcés, 2007, p.341) 


\section{Bibliografía}

Autores clásicos

Claudio Eliano. Historia de los Animales. Traducción de J.M. Díaz-Regañón López, 1984. Madrid: Biblioteca Clásica Gredos.

Estrabón. Geografía. Traducción de J. L. García Alonso, M. P. de Hoz García-Bellido y S. Torallas Tovar, 2015. Madrid: Biblioteca Clásica Gredos.

Floro. Epitome de la Historia de Tito Livio. Traducción de G. Hinojo Andrés e I. Moreno Ferrero, 2000. Madrid: Biblioteca Clásica Gredos.

Orosio. Historias. Traducción de E. Sánchez Salor, 1982. Madrid: Biblioteca Clásica Gredos.

Silio Itálico. La Guerra Púnica. Traducción de J. Villalba Álvarez, 2005. Madrid: Akal.

Tito Livio. Historia de Roma desde su fundación. Traducción de J. A. Villar Vidal, 1993. Madrid: Biblioteca Clásica Gredos.

\section{Bibliografía contemporánea}

Abásolo, J. A., 1974. Epigrafía romana de la región de Lara de los Infantes. Burgos: Diputación Provincial de Burgos.

Alfayé, S., 2009a. Santuarios y rituales en la Hispania Céltica. Oxford: Oxford Archaeopress.

Alfayé, S., 2009b. Imaginando allendes: escatología y ritual en la Céltica peninsular. SPAL monografias, 14, pp.107-138.

Alfayé, S., 2011. Imagen y ritual en la céltica peninsular. A Coruña: Toxosoutos.

Brown, J. A., 1981. The Search for Rank in Prehistoric Burials. En: R. Chapman, I. Kinnes y K. Randsborg, eds. The Archaeology of Death. Cambridge: Cambridge University Press. pp.25-37.

Camps, G., 1961. Aux origines de la Berbérie. Monuments et rites funéraires protohistoriques. París: Arts et Métiers Graphiques.

Carcedo, B. y Pradales, D., 2013. Cú Chullain y Fer Diadh. La muerte del guerrero y el ritual descarnatorio. En: R. M. Cid y E. García Fernández, eds. Debita verba. Estudios en homenaje al profesor Julio Mangas Manjarrés. Oviedo: Ediciones de la Universidad de Oviedo. pp.571-580.

Ciprés, P., 1993. Guerra y sociedad en la Hispania indoeuropea. Vitoria: Servicio Editorial de la Universidad del País Vasco. 
Ciprés, P., 2002. Instituciones militares indoeuropeas en la Península Ibérica. En: P. Moret y F. Quesada Sanz, eds. La guerra en el mundo ibérico y celtibérico (ss. VI-II a.C.). Madrid: Collection de la Casa de Velázquez. pp.135-152.

Garcés, I., 2007. Nuevas interpretaciones sobre el monumento ibérico de La Vispesa (Tamarite de Litera, Huesca). Caesarangusta, 78, pp.337-354.

García Quintela, M., 1997. Posible suplicio capital celtibérico en un fragmento cerámico procedente de Tiermes. Kalathos, 16, pp.103-111.

García Cardiel, J., 2012. La monomachia celtibérica. Vida y muerte al final de la Historia. En: C. del Cerro Linares, G. Mora Rodríguez, J. Pascual González y E. Sánchez Moreno, eds. Ideología, identidades e interacción en el Mundo Antiguo. Madrid: CERSA. pp.579-601.

García Cardiel, J., 2014. El combate contra el mal: imaginarios locales de poder a través de la conquista romana en el levante ibérico. Complutum, 25, 1, pp.159-175.

García Cardiel, J., 2016. Los discursos del poder en el mundo ibérico del sureste (siglos VII-I A.C.), Madrid: Consejo Superior de Investigaciones Científicas.

Gracia, F., 2015. Cabezas cortadas y rituales guerreros en la protohistoria del nordeste peninsular. En: J. Vidal y B. Antela, eds. Guerra y religión en el mundo antiguo. Zaragoza: Libros Pórtico. pp.25-110.

Gracia, F., 2017. Cabezas cortadas y cadáveres ultrajados. Madrid: Desperta Ferro Ediciones.

Green, M., 1992. Animals in Celtic Life and Myth. Londres y Nueva York: Routledge.

Jimeno, A. y Chaín, A., 2017. El ritual funerario: La necrópolis de Numancia. En: A. Jimeno, ed. Numancia Eterna. 2150 aniversario: la memoria de un simbolo. Salamanca: Junta de Castilla y León. Pp.155-176.

Jimeno, A., de la Torre, J. I., Berzosa, R. y Martínez, J. P., 2004. La Necrópolis Celtibérica de Numancia. Castilla y León: Junta de Castilla y León.

Liceras, R., Santos, A., Quintero, S., Chaín, A., de la Torre, J. I. y Jimeno, A., 2014. Nueva iconografía en una vasija de Numancia. En: F. Burillo y M. Chordá, eds. VII Simposio sobre Celtíberos: nuevos hallazgos, nuevas interpretaciones. Teruel: Centro de Estudios Celtibéricos de Segeda. Pp.331-337.

Marco, F., 1978. Las estelas decoradas de los conventos caesaraugustano y cluniense. Zaragoza: Institución Fernando el Católico.

Marco, F., 2008. Images of transition: the ways of death in Celtic Hispania. Proceedings of the Prehistoric Society, 74, pp.53-68.

Martínez Quirce, F. J., 1992. Imagen y articulaciones decorativas en la Meseta: imagen y cultura arévaca en la Segunda Edad del Hierro. En: R. Olmos, ed. Al otro lado del espejo: aproximación a la imagen ibérica. Madrid: Pórtico Librerías. pp.163-176.

Mellaart, J., 1975. The Neolithic of the Near East. Londres: MacMillan. 
Sanz, C. y Velasco, J. coords., 2003. Pintia, un oppidum en los confines orientales de la región vaccea. Investigaciones arqueológicas vacceas, romanas y visigodas (1999-2003). Valladolid: Universidad de Valladolid.

Sopeña, G. y Ramón, V., 2002. Claudio Eliano y el funeral descarnatorio en Celtiberia: reflexiones críticas a propósito de Sobre la naturaleza de los animales, X, 22. Palaeohispanica, 2, pp.227-269.

Sopeña, G., 1995. Ética y ritual. Aproximación al estudio de la religiosidad de los pueblos celtibéricos. Zaragoza: Institución Fernando el Católico.

Sopeña, G., 2004. El mundo funerario celtibérico como expresión de un Ethos agonístico. Historiae, 1, pp.56-107.

Sopeña, G., 2005. Celtiberian Ideologies and Religion. Journal of Interdisciplinary Celtic Studies, 6, pp.347-410. 


\title{
LAS VILLAE EN ARAGÓN: UN ESTADO DE LA CUESTIÓN
}

\author{
The villae in Aragon: a state of the question
}

Celia Corbatón Martínez ${ }^{1}$

Resumen: En el presente trabajo mostramos el estado actual de las investigaciones sobre villae en el marco geográfico de Aragón. Para ello, comenzamos por discernir qué es una villa romana tomando como referencia las fuentes clásicas y los vestigios arqueológicos, teniendo en cuenta la dicotomía entre su función como residencia del propietario y como explotación agropecuaria. Se recopilan las principales investigaciones y referencias bibliográficas modernas sobre el tema, y se presenta un estudio sobre las etapas con mayores descubrimientos en Aragón y sus posibles causas. Esto nos permite llegar a una serie de conclusiones sobre el estado de la musealización de estos yacimientos, así como una reclamación para su mejora.

Palabras clave: villae, arqueología, entorno rural, Aragón, musealización.

Abstract: In the present work we show the actual state of the investigations about villae in the geographical setting of Aragon. In order to do it, we begin by distinguish what is a roman villa, having as references the classic sources and the archaeological remains, keeping in mind the dichotomy of its function as the owner's reside residence and an agriculture and livestock exploitation. We sum up the main investigations and modern

1 Alumna del Máster en Mundo Antiguo y Patrimonio Arqueológico. Correo electrónico: celiacm70@gmail.com 
bibliographic sources about the question, and show a study of the periods with more discoveries in Aragon and its possible reasons. This allows us to give some conclusions about the current state of the musealization of those archaeological sites, so as to claim for its improvement.

Keywords: villae, archaeology, countryside environment, Aragón, musealization.

En primer lugar, me gustaría comentar que resulta complejo discernir qué es una villa romana. De hecho, cada vez es más difícil. A medida que va aumentando el interés de los investigadores sobre el paisaje rural en época romana, más evidente se hace que es una cuestión muchísimo más compleja de lo que se había pensado hasta la fecha y que las formas de hábitat son inmensamente variadas. La RAE define villa de la siguiente manera: "del latín villa, casa de recreo situada aisladamente en el campo». En realidad, ni necesariamente estaba aislada en el campo (puede ser suburbana) ni tenía que tratarse de una casa de recreo.

Debemos acudir a la información que nos proporcionan las fuentes clásicas para arrojar luz, comenzando por Marco Porcio Catón o Catón «el Viejo» (c. 234-149 a. E.) y su De Agri Cultura. En este tratado sobre agricultura, nos explica que un buen ciudadano propietario de un fundus (extensión de tierra) deberá saber cómo cultivar sus tierras y que, en caso de querer construir una zona de hábitat o recreo para sí mismo y su familia, esta jamás deberá entorpecer el principal cometido de la villa, que será la explotación de los recursos agrarios y ganaderos. Es este autor, por tanto, quien nos distingue de manera clara las dos zonas que conforman una villa: la pars rustica (dedicada a la explotación agropecuaria y todo lo derivado de ella) y la pars urbana (vivienda).

El siguiente autor a tener en cuenta es Marco Terencio Varrón (11627 a. E.), con la obra Rerum rusticarum. Su estancia en Hispania Ulterior como legatus y hombre de confianza de Pompeyo le permitieron un análisis del medio agrario de la zona y un gran esfuerzo por intentar sistematizar la agricultura en el mundo romano. Los tres libros que componen la obra nos proporcionan información sobre cómo conseguir una mayor productividad del fundus, dedicándose el primero a la agricultura per se, el 
segundo a la "ganadería extensiva» y el tercero a la explotación comercial intensiva. Además, distingue varias tipologías de villa. Una es la «simplex rustica» (una granja donde habita el propietario, sin ningún tipo de luxuria), en contraposición con la «villa urbana» (dedicada al lujo, ostentación y confort). Asimismo, añade un tipo ignorado por Catón, probablemente porque esté más presente en el siglo I a. C., que es la «villa villalitica», el tipo perfecto para él.

Por otro lado, cabe tener en consideración también a Marco Vitruvio Polión (c. 80/70 - c. 15 a. C.) y su De Architectura Libri Decem. Para él será de gran importancia que cualquier vivienda, tanto del medio urbano como agrario, esté orientada correctamente teniendo en cuenta las condiciones climáticas del lugar. Así, estancias como los baños estarán en la zona de poniente, donde se aprovecha mejor la luz del sol o junto a la cocina para aprovechar el calor, pero otras como las de los esclavos estarán en criptopórticos o zonas peor iluminadas. Nos interesa sobre todo el sexto capítulo del libro VI, dedicado a las "casas de campo", donde nos habla de la zona productiva, que será la prioridad.

Finalmente, Lucio Junio Moderato Columela (4-70 d. C.) nos proporciona información en su De re rustica. De los doce libros que lo componen, nos resultará de interés sobre todo el primero, donde describe cómo debe ser una villa óptima para obtener el máximo rendimiento de la propiedad. Divide en tres partes el conjunto: pars rustica, pars urbana y, como novedad, pars fructuaria. Esta última sería aquella dedicada a las actividades de transformación de las materias primas y su almacenamiento, tales como los torcularia para el prensado de la vid o la aceituna o la cella vinaria. Columela tuvo en cuenta, a diferencia de Catón y Varrón, la tipología de villa marítima.

Además, los autores clásicos insistieron, por lo general, en la importancia de los llamados loci saluberrimi. Es decir, en la importancia de ubicar la vivienda en un entorno en el que la fertilidad del suelo, el acceso a fuentes de agua y el aire sean favorables para el hábitat de los propietarios.

En cuanto a la información que nos proporcionan los restos arqueológicos, han hecho que podamos distinguir claramente las dos zonas que pueden componer una villa: la pars rustica (dentro de la cual estaría la pars fructuaria) y la pars urbana. Se ha debatido mucho acerca de cuál de 


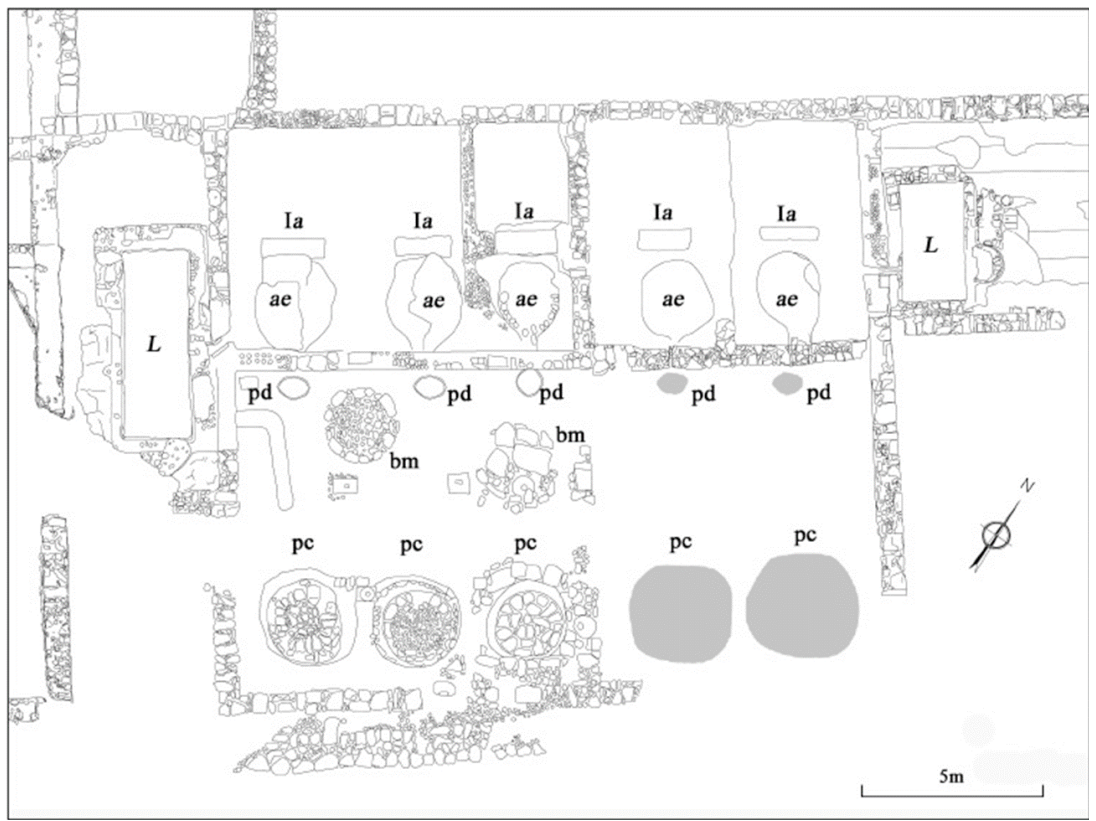

Fig. 1. Planimetría del complejo de prensado de La Loma del Regadío (Urrea de Gaén, Teruel). (Azuara, Villalgordo y Pérez, 2011-2012, p.227).

estas sería la preeminente. La mayoría de los autores, como J. G. Gorges (1979), son de la opinión de que en una villa siempre primará la función de explotación agropecuaria y que, a veces, también hace las funciones de vivienda estacional. En este sentido, destaca especialmente en el valle medio del Ebro el complejo de prensado de La Loma del Regadío (Fig. 1). Sin embargo, otros como M. C. Fernández Castro (1982) opinan que la parte principal será aquella destinada a vivienda.

Sin embargo, hay que tener en cuenta que una villa puede ser un "término polisémico». Con esto nos referimos a que, si bien anteriormente ciertas construcciones eran catalogadas sistemáticamente como villae por encontrarse en el medio rural y tener cierta "potencia arquitectónica», hoy en día sabemos que el mundo rural en época romana era mucho más complejo de lo que se creía y hay numerosas tipologías de construcciones: castelli, cauponae, hospitii, mansionis, vici, pagi, stabuli, tabernae, etcétera. 
Cabe hacer aquí mención a la contextualización geográfica escogida, el Valle Medio del Ebro. «Las villae se encuentran esencialmente localizadas en los terrenos fértiles cercanos a los cursos de agua, entre 200 y $500 \mathrm{~m}$ de altitud de manera dominante sobre su entorno. Estas se encuentran asimismo situadas cerca de las rutas, mientras permanecen lo suficientemente separadas entre ellas para mantener la vida privilegiada de sus habitantes» (Magallón, 2006, p.311). Por tanto, en este ámbito territorial será vital el análisis de las zonas cercanas al curso del Ebro y sus afluentes, entre otros ríos. De hecho, la mayor parte de los vestigios se situarán en la margen izquierda del Ebro, aunque hay excepciones de gran calibre como La Malena (Azuara, Zaragoza) en la margen derecha.

No obstante, el hecho de que estos restos se sitúen en los terrenos fértiles próximos a cursos fluviales también presenta problemas, pues son zonas explotadas de forma casi continuada hasta la actualidad y las labores agrícolas son uno de los factores más destructivos. En cuanto a su cercanía a las vías o diverculi, hay que tener en cuenta que debían estar lo suficientemente cerca para el comercio de sus productos y el abastecimiento de todo lo que la explotación no puede elaborar por sí misma, pero también lo suficientemente lejos como para que el paso de desconocidos no suponga un peligro para la villa.

En cuanto a la historia de las investigaciones y de los descubrimientos en Aragón, para el presente trabajo hemos tenido en cuenta los vestigios contemplados en la obra de J. G. Gorges (1979) y en las Cartas Arqueológicas de Teruel (1980) y Huesca (1985), además de las que presentaremos a continuación, y hemos elaborado unas tablas con los periodos y las fechas de los descubrimientos que nos han permitido extraer la información de nuestro interés para el presente artículo, que presentamos al final del mismo. También hemos confeccionado unas gráficas acordes a los datos que hemos ido recabando.

Durante el siglo XIX muchas villas salieron a la luz pública gracias a sus mosaicos, encontrados de forma casual en la mayoría de las ocasiones. En esta etapa aparecieron un 6\% de las villas tenidas en cuenta en el presente trabajo, tres en total y todas ellas en la provincia de Huesca: en la Ermita de Nuestra Señora del Socorro, en Coscojuela de Fantova (1879); en la Noguera, en Estada (1891); y, finalmente, en Fortunatus en Fraga (1893). 


\section{Descubrimientos de villae en Aragón}

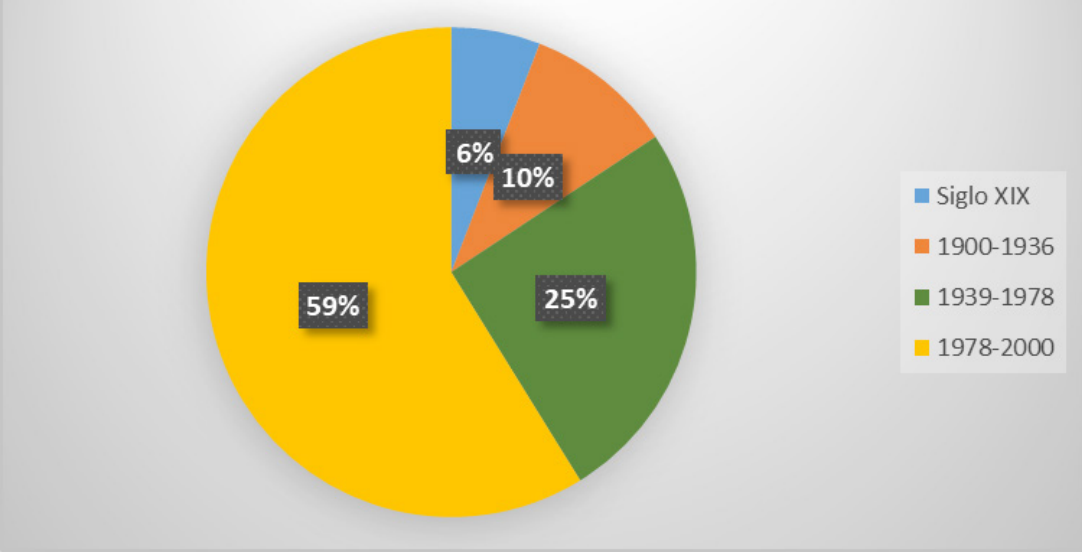

Fig. 2. Las villas descubiertas por etapas. Gráfica de autoría propia.

La siguiente etapa tenida en cuenta serían los años previos a la Guerra Civil (1900-1936). En los años 20 comienzan las excavaciones en la Villa Fortunatus de Fraga (Huesca), por iniciativa de un particular, entre otros estudios. Se encontraron el 10\% de las villas, cinco en total (dos en Huesca y tres en Zaragoza), destacando la de la Huerta de Santa Engracia (1907), que estaría situada en la actual Plaza de los Sitios de Zaragoza y que no se ha conservado.

El siguiente periodo escogido sería entre el fin de la Guerra Civil, cuando se reanudarían los trabajos arqueológicos, y los años 80. En los años 40 destacó la labor de J. de C. Serra Ráfols en la Villa Fortunatus. Los años 50 son bastante fecundos en cuanto a la investigación y las publicaciones, pues la mecanización del campo y la construcción de carreteras permitieron que un gran número de vestigios salieran a la luz accidentalmente. Llegarían también los avances con M. A. Mezquíriz Irujo, que cogería el relevo de B. de Taracena en las villas navarras, convirtiéndose en referencia para estos estudios.

De esta etapa fueron encontradas hasta trece villas, que suponen el $25 \%$ de las tenidas en cuenta en el presente trabajo. Cinco fueron halladas en Huesca, seis en Zaragoza y dos en Teruel. Será la primera vez que apa- 
rezcan este tipo de vestigios en la provincia turolense, y serán del calibre de La Loma del Regadío (1953), en Urrea de Gaén.

Habría que esperar a finales de la década de los 70 para encontrar un estudio que incluya un catálogo de villas hispanas, realizado por J. G. Gorges como ya hemos visto. También cabría destacar a inicios de los 80 el trabajo de M. C. Fernández Castro. Esta década supondrá un cambio no solo cuantitativo, sino también cualitativo, pues se percibe la influencia de trabajos como el de A. Carandini con la obra de tres volúmenes sobre la villa de Settefinestre (1985). En Aragón, destacará el papel de J. Lostal, con una obra (1985) donde se recopila prácticamente toda la información de época romana hasta esa fecha.

Hay otros volúmenes más recientes sobre la época romana en la cuenca media del Ebro que merecen una mención en el presente artículo, como es la de F. Beltrán Lloris, M. Martín-Bueno y F. Pina Polo (2000) o la de M. V. Escribano y G. Fatás (2001).

Entre 1978 y el año 2000 fueron encontradas hasta treinta villae en Aragón, el 59\% del total. Trece aparecieron en Huesca, catorce en Zaragoza y tres en Teruel, destacando entre ellas "La Malena» (1986), en Azuara.

Dejando de lado los trabajos generales de recopilación, en la actualidad

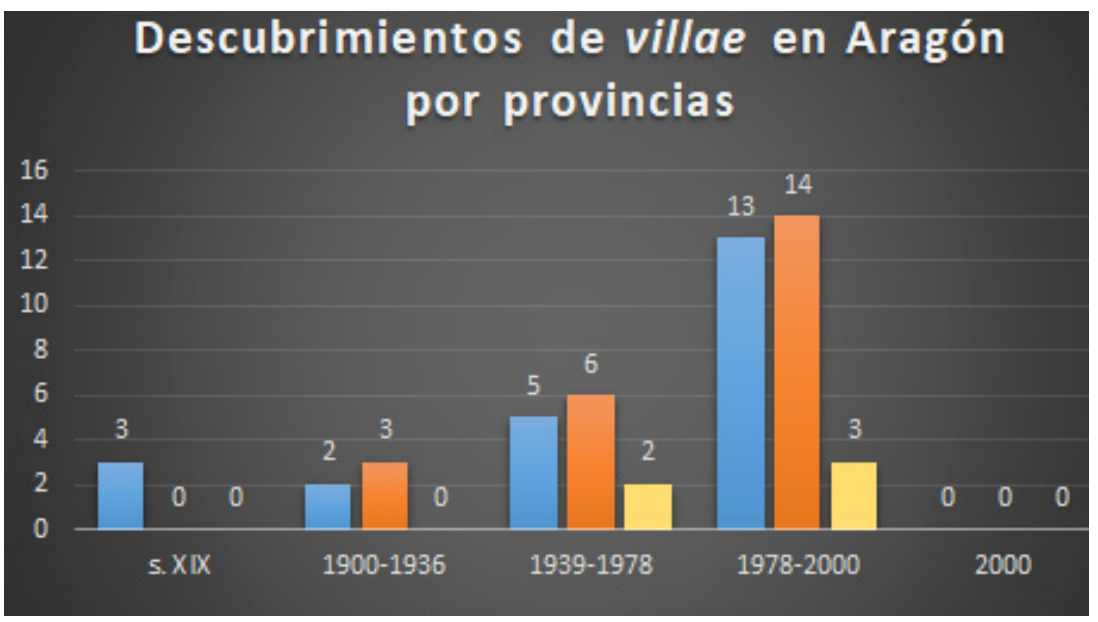

Fig. 3. Distribución de los descubrimientos de villas por provincias. Gráfica de autoría propia. 
las referencias más relevantes son las excavaciones que han llevado a cabo tanto el Museo de Teruel en «La Loma del Regadío» (Urrea de Gaén, Teruel) como la Diputación General de Aragón en «La Malena» (Azuara, Zaragoza).

Sin embargo, a partir del año 2000 y hasta la actualidad no se ha encontrado ninguna villa romana desconocida anteriormente. Resulta difícil pensar que no las haya, y quizás la causa de esto sea la falta de investigaciones al respecto o el escaso interés que los investigadores han tenido hacia esta cuestión en los últimos años.

Según hemos visto en las distintas gráficas (Fig. 2, 3 y 4), la mayor parte de las villas romanas se encuentran en las provincias de Huesca y Zaragoza. Esto no es casual, ya que ha sido donde más han influido los trabajos de instalaciones del regadío, la explotación agrícola de los suelos fértiles cercanos al curso del Ebro, la roturación de nuevos campos y la construcción de carreteras en los hallazgos fortuitos o casuales de yacimientos de este tipo. Sin embargo, en Teruel este desarrollo se ha ejecutado en menor intensidad y seguramente la escasez de hallazgos no se deba tanto a que no existan, pues eran suelos fértiles que podrían haberse explotado en igual medida, sino a la falta de investigaciones y el escaso interés que ha generado el medio rural de época romana en esta zona para los profesionales.

\section{Villae romanas en Aragón por provincias}

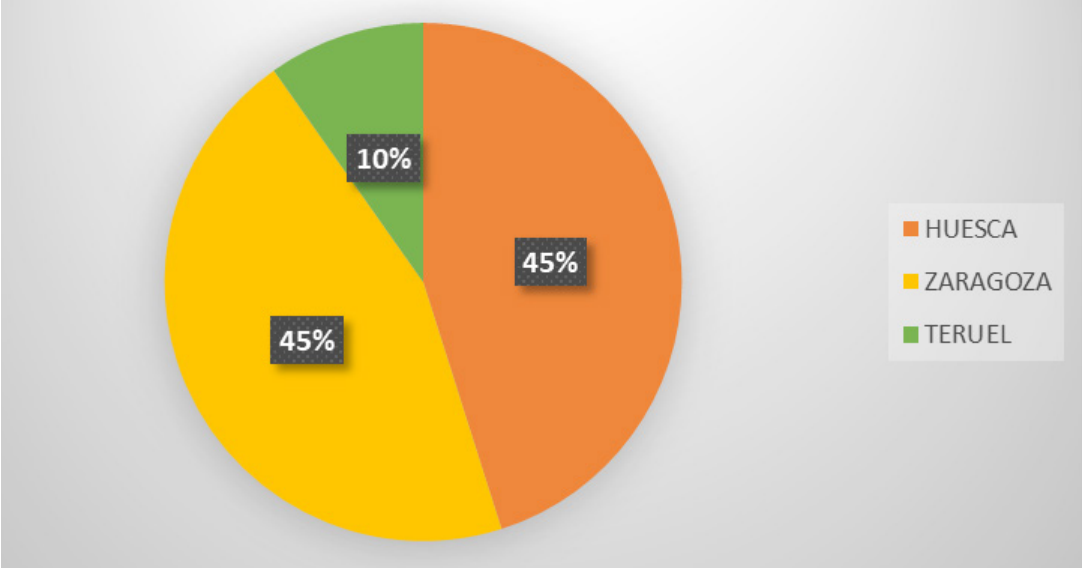

Fig. 4. Porcentaje de villas romanas descubiertas en las tres provincias aragonesas. Gráfica de autoría propia. 
Han destacado en gran medida los descubrimientos realizados en villas como Fortunatus o "La Malena», en las provincias de Huesca y Zaragoza respectivamente, por su espectacular pars urbana y la gran calidad de sus mosaicos figurados y con motivos vegetales y geométricos. Sin embargo, gracias a las últimas investigaciones en villas como «La Loma del Regadío", sabemos que en Teruel hay yacimientos de este tipo de una magnitud, atractivo, potencia estratigráfica, capacidad de explotación agropecuaria y belleza visual que nada tienen que envidiar a las anteriormente citadas.

Por otro lado, es importante hacer un análisis sobre la musealización y la puesta en valor de los vestigios en forma de villa romana en Aragón. Tan solo tres casos están musealizados o en vías de estarlo en un futuro más o menos próximo. La primera fue la Villa Fortunatus, ubicada a $5 \mathrm{~km}$ de la actual Fraga y cerca del Pilaret de Santa Quiteria, donde han aparecido más villas. Todas estarían cercanas al curso del Cinca, que hoy en día todavía conserva un abundante caudal.

Fue construida en el siglo II d. C. y habitada hasta el IV, y debe su nombre a uno de los mosaicos encontrados allí, con la inscripción «FORTV-NATVS» cortada por un crismón con la $\alpha$ y la $\omega$, como vemos bajo estas líneas. Esto nos proporciona importantes datos sobre el propietario que, si bien en una primera fase de construcción había sido pagano, en el momento de realizar este mosaico es cristiano. Se ha excavado gran parte de la pars urbana, como el gran peristilo o el tablinum, y se ha considerado que la zona donde se ubicaría el atrio sería empleada posteriormente como basílica cristiana. Sin embargo, todavía quedan por resolver las incógnitas sobre su pars rustica.

Como hemos visto, fue descubierta a finales del siglo XIX y en los años 40 destacarían los trabajos de J. de C. Serra Ráfols (Fig. 5). Posteriormente, en los 80 sería excavada por F. Tuset de la Universidad de Barcelona, y se realizarían trabajos de restauración en el conjunto arquitectónico. Después, desde 1998, el Gobierno de Aragón promovió una serie de trabajos para hacer visitable el yacimiento. Entre 2000 y 2001 se levantó el mosaico de la estancia no 13 , que se trasladó al Museo Provincial de Zaragoza, y se excavó bajo este pavimento para encontrar restos de ocupación anterior a su instalación. 


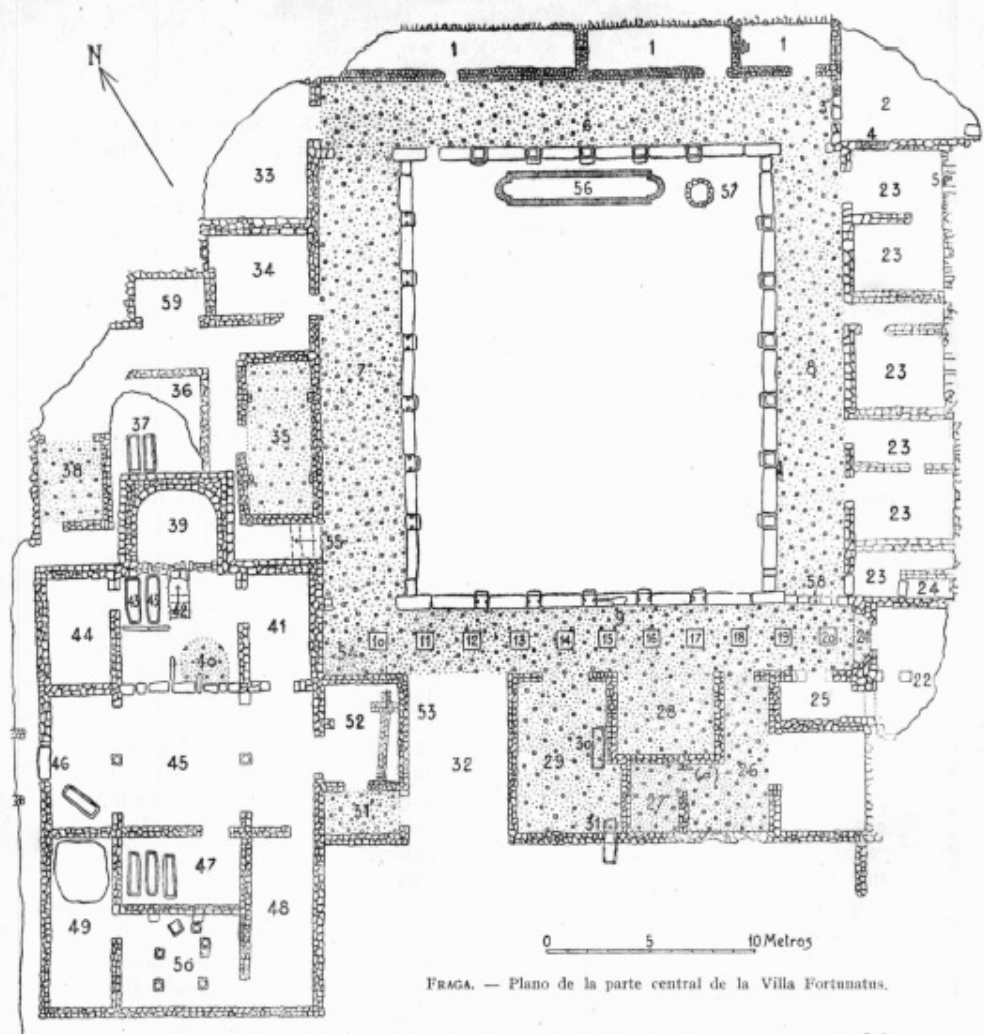

Fig. 5. Plano de la pars urbana de la Villa Fortunatus (Fraga). (Serra, 1943, p.12).

Fue a partir de 2006 cuando comenzó el proyecto de cubrir, proteger y adecuar la villa para su visita turística, pero no sería hasta 2012 cuando esto se materializaría en la construcción de una cubierta arquitectónica.

La siguiente villa en ser musealizada fue La Loma del Regadío, junto al afluente del Ebro conocido como el río Martín y a 2,1 km de Urrea de Gaén. Se ha constatado una primera fase de ocupación en torno al siglo I d. C., que quedó completamente arrasada en una remodelación de entre finales del siglo III e inicios del IV d. C., que convirtió la villa en un complejo de gran potencial productivo oleícola y vitivinícola. Fue habitada hasta comienzos del siglo $\mathrm{V}$. 
Los trabajos arqueológicos comenzaron en 1953, con un grupo de arqueólogos y espeleólogos llamado "Campamento volante de Río Martín». Fueron ellos mismos los que constataron que efectivamente se trataba de una villa, encontrando parte de las estructuras, fragmentos de piezas cerámicas y piezas musivas.

Entre 1959 y 1960, P. Atrián la excavaría parcialmente, encontrando dos mosaicos en dos estancias distintas, comunicadas entre sí por una puerta. Más tarde, se trasladaron al Museo Provincial de Teruel, salvaguardándolos de las condiciones climáticas que tanto dańaron los restos que permanecieron in situ. Fue en ese segundo año cuando apareció el peristilo de la villa, de gran lujo y dimensiones, profusamente decorado.

Después, La Loma del Regadío fue incluida en el Plan de Investigación del Museo de Teruel, llevándose a cabo siete campañas entre 1997 y 2011, primero bajo la dirección de J. Vicente y B. Ezquerra y a partir de 2005 de S. Azuara, B. Ezquerra y C. Villalgordo. Sería entonces cuando se descubriría el importante torcularium o complejo de prensado de esta villa. Entre 2007 y 2009 se instalaría la cubierta protectora.

Finalmente, queda hablar de La Malena, construida en torno al siglo III d. C. y habitada durante todo el siglo IV. Entre 1986 y 1994 se llevaron a cabo siete campañas de excavación, financiadas por el Departamento de Cultura y Turismo del Gobierno de Aragón.

En 1992, fue declarada Bien de Interés Cultural para su protección, y ese mismo año se sacó a concurso el proyecto de excavación del yacimiento. Se seleccionaron para el anteproyecto dos arqueólogos (J. A. Pérez y M. L. De Sus), dos arquitectos (F. Aguerri y J. Ibargüen) y un restaurador (J. A. Minguel). En 1994, tomaría el relevo de la dirección de las labores arqueológicas J. I. Royo Guillén, de la Dirección General de Cultura y Patrimonio del Gobierno de Aragón.

Los trabajos se abandonarían unos años hasta que, en los años 1999 y 2000, se realizaron algunas labores de restauración y conservación. Fue entonces cuando Fernández-Galiano estudió gran parte de los impresionantes mosaicos descubiertos, destacando el de "las bodas de Cadmo y Harmonía» (Fig. 6). Desde entonces, la villa ha sufrido un abandono casi total, a excepción de las labores de adecuación y mantenimiento del yacimiento que han realizado voluntarios y vecinos de Azuara. Estos, junto con 


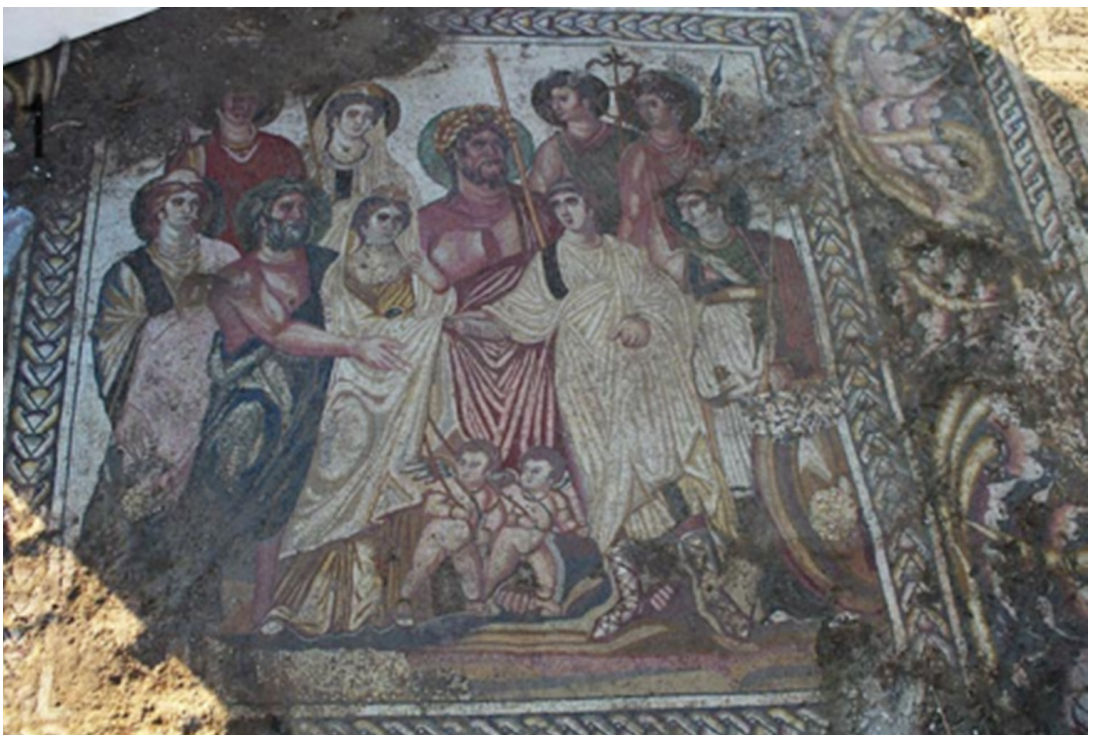

Fig. 6. Mosaico de las bodas de Cadmo y Harmonía de La Malena (Azuara). (Royo, 2010, p.178).

la asociación APUDEPA y en colaboración con arqueólogos, presentaron, en 2016, la Propuesta de Memoria Valorada para su puesta en valor.

Más tarde, en 2017, se redactó el plan director, debido a la situación de gravedad y urgencia en la que se encontraban los restos. Se especifican en él las labores de restauración previas a la construcción de una cubierta protectora, para la consolidación de las estructuras originales. Ese mismo año se cubrió la estancia 26 (a la que pertenece el mosaico citado anteriormente) y se destinaron $200.000 €$ a la consolidación de muros de mampostería. En 2018 se aprobó, finalmente, el anteproyecto financiado por la DGA para la construcción de la cubierta y la restauración de los mosaicos, muy dañados por haber estado tantos años a la intemperie. En enero de 2019 ya se han cubierto hasta tres estancias de la villa.

En las tareas de musealización resulta también de gran importancia hacer llegar el conocimiento de este tipo de yacimientos al mayor público posible, por lo que las Tecnologías de la Información y Comunicación (TIC) serán de gran utilidad. El impacto social de páginas web, redes sociales o periódicos digitales puede ser enorme. 
Además, siguiendo con las llamadas «nuevas tecnologías», la reconstrucción virtual ha resultado ser una gran aliada en la puesta en valor del patrimonio. Se trata de la creación de una imagen de ordenador en 3D que reproduce los restos como serían originalmente en su construcción. Un ejemplo serían los paneles interactivos, que permiten ver los restos in situ y sobreponer una imagen creada por ordenador de cómo serían originalmente. Un ejemplo lo vemos en la Malena, con la reconstrucción virtual de la villa en un audiovisual proyectado al inicio de la visita y en la maqueta del centro de interpretación. Resultan de gran utilidad este tipo de recursos, sobre todo en un público general con conocimientos escasos o básicos sobre este tipo de construcciones.

Por otro lado, un avance más reciente es el de la realidad aumentada, que combina la visión a tiempo real de los restos arqueológicos por parte del usuario con la superposición de las imágenes virtuales por ordenador, empleándose un dispositivo electrónico portátil (tablet, teléfono móvil o gafas de realidad virtual por ejemplo). Y ahí está lo verdaderamente interesante, en que el visitante puede ver a tiempo real un lugar de la Antigüedad, como si estuviera en ese momento y lugar.

No se ha desarrollado este tipo de tecnología en estas villas, pero podríamos tomar como ejemplo el proyecto LIFEPLUS, desarrollado por la Universidad de Ginebra en Pompeya, con el que los visitantes podían presenciar a través de uno de esos dispositivos escenas de la vida cotidiana en la ciudad, con los romanos como protagonistas (como la escena en el thermopolium de Vetutius Placidus).

Sin embargo, sí se ha desarrollado otro proyecto similar en el que estarán integradas la Villa Fortunatus y La Malena, aunque no La Loma del Regadío a pesar de la importancia del conjunto que hemos expuesto anteriormente. Se realizaría en colaboración con la empresa SignLab Nuevas Tecnologías, llevando adelante la aplicación Ruta de las villas romanas para dispositivos electrónicos móviles (Fig. 7). Esta herramienta hará más atractiva la visita, a través de la generación de contenidos de forma geo-localizada en los terminales colocados en el recorrido del yacimiento, sin ni siquiera requerir el uso de datos móviles e internet una vez descargada.

Esto supone, sin duda, un gran avance, ya que no solo integran las reconstrucciones virtuales e incluso la realidad virtual, dejando atrás el típico 

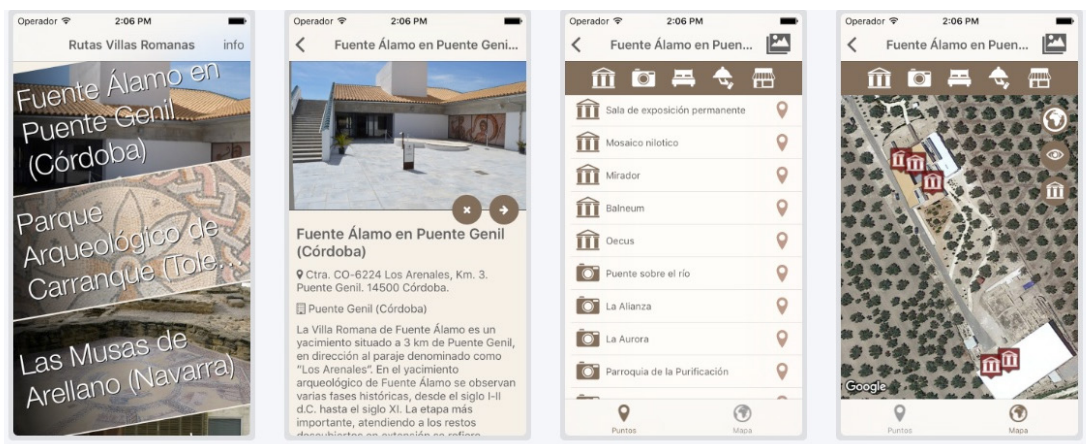

Fig. 7. Imágenes de la aplicación desarrollada por SignLab Nuevas Tecnologías SignLab Nuevas Tecnologías, 2016. Disponible en: www.villasromanas.es [Accedido el 14 de mayo de 2019].

vídeo al inicio de la visita (que no deja de ser una solución más rentable y sencilla), sino que además permite al turista elegir el ritmo al que quiere ir viendo los diferentes restos y gestionar la visita a la velocidad deseada.

Como conclusiones, en primer lugar, cabría destacar la falta de excavaciones sistemáticas que permitan distinguir los restos catalogados como villas por hallazgos casuales de otros que en realidad no lo son. Queda mucho por investigar y conocer en el Valle Medio del Ebro, y la primera comparación que podemos establecer son los estudios en profundidad en lugares como la Villa de Arellano (Falces, Navarra) realizados por B. de Taracena y M. A. Mezquíriz Irujo, publicados en los Trabajos de Arqueología Navarra.

Por otro lado, cuando se han excavado estos enclaves, en muchos casos se ha dado prioridad a la pars urbana y se ha descuidado la pars rustica y fructuaria. Debemos preguntarnos por qué, y no podemos evitar pensar que quizás la clave esté en el interés de los propios investigadores y de las fuentes de financiación, ya que muchas veces se prima lo «atractivo»o «bonito» de cara al futuro público.

Por más interesantes que puedan ser los estudios de la cultura material cotidiana o de las formas de producción, se ha tendido a pensar que resultarían mucho más atractivos vestigios como grandes mosaicos, que se encontrarían en la zona de vivienda. La excepción que confirma la regla es La Loma del Regadío (Urrea de Gaén, Teruel), donde a pesar de poseer un gran peristilo que denota la capacidad adquisitiva de su possessor, los estu- 
dios más recientes han puesto el énfasis en la reforma que convierte este lugar en una gran explotación agropecuaria que exportaba vino y aceite.

Además, en la musealización y las propuestas que hemos presentado en relación con las "Nuevas Tecnologías» nos encontramos un problema que resulta demasiado frecuente en los asuntos relacionados con el patrimonio: la falta de financiación. En este sentido, para la conservación y la puesta en valor de los vestigios será vital conseguir la implicación de la población. Esto lo vemos claramente, por ejemplo, en los vecinos de Azuara y su lucha por la conservación de La Malena en sus veintidós años de abandono.

Para ello, se ha demostrado la utilidad de las actividades desarrolladas en estos enclaves, destinadas a distintos públicos. Para los niños, destacarían los talleres como la elaboración de piezas cerámicas, los mosaicos con goma-eva o la creación de joyas inspiradas en las que pueden encontrarse en el lugar. Para los adultos, se podrían programar actividades relacionadas con la degustación de vino y comida de la época, y talleres de telares antiguos. También charlas sobre historia romana arcaica, republicana e imperial, la arqueología, la vestimenta típica de las distintas clases sociales romanas o la mitología en los mosaicos. Otro ejemplo a seguir sería la visita teatralizada, más entretenida y que pueda atraer a más público, como la que se viene realizando desde hace algún tiempo en el yacimiento de Ampurias (Gerona).

\section{BibliografíA}

\section{Autores clásicos}

Catón. De Agri Cultura. Edición de H. Keil, 1895. Leipzig: Teubner.

Catón. Tratado de Agricultura. Fragmentos. Edición de A. García-Toraño Martínez, 2012. Madrid: Biblioteca Clásica Gredos.

Columela. Libro de los árboles; La labranza: libros I-V. Edición de J. I. García Armendáriz, 2004. Madrid: Biblioteca Clásica Gredos.

Columela. De re rustica. Edición de H. Boyd Ash, 1960. London: Harvard University Press.

Varrón. Rerum rusticarum. Libri III. Edición de G. Goetz, 1912. Leipzig: Teubner. 
Varrón. Rerum rusticarum. Libri III. Edición de J. I. Cubero Salmerón, 2010. Sevilla: Junta de Andalucía.

Vitruvio. Los diez libros de Arquitectura. Edición de J. L. Oliver Domingo, 1995. Madrid: Alianza Editorial.

\section{Bibliografia contemporánea}

Ariño Gil, E., 1990. Catastros romanos en el convento jurídico caesaraugustano. La región aragonesa. s.l.: Departamento de Ciencias de la Antigüedad.

Atrián Jordán, P. et al., 1980. Carta Arqueológica de España: Teruel. Teruel: Instituto de Estudios Turolenses.

Azuara Galve, S. y Villalgordo Ros, C., 2007. La villa romana de La Loma del Regadio (Urrea de Gaén). Zaragoza: Prames.

Azuara Galve, S., Villalgordo Ros, C. y Pérez Arantegui, J., 2011-2012. El complejo de prensado de la villa romana de La Loma del Regadío (Urrea de Gaén, Teruel). Anales de Prehistoria y Arqueología, 27-28, pp.219-230.

Carandini, A. ed., 1985. Settefinestre: una villa schiavistica nell'Etruria romana, Modena: Panini.

De Sus Giménez, M. L., Pérez Casas, J. A. y Royo Guillén, J. I., 1997. Campaña de excavaciones arqueológicas para la delimitación de la villa romana de $\mathrm{La}$ Malena (Azuara, Zaragoza). En: J. I. Royo Guillén, ed. Arqueología aragonesa.1994. Zaragoza: Gobierno de Aragón. pp.163-175.

Domínguez Arranz, A., Magallón Botaya, M.A. y Casado López, M.P., 1985. Carta arqueológica de España: Huesca. Cuarte de Huerva (Zaragoza): Excma. Diputación Provincial.

Fernández Castro, M. C., 1982. Villas romanas en España. Madrid: Ministerio de Cultura.

Fernández-Galiano, D., 1992. Cadmo y Harmonía: imagen, mito y arqueología. Journal of Roman archaeology, 5, pp.162-177.

Fernández Ochoa, C., Salido Domínguez, J. y Zarzalejos Prieto, M., 2014. Las formas de ocupación rural en Hispania. Entre la terminología y la praxis arqueológica. CuPAUAM, 40, pp.111-136.

Gorges, J. G., 1979. Les villas hispano-romaines. Inventaire et problématique archéologique. Paris: Boccard

Maestro, E. et al., 1992. Fraga en la Antigüedad. Fraga: Ayuntamiento de Fraga.

Magallón Botaya, M. A., 1987. La red viaria romana en Aragón. D.L. Zaragoza: Universidad de Zaragoza.

Mezquíriz Irujo, M. A., 2008. Arellano y las villas tardorromanas del valle del Ebro. En: C. Fernández, V. García y F. Gil, eds. 2008. Las «villae» tardorromanas en el Occidente del Imperio: arquitectura y función. IV Coloquio Inter- 
nacional de Arqueología en Gijón. Gijón: Trea, pp.391-410.

Mezquíriz Irujo, M. A., 2009. Las villae tardorromanas del Valle del Ebro. Trabajos de arqueología Navarra, 21, pp.199-272.

Pita Mercé, R., 1954. Fraga en la antigüedad. Argensola, 17, pp.17-32.

Puertas Tricas, R., 1972. Trabajos de planimetría y excavación en la «Villa Fortunatus», Fraga (Huesca). Noticiario arqueológico hispánico, 1, pp.69-82.

Royo Guillén, J. I., 2003. La Malena (Azuara, Zaragoza). Precedentes y evolución de una villa tardorromana en el valle medio del Ebro. Azuara: Ayuntamiento de Azuara.

Royo Guillén, J. I., 2010. La Malena: una villa tardorromana excepcional. En: J. Cinca Yago y J. Ona González, eds. 2010. Comarca Campo de Belchite. Zaragoza: Gobierno de Aragón, pp.173-181.

Serra Ráfols, J. C., 1943. La Villa Fortunatus, de Fraga. Empúries, 5, pp.5-35.

SignLab Nuevas Tecnologías, 2016. Ruta de las villas romanas [online]. Disponible en: www.villasromanas.es [Accedido 13 de mayo de 2019]. 


\section{ApÉNDICE:}

\begin{tabular}{|c|c|c|c|c|c|c|}
\hline & Nombre de la villa & Antes de 1900 & $1900-1936$ & 1939-1978 & $1978-2000$ & Después del 2000 \\
\hline \multirow[b]{7}{*}{$\mathrm{Z}$} & Rienda & & 1923 & & & \\
\hline & Viñas del Sastre & & & & Са. 1979 & \\
\hline & Forao de la Tuta & & & & Са. 1979 & \\
\hline & La Malena & & & & 1986 & \\
\hline & Puente de Botorrita & & & 1974 & & \\
\hline & La Torre & & 1920 & & & \\
\hline & (Calatayud) & & & & Ca. 1979 & \\
\hline \multirow{2}{*}{ A } & Dehesa de Baños & & & 1974 & & \\
\hline & Soto de Baños & & & 1974 & & \\
\hline $\mathrm{R}$ & La Corona & & & & Ca. 1979 & \\
\hline \multirow{2}{*}{ A } & El Cabezuelo & & & & Ca. 1979 & \\
\hline & C/Los Lanceros & & & & Ca. 1979 & \\
\hline G & Lugar Viejo III & & & & Ca. 1979 & \\
\hline \multirow[t]{2}{*}{$\mathrm{O}$} & La Sinagoga & & & 1962 & & \\
\hline & Campo Real & & & & Ca. 1979 & \\
\hline $\mathrm{Z}$ & La Dehesa & & & & 1979 & \\
\hline \multirow[t]{7}{*}{ A } & La Pesquera & & & & 1980 & \\
\hline & Pueyo de los Bañales & & & & Ca. 1979 & \\
\hline & Cerro Bodegón & & & & Ca. 1979 & \\
\hline & Los Mojones & & & 1972 & & \\
\hline & Villarroya de la Sierra & & & & 1987 & \\
\hline & C/ Alfonso V y Rebolería & & & 1950 & & \\
\hline & Huerta de Sta. Engracia & & 1907 & & & \\
\hline
\end{tabular}

\begin{tabular}{|c|c|c|c|c|c|c|}
\hline & Nombre de la villa & Antes de 1900 & $1900-1936$ & $1939-1978$ & $1978-2000$ & Después del 2000 \\
\hline $\mathbf{T}$ & Redihuerta & & & & Ca. 1980 & \\
$\mathbf{E}$ & & & & & & \\
\cline { 2 - 7 } $\mathbf{R}$ & Camino de Albalate & & & 1964 & & \\
\cline { 2 - 7 } & & & & & Ca. 1979 & \\
$\mathbf{U}$ & Val de Nuria & & & & Ca. 1980 & \\
\cline { 2 - 7 } E & Campo Palacio & & & & & \\
\cline { 2 - 7 } & La Loma del Regadio & & & 1959 & &
\end{tabular}




\begin{tabular}{|c|c|c|c|c|c|c|}
\hline & Nombre de la villa & Antes de 1900 & $1900-1936$ & 1939-1978 & $1978-2000$ & Después del 2000 \\
\hline \multirow[b]{8}{*}{$\mathbf{H}$} & Galiay & & & 1968 & & \\
\hline & Torre Nogales & & & Med. s.XX & & \\
\hline & Antillón & & & & 1979 & \\
\hline & Bajo Cuesta & & & & 1981 & \\
\hline & El Conejar & & & & 1979 & \\
\hline & Era Forcada & & 1920 & & & \\
\hline & Ermita de Ntra. Sra. del Socorro & 1879 & & & & \\
\hline & Noguera & 1891 & & & & \\
\hline \multirow{2}{*}{$\mathrm{U}$} & Villa Fortunatus & 1893 & & & & \\
\hline & Pilaret de Sta. Quiteria II & & & & Сa. 1979 & \\
\hline E & EICastellot & & & & Ca. 1979 & \\
\hline \multirow{2}{*}{$\mathbf{S}$} & Torre Rausa & & & 1955 & & \\
\hline & Puypullin & & Ca. 1920 & & & \\
\hline C & Puente de las Pilas & & & & Сa. 1979 & \\
\hline \multirow{9}{*}{$\mathrm{A}$} & El Torreón & & & & Сa. 1984 & \\
\hline & Las Coronas & & & & 1993 & \\
\hline & Villa de Latas & & & & 1981 & \\
\hline & La Corona de S. Salvador & & & & 1989 & \\
\hline & Tozal del Moro & & & & Сa. 1979 & \\
\hline & El Escobizal & & & & Сa. 1979 & \\
\hline & Horta de Torrent & & & Med. s. XX & & \\
\hline & San Jaime de Valdecos & & & 1955 & & \\
\hline & San Valero & & & & Сa. 1979 & \\
\hline
\end{tabular}





\title{
LA BONA CONSCIENTIA EN SÉNECA: LA EDUCACIÓN DEL SER HUMANO FRENTE A LA IRA
}

\author{
Bona conscientia in Seneca: human education in \\ front of anger \\ Daniel Arenas Casado ${ }^{\mathrm{I}}$
}

Resumen. Séneca ilustra con su De ira el vigor que cobró la reconocida teoría de los humores en la posteridad. El presente artículo delibera que Séneca puesto que ciertas cualidades innatas y algunas circunstancias concomitantes incrementan en el ser humano su proclividad a la ira, sugiriese ejercer la conciencia humana como la principal terapia para frenar dicho impulso, cuestión postulada también por estudios psicobiológicos y sociológicos.

Palabras clave: conciencia, estoicismo, humores, ira, pasiones, Séneca.

Abstract. Seneca testifies in his work De ira the vigour which Hypocrates's humoral theory acquired. This paper argues that Seneca suggested exercising human conscience as the main therapy to restrain rage since certain inherent qualities and some concomitant circumstances propell anger. This issue has been postulated by psychobiological and sociological studies as well.

Keywords: conscience, Stoicism, humours, anger, passions, Seneca.

1 Doctorando. Universidad de Zaragoza. Correo electrónico: darenas@unizar.es. 
A petición de su hermano Novato, Séneca declara que los estoicos, mediante el sintagma brevis insania, conciben la ira como una «locura transitoria» que genera en cualquier persona el deseo de castigar a alguien a causa de recibir una supuesta ofensa (Dial. III, 1, 1-4 y 7). ${ }^{2}$ En la actualidad, como indica Elster (2001, p.30), la definimos como una emoción negativa desencadenada por una creencia sobre la acción de otra persona. En ambas definiciones, resulta muy importante destacar la noción de "creencia». Tal como Séneca describe la ira (Dial. IV, 1-2), se trata de una pasión generada por la creencia o impresión de un ultraje cuyo primer impacto en el espíritu trastorna su conducta. Esta noción encaja con la opinión de Warner (2008, pp.34-37), para quien la ira genera en la mente humana un procesamiento de falsos juicios que posicionan factores externos como causantes. ${ }^{3}$ En otras palabras, la persona como "víctima» de un supuesto ultraje experimenta un proceso de autoengaño en el que se abre paso a una reacción voluntaria de enfado y legitima algo que está fuera de su control como responsable de su enfado, quitándose así su correspondiente grado de culpa. De esta manera, justifica al mismo tiempo las acciones a las que tal reacción emocional conduce a priori, dando a entender que el sujeto irritado no es consciente de su forma de actuar ante este estado. Esta situación corresponde al concepto de opinio, es decir, "conjetura». El sujeto asiente haber recibido una ofensa y, en consecuencia, aprueba su reacción. A causa de este falso juicio, que trataremos más adelante,

2 Fillion-Lahille (1984, pp.94-96) ofrece las tres posibles definiciones de la ira presentes tanto en las Tusculanae Disputationes de Cicerón como en el De ira de Séneca. Dos de ellas procederían de los estoicos Crisipo y Posidonio según las palabras del autor cristiano Lactancio (De Ira Dei 17, 13). Respecto a la primera, encontramos huellas del autor Nemesio (SVF III, 416) y, respecto a la segunda, de Estobeo (SVF III, 395) y Filón de Alejandría (SVF II, 730 y 734). Cf. Cic. Tusc. III, 5, 11; IV, 9, 21; 14.31; 19.44 y Sen. Dial. III, 3, 4; IV, 4-5; V, 1-2. La tercera definición corresponde al concepto de ira como pasión diferente de la iracundia (Tusc. IV, 12, 27 y Dial. III, 4). Con estas fuentes, comprobamos que diversos autores, especialmente de índole estoica, contemplaban la ira como una pasión que causaba malformaciones en el espíritu humano. Sobre la definición de Aristóteles en palabras de Séneca, vid. Dial. III, 3, 1-5.

3 Respecto a estas definiciones en De ira III, 3(fr1), 1 y III, 3(fr2), 1, bien conocidos son los textos de Martín de Braga (De ira 2) y Lactancio (De Ira Dei 17, 13), que salvan la laguna presente en el tratado de Séneca. 
los estoicos utilizan el sintagma brevis insania (Fillion-Lahille, 1984, p.187). ${ }^{4}$

Del mismo modo que este concepto de locura corresponde a tal proceso ilusorio de autoengaño, Séneca describe las fases que un alma atraviesa en dicha ilusión. Así, como indica en su tratado (Dial. Iv, 2, 5 y 3, 1), la naturaleza humana dispone de unos principios preliminares de sentimientos que no han de confundirse con los sentimientos "per se: omnia ista motus sunt animorum moueri nolentium, nec adfectus sed principia proludentia adfectibus [...] Nihil ex his quae animum fortuito inpellunt adfectus uocari debetr. ${ }^{5}$ Sirviéndose de esta dicotomía, presenta un esquema consistente en tres fases o periodos que el espíritu atraviesa en un ataque de ira. Tal como señala en Dial. Iv, 4, la naturaleza humana consta de una primera emoción involuntaria — primus motus non voluntarius — que nos avisa de una posible agitación del espíritu — quasi praeparatio adfectus et quaedam comminatio-. Esta primera fase consta de síntomas fisiológicos que se prolongan tras caer en un estado de irritación: rubor o palidez, palpitaciones intensas, pérdida del control intestinal, nudos en la garganta, náuseas, aceleración del ritmo cardíaco, presión sanguínea, posturas corporales, diferente tono de voz, acción de sonreír, mostrar y rechinar los dientes o fruncir el ceño (Dial. IV, 35, 3; v, 4, 1-3; cf. Elster 2001, pp.43-44). Esta primera fase no puede dominarse mediante la razón, sino que se trata de una fase preliminar exclusiva del cuerpo humano. Ahora bien, la segunda fase ya supone la acción de ejercer un juicio deliberado con el que el alma justifica el deseo de venganza. Tras este asentimiento por parte del espíritu, se constituye la tercera fase, en la cual el espíritu se somete plenamente a dicha pasión.

Con estas explicaciones, Séneca pretende aclarar que los ataques de ira se producen en realidad de forma voluntaria, puesto que atravesamos

4 Insania, opuesto al adjetivo sanus, denota una cualidad o estado nocivo o enfermo aplicable tanto a nivel corporal como espiritual. Por tanto, los estoicos utilizan este término para referirse a una cualidad que se atribuye a un sujeto que «no se halla sano en cuanto a su espíritu», "que está loco o demente» o «que padece de insensatez» (Ernout-Meillet, 1985, pp.593-594; Gaffiot, 2000, p.835 y Cic. Tusc. III, 5, 11).

5 «Todas ellas son emociones de espíritus que no quieren emocionarse, tampoco sentimientos, sino principios preliminares de sentimientos [...] Nada de esto que sacude casualmente el espíritu debe llamarse sentimiento». Traducción de Juan Mariné Isidro. 
una línea divisoria - como una especie de umbral — entre la primera y la segunda fase. De la misma manera lo sostiene Elster (2001, pp.37 y 41), quien afirma que esta emoción goza de un denominado "punto de no retorno", el cual, tras ser rebasado, impide la disposición del autocontrol. Dicho de otra manera, nuestra conciencia se bloquea y ya no podemos controlar nuestras acciones. ${ }^{6}$

Puede resultar interesante la comparación del funcionamiento de la ira en el reino animal. Según nos muestra Bunge (1985, pp.189-195), un animal es consciente cuando él mismo advierte sobre la información que su cerebro está procesando. Este proceso cerebral tiene una base neurofisiológica: esta advertencia parece ser el sistema de activación reticular del tallo cerebral. Ahora bien, ¿en qué se diferencian la advertencia y la conciencia? En que la advertencia solo requiere sensores — presentes en todos los animales-, mientras que la conciencia también requiere inteligencia, capacidad de pensar. A raíz de esta distinción, aunque las emociones o pasiones sean reacciones instintivas o automáticas a determinadas causas, la conciencia advierte al sujeto de su reacción emocional y de cómo va a actuar en función de ella. Por tanto, Séneca postula en Dial. III, 3, 6-8 que los animales irracionales, a pesar de compartir impulsos similares con los humanos, carecen de tales adfectus o pasiones existentes en la naturaleza humana:

"Nulli nisi homini concessa prudentia est, prouidentia diligentia cogitatio, nec tantum uirtutibus humanis animalia sed etiam uitiis prohibita sunt [...] Ex eo procursus illorum tumultusque uehementes

6 Las posibilidades fenomenológicas de la ira son las siguientes: en primer lugar, reconocer que nuestra ira es inmotivada y dejar de sentirla; en segundo lugar, reconocer que no es motivada, pero reprimimos nuestra conciencia y nos inventamos una justificación - autoengaño-; en tercer lugar, la invención de la historia incluso puede tener lugar antes de reconocer la inocencia del otro - pensamiento desiderativo- - . Respecto al sustantivo conscientia, este procede del adjetivo conscius, denotando así el sentido de "conocimiento común, conciencia, complicidad", unido con frecuencia a términos como mens o animus (Ernout-Meillet, 1985, pp.138; 602-603 y Gaffiot, 2000, pp.402). Sin embargo, según Ernout y Meillet, el sustantivo conscientia posee a menudo un llamativo matiz peyorativo. En otras palabras, el verbo conscire puede traducirse, en ocasiones, como «tener conciencia de algo malo», es decir, «ser consciente de una amenaza». De ahí que «tener la conciencia tranquila» signifique que nuestra conciencia no se encuentra en estado de alarma. De este mismo sentido, extraemos la expresión «examen de conciencia». 
sunt, metus autem sollicitudinesque et tristitia et ira non sunt, sed his quaedam similia; ideo cito cadunt et mutantur in contrarium et, cum acerrime saenierunt expaueruntque, pascuntur, et ex fremitu discursuque uesano statim quies soporque sequitur».?

Como afirma Séneca, la ausencia de sentimientos humanos como la ira se debe a la ausencia de ratio, mientras que la conciencia humana abre la puerta a los adfectus después de los impulsos preliminares del cuerpo. ${ }^{8}$

Después de referir el motor principal de las pasiones, debe darse cuenta de la existencia de otros factores concomitantes. Uno relevante es el temperamento de las personas, ya procedente de la teoría hipocrática de los humores. Si retornamos a Hipócrates (Hum. 1, 8-9), las personas que padecen un exceso de bilis amarilla son más propensas a un temperamento cálido, esto es, colérico. En Dial. IV, 19, Séneca asocia cuatro tipos de temperamento con los cuatro elementos de Empédocles. En función del elemento cuya fuerza predomine en la naturaleza de un animal, de una persona e incluso de una región, su temperamento tenderá más hacia unas costumbres u otras. ${ }^{9}$ A raíz de estas postulaciones, este sería el esquema (Fig. 1).

A la hora de referirse al temperamento, Séneca emplea con acierto el término ingenia. Derivado del verbo genere, "crear, causar, producir» con validez tanto física como moral, el sustantivo compuesto ingenium significa «carácter o personalidad innata, natural» es decir, "carácter con el que nace una persona por naturaleza» o «disposiciones naturales del espíritu» de las que la conciencia no forma parte (Ernout-Meillet, 1985, pp.270-271).

7 «A nadie más que al hombre se le ha concedido la precaución, la previsión, la atención, el pensamiento, y no solo de las virtudes humanas están excluidos los animales, sino también de los vicios [...] De ahí que sus acometidas y enfados sean violentos, por el contrario no hay en ellos miedos ni preocupaciones, tristeza ni ira, sino algo similar a eso; por ello, en seguida se calman y pasan al extremo contrario y, cuando ya se han enfurecido o asustado violentísimamente, dan en pacer, y a los bramidos y carreras alocadas les siguen de súbito la calma y el sopor». Traducción de Juan Mariné Isidro.

8 Nociones semejantes encontramos en Veyne (2005, pp.684-387) y Fillion-Lahille (1984, p.154).

9 Cf. Sen. Ep. 95.65 y Fillion-Lahille (1984, pp.183-186). De la misma manera lo sostiene Galeno (SM 6, 789-791; 7, 791-793), presente ya en Platón (Ti. 86d-87a) y Aristóteles (PA 648a): los perjuicios del alma vienen originados por la mala mezcla de los humores y una educación mezquina. 


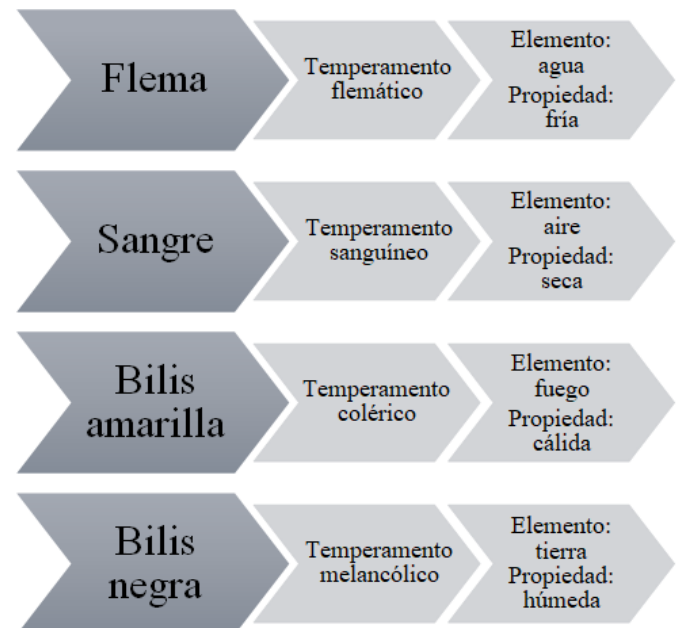

Figura 1. Elaboración propia. Asociación de los humores hipocráticos con sus temperamentos y los elementos que ofrecen los estoicos.

Además de prestar atención a la posibilidad de caer en un estado de ira por disposición natural, Séneca también atestigua la existencia de otros factores involucrados en el temperamento. ${ }^{10}$ Un ejemplo es el entorno de la región en la que un sujeto se halla. Según donde habite el sujeto, cuestiones naturales como el propio clima, la abundancia o carencia de viento y agua y la alimentación incrementan o disminuyen el calor. Por esta razón, algunas zonas territoriales resultan más apacibles y otras más violentas (Gal. SM 9, 807-808). Otro ejemplo es la edad: mientras la infancia y la adolescencia son edades más proclives al calor, es decir, a la violencia, la vejez es una edad fría según Galeno $(S M 10,810)$ y Séneca (Dial. Iv, 19-20, 1). Otro aspecto para tener en cuenta es el régimen de vida, fundamentado en la bebida y la alimentación, que aumenta el calor corporal. ${ }^{11}$

10 Cicerón denomina proclivitas a las pasiones, enfermedades e inclinaciones morales perversas a las que nos dirige nuestra constitución física. En el caso de que nuestra disposición nos incline a beneficios, utiliza el término facilitas. Véase Tusc. IV, 12, 28. Cf. Fillion-Lahille (1984, pp.88-89).

11 En cuanto a la bebida, un ejemplo común que ofrecen tanto Séneca como Galeno 
Como últimos factores implicados en nuestra alma, cabe destacar algunas concomitancias externas. Séneca menciona como ejemplos sucesos inesperados y malas costumbres procedentes de las normas sociales (Dial. IV, 2, 6; 2, 8-9, 1; 20, 1-4; v, 8, 1 y 7). ${ }^{12}$ Cuando actuamos bajo una pasión, nuestras tendencias van desde intereses personales hasta patrones sociales. Incluso una emoción y su forma de experimentarse pueden ser susceptibles de modificarse según las normas sociales. Por esta razón, a pesar de que las reacciones emocionales son involuntarias, las disposiciones se encuentran en una medida concreta de voluntariedad porque nos sometemos a ellas con un propósito o motivo. ${ }^{13}$

Ante la variedad de circunstancias que influyen en nuestro temperamento y nuestro carácter, ¿cómo es posible prevenir la perturbación de nuestro ánimo? Séneca cita algunos remedios específicos para prevenir o aliviar un ataque pasional, como la anticipación y la dilación. En primer lugar, numerosos impulsos de irritación derivan de expectativas que construimos nosotros mismos respecto a nuestro entorno (Dial. IV, 31, 1-2): "Indigna putamus quae inopinata sunt; itaque maxime commouent quae contra spem expectationemque euenerunt». En estos casos, ha de trabajarse la anticipación, es decir, prever los hechos que pueden acontecer en nuestra realidad y controlar nuestra reacción mediante la conciencia (Dial. IV, 10, $7 ; 22,1-4$ y 31,4$).{ }^{14}$

En segundo lugar, la dilación funciona como mejor remedio para Séneca junto con la anticipación (Dial. Iv, 29-30). Este remedio se debe a que mientras el ser humano goza de una facultad intelectual y perseverante - la razón-, la ira es una pasión precipitada y fugaz. En un pleno ataque de ira, si esperamos, esta decae y la razón se superpone para que el sujeto abandone el falso juicio que lo conducía a la opinio (Dial. III, 17-18). ${ }^{15}$

es el consumo del vino, el cual aumenta el calor de nuestro temperamento. Cf. Sen. Dial. Iv, 19, 5; Gal. $S M 10,809$ y Pl. $L g$. II, 666a-c.

12 Asimismo, lo comparte Elster (2001, pp.46 y 104-106).

13 La misma atención merecen las palabras de Bunge (1985, pp.167-170 y 187-188): las funciones mentales humanas se modelan desde el nacimiento por las cosas con las que nos relacionamos.

14 Precisamente la falta de anticipación es el causante de reacciones irascibles incluso ante objetos y seres inertes, tal como indica nuestro filósofo en Dial. IV, 26 y v, 30, 1.

15 Expertos contemporáneos lo señalan, como Elster (2001, pp.143-147) y Bunge 
Entre las diferentes estrategias para controlar las disposiciones emocionales, se halla mostrar una actitud estoica ante los hechos, la cual ha de ser perfeccionada día tras día visualizando todas las circunstancias que generarían ira y qué reacción y acciones tendrían lugar por nuestra parte. ${ }^{16}$ Estos remedios se encuentran hilados en un eje central, que es la educación (Dial. Iv, 18). Esta educación que Séneca exige se fundamenta en ejercitar la conciencia de forma que todo sujeto conozca el entorno que lo disponga a la ira y, mediante una razón robusta y bien forjada, no se deje dominar por dicha pasión. Cuando nuestro filósofo atiende a esta operación mental o psicológica, se refiere a realizar un examen en el que la conciencia interviene con el fin de captar nuestras malas acciones, es decir, nuestros hechos que suponen una amenaza, puesto que la conciencia capacita al ser humano para evaluarse a sí mismo y corregir su propio pensamiento y conducta (Ep. 16, 1-3, 31-32). ${ }^{17}$ La conciencia advierte no solo de hechos, sino también de cómo el cerebro procesa nuestra percepción. Mientras las acciones de otros están fuera de nuestro control, sí lo está el dominio de nuestra reacción. No es que los sentimientos y la conciencia actúen por separado, sino que se encuentran interrelacionadas. ${ }^{18}$ Ahora bien, el quid de la cuestión radica en cuál se superpone a cuál.

(1985, pp.56, 163-166). El ser humano ya tiene programada la capacidad de aprender y uno de los tipos de aprendizaje, el creativo, consiste en que el sujeto es capaz de construir hipótesis a la hora de solucionar tareas (Levine, 1974 citado en Bunge, 1985). Esta explicación refleja que el aprendizaje es un proceso plenamente activo y en él cobran un papel fundamental los sistemas subcorticales. Ahora bien, dentro del aprendizaje, aportan mayor facilidad la previsión y la anticipación.

16 De hecho, el mismo Elster sostiene que, según un estudio de Dawes (1994), a excepción de algunas terapias conductuales, la psicoterapia no ofrece en esencia ningún tipo de beneficio que supere los que se pueden obtener mediante una actitud apacible, consciente y serena.

17 Respecto a la introspección como terapia, véase Dial. IV, 12; v, 10; 13, 2; 25, 5; $36,1-3 ; 37,3)$.

18 Toda pasión procedente de cualquier impulso es un falso juicio de nuestra razón. Por ello, los seres irracionales o seres cuya razón no se ha ejercitado todavía en profundidad, como los niños, son más proclives a extender sus impulsos irracionales y transformarlos en pasiones. Si la pasión es un juicio, es también una operación intelectual, de forma que la pasión se encuentra en la misma sede que la razón, ergo la educación es clave para ejercitar el autocontrol o conciencia. Disponemos de nociones semejantes en Galeno (SM9, 807-808; 812-813 y 11, 814-817; 822). Cf. Arist. Rh. II, 1379a; Pl. Ti. 87b; Lg. II, 666a; viI, 793e; 791d; $R$. III, 403e; 411b. Cf. Fillion-Lahille (1984, pp.154-162 y 183-186). 
El estoicismo no es una doctrina de la intención, sino que designa las consideraciones completas o insuficientes que hacen tomar una decisión. En otras palabras, toda decisión parte desde un animus virtuoso o perturbado. Entonces, cuando esta decisión se empapa del officium, se convierte en una decisión recta. Esta rectitud no es casual, sino que es aplicada a través de la conciencia. Más bien, es una actitud causal. Por el contrario, un espíritu débil y perturbado toma una decisión en función de las circunstancias, es decir, de la materia. Por esta razón, el hombre sabio para los estoicos es quien posee un animus transformado y cuyas acciones se fundamentan en los officia. ${ }^{19}$ Así pues, la felicidad que el estoicismo persigue no corresponde a encontrar el placer o en "hacer el bien", sino que hacer el bien o hacer lo que nos permite ser felices equivale a hacer lo que forma parte de nuestra naturaleza humana (Veyne, 2005, pp.688-693).

Si una persona padece un estado de perturbación, se debe a que su ratio es débil. Ante este peligro, Séneca deseaba incitar a los suyos y a la humanidad futura a cultivar su capacidad racional, a través de la educatio, a fin de aprender a dominar las emociones, evitar su aprobación y actuar conforme a lo que dicta nuestra conciencia en lugar de nuestras pasiones, lo que denominamos «autocontrol». La cuestión es que disponer de una razón débil y someterse a las pasiones procedentes de juicios erróneos conllevan la autodestrucción. A fin de solventar este peligro en el ser humano, la educación requiere solidez y fundamento desde edades muy tempranas. Varios filósofos, entre ellos los estoicos, transmitieron sus explicaciones puesto que eran conscientes de la decadencia racional que el ser humano fue viviendo en diferentes épocas. De esta manera, Séneca ofrece en De ira la educación como un proceso con el que fortalecer la conciencia frente a las pasiones, entre ellas la ira, procedentes de impulsos de la disposición natural del ser humano.

19 Todos los officia se perciben como obligaciones a raíz de la naturaleza o el cosmos, en el que los seres humanos han recibido sus funciones correspondientes. Lo ajeno a los officia son indifferentia. Se trata de una doctrina eudemonista, no hedonista. 


\section{Bibliografía}

\section{Autores clásicos}

Claudio Galeno. Claudii Galeni. Scripta Minora. Edición de I. Müller, 2 vols., 1891, Leipzig: Teubner.

Lucio Aneo Séneca. Lucii Annaei Senecae Dialogorum libri duodecim. Edición de L. D. Reynolds, 1983, Oxford: Oxford Clarendon Press.

Lucio Aneo Séneca. Diálogos. Introducción, traducción y notas de J. Mariné Isidro, 2000. Madrid: Biblioteca Clásica Gredos.

\section{Bibliografía contemporánea}

Beltrán, J. A., 1999. Introducción a la morfología latina. Zaragoza: Universidad de Zaragoza.

Bunge, M., 1985. El problema mente-cerebro: un enfoque psico-biológico. Madrid: Tecnos [versión al español de B. G. Noriega].

De Vaan, M., 2008. Etymological Dictionary of Latin and the other Italic Languages. Leiden-Boston: Brill.

Elster, J., 2001. Sobre las pasiones: emoción, adicción y conducta humana. Barcelona-Buenos Aires-México: Paidós [versión al español de J. F. Álvarez y A. Kiczkowski].

Ernout, A. y Meillet, A., 1985. Dictionnaire Étymologique de la Lange Latine: Histoire des Mots. $4^{\mathrm{a}}$ ed. París: Klincksieck [1 $1^{\text {a }}$ ed. 1932].

Fillion-Lahille, J., 1984. Le De ira de Sénèque et la philosophie stoïcienne des passions. París: Klincksieck.

Gaffiot, F., 2000. Le Grand Gaffiot. Dictionnaire Latin-Français. Nouvelle édition revue et augmentée sous la direction de Pierre Flobert. París: Hachette [1 $1^{\text {a }}$ ed. 1934].

Veyne, P., 2005. L'empire grâeco-romain. París: Seuil.

Warner, C. T., 2008. La ira y similares ilusiones. Cuadernos de Información y Comunicación, 14, pp. 33-63. 


\title{
MAGIA «AGONÍSTICA» EN LAS METAMORFOSIS DE APULEYO (I, 9): FICCIÓN Y REALIDAD
}

\author{
"Agonistic» magic in Apuleius' Metamorphosis (I, 9): \\ fiction and reality \\ Diego Meseguer GonzÁlez ${ }^{1}$
}

Resumen: En este estudio se analiza un pasaje de Las Metamorfosis de Apuleyo (I, 9) en el que Meroe, una bruja de Tesalia, transforma en animales a tres rivales suyos: a un amante infiel lo convierte en castor; a un tabernero, en rana; y a un abogado, en carnero. Estas tres metamorfosis reflejan metafóricamente los defectos de cada uno de estos individuos y contribuyen a su caracterización literaria. Por otro lado, el contexto «agonístico» en el que se enmarcan permite establecer una relación entre este pasaje literario y las prácticas mágicas reales documentadas en los papiros mágicos y defixiones.

Palabras clave: metamorfosis, magia, Meroe, literatura, defixiones.

Abstract: This paper discusses a passage from Apuleius' Metamorphoses $(I, 9)$ in which Meroe, a witch from Thessaly, transforms into animals three rivals of her: an unfaithful lover is turned into beaver, an innkeeper becomes a frog and a lawyer changes to a ram. These three metamorphoses metaphorically show the faults of each man and contribute to their literary

1 Doctorando. Universidad de Zaragoza. Correo electrónico: diegoynh@gmail. com. 
characterization. On the other hand, the «agonistic» context in which they are framed allows us to connect this literary text to real magical practices reported in magical papyri and defixiones.

Keywords: metamorphosis, magic, Meroe, literature, defixiones.

\section{INTRODUCCIÓN}

Los tres primeros libros de Las Metamorfosis incluyen varios episodios en los que la magia ocupa un lugar destacado (Fick, 1985; Frangoulidis, 2008). En uno de ellos se narra la historia de Meroe, una tabernera experta en toda clase de maleficios que atormentaba a los ciudadanos de Hípata, en Tesalia, con sus malas artes y brujerías. Ésta podía someter a su arbitrio a cualquier persona, encadenarla con lazos de amor e incluso penetrar en su mente y leerle el pensamiento. Pero sin duda, uno de los mayores poderes de Meroe, y por extensión de todas las brujas de Tesalia, era transformar a sus víctimas en animales. Así lo expresa Aristómenes, el narrador de este episodio, cuando advierte a Lucio, protagonista de la novela, de lo que Meroe era capaz de hacer a aquel que se atrevía a desafiarla:

«A uno de sus amantes, que había tenido la osadía de ir con otra, lo transformó en castor con una sola palabra para que corriera la misma suerte que este animal salvaje, que por temor a la cautividad se libra de los cazadores seccionándose los genitales. A un tabernero vecino suyo, y que por tanto le hacía la competencia, lo transformó en rana; ahora, el pobre viejo aquel nada en un tonel y sumergido en las heces del vino saluda cortésmente con su ronca voz a sus antiguos clientes. A un abogado del foro que había hablado mal de ella lo transformó en carnero y ahora ahí tenéis al carnero aquel defendiendo pleitos» (Apul. Met. I, 9). ${ }^{2}$

2 Amatorem suum, quod in aliam temerasset, unico verbo mutavit in feram castorem, quod ea bestia captivitati metuens ab insequentibus se praecisione genitalium liberat, ut illi quoque simile, quod venerem habuit in aliam, proveniret. Cauponem quoque vicinum atque ob id aemulum deformavit in ranam, et nunc senex ille dolio innatans vini sui adventores pristinos in faece submissus officiosis roncis raucus appellat. Alium de foro, quod adversus eam locutus esset, in arietem deformavit, et nunc aries ille causasagit. 
El objetivo de este estudio es ahondar en el significado de estas tres metamorfosis e interpretar el contexto en el que se enmarcan. Para ello adoptaremos una doble perspectiva. Por un lado, mediante el análisis literario del texto trataremos de averiguar la función que desempeñan en las metamorfosis estos tres animales -el castor, la rana y el carnero- y examinaremos su posible relación con el carácter de las personas transformadas. Y por otro, a través de un enfoque que trasciende el plano de lo estrictamente literario, compararemos la magia de Meroe con las prácticas mágicas reales documentadas en los papiros y sobre todo en las defixiones. Con ello llegaremos a dos conclusiones distintas. En primer lugar, las metamorfosis no constituyen un fenómeno arbitrario, sino que Meroe escoge estos tres animales porque, de un modo u otro, revelan de manera cómica la naturaleza de sus víctimas. Y en segundo término, al contrastar ficción y realidad, podremos comprobar que, a pesar de su marcado carácter literario (Keulen, 2006), este pasaje de Apuleyo refleja un aspecto esencial de la sociedad de su tiempo: el espíritu competitivo y el afán por superar a un adversario. Como podremos comprobar, Meroe elimina con su magia a tres rivales suyos guiada por los mismos estímulos y emociones que impulsaron a actuar a los autores de las tablillas de maldición, de modo que sus operaciones se enmarcan en un contexto «agonístico» (Faraone, 1991).

\section{LA METAMORFOSIS EN CASTOR}

La primera víctima de las metamorfosis realizadas por Meroe es un amante que le había sido infiel y que, a consecuencia de sus actos, es transformado en castor. Como señala Apuleyo, el castor es un animal que, cuando se ve amenazado o acorralado por sus perseguidores, se secciona los genitales y huye a toda prisa. En este sentido, la autocastración de los castores constituye un tema proverbial en la literatura greco-latina. ${ }^{3}$ Sobre ella dan cuenta los estudiosos y naturalistas de la época, que atribuyen esta acción desesperada a su instinto de supervivencia y sobre todo al apreciado

3 Algunos gramáticos de la Antigüedad establecieron una relación etimológica entre castor y castratio (Serv. G. I, 58; Isid. Orig. XII, 2, 21), aunque esta hipótesis carece hoy de fundamento (Ernout y Meillet, 1951, p.185). 
valor del «castóreo», un líquido extraído de unas glándulas situadas junto a los órganos sexuales y que era muy codiciado en la Antigüedad por sus propiedades medicinales. ${ }^{4}$ Por su localización y forma de «bolsita», algunos autores, como Apuleyo, identificaron erróneamente estas glándulas con los testículos del animal.

Meroe pretende, por consiguiente, que su amante infiel corra la misma suerte que los castores y se ampute a sí mismo los genitales. En relación a ello, la metamorfosis resulta de lo más apropiada, ya que la castración constituía un castigo típico del adulterio. Así lo refleja la documentación de la época, que subraya con énfasis la crueldad de esta condena y su amplia difusión entre las élites. Por ejemplo, en una comedia de Plauto el esclavo Palinuro advierte a su señor de las terribles consecuencias que acarrearía ser descubierto in fraganti con una rica matrona y le dice irónicamente que tenga cuidado con los «testi...testigos» (Curc. v.28). Valerio Máximo señala que un tal Vibenio sorprendió a Carbón Atieno con su mujer y luego lo castró, y que Publio Cerennio hizo lo propio con Poncio (VI, 1, 1, 13). Por su parte, Horacio se burla de aquellos «a los que les segaron los testes y el rabo salaz» (Sat. I, 2, 40) y en un tono parecido Marcial aconseja a un marido engañado cortarle el miembro al amante de su esposa (III, 85).

En síntesis, la castración representa, junto a otros tormentos de índole sexual, ${ }^{5}$ el castigo por excelencia de los adúlteros, por lo que su presencia en el texto está plenamente justificada. Ahora bien, desde el punto de vista

4 Esopo ya subrayó en una de sus fábulas las virtudes curativas del castóreo (Aesop. 118), así como Plinio (NH VIII, 109; XXXII, 26-31), Celso (Med. VI, 7, 8) y Eliano (NA VI, 34). Sin embargo, otros autores, como Dioscórides (II, 24, 2) y Sextio Nigro (Plin. NH XXXII, 26), rechazaron esta historia como falsa y cuestionaron que los castores alcanzasen sus genitales con los dientes o sobreviviesen a la herida sin desangrarse. En todo caso, la creencia de que los animales eran conscientes de su propio valor mágico y curativo constituye un aspecto característico del pensamiento antiguo. Por ejemplo, las yeguas conocían perfectamente las virtudes del hipomanes, una excrecencia carnosa que tenían los potros en su frente y que devoraban nada más nacer para que no se utilizara como ingrediente en los filtros amorosos (Ael. NH III, 17).

5 Por ejemplo, la sodomía (Val. Max. VI, 1, 1, 13; Hor. Sat. I, 2, 40-50), la depilación del vello púbico (Ar. Pl. v.165; Nu. v.1083) o el llamado raphanismos, un castigo consistente en introducir un «rábano" (@́ $\alpha \varphi \alpha v i ́ \varsigma)$ por el ano del adúltero (Ar. Nu. v.1083; Catull. 15; Juv. X, 310-315; Luc. Peregr. 9). 
de la magia, la mutilación de los genitales no figura entre las operaciones comúnmente realizadas por las brujas para resolver un infortunio amoroso. En vez de castigar al adúltero, la estrategia más habitual era seducirlo de nuevo con filtros y pócimas de amor, como hace Canidia con su querido Varo (Hor. Epod. V, 55-60) o Deyanira con Hércules (Sen. Herc. Oet.v.453). ${ }^{6}$ Otra alternativa, más prudente y sensata, era comprobar de antemano si el amante había sido realmente infiel. En relación a ello, los Papiros Mágicos Griegos (PGM) incluyen varias recetas pensadas para verificar la castidad de un amante, normalmente una mujer, empleando para ello diferentes técnicas e instrumentos. ${ }^{7}$ Por ejemplo, para que una mujer confiese el nombre del que ama mientras duerme, se recomienda "poner bajo sus labios o sobre su corazón una lengua de pájaro» y preguntarle (PGM LXIII, 10-15). ${ }^{8}$ Por otro lado, las infidelidades amorosas era una de las preguntas habituales que se hacían a los oráculos, como se observa en una tablilla descubierta cerca de Dodona (Parke, 1967, p.266) o en un pasaje de El falso profeta de Luciano, donde un cliente pregunta al adivino Alejandro si su mujer le estaba engańando con otro a escondidas (Luc. Alex. 50).

No obstante, aunque Meroe era una experta en magia amorosa y practicaba con frecuencia la adivinación, ${ }^{9}$ al final optó directamente por

6 Un paralelo real de época moderna comparte ciertos rasgos en común con las narraciones literarias. A comienzos del siglo XIX se llevó a cabo en Mahón (Mallorca) un proceso de fe contra Antonia Mañana, una mujer con fama de bruja que ayudó a una amiga suya a seducir de nuevo a su amante. Para ello le ordenó obtener un «pelo deshonesto» del hombre en cuestión y hacerse un lazo con él empleando para ello seda negra y coloreada. Este lazo debía llevarlo tres días bajo el pecho y en contacto con la piel. Transcurridos los tres días, su amiga debía acudir a la casa del amante derramando por el camino, gota a gota, un líquido de color verde que Antonia le había proporcionado, al tiempo que recitaba tres veces seguidas la oración de Santa Elena (Picazo Muntaner, 2018, p.9).

7 Para la traducción de los PGM hemos consultado la edición de J. L. Calvo Martínez y Ma D. Sánchez Romero (1987).

8 Plinio el Viejo transmite unas prácticas muy similares a las descritas en los PGM. Por ejemplo, señala que «un corazón de búho colocado sobre el pecho izquierdo de una mujer mientras duerme, hace que revele todos sus secretos» (NH XXIX, 81), aunque es igual de efectivo emplear una lengua de rana y colocarla en su corazón, ya que así «dirá la verdad a cualquier cosa que se le pregunte» (NH XXXII, 49).

9 Según el narrador de este episodio, Meroe podía hacer que se enamoraran de ella «los habitantes de la comarca y hasta los indios y los etíopes» $(\mathrm{I}, 8,6)$, y respecto a sus dotes 
transformar a su amante en castor, un castigo que, si bien no era el más habitual, como ya hemos apuntado, encaja perfectamente con la caracterización literaria de las brujas de Tesalia, a las que se atribuía la facultad de metamorfosearse en diferentes animales o transformar en ellos a sus rivales. ${ }^{10}$ Por este motivo, el texto de Apuleyo constituye una valiosa fuente de información, ya que supone uno de los escasos testimonios que documentan el uso de magia negra para castigar a un adúltero. Otras brujas famosas de la literatura reaccionaron contra sus maridos infieles de manera más o menos similar, pero volcaron su carácter vengativo directamente sobre la amante del marido, en vez de castigar a este. Es el caso de Medea, que decide castigar a Jasón asesinando a Creusa, su nueva esposa, y a los dos hijos que había tenido con él (Sen. Med. vv. 833-840).

Al silencio de las fuentes literarias se suma la ausencia de tablillas o maldiciones que documenten dicho fenómeno. Varias defixiones hacen alusión a los testículos o al pene de la víctima, pero su mención junto a otras partes del cuerpo y en largas listas anatómicas cuestiona su interpretación como maldiciones destinadas a castrar y someter a un adúltero (Versnel, 1998). Además, aunque existiese una tablilla que buscara explícitamente la castración o disfunción sexual de la víctima, seguramente el objetivo del defigens respondería a unos propósitos más ambiciosos, como romper una relación o separar a dos amantes (Pachoumi, 2013). S. Montero propone como ejemplo tres tablillas que, desde su punto de vista, actuarían como «instrumento de venganza contra cónyuges infieles» (1999, p.180), pero si echamos un vistazo a su contenido, ninguna de ellas sugiere abiertamente esta interpretación. La primera de ellas (DT 135) es una maldición dirigida contra un tal Malción y consiste en una lista de órganos y partes corporales entre los que se incluye el pene de la víctima. Aun así, la mención de sus

de adivinación, más adelante predice con ayuda de sus encantamientos el día exacto en el que iba a ser lapidada (I, 10, 2).

10 Sin ir más lejos, en esta misma novela se describe con detalle la metamorfosis de una bruja en búho (III, 21), aunque estas también eran capaces de transformarse en perros, ratas, moscas (II, 22, 3) e incluso en comadrejas (II, 52). Como Meroe, la bruja Pánfila también transformaba a sus amantes menos complacientes en "piedras, reses o en cualquier animal» (II, 5, 4-8). Las metamorfosis en animales constituyen, en definitiva, un verdadero tópico literario: $c f$. Verg. Aen. VII, 190; Ov.Met.XIV, 1-74; Am. I, 8, 14; Fast.VI, 141; Luc. DMeretr.I, 2; Onos $12 \ldots$ 
«ganancias» (quaestu) y «beneficios» (lucru) apunta a una rivalidad de tipo económico o comercial. La segunda tablilla (DT 228) posee una clara temática amorosa, pero no hay evidencias suficientes que la relacionen con el adulterio. La víctima, una mujer llamada Julia Faustilla, es encomendada a las divinidades infernales sin especificar ningún motivo aparente. Lo mismo podríamos decir de la tercera y última tablilla a la que aduce $S$. Montero (DT 270), donde el propósito del defigens, una tal Septima, no era otro que atraer para sí a un tal Sextilio, sin hacer alusión alguna al tema de la infidelidad y el adulterio.

En definitiva, este pasaje de Las metamorfosis documenta una novedosa imbricación entre magia y adulterio. Casi todas las fuentes referidas al tema manifiestan un carácter preventivo y adoptan la forma de recetas que buscan o bien evitar una infidelidad o bien anticiparse a ella mediante la adivinación. Meroe, sin embargo, pasa directamente a la acción y decide castigar a su amante al estilo de las brujas tesalias, esto es, recurriendo al poder de la metamorfosis. La ausencia de maldiciones destinadas a castigar a un adúltero no niega la existencia de este tipo de operaciones, sino que, más bien, confirma lo complejo que es interpretar estos textos y asignarles una finalidad concreta. O dicho de otro modo, el hecho de que ninguna defixio conservada se refiera explícitamente a la castración u otra forma similar de castigo no impide pensar que, implícitamente, el objetivo último del ritual fuese maldecir a un adúltero. De hecho, es posible que Apuleyo estuviese adaptando al plano estético y literario una práctica real.

\section{LA METAMORFOSIS EN RANA}

La segunda metamorfosis, la transformación de un tabernero en rana, plantea nuevas incógnitas y dificultades. Estamos de nuevo ante una forma de castigo, pero dirigida en este caso no contra un amante infiel, sino contra un tabernero que, como señala expresamente Apuleyo, «le hacía la competencia» a Meroe. ${ }^{11}$ Ahora bien, aunque el motivo subyacente parece

11 Conviene recordar que Meroe era tabernera de profesión (cauponam Meroen, I, 7, 
bastante claro, no lo es tanto el hecho de que Meroe escogiese la rana como animal para la metamorfosis, una elección que, como casi todo lo que rodea a la novela, no es fruto de la casualidad.

La rana ocupa un lugar destacado en el folklore y desde tiempos muy antiguos se ha considerado un animal muy valioso de cara a proteger las cosechas, ya que, según se pensaba entonces y todavía incluso en la actualidad, la rana tiene la facultad de anunciar la lluvia con su croar siempre que se encierre en el interior de un recipiente o permanezca en un lugar subterráneo (Marcos Casquero, 2000, pp.193-196). ${ }^{12}$ Así, en una de sus cartas Cicerón confiesa a Ático que si no falla en sus pronósticos, «las ranas discursean» (Att. XV, 16a) y como señala Virgilio, la lluvia sobreviene siempre que "las ranas cantan en los charcos sus antiguas quejas» (G. I, 378). ${ }^{13}$ Aun así, no tiene mucho sentido que Meroe transforme a un tabernero en rana para que pronostique las condiciones meteorológicas, a no ser, como han sugerido algunos autores, que en el fondo no esté anunciando la lluvia, sino reclamando con su «ronco croar» más vino para el tonel (Ruíz Sánchez, 2000, p.38). Este detalle cómico encajaría a la perfección con la embriaguez proverbial de los taberneros, con la crueldad ilimitada de las brujas y con el tono paródico que envuelve la narración. ${ }^{14}$

7). En la Antigua Roma la caupona gozaba de muy mala reputación y tenía fama de bruja (Kleberg, 1957, p. 85; Moine, 1975). San Agustín asegura que todas las taberneras poseen poderes sobrenaturales (August. De civ. D. XVIII, 18) y un poema atribuido a Virgilio enfatiza su carácter lujurioso y su ebriedad (App. Verg.Cop. v.3).

12 Motivo A 2426.4.1.2 de S. Thompson (1966): Why frog croaks in wet weather. Una reciente investigación ha confirmado esta creencia popular y demuestra que las ranas y los sapos son capaces de detectar las vibraciones a baja frecuencia que produce la lluvia gracias a unos órganos especiales que poseen en su oído interno. Lo hacen cuando se encuentran en refugios subterráneos y empiezan a croar cuando aumenta la humedad ambiental (Márquez, et al., 2016).

13 Las ranas no eran, sin embargo, los únicos animales a los que se atribuía dicha habilidad. Según Eliano, cuando una vaca muge y olfatea el aire es señal de que va a llover, y lo mismo se deduce cuando las ovejas escarban la tierra con sus pezuñas o las cabras se acuestan juntas en el aprisco (Ael. NA VII, 8).

14 El propio nombre de Meroe se construye a partir del sustantivo merum, que significa «vino puro» o «sin mezclar» (Hijmans, 1978; Dos Santos, 1981). Este mismo juego de palabras se usó con el emperador Tiberio, cuyo apego al vino llegó a tal extremo que algunos le llamaban «Biberio en lugar de Tiberio, Caldio en vez de Claudio y Merón (Mero) por Nerón» (Suet. Tib. 42). 
Ahora bien, sin negar la validez de esta última interpretación, creemos que existe una segunda hipótesis que explicaría mejor la razón por la que Meroe transforma al tabernero en rana, una hipótesis que concuerda con el perfil social de la víctima y con el contexto "agonístico» en el que nos enmarcamos. Desde nuestro punto de vista, Meroe transforma al tabernero en rana porque era un competidor suyo ( $o b$ id aemulum) y la rana ha simbolizado, desde tiempos inmemoriales, la idea de decadencia y degradación material. Una muestra de ello serían todas esas historias en las que los reyes y príncipes adoptan la forma de rana y ven cómo su fortuna se desvanece; o al contrario, ranas que por arte de magia se transforman en rey y recuperan con ello su prosperidad..$^{15}$ "Antaño era rana, hoy es rey», es la expresión que utiliza Petronio para describir el ascenso de Trimalción en la escala económica y social (Petron. Sat. 77, 6). Por otro lado, Esopo contrasta el desgobierno y la debilidad de las ranas frente al poder majestuoso de los reyes. En una de sus fábulas, las ranas reclaman a Zeus un rey autoritario que ponga fin a su anarquía y este les entrega un trozo de madera. Ante su indiferencia, las ranas se cansan pronto de él y exigen un soberano de verdad, y es entonces cuando el dios les envía una serpiente que termina comiéndose a todas. Más allá de la moraleja subyacente-«es mejor tener gobernantes tontos pero sin maldad que liantes y malvados» (Aesop. 44) - lo que ponen de relieve todas estas historias es la naturaleza caótica de las ranas y su degradación.

Así pues, a través del simbolismo de la rana, Apuleyo lanza un mensaje directo al lector: Meroe se ha coronado como la reina de las taberneras y su rival más próximo (vicinum) se ha metamorfoseado en un animal asociado tradicionalmente a la idea de fracaso. De nuevo, Apuleyo está adaptando a los códigos de la ficción una realidad tan cotidiana como las maldiciones dirigidas contra rivales económicos. En un mundo tan competitivo (Hes. $O p$. 23) y en el que los recursos constituían un «bien limitado», de suerte que las ganancias de uno suponían las pérdidas del vecino (Tonner, 2012, p.27), la magia se convierte en una herramienta capaz de aliviar las tensiones sociales y desequilibrar la balanza hacia un lado u otro. Un ejemplo de ello son las numerosas defixiones dirigidas contra comerciantes y propie-

15 Motivo D 195 de S. Thompson (1966): Transformation: man to frog. 
tarios de diferentes establecimientos, algunos de ellos taberneros. Aunque en ocasiones puede ponerse en duda la finalidad de estas maldiciones, ya sea porque en ellas aparecen varios nombres o porque a veces el negocio constituye una mera etiqueta ("el herrero», $S G D$ 3; «la costurera», $S G D 72$, etc.), algunos textos son más explícitos que otros, y apuntan claramente a un contexto de disputa comercial:

«Ato con un conjuro las cosas de Ofilión, y a Ofilión, y su taberna "Olimpo". Ato con un conjuro todas las cosas de Melantio, y su taberna "Agatón". Ato con un conjuro todas las cosas de Sirisco, a todas las cosas de Sirisco hago una atadura mágica ${ }^{16}$ (DTA 70)

«Hago una atadura mágica a Anacarsis y a su negocio hago una atadura mágica. A Ártemis el (...) hago una atadura mágica, y al señor de Ártemis hago una atadura mágica. A Hímnide la (...). A Rodión el tabernero hago una atadura mágica, a Rodón $(s i c)$. Que perezca junto a la taberna (...) donde trabaja. Hago una atadura mágica a Rodio el tabernero. Hago una atadura mágica a su taberna. Hago una atadura mágica también al almacén». ${ }^{17}$ (DTA75).

El contenido, el tono, la forma y el lenguaje de estas defixiones se alejan completamente de la narración de Apuleyo, pero ambos textos se apoyan en un sustrato ideológico común, en impulsos y en sentimientos profundamente arraigados en la sociedad de la época. ${ }^{18}$

\section{LA METAMORFOSIS EN CARNERO}

La tercera y última metamorfosis, la transformación de un abogado en carnero, es seguramente la más difícil de interpretar. Apuleyo deja claro el motivo de la metamorfosis -el abogado, según parece, «había hablado mal de Meroe»- pero, una vez más, deja abierta la cuestión relativa al animal:

16 López Jimeno, 2001, p.42.

17 López Jimeno, 2001, pp.43-44.

18 Junto a los ejemplos señalados arriba, también pueden incluirse dentro de esta categoría las tablillas DTA 68; DT 47; 52; 72-73; 92; SGD 20; 52; 73; 75; 88 y 124. 
¿por qué un carnero? Al no ofrecer ninguna explicación, el autor otorga a la narración cierta dosis de ambigüedad, pudiendo dar pie a dobles o incluso triples lecturas, como hemos visto con la rana (Winkler, 1985). Pero también es posible que Apuleyo renuncie a dar explicaciones porque las estimaba innecesarias y porque era plenamente consciente de que el lector de su época conocía las relaciones simbólicas que existían entre el carnero y el abogado, unas relaciones que podían arraigar en la tradición folklórica o basarse en algún estereotipo o rasgo fisiognómico. Sea como fuere, la elección del carnero no es de ningún modo casual y, lo mismo que sucedía con el castor y la rana, responde sin duda a un propósito estético y literario.

En este sentido, la principal característica del carnero, o al menos el rasgo en el que más inciden las fuentes, es, por un lado, su retorcida cornamenta y, por otro, la violencia que exhiben en el momento del apareamiento, cuando «se disputan las ovejas luchando contra sus rivales» (Ar. Hist. An. 571b; Ael. NA I, 26). De este modo, dada la vehemencia con la que algunos abogados se acusaban mutuamente en el foro, tal vez la comparación entre un abogado y un carnero no sea del todo inverosímil. Sin embargo, carecemos de otras fuentes y testimonios que refuercen dicho parangón. Otra posibilidad es interpretar la metamorfosis en carnero como la expresión simbólica de la sumisión y obediencia hacia Meroe. Por lanzar calumnias contra ella, el abogado merecía un castigo ejemplar y la mejor forma de cumplirlo era transformarse en carnero, un animal que se caracterizaba precisamente por "preferir a las ovejas viejas en lugar de a las jóvenes» (Hist. An. 546a), y Meroe era, como señala Apuleyo, una mujer galante pero «entrada en ańos» $(I, 7,7)$. Ya por último, si vamos un poco más allá, la estampa típica de un abogado conduciendo al resto de juristas y letrados a los tribunales podría evocar en el lector la imagen cómica de un carnero guiando a las ovejas al redil (Prop. III, 13, 40).

Ninguna de estas hipótesis, sin embargo, parece del todo convincente, de manera que la relación análoga entre el abogado y el carnero sigue siendo objeto de discusión. No obstante, si nos alejamos del plano metafórico y damos un salto a la realidad, detrás de esta tercera metamorfosis se esconde todo un trasfondo ideológico que apunta de nuevo a unas prácticas mágicas reales. En efecto, la magia negra constituía un instrumento recurrente en los procesos judiciales, pensado para atacar a un demandante o evitar la declaración de un testigo. Los abogados, de hecho, también figuraban 
entre los principales objetivos. Por ejemplo, Aristófanes cuenta cómo a Tucídides «se le quedaron de repente las mandíbulas paralizadas cuando fue acusado en un juicio» (Ar. V.v.946), un gesto espontáneo cuya causa se debía, según tales creencias, a un conjuro lanzado contra él (Faraone, 1989). Cicerón describe una situación casi idéntica: según él, el abogado Curio se olvidó repentinamente de lo que iba a decir durante su intervención en un juicio y acusó a una mujer llamada Titinia de haberlo hechizado con sus encantamientos (Cic. Brut.217; Orat. 129). Podría objetarse, con razón, que estos testimonios no documentan unas prácticas auténticas, sino que reflejan más bien el comportamiento de unos abogados que, para justificar sus lapsus y desvaríos, utilizaban la magia como una simple excusa. Ahora bien, aunque es cierto que la magia se empleaba a veces como argumento para "externalizar» un fracaso o eludir una responsabilidad, el hallazgo de un gran número de defixiones dirigidas contra abogados, testigos y juristas confirman el alcance de este tipo de prácticas y su amplia difusión en la esfera judicial.

El objetivo de estas maldiciones era casi siempre entorpecer el discurso del adversario y mermar sus facultades verbales y cognitivas, de ahí que la lengua encarne su principal blanco:

«Señor Retenedor, ato con un conjuro a Diocles, porque es mi oponente, la lengua y las entrańas y a todos los ayudantes de Diocles, y su discurso y su testimonio y todas y cada una de las reclamaciones legales que esté preparando contra mí. Retenlo. Que Diocles no gane ninguno de los procesos que está preparando contra mí.Que los ayudantes de Diocles y el propio Diocles sean inferiores a mí ante todo el tribunal y que Diocles no alcance justicia alguna». ${ }^{19}$ (DTA 94)

«A Menón maldigo, elimino y entierro, para que no sostenga el proceso que va a tener lugar en el mes de Memacterión (noviembre). Lo entierro bien enterrado, a él y a sus síndicos». ${ }^{20}$ (SGD 49)

La mayor parte de estas tablillas data de época clásica y casi todas ellas proceden de Atenas. Sin embargo, su concentración en este periodo

19 López Jimeno 2001, p.50.

20 López Jimeno 2001, p.99. 
determinado y en esta ciudad en concreto no significa que tales prácticas fuesen ajenas a este contexto (Faraone, 2012); al contrario, seguramente la magia judicial continuó desempeñando un papel significativo en épocas posteriores e incluso en tiempos de Apuleyo. Prueba de ello son los amuletos diseñados específicamente para protegerse de un litigante o las maldiciones cristianas donde se hechiza la lengua del rival (Meyer y Smith 1999, p.198). ${ }^{21}$ Es cierto que, a diferencia de lo que se observa en las tablillas de maldición, Meroe recurre a la magia después de que el abogado hablara en contra de ella y no antes de celebrarse el juicio, como suele ser lo habitual (Faraone 1991, p.15). Pero si obviamos este matiz entre magia vengativa y magia preventiva, una vez más la bruja se deja arrastrar por los mismos impulsos que empujaban a actuar a los autores de las maldiciones.

\section{ConClusiones}

Llegados a este punto y tras haber analizado detenidamente las tres metamorfosis, podemos extraer varias conclusiones generales que inviten a reflexionar acerca del ambiente y el contexto social en el que se desenvolvían estas prácticas mágicas.

Como ya avanzamos en la introducción, este pasaje de Las Metamorfosis posee un extraordinario interés, ya que puede abordarse desde diferentes enfoques y puntos de vista. En el plano estrictamente literario, Apuleyo recurre al significado de ciertos animales para expresar de manera cómica el castigo impuesto contra el adúltero, el tabernero y el abogado. En algunos casos, la relación que se establece entre la víctima del hechizo y su nueva forma animal resulta del todo evidente y no requiere mayores explicaciones. Es lo que sucede, por ejemplo, con la transformación del

21 Plinio el Viejo menciona varios amuletos que presuntamente aseguraban el triunfo en los tribunales, como un misterioso huevo de serpiente, que gozó de gran popularidad en la Galia (NH XXIX, 54), o la piedra hematites, que ayudaba a todos aquellos involucrados en litigios y procesos judiciales (NH XXXVII, 169). Por otro lado, el autor de la Historia Augusta nos informa acerca del valor mágico que tenía el birrete o pilleus de los recién nacidos, una especie de membrana que cubría la cabeza del feto y que las comadronas vendían a los «abogados crédulos» porque, «según dicen, ayuda en los juicios» (SHA Diadum. 4, 2). 
amante infiel en castor, un animal que evocaba automáticamente la imagen de la castración y el adulterio. Sin embargo, en las otras metamorfosis esta analogía no se antoja tan manifiesta. Como hemos visto, la transformación del tabernero en rana admite varias interpretaciones dentro de la tradición y del folklore, mientras que la conversión del abogado en carnero sigue sin tener una explicación convincente. Apuleyo no ofrece ninguna aclaración que nos ayude a comprender mejor el contexto en el que se inscriben estas dos metamorfosis o que nos permita, al menos, «descodificar» el lenguaje simbólico que subyace en cada una de ellas. Sea como fuere, lo que resulta incuestionable es que los tres personajes -el adúltero, el tabernero y el abogado- desafiaron de un modo u otro a Meroe y lo pagaron con un castigo que refleja metafóricamente su propia naturaleza.

Si vamos más allá del plano de la ficción, las represalias que adopta Meroe contra cada uno de sus rivales encuentran ecos interesantes en las prácticas mágicas reales. De este modo, la primera metamorfosis, la del amante infiel en castor, constituye una versión literaria de las maldiciones dirigidas contra los adúlteros, una magia de la que apenas tenemos constancia en las fuentes, pero que, a juzgar por las recetas de los papiros y las preguntas oraculares, desempeñaba sin lugar a dudas un papel importante en las relaciones amorosas. Por su parte, la transformación del tabernero en rana proyecta las mismas expectativas mentales que las de aquellos individuos que, viendo peligrar su propio negocio o bienestar, recurrían a la magia con la intención de eliminar a un competidor y proteger su fortuna. Las defixiones comerciales representan, en este sentido, un documento muy ilustrativo. Y ya por último, la metamorfosis del abogado en carnero constituye una adaptación de los hechizos y maldiciones que se lanzaban contra los oponentes de un pleito judicial, como jueces, abogados, testigos $y$, en definitiva, cualquier individuo que formara parte del grupo litigante.

A la luz de estos paralelismos, es posible establecer una conexión entre este pasaje perteneciente a la ficción literaria y las prácticas mágicas reales documentadas en los papiros y defixiones. Ahora bien, cometeríamos un grave error de apreciación si consideráramos dicha conexión como algo más que una mera coincidencia: el hecho de que en este pasaje converjan los tres tipos más comunes de defixiones-amorosas, comerciales y judiciales- no significa que Apuleyo y sus coetáneos reconozcan la existencia de esta taxonomía. Lejos de ello, la clasificación de las defixiones responde 
a unos criterios subjetivos y carece de valor heurístico. Pero de lo que sí estamos seguros, y ello nos lleva a una última reflexión, es que, a través de este episodio, Apuleyo refleja un rasgo característico de la sociedad de su tiempo, y es el espíritu competitivo y afán de superación que imperaba en todos los ámbitos de la vida, sea en las lides del amor, en el mundo de los negocios o en el farragoso campo de las leyes. En este contexto «agonístico", la magia se constituye como uno de los principales instrumentos de acción, desplegándose a través de unas prácticas que en el plano ficticio de la literatura adopta la forma de las metamorfosis y que en el mundo real seguía recurriendo a los hechizos y tablillas de maldición.

\section{BibliografíA}

\section{Autores clásicos}

Apuleyo. El asno de oro. Edición de L. Rubio Fernández, 1987. Madrid: Gredos. $D T=$ Audollent, A., 1904. Tabellae Defixionum. París: Fontemoing.

DTA = Wünsch, R., 1897. Defixionum Tabellae Atticarum. Berlín: AcademiaeLitterarumRegiaeBorussicae.

PMG = Preisendanz, K., 1974. PapyriGraecae Magicae. Die GriechischenZauberpapyri. $2^{\text {a }}$ ed. Stuttgart: Teubner.

Textos de magia en Papiros Griegos. Edición de J.L. Calvo Martínez y Ma D. Sánchez Romero, 1987. Madrid: Gredos.

Textos griegos de maleficio. Edición de A. López Jimeno, 2001. Madrid: Akal.

\section{Bibliografía contemporánea}

Dos Santos, Ma G., 1981. Nomes propios nasMetamorfoses de Apuleio. Euphrosyne, 11, pp.142-148.

Ernout, A. y Meillet, A., 1951.Dictionnaireétymologique de la langue latine: histoire des mots. $3^{\text {a }}$ ed. París:Klincksieck.

Faraone, C., 1989. An accusation of magic in Classical Athens (Ar. Wasps 946948).TAPhA, 119, pp.149-160.

Faraone, C., 1991. The Agonistic Context of Early Greek Binding Spells. En: C. Faraone y D. Obbink, eds., Magika Hiera: Ancient Greek magic and religion. Oxford: OUP, pp.3-32. 
Faraone, C., 2012. The problem of dense concentrations of data for cartographers (and chronographers) of Ancient Mediterranean Magic: some illustrative case studies from the East. En: F. Marco Simón y M. Piranomonte, eds., Contestimagici. Contextos magicos. Roma: De Luca Editored'Arte, pp.115-122.

Fick, N., 1985. La magiedans les Métamorphosesd'Apulée. REL, 63, pp.132-147. Frangoulidis, S., 2008. Witches, Isis and Narrative.Approaches to Magic in Apuleius' Metamorphoses. Nueva York: Walter de Gruyter.

Hijmans, B.L., 1978. Significant names and their function in Apuleius' Metamorphoses. En: B.L. Hijmans y R. Van der Paardt, eds., Aspects of Apuleius' Golden Ass. Groningen: Bouma'sBoekhuis, pp.107-122.

Keulen, W., 2006. The Wet rituals of the excluded mistress: Meroe and the mime. En: R. R. Nauta, ed., Desultoria Scientia: genre in Apuleius' Metamorphoses and related text. Leuven: Peeters, pp.43-61.

Kleberg, T., 1957.Hôtels, restaurants et cabarets dansl'Antiquité romaine. Upsala: Almquist\&Wiksells.

Marcos Casquero, M., 2000. Supersticiones y creencias en ranas y sapos. En: M. Marcos Casquero, Supersticiones, creencias y sortilegios en el mundo antiguo. Madrid: SigniferLibros, pp.173-225.

Márquez, R., et al., 2016.Synthetic rainfall vibrations evoke toad emergence. Current Biology, 26 (24), pp.1270-1.

Meyer, M. y Smith, R., 1999. Ancient Christian Magic: Coptic Texts of Ritual Power.Nueva York: Harper Collins.

Moine, N., 1975. Augustin et Apulée sur la magie des femmesd'auberge. Latomus, 34(2), pp.550-566.

Montero, S., 1999. Magia y adulterio en la Roma Antigua. En Religión y magia en la antigüedad: seminario celebrado en Valencia del 16 al 18 de abril de 1997. Valencia: GeneralitatValenciana, pp.167-182.

Pachoumi, E., 2013. The Erotic and Separation Spells of the Magical Papyri and Defixiones. GRBS, 53, pp.294-325.

Parke, H., 1967. The Oraclesof Zeus. Cambridge: Harvard University Press.

Picazo Muntaner, A., 2018. El miedo a la bruja en un entorno rural. Dos ejemplificaciones de terror colectivo. Revista de Folklore, 433, pp.1-10.

$S G D=$ Jordan, D., 1985. A Survey of Greek Defixiones. GRBS, 26 (2), pp.151-197.

Thompson, S., 1966.Motif-index of folk-literature: a classification of narrative elements in folktales, ballads, myths, fables, mediaeval romances, exempla, fabliaux, jest-books and local legends. $2^{\mathrm{a}} \mathrm{ed}$. Bloomington: Indiana UniversityPress.

Tonner, J., 2012. Sesenta millones de romanos. La cultura del pueblo en la Antigua Roma. Trad. de Luis Noriega. Barcelona: Crítica.

Ruíz Sánchez, R., 2000. Assinus in fabula: relaciones intratextuales e intertextuales en la primera parte de El asno de oro de Apuleyo. EstudiosClásicos, 42 (117), pp.35-74. 
Versnel, H., 1998. An Essay on Anatomical Curses. En: F. Graf, ed., AnsichtengriechischerRituale. Geburtstags-Symposium für Walter Burkert. Stuttgart: Teubner, pp.217-267.

Winkler, J., 1985. Auctor \& Actor: a narratological reading of Apuleius' Golden Ass. Berkeley: University of California Press. 



\section{PROBLEMAS METODOLÓGICOS EN EL ESTUDIO DEL CEREMONIAL TARDOANTIGUO: A PROPÓSITO DE AMIANO MARCELINO}

\section{Methodological problems in Late Antique empire ceremonial: apropos of Ammianus Marcellinus}

\section{LuZ Miriam Soler GonZÁlez ${ }^{1}$}

Resumen: Este artículo surge como una reflexión sobre la idoneidad y límites de la aplicación de los marcos teóricos provenientes de la antropología y sociología al estudio de los ceremoniales tardoantiguos. Dirigiendo la mirada al debate ya efectuado al respecto desde el medievalismo por autores como P. Buc y G. Althoff, y partiendo como caso práctico de las coronaciones descritas en las Res Gestae por Amiano Marcelino, el objetivo es poner en valor las ventajas de la interdisciplinariedad y la importancia de respetar un método crítico en su aplicación que garantice el valor científico de las hipótesis.

Palabras clave: ritual, coronación, investidura, legitimidad, Juliano, Procopio.

Abstract: This paper emerges as a reflection on the suitability and limits of the use of theoretical frameworks from anthropology and sociology in the study of late-antique ceremonies. Following the debate on the subject

1 Doctoranda. Universidad de Zaragoza. Correo electrónico: mirsoler@unizar.es. El presente artículo ha sido realizado en el marco del proyecto I+D de Excelencia HAR201677003-P financiado por el Ministerio de Ciencia, Innovación y Universidades y cofinanciado por el Fondo Social Europeo. 
by medievalist authors like P. Buc and G. Althoff, and focusing on the coronations described by Amiano Marcelino in the Res Gestae as case-study, the aim of this paper is to emphasise the advantages of an interdisciplinary approach as well as the importance of a critical method that guarantees the scientific value of the hypotheses outlined.

Keywords: ritual, coronation, investiture, legitimacy, Julian, Procopius.

\section{INTRODUCCIÓN}

Desde la segunda mitad del siglo XX muchos son los marcos teóricos que se han desarrollado en el estudio del ritual, ahondando en el conocimiento de este tipo de prácticas por su propia naturaleza y atrayendo miradas desde diferentes disciplinas, que abarcan desde la antropología o la sociología a la filosofía o psicología. Perspectivas cognitivas, simbólicas, neofuncionalistas o basadas en la práctica y la performatividad multiplican la variedad de enfoques con los que se puede analizar un ritual concreto ilustrando diversos aspectos del mismo. Sin embargo, el historiador se enfrenta a un hándicap notable cuando pretende aplicar estos métodos a su propia especialidad y el estudio de los rituales de diferentes periodos históricos, partiendo de unas fuentes que difieren mucho de las utilizadas por las disciplinas anteriores y sujetas a sus propios sesgos y condicionantes.

Este rasgo, inevitable, es la base principal que fundamenta las distintas voces críticas con la aplicación indiscriminada de este tipo de enfoques en el terreno histórico: unas críticas que dieron lugar a un acalorado debate en la década de los 2000 a raíz de la publicación de la obra de Philip Buc The Dangers of Ritual (2009 [2001]). Aunque dirigida especialmente hacia el estudio de la Edad Media, la problemática que destaca Buc en su libro atiende a factores que son familiares a cualquier investigador de la Antigüedad y que es necesario tener presente porque limita la validez de las conclusiones obtenidas en cualquier estudio de este género.

Sin embargo, cabe plantearse si este salto entre disciplinas es realmente insalvable, y si es posible efectivamente un conocimiento de las prácticas rituales del pasado, observadas a través de los textos, capaz de suministrar información relevante sobre el papel de las mismas en su sociedad circun- 
dante. Para comprobarlo, se tomará como caso de estudio las coronaciones imperiales de las Res Gestae de Amiano Marcelino, donde la diferencia entre el hecho histórico, la práctica ritual y su importancia cultural en el siglo IV d. C. se hace especialmente patente.

\section{LA INTERDISCIPLINARIEDAD Y LOS ESTUDIOS DEL RITUAL}

Trabajar el ceremonial tardoantiguo desde los modelos provenientes de la antropología y la sociología requiere en primer lugar abordar una de las cuestiones más problemáticas asociada a los estudios sobre el ritual, que es la propia definición del concepto: un concepto cuya principal característica es generar desacuerdo entre los especialistas, como señalaba ya Leach (1968, p.526).

En función de las diferentes corrientes teóricas, del papel atribuido al mismo y de la inmensa variedad de casos que ha encontrado la antropología, es posible encontrar así mismo una multitud de definiciones de distinto calado, algunas incluso elegidas ad hoc para determinados estudios, o, directamente, casos en los que se elude la definición o se niega el concepto en sí, partiendo de esta dificultad taxonómica (Snoek, 2006, p.3).

Otros enfoques más recientes, sin embargo, han optado por plantear la definición desde una clasificación politética, tal y como se entiende desde la teoría de conjuntos difusos desarrollada por Zadeh (1965; 1976). En este modelo, los miembros de un conjunto no se definen por mostrar todas las características requeridas, como en una clasificación aristotélica clásica, sino por presentar un número suficientes de rasgos que pueden o no estar presentes en el resto de elementos del conjunto (Zadeh, 1965, p.339; Snoek, 2006, pp.4-5). Detectar un ritual, en este contexto, sería similar a efectuar un diagnóstico médico en el que la presencia de una serie de síntomas, aunque no sean todos los posibles, apuntan a una determinada enfermedad.

La definición mediante este modelo, en esencia, mostraría unos límites difusos y abiertos en función de la presencia de un mayor o menor número de características en el objeto de estudio. Por otro lado, este es un rasgo generalmente reconocido dentro de cualquier estudio del ritual, y 
permitiría integrar mejor en el concepto lo que Bell denominaba ritual-like activities, prestando atención al proceso de ritualización de actividades que abarcan desde lo profano a lo sagrado (Bell, 1997, pp.138-139).

El conjunto de características que determinarían el carácter ritual de una ceremonia concreta, por su parte, coincidiría en gran medida con aquellos aspectos más frecuentemente señalados en las definiciones y conceptualizaciones tradicionales: el formalismo frente a lo informal, que marca una diferenciación entre ambos comportamientos; el tradicionalismo vinculante con un pasado que lo sanciona como tal; una tendencia a la reglamentación, con una estructura, localizaciones y periodización generalmente estandarizada y poco variable; las referencias a elementos de carácter simbólico especialmente significativos o sacralizados para sus participantes; $y$, finalmente, una elevada contextualización situacional que condiciona también esa diferencia entre actividad ritualizada y comportamiento cotidiano (Bell, 1997, pp.138-169; Snoek, 2006, pp.14-13). Sin embargo, estas no serían las únicas características, ni serían imprescindibles si se da un cierto número de las otras, para considerar un fenómeno como ritual.

Siguiendo estos planteamientos, Snoek (2006, p.13) propone finalmente la siguiente definición del comportamiento ritualizado: ${ }^{2}$

\begin{abstract}
"Ritual behavior is a particular mode of behavior, distinguished from common behavior. Its performers are (at least part of) its own audience. In general, all human actions can be part of ritual behavior, including speech acts. However, in each particular case the large majority of these will be traditionally sanctioned as proper ritual actions. Most ritual behavior takes place at specific places and/or at specific times. Most ritual behavior is more formally stylized, structured, and standardized than most common behavior. Most ritual behavior is based on a script. Most ritual behavior is to some extent purposeful and symbolically meaningful for its participants. At least those playing an active part consider themselves to be participating in noncommon behavion.
\end{abstract}

2 Nótese que por comodidad y simplificación en este artículo no se va a hacer distinción entre los términos rito, ritual, ceremonia o comportamiento ritualizado, haciendo siempre referencia a esta definición descrita. Los problemas de definición también afectan a estos términos con su propia problemática y no es objetivo del artículo profundizar en este detalle, pero se puede obtener un esbozo en J. Snoek (2006, pp.8-10). 
Detectar qué es y qué no es un ritual con base en un criterio uniforme es en última instancia necesario porque el comportamiento ritual tiene unas determinadas implicaciones. El concepto fue entendido desde el siglo XIX como una herramienta de análisis para abarcar lo que se entendía como una categoría universal de la experiencia humana, utilizado como herramienta para definir la propia esencia de la religión, para comprender los valores de una sociedad concreta o las dinámicas de su cultura, entre otras distintas aproximaciones iniciales (Bell, 2009, pp.14-16). Con el tiempo, se trascendió la idea de la naturaleza eminentemente religiosa del ritual que podemos encontrar ya en Durkheim (1968, pp.39-40) y que permeó en las visiones mito-ritualistas, fenomenológicas, funcionalistas y estructuralistas del siglo XX, para abarcar también un espectro más amplio de actividades sociales, como explicaba ya en su momento Gluckman (1966, pp.20-24).

Así, las diferentes corrientes teóricas de los estudios del ritual los han ido contemplando de distintas maneras. Por ejemplo, como inauguraron los trabajos de Geertz (2003), han sido percibidos como elementos de comunicación de patrones de significado; o siguiendo los postulados del lingüista Austin (1990), como elementos performativos: no sólo capaces de transmitir un significado, sino efectivamente de hacer y crear $\operatorname{cosas}^{3}$. También han sido entendidos como una performance o drama social en el que los ideales culturales son asumidos dentro de las actitudes sociales (Turner, 1987), y como un tipo concreto de praxis especialmente capaz de reconciliar la acción y el pensamiento, ergo la creencia y el comportamiento (Bell, 2009, p.20), en lo que se advierte la profunda influencia de la teoría de la práctica desarrollada por Bourdieu (2007), prestando de esta forma atención a cómo funcionan las mecánicas de ritualización y cómo los ritos van adaptándose y evolucionando con el tiempo. Autores como Boyer y Liénard, trabajando con marcos teóricos provenientes de la psicología cognitiva y la neuropsicología, profundizan por su parte en el ritual como conjunto de acciones seleccionadas a través de la transmisión cultural en función de los efectos específicos producidos en la psicología de sus participantes (Boyer y Liénard, 2006; Liénard y Boyer, 2006).

3 Del mismo modo que la frase «Se abre la sesión» no sólo comunica la apertura, sino que realmente inicia la acción. 
En conjunto, los avances teóricos desde distintos campos multiplican las interpretaciones posibles a realizar en el estudio de cualquier ritual y no solo en la esfera de lo religioso o lo sagrado, tradicionalmente entendida como ámbito exclusivo del rito, sino en múltiples campos de la vida.

Centrándonos en los eventos públicos y prestando atención especialmente a su dimensión social y cultural, se puede señalar de este modo cómo se ha incidido en el carácter del rito como integrador social, modificando la percepción del grupo a través de la performance para intentar reconciliar diferentes contradicciones y conflictos (Rao, 2006, pp.158-159). Los rituales no solo comunican, sino que crean relaciones de poder, autoridades y subordinaciones (Bell, 1997, pp.82-83), al tiempo que ayudan a internalizar los sistemas de creencias y comportamientos que representan (Geertz, 2003, pp.107-108). Sin embargo, más allá de la visión del ritual como una repetición estática e invariable, son también un espacio para el cambio, la discusión de esos mismos patrones y valores y la reinterpretación de los mismos en una arena subjetiva donde sólo la evaluación contextual del mismo separa el ritual fallido de la innovación (Bell, 1997, p.136; Hüsken, 2007, pp.360-361), con las implicaciones que esto supone en cualquier estudio sobre legitimidades y pugnas por el poder.

En definitiva, los trabajos antropológicos y sociológicos que han ampliado el conocimiento sobre el funcionamiento y naturaleza del rito abren diversas formas de comprensión del ceremonial del mundo antiguo y el papel que este ejerció a nivel social y cultural en sus contemporáneos.

\section{Considerando los PELIGROS DEL RITUAL}

El problema surge, sin embargo, en el salto desde este conjunto de modelos teóricos al terreno histórico. A principios de los años 2000, el medievalista Philip Buc comenzaba su obra señalando que sus conclusiones advertian: "against the use of of the concept of ritual for the historiography of the Middle Ages» (Buc, 2009, p.1). Se iniciaba así una feroz argumentación contra el uso de modelos antropológicos y sociológicos, e incluso el propio concepto de ritual, que considera «reductionist, too-often vague and essentially alien» (Buc, 2009, p.247) en su aplicación sobre las fuentes escritas que sostienen el trabajo del historiador. 
Para este autor, que se situaría en lo que Warner (2010, p.1215) denomina la escuela postmodernista de los estudios del ritual, lo que encontramos en un texto medieval sobre un rito no puede relacionarse directamente con la performance real, sino con una interpretación realizada a través de una narrativa concreta con intereses en destacar, enfatizar o desdeñar la solemnidad o impacto del mismo, de tal forma que es esa interpretación, y no la propia ejecución del rito, lo que soportaría las relaciones de poder y autoridad; unas relaciones que derivarían así de la propia interpretación y no de la práctica, y que serían esencialmente similares a las ejercidas por los sociólogos y antropólogos actuales, cuya conceptualización del ritual-siendo ésta la hipótesis más polémica de sus trabajos- tendrían raíces medievales desarrolladas fundamentalmente desde el periodo reformista y, por lo tanto, bases teológicas (Buc, 2000, pp.185-186; 2009, pp.2, 168-170, pass.).

Esta agenda partidista en las fuentes, que ilustra a través de diferentes casos en la primera parte de su libro, ${ }^{4}$ por un lado, y ese problema metodológico y conceptual que atiende en la segunda, ${ }^{5}$ por otro, son los que llevan a rechazar las aproximaciones al ceremonial medieval y antiguo ya que, desde su punto de vista, sería imposible reconstruir la función social y la práctica real del ritual a partir de esas bases inestables y esa circularidad metodológica.

El libro, por supuesto, inició un acalorado debate académico que se prolongó con los matices y respuestas del propio autor perfeccionando su teoría (Buc, 2007). Diversos autores se sumaron a las precauciones, como Warner (2001), que puso en cuestión igualmente la diferencia entre el ritual ejecutado y la memoria conservada del mismo, o Pössel (2009) quien, siguiendo las argumentaciones de Buc, establece diferencias más profundas entre texto y performance del rito, y denuncia la proyección de una imagen supersticiosa y pre-racional sobre los actores medievales del mismo.

4 En su primera sección, Buc analiza las descripciones del ceremonial asociado a la realeza de Liutprando de Cremona y Gregorio de Tours, así como la reinterpretación y apropiación del martirio como ritual en la tardoantigüedad, destacando en todo momento la intencionalidad de las fuentes.

5 En la segunda sección de su obra, Buc realiza un recorrido historiográfico por los orígenes del concepto ritual, que sitúa en la Edad Media y cuyas raíces actuales vincula a la reinterpretación protestante de los ritos católicos, vinculándolos más al ámbito político que al religioso. 
Otros autores, sin embargo, se situaron en el espectro opuesto, como Rollo-Koster $(2001, \$ 18)$, que acusa a Buc de utilizar en sus análisis los mismos modelos sociológicos que critica, Rampton $(2002, \$ 4$ ), que añade a esto último que incluso desde la propia antropología y sociología que se condena se reconoce la imposibilidad de un testimonio objetivo, tanto a través del texto como del espectador directo, o Walsham (2003, pp.284286), que por motivos similares se muestra escéptica con la extrema posición gnoseológica de Buc y señala que, incluso de ser certera la génesis conceptual del término ritual que propone el autor, eso no es óbice para utilizarlo, tal y como ha sido refinado en la teoría actual y siendo consciente de sus límites.

El principal debate, sin embargo, fue encabezado por Koziol (2002) y por Althoff (2002). El primero argumenta que en la práctica profesional ningún historiador o etnólogo trabaja de la forma acrítica que Buc presupone, ni aplica los modelos antropológicos desfasados que denuncia (Koziol, 2002, pp.372-373); mientras que, al mismo tiempo, defiende el uso de las corrientes más recientes de los estudios rituales, basadas en una definición de amplio espectro, una alta contextualización de las prácticas y un estudio de carácter relacional (Koziol, 2002, pp.385-386). El segundo, que trabaja el ritual desde una perspectiva funcionalista no exenta de críticas (Koziol, 2002, pp.381-382; Zupka, 2016, p.31), ofrece por su parte uno de los argumentos más sólidos para reforzar la validez del estudio ritual a través del texto. Según Althoff, aunque los textos puedan ser partisanos, sesgados o manipulados, uno de los requisitos necesarios para que actúen de forma efectiva es su verosimilitud de cara a la audiencia: para cumplir su cometido deben encajar dentro de los marcos culturales del público objetivo y, por lo tanto, aunque se pueda ser escéptico con los eventos históricos narrados, esto no es óbice para poder estudiar las prácticas (Althoff, 2002, p.87).

En definitiva, el debate generado por The Dangers of Ritual entre los especialistas de la historia medieval no deja de atender a un problema epistemológico asociado al método histórico en general, como ya señala Warner (2010, p.1216), y que, en conjunto, se podría resumir entre la idoneidad de una aproximación etic o emic a la Edad Media como cultura, y su factibilidad considerando la barrera textual. 


\section{Amiano y las coronaciones de Juliano y Procopio}

Todo este debate teórico se revela de especial interés cuando nos enfrentamos al estudio del ceremonial tardoantiguo y en particular a los ritos de investidura imperial, un conjunto de ceremonias que, efectivamente, no fueron denominadas como ritus por sus coetáneos (Icks, 2011, p.349), pero que formalmente serían susceptibles de ser incluidas dentro de esa definición politética ofrecida desde la antropología más reciente. En el siglo IV d. C. encontramos este ritual ya en un grado avanzado de estandarización -aunque la casuística sigue siendo variada- y se puede reconocer esa tendencia a la formalidad y teatralidad ajena a lo cotidiano, a la reglamentación con unas determinadas pautas y símbolos casi sacralizados -aunque la ceremonia no se enmarque en el espectro directamente religioso sino civil- y a la sanción a través de la costumbre, si bien en estos momentos es cuando ésta comienza a consolidarse.

Así, la ceremonia de acceso al trono no es todavía un ritual reglamentado hasta el pormenor como se puede encontrar en el mundo bizantino, con unas localizaciones y periodizaciones precisas -aunque existan ciertos patrones habituales- y un formato invariable, sino que es el resultado de un largo proceso de adaptaciones e innovaciones desde el siglo II d. C. que se consolidaría a finales del siglo III, especialmente con Diocleciano y Constantino como hitos afianzando el papel ceremonial de elementos tan significativos como el paludamentum púrpura y la diadema (Ensslin, 1939, pp.364-367; Arena, 2007, pp.329-330). Las fuentes muestran a su vez una evolución que se produjo de forma paralela al desarrollo de nuevas formas de legitimidad basadas en el principio de elección divina (MacCormack, 1981, pp.169-170; Icks, 2011, p.368; Tommasi, 2017) y de una nueva conceptualización del tyrannus, ahora entendido como usurpador más que como mal gobernante (Wardman, 1984; Barnes, 1996; Escribano Paño, 1997; 1998; Humphries, 2008; Omissi, 2018, pp.28-30). Los rituales, como señala Hüsken (2007, pp.338-339), lejos de ser estáticos ofrecen un notable grado de varianza y adaptación, y los periodos de crisis y conflicto, como señalan Bell (1997, p.251) o Rao (2006, p.145), son los principales testigos de la renovación del rito.

En términos muy esquemáticos, en este periodo la ceremonia de investidura consistía en la reunión de las tropas ante un estrado donde el 
ejército aclamaba al nuevo Augustus como tal, tras lo cual era investido con los regalia imperiales: el manto militar púrpura y la diadema. Tras ello, el purpuratus se dirigía a las tropas con una adlocutio que generalmente incluía la promesa de un donativo a las tropas y partía hacia palacio (Ensslin, 1939, pp.364-367; Icks, 2011, p.351).

Para conocer estos rituales, Amiano Marcelino es la fuente más relevante y descriptiva de este periodo. Considerado muy frecuentemente como el último de los historiadores clásicos y una de las fuentes más objetivas para el estudio del siglo IV, lo cierto es que actualmente se le reconoce al antioqueno un elaborado tono alusivo que, a través del uso de rumores seleccionados o de incitar el cuestionamiento de hechos y ausencias, proyecta una visión histórica propia en el espectador (Barnes, 1998, p.88; Kelly, 2008, p.88; 2009, p.360; Weisweiler, 2015, pp.129-130). Concluidas sus Res Gestae c. 390-392 d. C. -fecha discutida pero más probable- hay que considerar que Amiano dispuso por lo tanto de un tiempo notable para elaborar su relato (Matthews, 2007, pp.25-30; Boeft et al., 2008, p.xiii), y autores como Kelly (2008) o Ross (2016) ofrecen ejemplarmente un análisis de los recursos retóricos, narrativos e intertextualidad aplicada de este historiador, que puso al servicio, especialmente, de la defensa de la memoria de Juliano el Apóstata ante el auditorio romano (Ross, 2016, p.51), como último emperador en ostentar el conjunto de las uirtutes de un optimus princeps en contraste con el resto de purpurati del periodo. ${ }^{6}$

$\mathrm{Al}$ igual que los autores medievales analizados por Buc (2009), Amiano no es un testigo imparcial de los acontecimientos, y una de las vías en las que proyecta esa opinión es a través de las investiduras que describe, cada una de ellas con sus propias peculiaridades y casuística dentro del esquema básico antes mencionado. Dos casos destacan especialmente en su contraste, iniciados ambos como usurpaciones: la investidura de Juliano (Amm. XX, 4-5) y la de Procopio (Amm. XXVI, 6, 13-19), que se enfrentó a Valente y Valentiniano presentándose como último candidato de la dinastía constantiniana, y que es clave por cuanto es descrita como una parodia perfecta del ritual tradicional.

6 Véase, como uno de los ejemplos más explícitos de esta exposición de virtudes, Amm. XXV, 4. 
Amiano, que dice ser testigo ocular de los hechos, describe de la siguiente forma la coronación de Juliano como Augusto. Esta se produciría en el año 360 , en un contexto en el que las tropas galas mostrarían su resistencia a la demanda de Constancio II de trasladarlas a Oriente:?

«Pero al comenzar la noche, se pusieron en movimiento y, con el ánimo enardecido según el grado en que este hecho inesperado afectaba a cada uno, se lanzaron a la lucha y a la acción. Así, con enormes alaridos, se fueron todos hacia el palacio y, después de rodearlo para evitar que pudiera escapar alguien, con grandes voces aclamaron a Juliano como Augusto, y reclamaron que acudiera decidido ante ellos. A pesar de que tuvieron que aguardar hasta la llegada del día, finalmente, consiguieron que se presentara ante ellos y entonces, al verle, redoblando sus gritos, le nombraron Augusto por unanimidad.

Él, resuelto, se enfrentaba a todos y cada uno, ya mostrando indignación, ya tendiendo sus manos, rogando y suplicando que, después de haber conseguido tantos triunfos y victorias, no cometieran ninguna acción inapropiada, no fuera que esa temeridad inoportuna y ese error provocara una guerra. [...]

Después de estas palabras, los gritos no se calmaron en absoluto. Todo lo contrario, continuaron con el mismo empeño, de manera que, ante los grandes y terribles insultos, el César tuvo que acceder. Entonces, colocado sobre el escudo de un soldado de a pie, y elevado, sin que nadie pudiera mantenerse en silencio, fue nombrado Augusto y se vio forzado a ponerse la diadema. Pero, cuando afirmó que nunca había tenido una, pidieron a su mujer una joya que pudiera ponerse en el cuello o en la cabeza.

Sin embargo, al afirmar él que no era apropiado, como primeros auspicios, ponerse una joya de mujer, buscaron el adorno de un caballo para que coronado así, aun de esa forma vulgar, mostrara una autoridad superior. Pero cuando él insistió en que también eso era vergonzoso, un tal Mauro -que después fue conde y fracasó en el paso de Succo, pero que entonces era lancero de los petulantes-, se quitó un collar que portaba como insignia y lo puso con confianza sobre la cabeza de Juliano. Entonces éste, forzado hasta esta situación extrema, siendo consciente de que no podría evitar un peligro ya inminente si continuaba negándose, prometió a cada uno cinco piezas de oro y una libra de plata. [...]» (Amm. XX, 4, 14-19, trad. Harto Trujillo).

7 Cf. la versión de Amiano con las menciones, de menor entidad, en Julian. Or. V, 11; Lib. Or. XIII, 33-34, XVIII, 95-104; Zos. III, 9, 1-3. 
Este relato muestra la presencia de diversas rupturas y continuidades significativas con el ritual de acceso al trono tradicional. Por un lado, mantiene sus elementos básicos: la presentación ante las tropas, la aclamación espontánea y unánime de los soldados y la investidura con las insignias. 8 Por otro, encontramos rupturas significativas como el recurso al alzamiento sobre escudos en lugar de un estrado -costumbre cuyo único antecedente lo encontramos en Tácito (Hist. IV, 20)9- o la coronación con un torque de soldado en lugar de la diadema, ambas innovaciones que resurgirán en los ritos de coronación bizantinos de la segunda mitad del siglo IV (Walter, 1975, 2001; Teitler, 2002).

Estos aspectos, a pesar de incluir elementos con un origen que parece vincularse más al carácter galo y germano de las tropas del purpuratus que a la propia tradición romana, sin embargo refuerzan la sinceridad de la recusatio imperii de Juliano y el carácter espontáneo de la revuelta, descargando al César de la ambición asociada a un usurpador y resaltando la espontaneidad y unanimidad de la aclamación, un elemento que, con estas características, porta connotaciones de inspiración divina reforzando la legitimidad del Augustus (MacCormack, 1981, p.202; Roueché, 1984, p.187; Wiemer, 2004; Kruse, 2006, pp.313-315).

Del mismo modo, estos elementos, aunque son ajenos al mos romano, en un nivel simbólico destacan las virtudes militares y dinásticas de Juliano. El alzamiento en escudos, en ese sentido, remitiría a un lector informado al líder Brinno, elegido de esa misma forma entre los suyos por su valor y linaje (Tac. Hist. IV, 20), y destacaría así la percepción de las tropas del coraje y ascendencia de Juliano. La coronación con un torques es igualmente significativa, siendo una insignia asociada al valor en batalla y uno de los pocos dona militaria que perduraban en este siglo ${ }^{10}$. El relato su

8 Si bien el paludamentum no se menciona en esta investidura, cierto es que debía formar parte ya de las insignias de Juliano tras su nombramiento como César (Amm. XV, $8,11)$, por lo que hubiera resultado redundante la presentación del manto.

9 La expresión utilizada, impositusque scuto es de hecho exactamente la misma que Tácito utiliza para describir el nombramiento del líder germano rebelde Brinno, como señala ya Teitler (2002, p.504).

10 "[...] la cadena maciza de oro era un premio al valor, y quien se hacía merecedor de ella en ocasiones merecía también aparte de la gloria del ensalzamiento el doble de pro- 
elección, narrado con una estructura triple que asemeja más al ornato de la fábula que a la descripción histórica, contrapone el torques como tercera y definitiva opción cuando Juliano rechaza primero una joya de mujer -con lo que Amiano refuerza la masculinidad del purpuratus- y segundo la equi phalera, una pieza del arnés del caballo cuya tradición remite a los equites y sus animales (Maxfield, 1981, pp.91-95) -y por lo tanto poco digna de un descendiente de Constantino con plena autonomía-. En definitiva, el alzamiento sobre el escudo y la coronación con un torques son elementos que destacan el valor, linaje y servicio en batalla de un Juliano pleno de uirtutes que acepta a disgusto una obligación impuesta por el numen.

Frente a ella, encontramos la investidura de Procopio, en oposición al gobierno de los panonios Valente y Valentiniano. Procopio, del que Amiano ofrece una visión contradictoria entre víctima de las circunstancias y manipulador despiadado, era un familiar de Juliano con una brillante carrera como notario y tribuno (Amm. XXVI, 6, 1), del que se rumoreaba que había sido elegido como sucesor del Augustus mediante la entrega de un paludamentum (Amm. XXIII, 3, 2). Tras las muertes de Juliano y Joviano, Procopio reapareció en el año 365 como usurpador en Constantinopla, convirtiéndose en una seria amenaza al gobierno de Valente y siendo derrotado sólo tras la deserción en batalla de parte de sus generales principales. ${ }^{11}$

Su investidura se relata en estos términos:

«De este modo, tal como habían pactado, cuando comenzó a brillar la luz del sol, el citado Procopio, teniendo que atender diversos cuidados, se dirigió a los Baños de Anastasia, llamados así por la hermana de Constantino, donde sabía que estaban acampadas las legiones. Y como, gracias a sus cómplices, sabía que todos se habían mostrado de acuerdo con su plan en una reunión celebrada durante la noche, obtuvo la promesa de que

visiones» (Veg. Mil. II, 7). Sobre el uso y connotaciones del torques en el tardoimperio se puede consultar también Speidel (1996) o Walter (2001).

11 Para profundizar más sobre el contexto de esta usurpación, particular por ser la única con raíces orientales, se pueden consultar como fuentes principales, aunque no las únicas, Amm. XXVI, 5-10; Them. Or. VII; Symm. Or. I, 17-22; Zos. IV, 4-8. Igualmente resultan de interés los trabajos de Solari (1932), Austin (1972), Grattarola (1986), Lenski (2002, pp.68-115) o Matthews (2007, p.191). 
conservaría su vida y fue recibido con honor por una multitud de soldados sobornables, aunque lo cierto es que lo tenían como prisionero. [...]

Y así permanecía descompuesto, hasta tal punto que podría pensarse que había salido de los infiernos. Entonces, como no se encontraba una vestimenta imperial, le pusieron una túnica con adornos de oro, semejante a un sirviente de palacio, ya que de los pies a la cintura parecía un paje del servicio de palacio. Además, llevaba los pies cubiertos de púrpura, una lanza $y$, asimismo, un paño púrpura en su mano izquierda, semejante a un personaje grotesco en un escenario teatral o en una representación de mimos.

Así pues, elevado a esta parodia completa de todo tipo de honores, con halagos propios de un esclavo, se dirigió a los que le apoyaban prometiéndoles grandes riquezas y dignidades, como primer fruto de su principado. A continuación, se presentó en público rodeado por una multitud de soldados y se apresuró a marchar con gran orgullo entre los estandartes izados, acompańado por el terrible resonar de los escudos, que lanzaban un lúgubre sonido y que los soldados colocaban apińados sobre sus cascos por temor a que, desde lo alto de las casas, fueran atacados con piedras o trozos de tejas.

Mientras Procopio avanzaba sin temor alguno, el pueblo ni se enfrentaba a él ni le apoyaba. Sin embargo, se dejaban llevar por el atractivo de la novedad, algo innato entre la plebe y, sobre todo, les incitaba el hecho de que todos sin excepción detestaban a Petronio, como hemos relatado, pues este con su violencia estaba aumentando sus riquezas y enfrentándose a diversos órdenes debido a la investigación tanto de algunos asuntos sepultados tiempo atrás como de deudas ya condonadas.

Y así, cuando el citado Procopio ascendió al estrado, como todos se quedaron inmóviles por la sorpresa, sintió temor ante este silencio agobiante y creyó que se había dirigido derecho a la muerte, como esperaba, ante lo cual todo su cuerpo comenzó a temblar y, sin poder hablar, permaneció callado durante bastante tiempo. Finalmente, comenzó a decir unas pocas palabras con voz entrecortada y moribunda, justificándose por su parentesco con la familia imperial. Y entonces, mediante los comentarios de unos pocos que habían sido sobornados, y después ya con la aclamación tumultuosa de la plebe, fue nombrado emperador en medio de una gran confusión. Después de esto, se dirigió rápidamente a la Curia. Pero, como 
no encontró allí a nadie ilustre, sino tan solo a unas pocas personas de baja condición, entró raudo en el palacio con los peores presagios.

Algunos se sentirán admirados de como algo que comenzó de forma tan irrisoria, precipitada y azarosa, se convirtió en una calamidad temible para el estado. Y tal vez, si son desconocedores de otros ejemplos del pasado, pensaran que era la primera vez que sucedía esto» (Amm. XXVI, 6, 14-19, trad. Harto Trujillo).

En esta descripción, en múltiples detalles, se advierte claramente un tono satírico y ominoso que presagia el mal final del usurpador, en el que los elementos claves de la ceremonia de acceso al trono tradicional se muestran completamente ausentes -no hay aclamación explícita por el ejército, no hay diadema o manto púrpura- y se intentan sustituir por otros elementos que acaban por ofrecer una imagen despectiva y cómica de farsa teatral. Frente a la espontaneidad y unanimidad de la aclamación de Juliano por las tropas, Procopio sólo consigue los gritos de un pueblo comprado y manipulado, y frente a la recusatio imperii y templanza de Juliano, Procopio muestra que no está a la altura de las circunstancias, nefasto en su oratoria y carente de las virtudes exigidas a un emperador.

Este relato contrasta vivamente con el desarrollo posterior de los hechos, los notables apoyos que consiguió Procopio en las fases iniciales de su revuelta debido a una especial habilidad en el control de la propaganda y la cuidadosa planificación que dio lugar a la toma en un día, sin especial violencia, de la ciudad de Constantinopla (Austin, 1972; Lenski, 2002, pp.97-104). Construido a través de inversiones y tergiversaciones retóricas, es muy probable que Amiano, que no fue testigo de estos hechos, estuviera recogiendo la versión oficial de la propaganda imperial, sobre todo en contraste con otras descripciones ${ }^{12}$ (Grattarola, 1986, p.89; Lenski, 2002, p.73; Matthews, 2007, p.194; Icks, 2012, p.473).

Los posibles sesgos de estos relatos no impiden sin embargo aproximarnos al valor de esta ceremonia, que se revela especialmente relevante en este periodo por cuanto es disputada en las diversas fuentes. El énfasis que se le otorga apunta a cómo el acto de investidura se había convertido

12 Cf. Them, Or. VII, 10, 91b-c; Zos, IV, 5, 5. 
en estos momentos en un importante elemento de legitimidad que podía diferenciar el ascenso de un usurpador victorioso, Juliano, de otro fallido, Procopio, aunque en la práctica el donatiuum de uno fuera entendido como el soborno de otro.

Si bien por todo esto podemos dudar de la veracidad absoluta de los hechos, tal y como advierte reiteradamente en su obra Buc (2009) respecto a la objetividad de las fuentes antiguas, lo cierto es que ambos relatos permiten advertir, en las ausencias significativas e inversiones, las claves de lo que sería considerado un ritual legítimo; y se revela de nuevo la importancia de la aclamación, de los atributos del poder (la diadema y la púrpura) y de la propia performance del purpuratus, que debía ejemplificar las virtudes imperiales. Y aquí, como propone Althoff (2002, p.87), estos elementos tenían que ser indicadores que los lectores de las Res Gestae debían comprender, porque formaban parte de los patrones culturales de la monarquía romana, y que habían de servir para diferenciar un ritual exitoso a pesar de las innovaciones, como el de Juliano, del ritual fallido a pesar de la sobrecompensación, como el de Procopio.

\section{A MOdo DE CONCLUSIÓN}

No es una novedad señalar en el campo de la Historia que la exégesis adecuada de un texto es imprescindible para comprender qué nos está transmitiendo un autor, dónde situarlo y cuáles son sus intenciones. En el caso de cualquier ritual, ratificar la veracidad absoluta de un texto es imposible incluso ante el testigo más fiel considerado, y lo más frecuente es encontrar proyecciones sesgadas o elaboradas de un rito y no visiones directas y observables. Y en ese sentido, Buc realiza una advertencia certera al señalar que ese es un condicionante mayor para el estudio de los rituales históricos.

Sin embargo, sí que es posible en determinados casos trascender esa visión y aproximarnos a las prácticas, aunque los eventos no sean totalmente precisos y veraces. En los casos aquí descritos, es difícil asegurar con la total certeza, por ejemplo, la triple búsqueda de una corona para Juliano y la sinceridad de su recusatio imperii, la presencia o ausencia del conflictivo paludamentum de Procopio o la comicidad y fracaso del ritual de investidura que describe Amiano desde la distancia. 
Sin embargo, sí que se puede apreciar a partir de su texto la importancia de la diadema y el paludamentum en el ritual, de una correcta performance del investido que resalte su uirtus, o la centralidad de la aclamación en el rito como expresión del consenso y, por lo tanto, de la legitimidad del purpuratus. Y siendo factible esta aproximación a las prácticas, los marcos teóricos procedentes de la antropología y la sociología, contrastados con los textos, nos pueden ayudar a la interpretación y comprensión del papel que ejercieron en la construcción y sostenimiento de las relaciones de poder y autoridad. La importancia creciente de estos rituales de acceso al trono en los textos y en las disputas por el poder, como se advierte en este caso en Amiano Marcelino, deberían ser una muestra de que no eran una mera formalidad o peculiaridad cultural, sino que efectivamente eran un elemento performativo de cara a sus coetáneos y un recurso de legitimidad.

La reflexión final, por lo tanto, es una puesta en valor de la antropología y la sociología como herramientas para comprender la práctica ritual en otros tiempos históricos, aunque como historiadores - de la época que seatenemos que ser conscientes de la diferencia en la naturaleza de nuestras fuentes y trabajar esencialmente desde estas. Aplicar una disciplina sobre otra sin un método crítico que garantice el valor científico de las hipótesis es tan equivocado como rechazar tajantemente la ventaja de aplicar nuevas miradas y preguntas a un fenómeno. Mantener el equilibrio en ello, sin embargo, es lo que exige una ardua labor.

\section{Bibliografía}

\section{Autores clásicos}

Amiano Marcelino. Historia. Edición de M.L. Harto Trujillo, 2002. Madrid: Akal. Amiano Marcelino. Rerum Gestarum, Vol. I. Edición de J.C. Rolfe, 1935. Cambridge (MA): Harvard University Press.

Amiano Marcelino. Rerum Gestarum, Vol. II. Edición de J.C. Rolfe, 2000. Cambridge (MA): Harvard University Press.

Amiano Marcelino. Rerum Gestarum, Vol. III. Edición de J.C. Rolfe, 1986. Cambridge (MA): Harvard University Press, 1986. 
Quinto Aurelio Símaco. Informes - Discursos. Edición de J.A. Valdés Gallego, 2003. Madrid: Gredos.

Tácito. Histories, Annals, Vol. II. Edición de C.H. Moore, 1962. London: William Heinemann.

Temistio. Discursos políticos. Edición de J. Ritoré Ponce, 2000. Madrid: Gredos.

Vegecio. Compendio de técnica militar. Edición de D. Paniagua Aguilar, 2006. Madrid: Cátedra.

Zósimo. Nueva Historia. Edición de J.M. Candau Morón, 1992. Madrid: Gredos.

\section{Bibliografía contemporánea}

Althoff, G., 2002. The Variability of Rituals in the Middle Ages. En: G. Althoff, J. Fried y P.J. Geary, eds., Medieval Concepts of the Past: Ritual, Memory, Historiography. Cambridge: Cambridge University Press, pp.71-88.

Arena, P., 2007. Crises and the Ritual of Ascension to the Throne (First - Third Century A.D.). En: O. Hekster, G. de Kleijn y D. Slootjes, eds., Crises and the Roman Empire. Proceedings of the Seventh Workshop of the International Network Impact of Empire (Nijmegen, June 20-24, 2006). Leiden: Brill, pp.327-336.

Austin, J.L., 1990. Como hacer cosas con palabras: Palabras y acciones. Barcelona: Paidós.

Austin, N.J.E., 1972. A Usurper's Claim to Legitimacy. Procopius in A.D. 365/6. Rivista Storica dell'Antichità, 2, pp.187-194.

Barnes, T.D., 1996. Oppressor, Persecutor, Usurper: the Meaning of «Tyrannus» in the Fourth Century. En: G. Bonamente y M. Mayer, eds., Historiae Augustae Colloquium Barcinonense. Bari: Edipuglia, p. 55-65.

Barnes, T.D., 1998. Ammianus Marcellinus and the Representation of Historical Reality. Ithaca: Cornell University Press.

Bell, C., 1997. Ritual. Perspectives and dimensions. Oxford: Oxford University Press. Bell, C., 2009. Ritual Theory, Ritual Practice. Oxford: Oxford University Press.

Boeft, J. den, Drijvers, J.W., Hengst, D. den y Teitler, H.C., 2008. Philological and Historical Commentary on Ammianus Marcellinus XXVI. Leiden: Brill.

Bourdieu, P., 1992. Rites as acts of institution. En: J.G. Peristiany y J. Pitt-Rivers, eds., Honor and Grace in Anthropology. Cambridge: Cambridge University Press, pp.79-89.

Bourdieu, P., 2007. El sentido práctico. Buenos Aires: Siglo XXI.

Boyer, P. y Liénard, P., 2006. Why ritualized behavior? Precaution systems and action parsing in developmental, pathological and cultural rituals. Behavioral and Brain Sciences, 29, pp.1-56. 
Buc, P., 2000. Ritual and interpretation: the early medieval case. Early Medieval Europe, 9(2), pp.183-210.

Buc, P., 2007. The monster and the critics: A ritual reply. Early Medieval Europe, 15(4), pp.441-452.

Buc, P., 2009. The Dangers of Ritual: Between Early Medieval Texts and Social Scientific Theory. Princeton: Princeton University Press.

Durkheim, É., 1968. Las formas elementales de la vida religiosa. Buenos Aires: Schapire.

Ensslin, W., 1939. The End of the Principate. En: S.A. Cook, F.E. Adcock, M.P. Charlesworth y N.H. Baynes, eds., The Cambridge Ancient History Vol. XII: The Imperial Crisis and Recovery A.D. 193-324. Cambridge: Cambridge University Press, pp.352-382.

Escribano Paño, M.V., 1997. La ilegitimidad política en los textos historiográficos y jurídicos tardíos (Historia Augusta, Orosius, Codex Theodosianus). Revue internationale des droits de l'antiquité, 44, pp.85-120.

Escribano Pańo, M.V., 1998. Constantino y la rescissio actorum del tirano-usurpador. Gerión, 16, pp.307-338.

Geertz, C., 2003. La Interpretación de las Culturas. Barcelona: Gedisa.

Gluckman, M., 1966. Les Rites de Passages. En: M. Gluckman, ed., Essays on the Ritual of Social Relations. Manchester: Manchester University Press, pp.1-52.

Grattarola, P., 1986. L'usurpazione di Procopio e la fine dei Constantinidi. Aevum. Rassegna di Scienze Storiche, Linguistiche e Filologiche, 60(1), pp.82-105.

Humphries, M., 2008. From Usurper to Emperor: The Politics of Legitimation in the Age of Constantine. Journal of Late Antiquity, 1(1), pp.82-100.

Hüsken, U., 2007. Ritual Dynamics and Ritual Failure. En: U. Hüsken, ed., When Rituals Go Wrong: Mistakes, Failure, and the Dynamics of Ritual. Leiden: Brill, pp.337-366.

Icks, M., 2011. Elevating the Unworthy Emperor: Ritual Failure in Roman Historiography. En: A. Chaniotis, ed., Ritual Dynamics in the Ancient Mediterranean: Agency, Emotion, Gender, Representation. Stuttgart: Franz Steiner Verlag, pp.347-376.

Icks, M., 2012. Bad Emperors on the Rise: Negative Assessments of Imperial Investitures, AD 284-395. Klio, 94(2), pp.462-481.

Kelly, G., 2008. Ammianus Marcellinus: The Allusive Historian. Cambridge: Cambridge University Press.

Kelly, G., 2009. Ammianus Marcellinus: Tacitus' heir and Gibbon's guide. En: A. Feldherr, ed., The Cambridge Companion to the Roman Historians. Cambridge: Cambridge University Press, pp.348-361.

Koziol, G., 2002. The dangers of polemic: Is ritual still an interesting topic of historical study? Early Medieval Europe, 2(4), pp.367-388.

Kruse, T., 2006. The Magistrate and the Ocean: Acclamations and Ritualised Communication in Town Gatherings in Roman Egypt. En: E. Stavrianopou- 
lou, ed., Ritual and Communication in the Graeco-Roman World. Liége: Presses Universitaires de Liège, pp.297-315.

Leach, E.E., 1968. Ritual. En: D.L. Sills, ed., International Encyclopedia of the Social Sciences. Vol. 13. London: The Macmillan Company, pp.520-526.

Lenski, N.E., 2002. Failure of Empire: Valens and the Roman State in the Fourth Century A.D. Berkeley: University of California Press.

Liénard, P. y Boyer, P., 2006. Whence Collective Rituals? A Cultural Selection Model of Ritualized Behavior. American Anthropologist, New Series, 108(4), pp.814-827.

MacCormack, S.G., 1981. Art and Ceremony in Late Antiquity. Berkeley: University of California Press.

Matthews, J., 2007. The Roman Empire of Ammianus. With a New Introduction. Ann Arbor: Michigan Classical Press.

Maxfield, V.A., 1981. The Military Decorations of the Roman Army. Berkeley: University of California Press.

Omissi, A., 2018. Emperors and usurpers in the later Roman empire: civil war, panegyric, and the construction of legitimacy. Oxford: Oxford University Press.

Pössel, C., 2009. The Magic of Early Medieval Ritual. Early Medieval Europe, 17(2), pp.111-125.

Rampton, M., 2002. The Dangers of Ritual: Between Early Medieval Texts and Social Scientific Theory. Interface: The Journal of Education, Community and Values, [en línea] 2(9). Disponible en: <https://commons.pacificu.edu/inter02/71/> [Accedido $21 \mathrm{abr}$. 2019].

Rao, U., 2006. Ritual in Society. En: J. Kreinath, J.A.M. Snoek y M. Stausberg, eds., Theorizing Rituals: Issues, Topics, Approaches, Concepts. Leiden: Brill, pp.143-160.

Rollo-Koster, J., 2001. Review of: Buc, Philippe. The Dangers of Ritual: Between Early Medieval Texts and Social Scientific Theory. The Medieval Review. [en línea] Disponible en: <https://scholarworks.iu.edu/journals/index.php/tmr/ article/view/ 15356> [Accedido 21 abr. 2019].

Ross, A.J., 2016. Ammianus'Julian: Narrative and Genre un the Res Gestae. Oxford: Oxford University Press.

Roueché, C., 1984. Acclamations in the Later Roman Empire: New Evidence From Aphrodisias. The Journal of Roman Studies, 74, pp.181-199.

Snoek, J.A.M., 2006. Defining «Rituals». En: J. Kreinath, J.A.M. Snoek y M. Stausberg, eds., Theorizing Rituals: Issues, Topics, Approaches, Concepts. Leiden: Brill, pp.3-14.

Solari, A., 1932. La Rivolta Procopiana: A Constantinopoli. Byzantion, 7(1), pp.143-148.

Speidel, M.P., 1996. Late Roman Military Decorations I: Neck- And Wristbands. Antiquité Tardive, 4, pp.235-243. 
Tambiah, S.J., 1985. Culture, Thought, and Social Action: An Anthropological Perspective. Cambridge (MA): Harvard University Press.

Teitler, H.C., 2002. Raising on a Shield: Origin and Afterlife of a Coronation Ceremony. International Journal of the Classical Tradition, 8(4), pp.501-521.

Tommasi, C.O., 2017. Immagini cosmiche nella regalità tardoantica: qualche caso dai panegirici latini. En: R. Barcellona y T. Sardella, eds., Mirabilia, Miracoli, Magia: Retorica e simboli del potere nella Tarda Antichità. Ragusa: Edizioni di Storia e Studi Sociali, pp.129-138.

Turner, V., 1987. The Anthropology of Performance. New York: PAJ Publications.

Walsham, A., 2003. Review Article - The Dangers Of Ritual. Past \& Present, 180, pp.277-287.

Walter, C., 1975. Raising on a Shield in Byzantine Iconography. Revue des études byzantines, 33, pp.133-176.

Walter, C., 2001. The Maniakion or Torc in Byzantine Tradition. Revue des études byzantines, 59, pp.179-192.

Wardman, A.E., 1984. Usurpers and Internal Conflicts in the 4th Century A.D. Historia: Zeitschrift für Alte Geschichte, 33(2), pp.220-237.

Warner, D.A., 2001. Ritual and Memory in the Ottonian Reich: The Ceremony of Adventus. Speculum, 76(2), pp.255-283.

Warner, D.A., 2010. Rituals, Kingship and Rebellion in Medieval Germany. History Compass, 8(10), pp.1209-1220.

Weisweiler, J., 2015. Unreliable Witness: Failings of the Narrative in Ammianus Marcellinus. En: L. Van Hoof y P. Van Nuffelen, eds., Literature and Society in the Fourth Century AD: Performing Paideia, Constructing the Present, Presenting the Self. Leiden: Brill, pp.103-133.

Wiemer, H.-U., 2004. Akklamationen im spätrömischen Reich. Zur Typologie und Funktion eines Kommunikationsrituals. Archiv für Kulturgeschichte, 86, pp.27-73.

Zadeh, L.A., 1965. Fuzzy Sets. Information and Control, 8, pp.338-353.

Zadeh, L.A., 1976. A Fuzzy-Algorithmic Approach to the Definition of Complex or Imprecise Concepts. International Journal of Man-Machine Studies, 8(3), pp.249-291.

Zupka, D., 2016. Rituals and Symbolic Communication: Theory, Terminology and Methodology. En: Ritual and Symbolic Communication in Medieval Hungary under the Arpád Dynasty (1000-1301). Leiden: Brill, pp.15-34. 




\section{Universidad inie Zaragoza

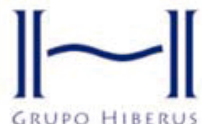

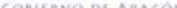

BYBLÍON

GRUPO DE INVESTIGACIÓN 